

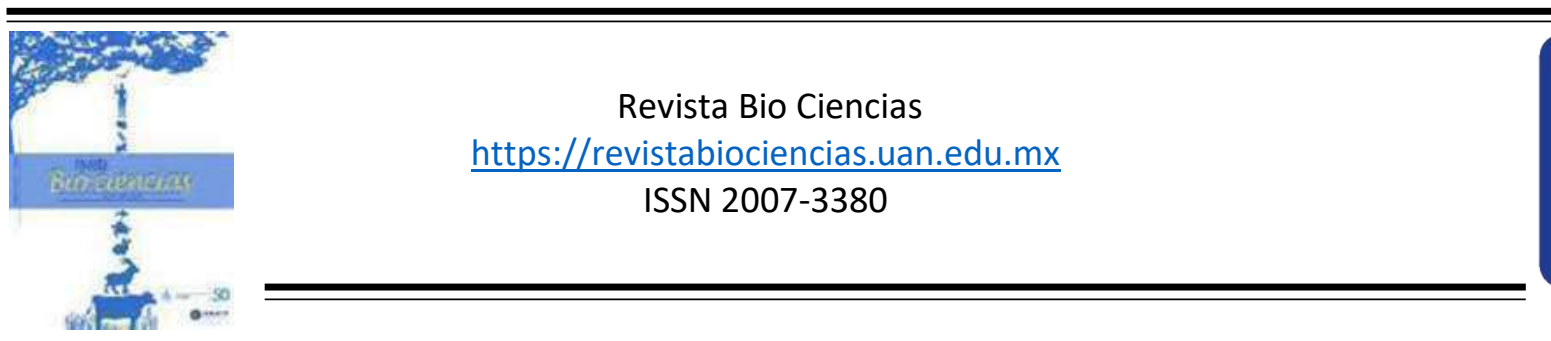

Trabajos libres: Biología Celular y Bioquímica

Modalidad de Presentación: Cartel

\title{
The nuclear Zn transporter ZIP11 is necessary for the proliferation of HeLa cells
}

\author{
Kan, J., Padilla Benavides, T. \\ Wesleyan University. Laboratory of Molecular Biology and Biochemistry. \\ *Autor Corresponsal: Teresita Padilla Benavides. E- mail: tpadillabenavides@wesleyan.edu
}

Zinc $(\mathrm{Zn})$ is an essential trace element as part of several biological processes, including transcriptional regulation, signaling, and catalysis. A subcellular network of $\mathrm{Zn}$ transporters ensures the adequate distribution of $\mathrm{Zn}$ to maintain homeostasis. Among these, the family of importers Zrt//rt-like protein (ZIP) constitutes 14 members (ZIP1-ZIP14) that mobilize $\mathrm{Zn}$ into the cytosol. Expression of these transporters varies among tissues and during developmental stages. The presence of ZIP transporters at various cellular locations is essential for defining the net cellular transport of $\mathrm{Zn}$. Normally, the ion is bound to proteins or sequestered in organelles and vesicles. Research has focused on $\mathrm{Zn}$ internalization in mammalian cells. However, little is known regarding $\mathrm{Zn}$ mobilization within the cells and the organelles, including the nucleus. ZIP11 is the only ZIP transporter localized in the nucleus of mammalian cells. However, the cellular role and the mechanism and direction of transport of ZIP11 are not defined. We hypothesized that ZIP11 is a nuclear $\mathrm{Zn}$ transporter essential to maintaining nuclear $\mathrm{Zn}$ homeostasis in mammalian cells. To test this idea, we knocked down Zip11 in normal fibroblasts and HeLa cancer cells. Preliminary data shows that partial deletion of Zip11 reduced the proliferation of HeLa cells, and when HeLa cells reached confluency, they acquired an epithelial morphology. Our work has the potential to discover a novel molecular mechanism where nuclear $\mathrm{Zn}$ homeostasis is essential for cancer progression. 


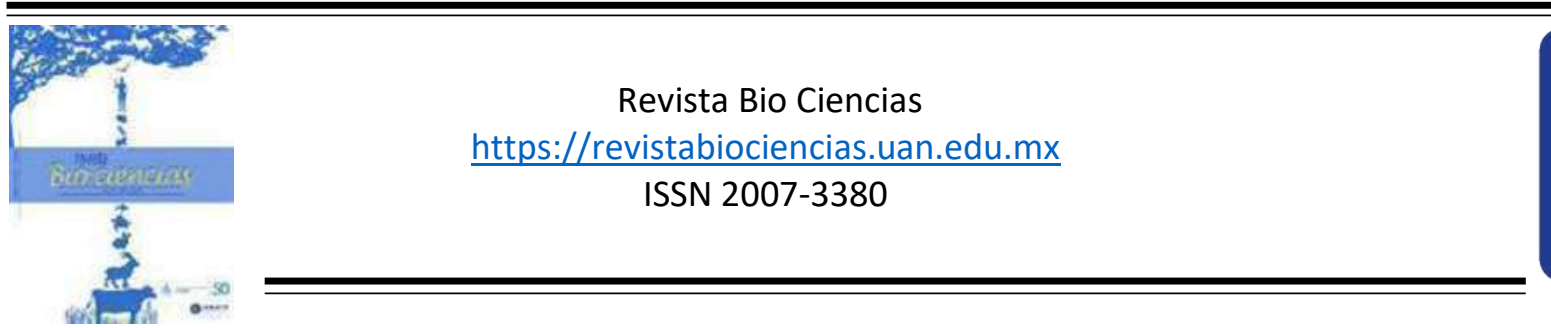

Trabajos libres: Biología Celular y Bioquímica

Modalidad de Presentación: Oral

\title{
Moringa oleífera reduce el estrés del reticulo endoplasmáico, disminuye la lipogénesis de novo y modifica la expresión de miRNAs en un modelo de hígado graso no alcohólico (NAFLD)
}

\author{
Monraz Méndez, C. A. ${ }^{1 *}$, Escutia Gutiérrez, R. ${ }^{1}$, Rodríguez Sanabria, S. ${ }^{1}$, Sánchez Orozco, L. V. ${ }^{1}$, \\ Santos García, A. ${ }^{2}$, Armendáriz Borunda, J. ${ }^{1}$, Sandoval Rodríguez, A. S. ${ }^{1}$ \\ ${ }^{1}$ Universidad de Guadalajara. Ciencias Basicas. ${ }^{2}$ Tecnologico de Monterrey \\ ${ }^{*}$ Corresponding Author: Christian Alejandra Monraz Méndez. \\ E-mail:Inmonraz@gmail.com
}

INAFLD es una enfermedad inflamatoria hepática de carácter crónico definido por la presencia de gotas lipídicas en el citoplasma de los hepatocitos (más del 5\%), relacionad con la obesidad y la resistencia a insulina. La Moringa oleífera (MO) ha demostrado efectos anti-inflamatorios, anti-oxidantes e hipolipemiantes en diferentes modelos murinos. Objetivo: Evaluar en un modelo murino de NAFLD el efecto de MO sobre la expresión proteica de moléculas involucradas en la esteatosis e inflamación hepática y sobre miRNAs implicados en el desarrollo de NAFLD. Materiales y métodos Ratones macho C57BL/6J se alimentaron con dieta alta en grasa (HF, 60\% lípidos, 42gr/L de azúcar en agua) durante 16 semanas. La dosis administrada del extracto de MO fué 300 y 500 $\mathrm{mg} / \mathrm{Kg} / \mathrm{día}$ de la semana 9 a la 16 . Se midieron los niveles séricos de adipocinas, se calculó el HOMA-IR; en hígado se evaluó miR-21a-5p, miR-103-3p, miR-21a-5p y SIRT, SREBP1 y CPT1 por Western Blot. El transcriptoma se evaluó por microarreglos. En cortes histológicos se analizó la inflamación, la reactividad a $\alpha S M A$ y fibrosis. Aprobado por los Comités de Ética, Investigación y Bioseguridad del CUCS:Cl-00120. Resultados El tratamiento con Moringa redujo los niveles séricos de insulina, PAI-1, leptina y resistina. En hígado la proteína SREBP1 y CPT1 disminuyeron y SIRT1 aumentó. Se redujo la expresión del mir-21a, mir-103 y mir-122a. En el transcriptoma se subexpresarón los mRNAs implicados en la respuesta al daño del DNA y estrés del retículo endoplasmático y biosíntesis de lípidos. En las histologías hepáticas disminuyó el número de nódulos inflamatorios, la presencia de $\alpha S M A$ y fibrosis. Conclusiones La suplementación con MO redujo la lipogénesis de novo. La cuantificación histológica de MEC, colágena, nódulos inflamatorios y aSMA decreció; los miRNAs se modificaron. El extracto de Moringa mostró efecto antiinflamatorio, antifibrogénico y antilipogénico en un modelo de NAFLD.

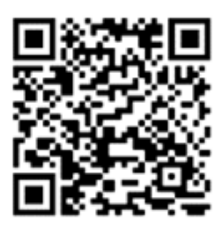

Como citar este artículo: Monraz Méndez, C. A., Escutia Gutiérrez, R., Rodríguez Sanabria, S., Sánchez Orozco, L. V., Santos García, A., Armendáriz Borunda, J., Sandoval Rodríguez, A. S. (2020). Moringa oleífera reduce el estrés del reticulo endoplasmáico, disminuye la lipogénesis de novo y modifica la expresión de miRNAs en un modelo de hígado graso no alcohólico (NAFLD). Revista Bio Ciencias 7: (Suppl) Memorias de Congreso. LXIII Congreso Nacional de la Sociedad Mexicana de Ciencias Fisiologicas, A. C. e1097. http://doi.org/10.15741/revbio.07Suppl.e1097 


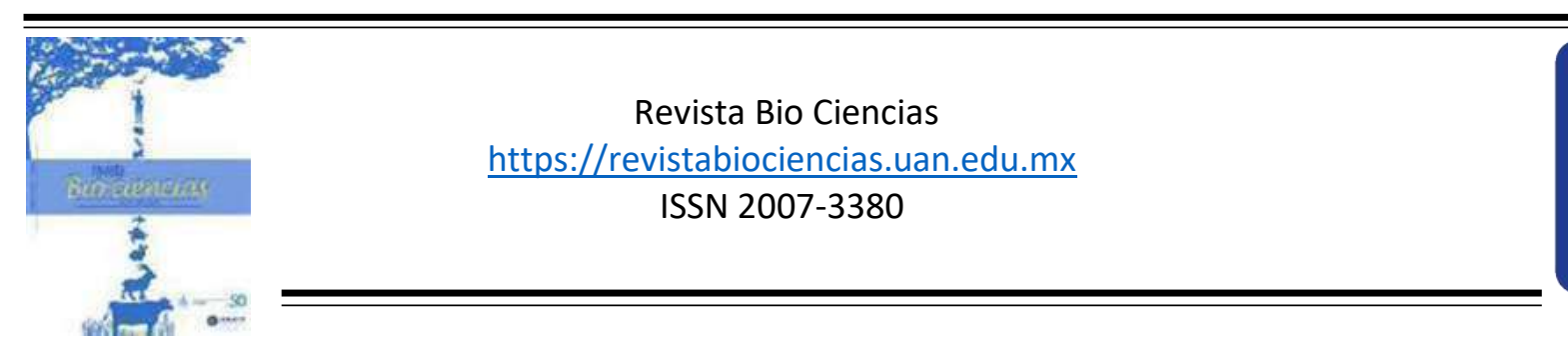

Trabajos libres: Biología Celular y Bioquímica

Modalidad de Presentación: Cartel

\section{Efecto hepatoprotector de la Moringa oleífera sobre la inducción de hepatocarcinogenesis in vivo}

Campos Valdez, M., Sánchez Meza, J., Monroy Ramírez, H. C., Santos García, A. S., Armendáriz Borunda, J., Sánchez Orozco, L. V.*

Universidad de Guadalajara. Departamento de Biología Molecular y Genómica

${ }^{*}$ Corresponding Author: Laura Verónica Sánchez Orozco.

E-mail: laura.sorozco@academicos.udg.mx

En el modelo modificado del hepatocito resistente (MMHR) un daño químico y una hepatectomía parcial (HP) detonan el proceso de hepatocarcinogénesis. Se ha demostrado que la Moringa oleífera (Mgol) y/o sus extractos reducen la viabilidad de células de hepatocarcinoma y, ejercen efecto quimioprotector en modelos de hepatocarcinoma inducidos solamente por dietilnitrosamina. El objetivo fue demostrar si la administración hoja seca pulverizada de $\mathrm{Mg}$-ol tiene un efecto hepatoprotector en el MMHR. Se establecieron 3 grupos de ratas Wistar: control (CTL) $(n=2), \quad$ tratamiento carcinogénico (TC) $(n=3)$ y grupo TC+Mgol $(n=2)$, al cual se le administró 500 $\mathrm{mg} / \mathrm{Kg}$ de $\mathrm{Mg}$-ol (hoja pulverizada) durante 5 semanas vía i.g (se utilizó carboximetilcelulosa como vehículo). Se disecó el tejido hepático de los animales 12 días posteriores a la HP. Se realizó análisis histológico (Tinciones tricrómica de Masson y hematoxilina-eosina). La expresión de TGF- $\beta$ y $\alpha$-SMA se evaluó mediante western-blot inmunofluorescencia acoplada a microscopia confocal. La apariencia del tejido CTL era brillante y firme. En el tejido TC se observó la aparición de pequeñas lesiones, además de una coloración opaca. Al comparar el tejido TC con el de TC+Mg-ol se observó una mejoría del tejido hepático. El grupo TC mantuvo un peso significativamente menor comparado con los otros grupos a lo largo del desarrollo del modelo. Se hallaron diferencias en el área de fibrosis en grupos CTL $(11.33 \% \pm 4.11)$ y de TC+Mgol $(14.97 \% \pm 4.67)$ en comparación con el grupo TC $(20.88 \% \pm 6.66)$. Se evaluó la expresión de TGF- $\beta$ y $\alpha$-SMA, los cuales se incrementaron significativamente en el tejido hepático de TC, mientras que en el de TC+Mg-ol la expresión disminuyó a niveles incluso menores que el grupo CTL. Los resultados demuestran que la administración de Mg-ol podría atenuar los efectos pro-fibrogénicos producidos por daño químico que a su vez inducen el desarrollo de la hepatocarcinogénesis en el MMHR. 


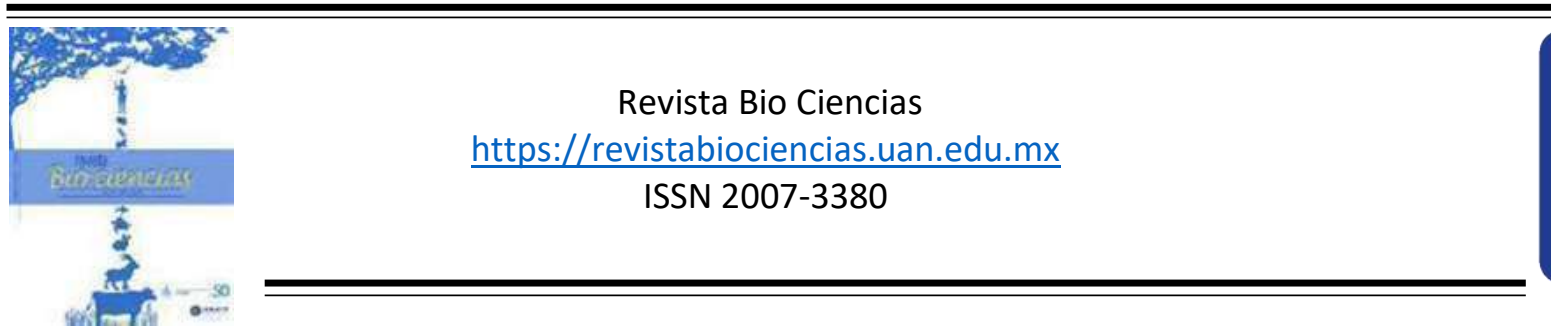

Trabajos libres: Biología Celular y Bioquímica

Modalidad de Presentación: Cartel

\title{
Influencia de los esteroides cardiotonicos endogenos Digoxina y Marinobufagenina sobre las uniones comunicantes y las uniones estrechas de células MDCKiones
}

\author{
Ogazón Del Toro, E. A., Ponce Balderas, A. * \\ Centro de Investigación y de Estudios Avanzados (Cinvestav). Fisiologia, Biofisica y Neurociencia \\ ${ }^{*}$ Corresponding Author: Arturo Ponce Balderas. E- mail: aponce25@gmail.com
}

Los esteroides cardiotónicos son una familia de sustancias, notables por sus efectos sobre el musculo cardíaco. Mas allá de sus propiedades farmacológicas, el interés por los esteroides cardiotónicos se ha renovado al descubrirse la existencia de formas endógenas de algunos de ellos, de los cuales el más estudiado es la ouabaína, si bien se han descubierto otros como digoxina y marinobufagenina. Dichos esteroides influyen sobre gran cantidad de procesos celulares como la proliferación, diferenciación y migración. Nuestro grupo ha demostrado previamente que ouabaína a concentraciones endógenas es un importante modulador de propiedades de los epitelios al regular las uniones estrechas, las uniones comunicantes, las uniones adherentes y la ciliogenesis. Puesto que Digoxina y Marinobufagenina son también producidos endógenamente y en vista del poco conocimiento que se tiene sobre sus efectos sobre los epitelios, evaluamos en el presente trabajo si Digoxina y marinobufagenina tienen influencia sobre las uniones estrechas y uniones comunicantes de células MDCK, encontrando que ambos esteroides modulan dichas estructuras, incrementando la resistencia eléctrica transepitelial y la comunicación intercelular mediada por Gap Junctions, usando a la Na-K ATPasa como receptor y el proceso involucra a las proteínas de señalización c-Src, ERK 1/2 y ROCK. 


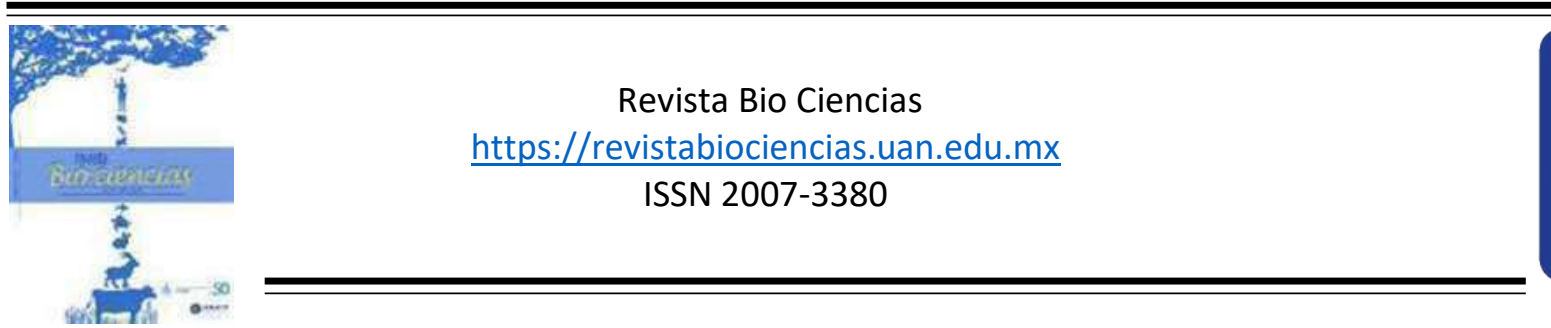

Trabajos libres: Biología Celular y Bioquímica

Modalidad de Presentación: Cartel

\title{
La hormona de crecimiento favorece un fenotipo híbrido epitelial-mesenquimal en células de cáncer de próstata andrógeno-independientes
}

\author{
Juárez Aguilar, E. *, Olascoaga Caso, E. M., Rodríguez Alba, J. C. \\ Unviersidad Veracruzana. Instituto de Ciencias de la Salud \\ *Autor corresponsal: Enrique Juárez Aguilar.E- mail: ejuarezaguilar@gmail.com
}

La transición epitelial-mesenquimal (TEM) es el mecanismo que adoptan las células cancerosas para hacer metástasis. En el cáncer de próstata $(\mathrm{CaP})$, la TEM puede ocurrir previo al tratamiento médico, cuando las células son dependientes de andrógenos y en aquellas que evolucionan a un fenotipo andrógeno-independiente, consecuencia de la terapia de privación hormonal. Evidencia reciente sugiere que la hormona de crecimiento $(\mathrm{HC})$ es capaz de regular la TEM de cáncer de mama y melanoma; sin embargo, se desconoce si afecta a las células de $\mathrm{CaP}$ y si la sensibilidad de estas a los andrógenos pudiera tener algún papel en la TEM. Para analizar esta posibilidad, el presente trabajo evaluó el efecto de la HC (100 ng/mL) sobre la TEM en las líneas celulares de CaP dependiente (LNCaP) e independiente (DU-145) de andrógenos. La TEM se evaluó mediante citometría de flujo a través del análisis de la expresión de las proteínas E-cadherina, marcador molecular epitelial y vimentina, característica del fenotipo mesenquimal. Además, se evaluaron parámetros morfológicos como tamaño y granularidad y la expresión del receptor de HC $(\mathrm{RHC})$. Los resultados mostraron que ambas líneas celulares presentan una alta expresión del RHC. A pesar de esto, la $\mathrm{HC}$ solo incrementó el tamaño y granularidad de las células DU-145 e incrementó la expresión de E-cadherina y de vimentina, favoreciendo un fenotipo híbrido epitelial-mesenquimal (E$\mathrm{cad}+/ \mathrm{Vim}+)$. En contraste, la HC no tuvo ningún efecto sobre las células dependientes de andrógenos, LNCaP. Estos resultados sugieren que la $\mathrm{HC}$ es capaz de favorecer la TEM parcialmente en aquellas células de $\mathrm{CaP}$ independientes a andrógenos y no en aquellas dependientes de estos. Actualmente se sabe que la TEM parcial (fenotipo híbrido) de las células cancerosas es suficiente para hacer metástasis. No obstante, se requiere mayor investigación para conocer cómo afectan los andrógenos a la actividad de la HC. 


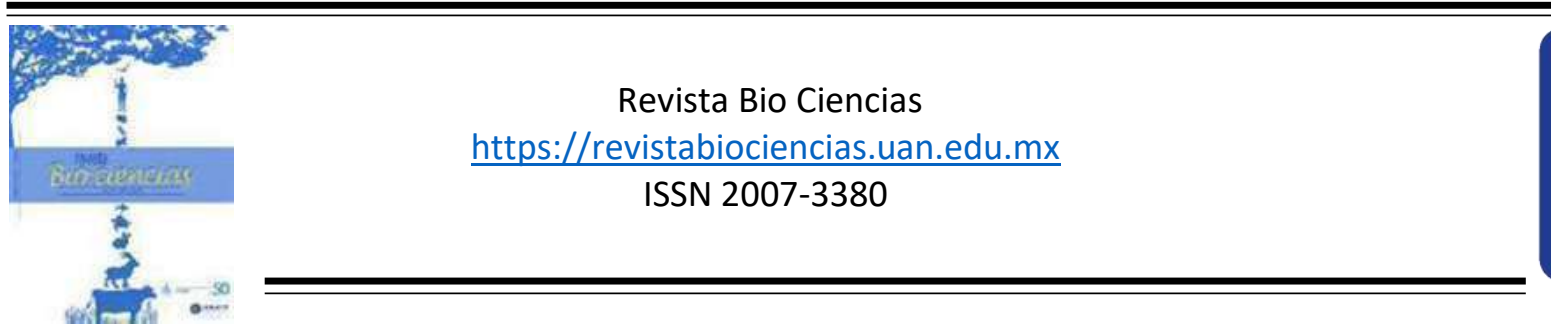

Trabajos libres: Biología Celular y Bioquímica

Modalidad de Presentación: Cartel

\title{
Efecto de nanopartículas de quercetina sobre la fibrosis renal en un modelo murino de daño renal crónico
}

\author{
Sánchez Jaramillo, E. A., Gasca Lozano, L. E., Hernández Ortega, L. D., Vera Cruz, J. M., Gurrola \\ Díaz, C. M., Salazar Montes, A. M.* \\ Unviersidad de Guadalajara. Ciencias de la Salud \\ *Autor corresponsal: Adriana María Salazar Montes. E-mail: asalazar_montes@hotmail.com
}

La fibrosis renal se ha convertido en un importante problema de salud. Quercetina, un flavonoide con propiedades antiinflamatorias, antioxidantes y antifibrogénicas, es efectiva en la prevención de la fibrosis en diversos órganos. La presentación como nanopartículas ha demostrado aumentar la biodisponibilidad y absorción de compuestos orgánicos. OBJETIVO: Determinar el efecto de la aplicación de nanopartículas de quercetina versus macropartículas de quercetina sobre el daño renal crónico en un modelo murino. MATERIALES Y MÉTODOS: Ratones macho de la cepa C57BL/6 con $25 \mathrm{~g}$ de peso fueron intoxicados con una dosis de $50 \mathrm{mg} / \mathrm{kg}$ de adenina durante 4 semanas vía orogástrica. Concomitantemente fueron tratados con diversas dosis de quercetina (25, 50 y $100 \mathrm{mg} / \mathrm{kg}$ ) en forma de macro o nanopartículas. El grupo control recibió sólo vehículo. Los animales fueron sacrificados y se obtuvieron sangre, orina y tejido renal para realizar análisis bioquímicos e histológicos. RESULTADOS: El tratamiento con nanopartículas de quercetina previno la fibrosis renal de una manera dosis dependiente, tanto en presentación de macro como nanopartículas. Las nanopartículas fueron más efectivas observando mejores efectos con dosis menores. Los niveles más cercanos a niveles normales de los parámetros bioquímicos (creatinina, urea, ácido úrico) son observados en los grupos que recibieron tratamiento con nanopartículas. CONCLUSIONES El uso de nanopartículas de quercetina es más efectivo en la prevención de la fibrosis renal que el uso de macromoléculas de quercetina. Los parámetros bioquímicos (creatinina, urea, ácido úrico) mostraron una mejoría de la función renal dependiente de dosis observándose un mayor efecto protector con el uso de nanopartículas. En los análisis morfométricos se pudo observar una disminución en el porcentaje de fibrosis, dependiente de dosis y más marcada con el uso de nanopartículas. Se observó una necrosis reducida en los túbulos renales con el uso de nanopartículas de quercetina.. 


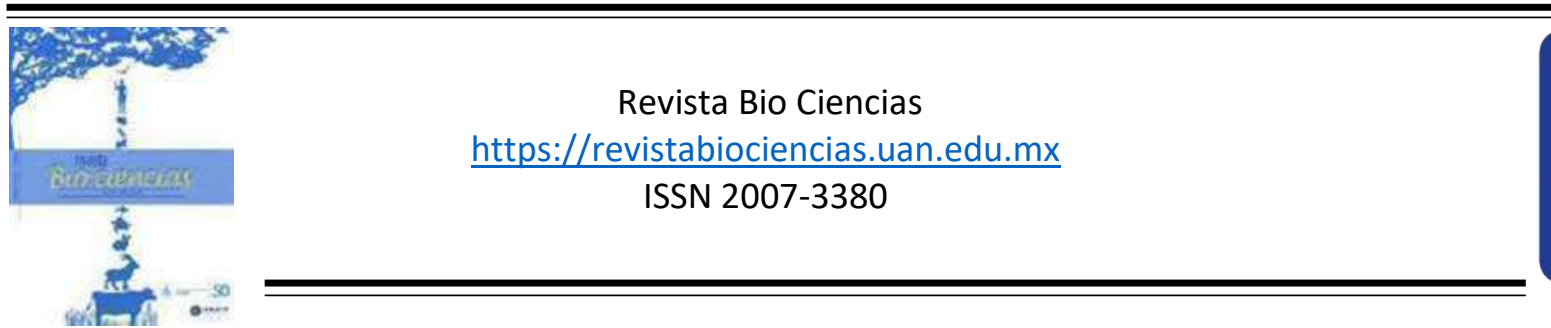

Trabajos libres: Biología Celular y Bioquímica

Modalidad de Presentación: Oral

\section{Efecto de la apocinina sobre el estrés oxidante del músculo cardíaco de ratas con diabetes}

Bravo Sánchez, E. ${ }^{1}$, Sánchez Duarte, S. ${ }^{1}$, Sánchez Duarte, E. ${ }^{2}$, Saavedra Molina, A. ${ }^{1}$, Peña Montes, D. ${ }^{1}$, Montoya Pérez, R. C. ${ }^{1 *}$

1 Unviersidad de Michoacana de San Nicolás de Hidalgo. Laboratorio de Fisiología Muscular.

2Departamento de Ciencias Aplicadas al Trabajo, Universidad de Guanajuato, Campus León

*Autor corresponsal: Rocío del Carmen Montoya Pérez. E- mail: rmontoya@umich.mx

La diabetes mellitus (DM) es un conjunto de síndromes hiperglucemiantes resultantes de un defecto en la función de las células $\beta$ del páncreas y la disminución de la sensibilidad de la insulina. La hiperglucemia es un mecanismo que conduce al aumento de especies reactivas de oxígeno (ERO). La apocinina, un activo aislado de la hierba Pricorhiza kurroa, es considerado un agente antioxidante al inhibir la actividad de la NADPH oxidasa y disminuir los niveles de ERO. En este trabajo se analizó la influencia de la apocinina sobre el estrés oxidante en músculo cardíaco y la sensibilidad a la insulina en ratas con diabetes. Se utilizaron ratas Wistar macho divididas en 4 grupos: control (C), control + apocinina $(C+A)$, diabetes $(D)$, diabetes + apocinina $(\mathrm{D}+\mathrm{A})$. El tratamiento con apocinina fue de $3 \mathrm{mg} / \mathrm{kg} /$ día durante 5 semanas. Se monitorearon biomarcadores metabólicos durante el tratamiento y se realizó la curva de resistencia a la insulina al final del tratamiento. Con los homogenados del tejido cardíaco se midieron los marcadores de estrés oxidante. Los resultados mostraron una disminución en los niveles de glucemia en el grupo diabético tratado (139.84 $\pm 10.97 \mathrm{mg} / \mathrm{dL})$. La apocinina mejoró la resistencia a la insulina en animales diabéticos con tratamiento (6758.2 $\left.\pm 1510.53 \mathrm{mg} / \mathrm{dl}^{*} \mathrm{~min}\right)$. Los niveles de ERO fueron mayores en ratas diabéticas $(140.10 \pm 16.009 \Delta \mathrm{F})$, y el fármaco mostró una disminución de estos valores en el grupo $D+A(74.68 \pm 5.03$ $\Delta \mathrm{F})$. La actividad de la catalasa se encontró deteriorada en el grupo diabético (22.72 $\pm 9.32 \mathrm{U}^{*} \mathrm{mg}$ de prot), en cambio se observó que esta es restaurada en el grupo $\mathrm{D}+\mathrm{A}\left(134.69 \pm 24.44 \mathrm{U}^{*} \mathrm{mg}\right.$ de prot). En conclusión, la apocinina tiene efectos significativos en los niveles de glucemia y resistencia a la insulina, y reduce el estrés oxidante al mejorar la actividad de la catalasa. 


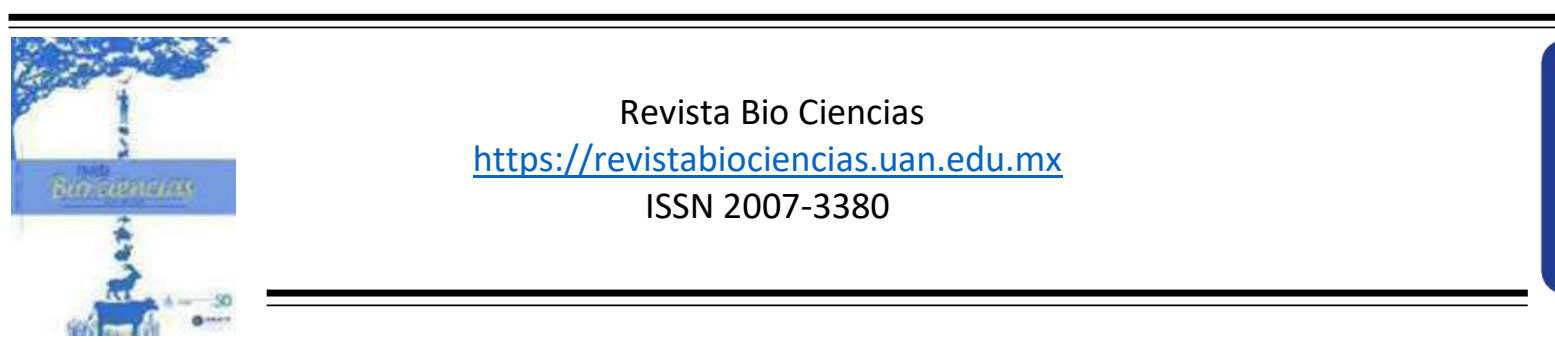

Trabajos libres: Biología Celular y Bioquímica

Modalidad de Presentación: Cartel

\section{Influencia de Hormonas Sexuales en la Hidrólisis Enzimática de ATP extracelular en un modelo asmático de cobayo}

Rodriguez Sanabria, J. S.

Unviersidad de Guadalajara. Ciencias de la Salud

*Autor corresponsal: Jonathan Samael Rodriguez Sanabria. E- mail: pirlo_43@hotmail.com

El incremento de la prevalencia de NASH coincide con la pandemia actual de obesidad. La dieta occidental compuesta de alimentos hipercalóricos, altos en grasa y azucares simples puede inducir $\mathrm{NASH}$, que se caracteriza por inflamación, balonamiento de hepatocitos y esteatosis. Objetivos Evaluar los cambios moleculares, histológicos y bioquímicos en un modelo murino de NASH sometidos a una dieta alta en grasa por 16 semanas. Materiales y métodos Ratones macho de 4-5 semanas de edad, C57BL/6J alimentados con dieta alta en grasa y azucares durante 16 semanas. Se dio seguimiento a las $4,8,12$ y 16 semanas. Se midió glucosa sérica, peso del animal e ingesta calórica. El hígado fue pesado al igual que el tejido adiposo epididimal. Se midió AST, ALT, TAG, Chol y VLDL. Se realizó tinción de hematoxilina-eosina, tricrómica de Masson y rojo sirio. Se determinó la expresión hepática de mRNAs de IL-6,
TNF $\alpha$, COLIAl y TGF- $\beta$ por qRT-PCR. Las variables cuantitativas se analizaron con ANOVA, Tukey para datos paramétricos y Kruskal-Wallis para datos no paramétricos. Resultados Los animales mostraron peso corporal elevado, presencia de esteatosis e inflamación hepática. La glucosa sérica incrementó a la semana 12 y 16 . El peso del hígado y la grasa epididimal aumenta conforme se establece el modelo. Los parámetros histológicos y bioquimicos coinciden con el establecimiento de una esteatohepatitis. Los genes inflamatorios y fibróticos aumentan. Conclusión La exposición a la dieta alta en grasa y azúcares simples indujo aumento de peso corporal, esteatohepatitis, inflamación, hiperglucemia y aumento en la expresión de enzimas hepáticas y genes implicados en inflamación y fibrosis. 


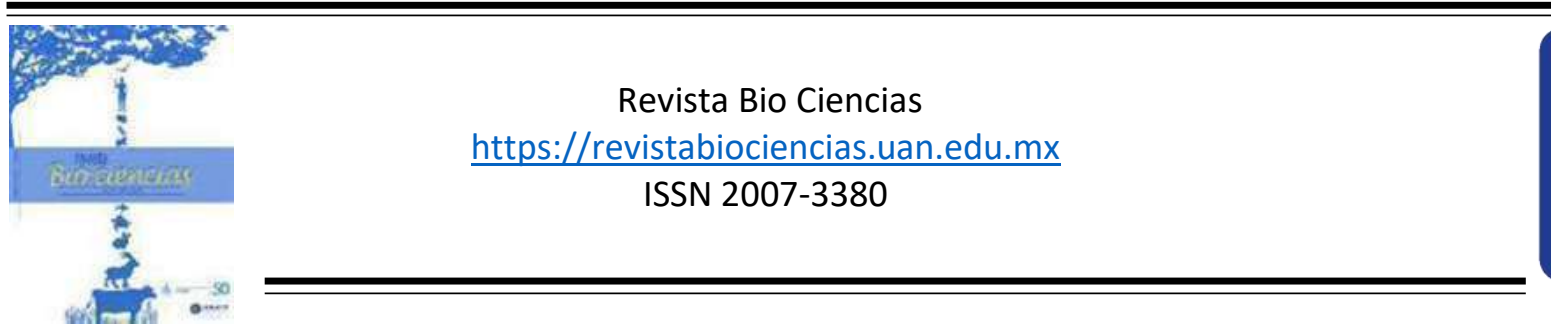

Trabajos libres: Biología Celular y Bioquímica

Modalidad de Presentación: Oral

\title{
Influencia de Hormonas Sexuales en la Hidrólisis Enzimática de ATP extracelular en un modelo asmático de cobayo
}

\author{
González Cosío, O., Chávez Alderete, J.* \\ Instituto Nacional de Enfermedades Respiratorias Ismael Cosío Villegas. Departamente de \\ Investigación en Hiperreactividad Bronquial \\ *Autor corresponsal: Jaime Chávez Alderete. E- mail: chavez_j28@hotmail.com
}

El asma es una enfermedad heterogénea, usualmente caracterizada por inflamación crónica de la vía aérea, con variación del flujo aéreo espiratorio; a pesar de ello, la inflamación crónica junto con la hiperreactividad bronquial juega un papel sumamente importante en el entendimiento de la fisiopatología de ciertos procesos, tras la maduración sexual la prevalencia de asma cambia en hombres y mujeres. Existen diferentes moléculas que se han asociado al asma; entre las que se encuentra el ATP. El ATP extracelular juega un papel importante en la broncoconstricción en el asma, este mismo es hidrolizado por enzimas denominadas genéricamente ectonucleotidasas, impidiendo que sobreestimulen a sus receptores purinérgicos $y$ por consiguiente su actividad biológica. De igual manera, se ha identificado el papel de las hormonas sexuales en la fisiopatología del asma; por lo que el objetivo de este trabajo es investigar el papel de algunas hormonas a través de la hidrólisis extracelular de ATP.
Se usaron cobayos machos sensibilizados a OVA. El día del estudio, se obtuvieron leucocitos periféricos totales. Las células, se incubaron durante 1 ó 2 horas a $37 \stackrel{\circ}{\circ} \mathrm{C}$ con 178 uM de testosterona (TES), dihidroepiandrosterona (DHEA) 0 17- $\beta$ estradiol (EST). Posteriormente, se estimularon con 250 uM de ATP y se tomó una muestra cada 10 min para cuantificar la hidrólisis del ATP mediante cuantificación colorimétrica. Los datos preliminares demuestran que la hidrólisis de ATP en los cobayos no sensibilizado se ve afectada tras la incubación con TES $(p<0.01)$, DHEA $(p<0.05)$, EST $(p<0.01)$. Cuando se evaluó la hidrólisis de ATP en cobayos sensibilizados tanto a 1 como a $2 \mathrm{~h}$ de incubación, en ningún grupo hubo cambio con respecto al grupo de ATP. Aunque estos datos son preliminares, se demostró que las hormonas sexuales favorecen en la hidrólisis de ATP. 


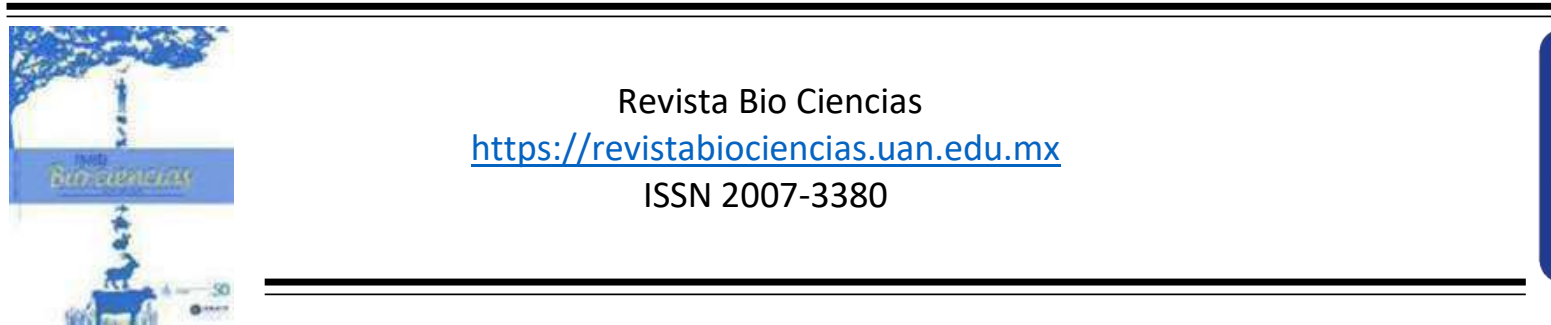

Trabajos libres: Biología Celular y Bioquímica

Modalidad de Presentación: Oral

\title{
Pirfenidona de liberación prolongada disminuye la expresión del miR-21a-5p y sus genes blancos en un modelo experimental de EHGNA/ EHNA
}

\author{
Escutia Gutiérrez.R. ${ }^{1 *}$., Rodríguez Sanabria, J. S. ${ }^{1}$, Monraz Méndez, C. A. ${ }^{1}$, Santos García, A. S. ${ }^{2}$, \\ Sandoval Rodríguez, A. ${ }^{1}$, Armendáriz Borunda, J. ${ }^{1}$ \\ 1 Universidad de Guadalajara. Ciencias de la Salud. ${ }^{2}$ Tecnologico de Monterrey \\ *Autor corresponsal: Rebeca Escutia Gutiérrez. E- mail: rebe_ka09@hotmail.com
}

La enfermedad de hígado graso no alcohólico (EHGNA) / esteatohepatitis no alcohólica (EHNA) se caracteriza por acumulación de lípidos, inflamación y fibrosis. El miR-21a puede estar implicado en etapas iniciales por aparición de esteatosis y en etapas posteriores por inflamación y fibrosis de EHGNA. EI fármaco pirfenidona es un agente antifibrótico, anti-inflamatorio y antioxidante. Evaluar el efecto de pirfenidona de liberación prolongada (PFD-LP) sobre parámetros histológicos, bioquímicos, activación de células estelares hepáticas, expresión del miR-21a-5p y sus genes blancos en un modelo experimental de EHGNA/EHNA. Ratones macho C57BL/6J, fueron alimentados con dieta alta en grasa (DAG, $60 \%$ lípidos, 42gr/L de azúcar en agua) por 16 semanas. Se administró en el alimento $300 \mathrm{mg} / \mathrm{kg} / \mathrm{día}$ pirfenidona de liberación prolongada de la semana 8 a la 16 . Se realizó inmunohistoquímica para $\alpha$-SMA, tinción $\mathrm{H} \& \mathrm{E}$, tricrómica de Masson y rojo sirio. Se midieron los niveles de enzimas hepáticas AST y ALT y perfil lípidico (VLDL, triglicéridos y colesterol total) $\mathrm{Se}$ determinó la expresión hepática de miR21a-5p y de genes COL1A1 y SREBP1 por QRT-PCR; y transcriptoma por microarreglos. Los animales tratados con PFD-LP mostraron una reducción de los nódulos inflamatorios, macroesteatosis, fibrosis, colágena y activación de células estelares hepáticas. El tratamiento con PFD-LP logró disminuir niveles de AST, ALT, VLDL, triglicéridos y colesterol total en comparación con el grupo DAG. PFDLP redujo la expresión hepática de miR21a-5p y sus genes blancos COL1A1 y SREBP1. En análisis del transcriptoma se encontraron 36 genes sobre-expresados que participan en transporte de lípidos y actividad antioxidante en grupo tratado con PFD-LP. Asimismo, disminuyó la expresión de 52 genes implicados en biosíntesis de lípidos y colágena, y respuesta inflamatoria. Pirfenidona de liberación prolongada disminuyó la expresión de miR-21a-5p y sus genes blancos COL1A1 y SREBP1. PFD-LP mostró un efecto anti-esteatogénico, antiinflamatorio y antifibrótico en el modelo experimental de EHGNA/EHNA.

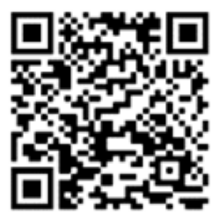

Como citar este artículo: Escutia Gutiérrez.R., Rodríguez Sanabria, J. S., Monraz Méndez, C. A., Santos García, A. S., Sandoval Rodríguez, A. S., Armendáriz Borunda, J. (2020). Pirfenidona de liberación prolongada disminuye la expresión del miR-21a-5p y sus genes blancos en un modelo experimental de EHGNA/ EHNA. Revista Bio Ciencias 7: (Suppl) Memorias de Congreso. LXIII Congreso Nacional de la Sociedad Mexicana de Ciencias Fisiologicas, A. C. e1097. http://doi.org/10.15741/revbio.07Suppl.e1097 


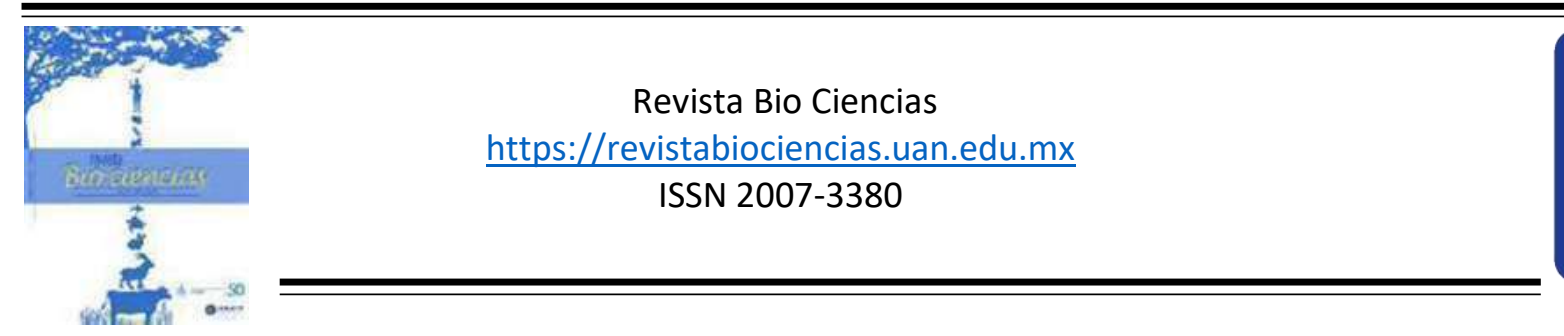

Trabajos libres: Cardiovascular y Sistema Muscular

Modalidad de Presentación: Oral

\title{
Electro-acupuntura temprana en la región sacra mejora la continencia urinaria y reduce la hiperactividad vesical en ratas hembra con lesión medular torácica severa
}

\author{
Munoz Toscano, A. ${ }^{1}$, Yuan. T. ${ }^{2}$, Jiaojiao, L. ${ }^{2}$, Yanhua, Z. ${ }^{2}$, Xiaoling, Z.. ${ }^{2}$ Xiang J. ${ }^{2}$, Shuo. Y. ${ }^{2}$ Li, X. ${ }^{*}$ \\ The Third Xiangya Hospital of Central South University, Changsha, China. Centro Universitario del \\ Norte, Universidad de Guadalajara. \\ *Autor Corresponsal: Xuhong Li. E- mail lixh0901@126.com
}

Pacientes con lesión de médula espinal (LME) tienen como prioridad mejorar la continencia, tanto fecal como urinaria. Se sabe que la estimulación con electro-acupuntura (EA) tradicional China pude reducir la hiperactividad vesical y mejorar propiedades cistométricas. Nuestro objetivo fue determinar si EA en la región sacra mejora, a corto plazo, disfunciones urinarias en ratas con LME severa a nivel torácico. Utilizamos 24 ratas Wistar hembra (12-16 semanas; $\mathrm{N}=6$ por grupo) divididas en Intactas, Sham (laminectomía sin LME), LME (LME por compresión, 30g, 60s) y LME+EA (LME con EA diaria en el punto "Zhong Liao" empezando 7 días post-LME durante 7 días consecutivos, 20 minutos, $2 \mathrm{~Hz}$, intensidad umbral dependiente de movimiento de patas). Se midió el peso, consumo de agua/alimento y conducta de micción con papel húmedo ( 6 horas) a 0, 7 días y 14 días. Al final de la segunda semana, se evaluó la contracción vesical mediante un catéter suprapúbico para infusión de solución salina in animales anestesiados $(0.2 \mathrm{ml} / \mathrm{min})$. Las ratas LME y $\mathrm{LME}+\mathrm{EA}$ consumieron menos alimento que intactas o Sham. No se observaron diferencias en el índice de defecación. Después de una semana, el porcentaje de área húmeda fue mayor en el grupo LME vs Intactas/Sham, pero no vs $L M E+E A$. Después de una semana de $E A$, animales en el grupo $L M E+E A$ presentaron un área húmeda similar al de las ratas control (LME vs $L M E+E A p<0.01$ ). Los estudios cistométricos mostraron que el volumen de micción $(p<0.05)$ y la eficiencia de micción $(p<0.01)$ fueron significativamente mejorados en ratas $L M E+E A$. Similarmente, la frecuencia de contracciones no voluntarias, indicativas de hiperactividad vesical, fue disminuida significativamente por el procedimiento de EA (LME vs $\mathrm{LME}+\mathrm{EA}$ $p<0.001)$. Estos resultados sugieren que la estimulación temprana con EA en la región sacra mejora las disfunciones urinarias observadas en ratas con vejiga neurogénica causada por LME severa. 


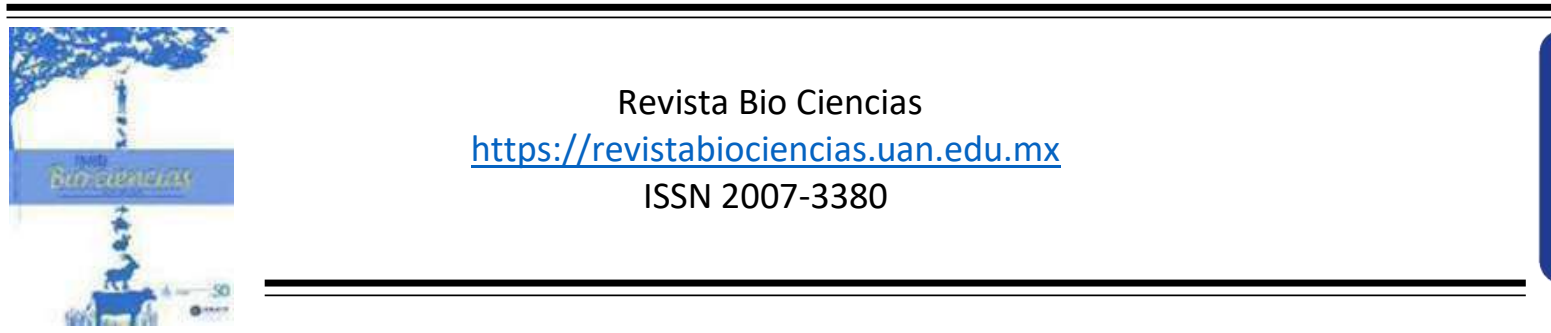

Trabajos libres: Cardiovascular y Sistema Muscular

Modalidad de Presentación: Cartel

\title{
El corazón neurogénico del acocil ¿Secuencia de contracción de un tubo?
}

\author{
De la O Martínez, A., Camacho López, N., Dávila Peña, K. J., Parra Gámez, L. P., Mendoza \\ Angeles, K., Hernández Falcón, J. *
}

Universidad Nacional Autónoma de México. Facultad de Medicina, Departamento de Fisiología. *Autor Corresponsal: Jesús Hernández Falcón. E- mail: jesushf@unam.mx

En los crustáceos decápodos el corazón es un "casi tubo" con válvulas y orificios (ostias) por donde ingresa la hemolinfa almacenada en el seno cardiaco. En el acocil, la actividad mecánica de este cuasi-tubo es controlada por el ganglio cardiaco. Éste está formado por 5 neuronas grandes y 4 pequeñas. Las primeras son motoneuronas conectadas, vía sinapsis química, con el músculo cardiaco. Eléctricamente acopladas se encuentran las 4 neuronas restantes que además funcionan como marcapasos. El ganglio cardiaco es un Generador Central de Patrones que recibe entrada moduladora desde el tritocerebro a través de los nervios cardioexcitatorios y cardioinhibitorios. El ganglio se encuentra a mitad de la pared anterior del corazón, las células grandes se localizan hacia la región más cefálica y las 4 pequeñas en la línea media hacia la región caudal. La descarga de las 5 células grandes produce PPSE en las células musculares. Una red dendrítica se distribuye en las paredes del corazón y transmite la excitación de las células grandes a toda la estructura muscular cardiaca. Las células grandes reciben la descarga de las células pequeñas que se consideran marcapasos. Sin embargo, no parecen descargar todas en forma simultánea, todo indica que primero descarga la célula más cefálica, la 5 y luego en secuencia la 3 la 2 y la 1. Con el propósito de averiguar si existe una secuencia de contracción en este corazón, estudiamos la actividad eléctrica de campo, el electrocardiograma - ECG, y la correlacionamos con el fenómeno contráctil in situ. Nuestros resultados mostraron que el trazo del ECG está formado por dos ondas, una que llamamos PM y otra de mayor voltaje, que llamamos M. La primera corresponde con la contracción de la porción cefálica del corazón, la segunda con la contracción del resto del corazón. 


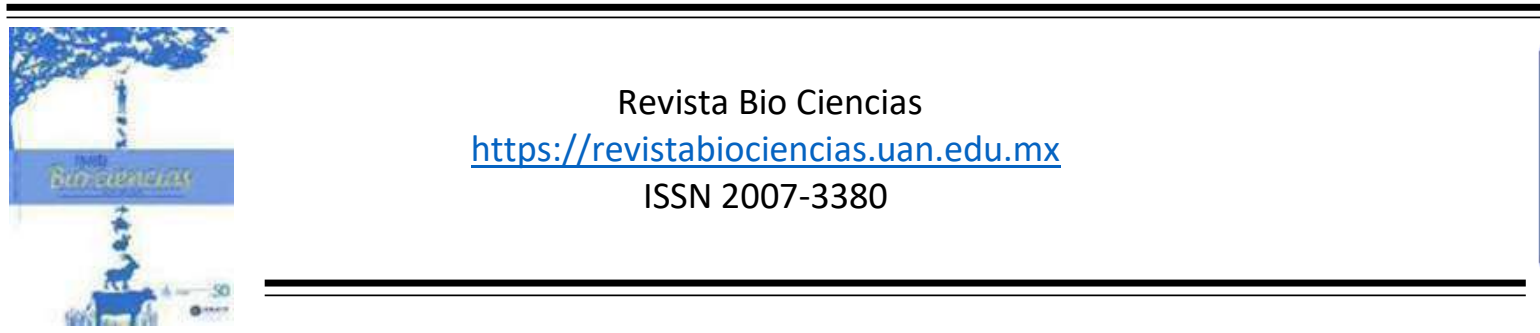

Trabajos libres: Cardiovascular y Sistema Muscular

Modalidad de Presentación: Oral

\title{
Efecto del sobrepeso y obesidad sobre la regulación autonómica cardíaca
}

\author{
Vazquez Guadarrama, F. A. ", Soto Valadez, A. D., Morales Campos, B. M., Escobar Noriega, A. E.,
} Atonal Flores, J.F.

\author{
Benemerita Universidad Autonoma de Puebla. Departamento de Fisiología \\ *Autor Corresponsal Francisco Alejandro Vazquez Guadarrama. \\ E-mail: francisco.vazquezg@alumno.buap.mx
}

Se estima que, para el año 2030, morirán cerca de 23,000,000 de personas por enfermedades cardiovasculares, se ha establecido que seguirán siendo la principal causa de muerte a nivel global. Entre los factores de riesgo para ECV se encuentran la hipertensión arterial, la obesidad, el sedentarismo. La obesidad ha alcanzado cifras pandémicas en las últimas décadas. México se encuentra dentro de los países con mayor número de muertes relacionadas a esta, de acuerdo con la ENSANUT 2018 el $75.2 \%$ de la población de 20 años o más, presentó sobrepeso u obesidad. La variabilidad de la frecuencia cardiaca, como indicador de valor pronóstico de riesgo cardiovascular es la variación entre los intervalos RR del electrocardiograma, refleja la regulación autónoma cardíaca. Actualmente, los datos de investigaciones acerca de la relación entre VFC y obesidad son controversiales; además, en México no existen datos acerca del efecto del sobrepeso y obesidad sobre la VFC. En este estudio analizamos la relación entre la VFC y el índice de masa corporal en adultos jóvenes. Se realizó un estudio transversal analítico en 200 individuos. Los participantes firmaron consentimiento informado. Se les practicó registro de electrocardiograma con la derivación DII en un horario de 09:00-13:00. A partir del electrocardiograma se obtuvieron los parámetros en el dominio del tiempo y de la frecuencia. Los datos son presentados como el promedio \pm EEM. Los grupos analizados en base al IMC fueron comparados con $t$ de Student. Los indicadores que reflejan la actividad parasimpática (RMSSD, NN50, HF) fueron disminuidos significativamente $(p<.05)$ y los indicadores que reflejan la actividad simpática (LF, LF/HF) fueron incrementados significativamente $(p<.05)$ en las personas con sobrepeso u obesidad. No se observaron diferencias significativas entre hombres $y$ mujeres. Concluimos que, en la población estudiada, el exceso de peso genera hiperactividad simpática y disminución parasimpática sobre el corazón. 


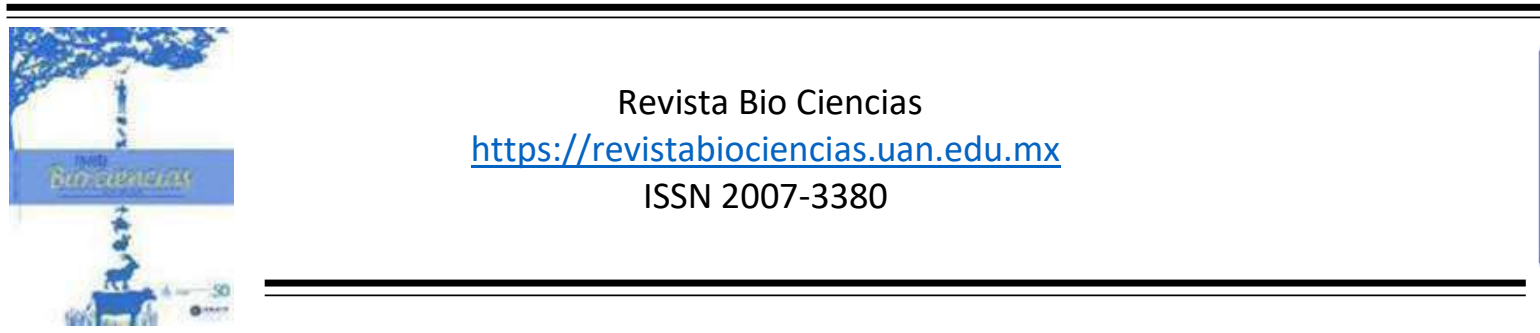

Trabajos libres: Cardiovascular y Sistema Muscular

Modalidad de Presentación: Cartel

\title{
La función muscular es afectada por el ejercicio y el extracto de Erynguim carlinae
}

\author{
Moreno Calderón, M., Gómez Barroso, M., Saavedra Molina, A., Cortés Rojo, C., Montoya Pérez, \\ R. *; Oregel Prado, J D.
}

Universidad Michoacana de San Nicolás de Hidalgo. Laboratorio de Fisiología Muscular

*Autor Corresponsal: Rocío Montoya Pérez. E- mail: rmontoya@umich.mx

El músculo esquelético representa casi el $40 \%$ del peso de una persona, tiene distintas funciones como la de movilidad, la protección de órganos y otros tejidos y además es indispensable para la homeostasis de la glucosa ya que es el responsable de aproximadamente el $80 \%$ de la absorción y eliminación de glucosa estimulada por insulina. Siendo un tejido altamente adaptable es sensibles a los cambios a los que puede estar expuesto el organismo. El presente trabajo pretende identificar los cambios que hay en la función muscular cuando el organismo es sometido a cambios como el ejercicio y la administración del extracto hexánico de Eryngium carlinae. Se utilizaron ratas macho Wistar de entre 350 y $400 \mathrm{~g}$ con los cuales se formaron tres grupos: control, extracto $(30 \mathrm{mg} / \mathrm{kg}$ de extracto hexánico de Eryngium carlinae durante 60 días) y ejercicio (ejercicio de moderada intensidad durante 8 semanas en una caminadora), se midió la fuerza de contracción y el tiempo de resistencia a la fatiga de los músculos sóleo y extensor digitorium longus (EDL), también se tomó en cuenta la glucosa en ayuno y el peso durante todo el tratamiento. Se observó una disminución en la glucosa en ayuno, una mayor generación de fuerza y un mayor tiempo de resistencia a la fatiga en las ratas ejercitadas respecto al control, mientras que el extracto tuvo un efecto negativo tanto en la generación de fuerza como en el tiempo de resistencia a la fatiga del músculo sóleo, pero no se observaron efectos en la glucosa ni en el peso. Existe una diferencia en la generación de fuerza y el tiempo de fatiga en los diferentes tratamientos, es importante tomar en cuenta las características de cada músculo ya que pueden verse afectados de diferente manera con distintos tratamientos. 


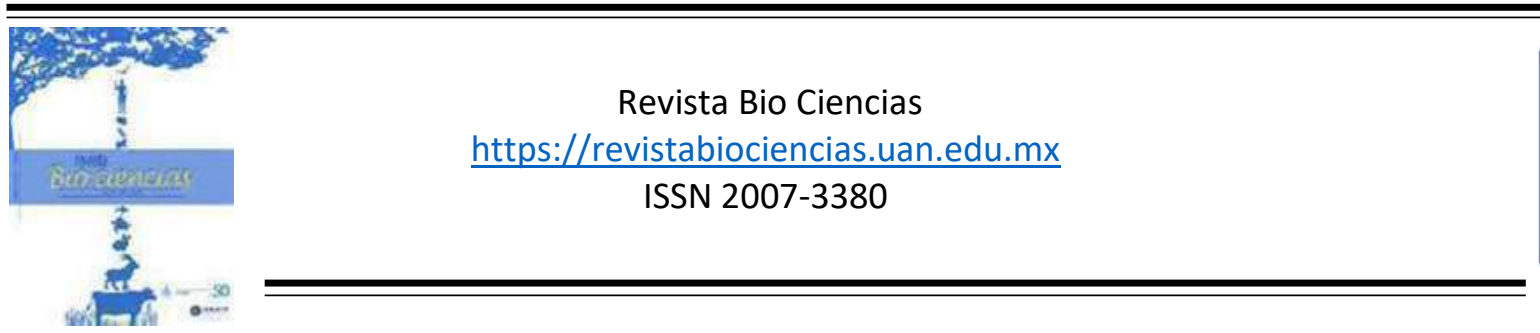

Trabajos libres: Cardiovascular y Sistema Muscular

Modalidad de Presentación: Cartel

\title{
Efecto del diazóxido y del hierro sobre el desarrollo de la fuerza muscular, el perfil de lípidos y el estrés oxidante en músculo de ratas con diabetes
}

\author{
Vargas Vargas, M. A., Gómez Barroso, M., Peña Montes, D., Cortés Rojo, C., Saavedra Molina, A., \\ Montoya Pérez, $R$. *
}

Universidad Michoacana de San Nicolás de Hidalgo. Laboratorio de Fisiología Muscular

*Autor Corresponsal: Rocío Montoya Pérez. E- mail: biochio@gmail.com

La diabetes existe un aumento en el estrés oxidante (EO) mismo que está involucrado en las complicaciones. Un síntoma frecuente es la fatiga muscular. El diazóxido (dzx) es un fármaco que actúa sobre los canales de $\mathrm{K}_{+}$ sensibles a ATP mitocondriales (mitoKATP); Dicho fármaco mejora el desarrollo de la fuerza muscular y por otro lado se sabe que la sobrecarga de hierro (SH) aumenta el EO, mientras que la restricción de hierro $(\mathrm{RH})$ tiene un papel protector. Objetivo evaluar el efecto del hierro y el dzx sobre el desarrollo de la fuerza muscular, EO y el perfil lipídico en ratas diabéticas. Se utilizaron ratas Wistar macho $(250 \mathrm{~g})$ en ocho grupos: control, diabéticos, $\mathrm{SH}$, diabéticas $+\mathrm{SH}, \mathrm{RH}$, diabéticas $+\mathrm{RH}, \mathrm{dzx}$, diabéticas+dzx. Resultados Las ratas con $\mathrm{RH}$ $y$ las administradas con dzx mejoraron la fuerza muscular y la fatiga tardó más en aparecer. En la peroxidación de lípidos, las ratas diabéticas con $\mathrm{RH}$ y dzx presentaron los niveles más bajos. En los niveles de glutatión, las ratas diabéticas+dzx obtuvieron los niveles más altos de glutatión reducido y los niveles de glutatión oxidado (GSSG) en ratas diabéticas con una dieta baja en hierro obtuvieron los valores más bajos. En cuanto a los niveles totales de ERO, las ratas diabéticas+dzx obtuvieron los niveles más bajos. En cuanto al perfil lipídico, las ratas diabéticas+dzx obtuvieron niveles más bajos. Los niveles de lipoproteínas de muy baja densidad (VLDL) el grupo de ratas diabéticas+dzx obtuvo niveles similares al grupo control. La apertura de los mitoKATP promueve una disminución del EO. Por otro lado, el hierro participa en la formación del radical hidroxilo. Los niveles más altos de EO y fuerza muscular fueron menores en los grupos 1O; sin embargo, la restricción de hierro tuvo un efecto protector sobre los niveles de EO. desarrollo de la fuerza muscular, el perfil de lípidos y el estrés oxidante en músculo de ratas con diabetes. Revista Bio Ciencias 7: (Suppl) Memorias de Congreso. LXIII Congreso Nacional de la Sociedad Mexicana de Ciencias Fisiologicas, A. C. e1097. 


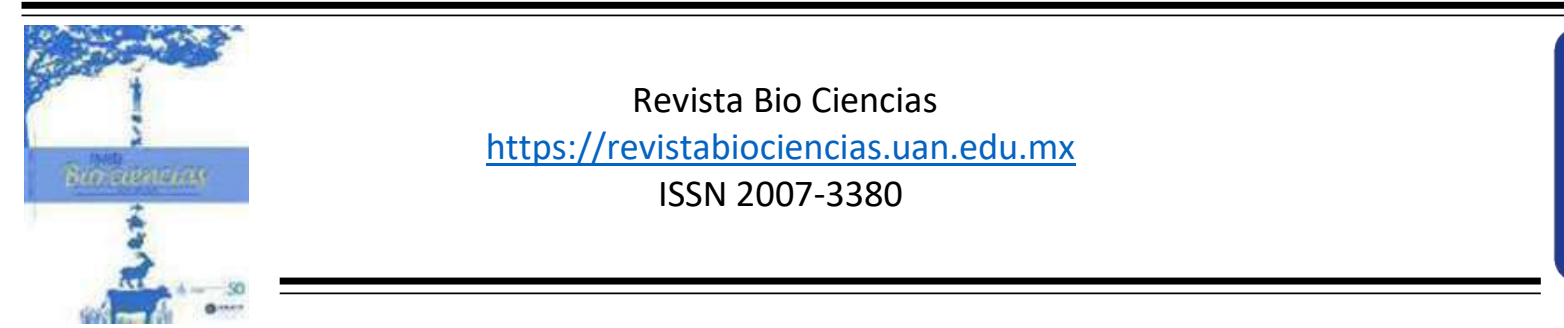

Trabajos libres: Cardiovascular y Sistema Muscular

Modalidad de Presentación: Cartel

\title{
Efecto de diferentes intensidades de ejercicio sobre peroxidación-lipídica y estado- redox del glutatión en músculo esquelético
}

\author{
Gómez Barroso, M., Vargas Vargas, M. A., Peña Montes, D., Saavedra Molina, A., Cortés Rojo, C., \\ Montoya Pérez, $R$. *
}

Universidad Michoacana de San Nicolás de Hidalgo. Laboratorio de Fisiología Muscular

*Autor Corresponsal: Rocío Montoya Pérez. E- mail: rmontoya@umich.mx

En la actualidad el ejercicio ha sido implementado como un eficiente método para mantener un estado óptimo de salud, además, de ser utilizado como tratamiento complementario no farmacológico en numerosas patologías. Se ha documentado que la aplicación de protocolos de ejercicio mejora el funcionamiento muscular, evita el daño celular y mejora la defensa antioxidante. El objetivo de este trabajo fue evaluar el efecto de tres diferentes intensidades de ejercicio, baja, media y alta, sobre la peroxidación lipídica del tejido muscular y el estado redox del glutatión, esto, con la finalidad de identificar el protocolo con mayor eficiencia. Se utilizaron ratas Wistar macho (250-300 g) en cuatro grupos: control, ejercitadas baja intensidad, ejercitadas media intensidad, ejercitas alta intensidad. El músculo sóleo y el extensor digitorio longus (EDL) de una de las extremidades se extrajo para realizar las pruebas de peroxidación de lípidos y estado redox del glutatión. Los resultados mostraron una disminución de la peroxidación lipídica tanto en músculo sóleo como EDL en el ejercicio de baja (33.14\%, $37.12 \%$ respectivamente) y media intensidad (53.4\%, $47.2 \%$ respectivamente), mientras que el ejercicio de alta intensidad no mostró diferencia significativa en ninguno de los dos músculos. Mientras que el estado redox del glutatión no mostró diferencia significativa en el grupo de baja y media intensidad de ejercicio para ninguno de los dos músculos, sin embargo, el protocolo de alta intensidad mostró un incremento del estado redox del glutatión del $83.12 \%$ para músculo sóleo y del $71.12 \%$ para músculo EDL. Estos resultados comprueban que la implementación de un protocolo de ejercicio mejora el estado del músculo esquelético, al disminuir la peroxidación lipídica e incrementar la defensa antioxidante. Además de que se comprobó que el ejercicio de alta intensidad resulto ser más eficiente mejorando el estado redox del glutatión. 


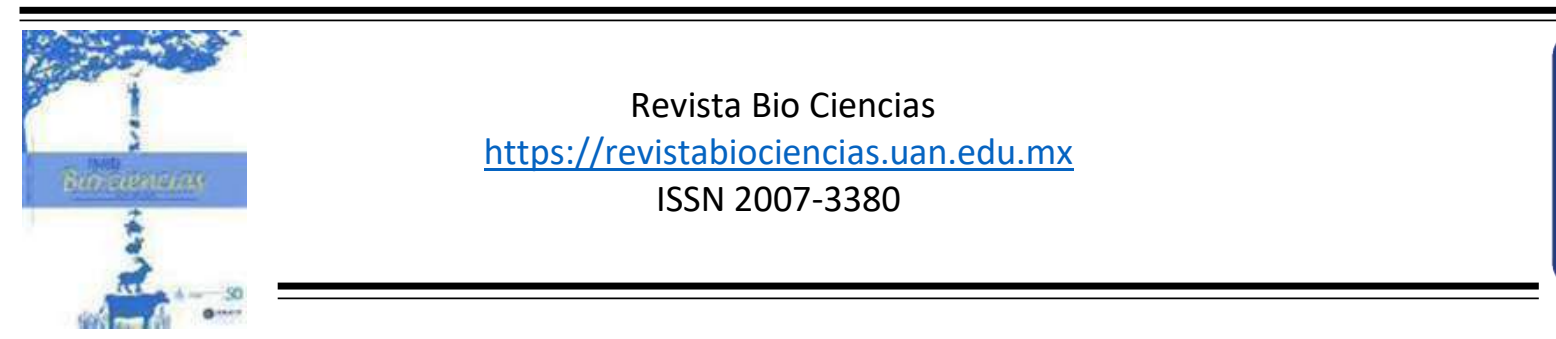

Trabajos libres: Cardiovascular y Sistema Muscular

Modalidad de Presentación: Cartel

\title{
La apocinina mejora la función muscular en ratas con diabetes experimental
}

\author{
Sánchez Duarte, S. ${ }^{1}$, Sánchez Duarte, E. ${ }^{2}$, Márquez Gamiño, S. ${ }^{2}$, Vera Delgado, K., $S^{2}$, Bravo \\ Sánchez., E. ${ }^{1}$, Montoya Pérez, R. $^{1 *}$ \\ ${ }^{1}$ Universidad Michoacana de San Nicolás de Hidalgo. Laboratorio de Fisiología Muscular. \\ ${ }^{2}$ Departamento de Ciencias Aplicadas al Trabajo, Universidad de Guanajuato, Campus León
}

*Autor Corresponsal: Rocío Montoya Pérez. E- mail: rmontoya@umich.mx

El estado hiperglucémico crónico durante la diabetes mellitus (DM) se ha relacionado con un incremento del estrés oxidante, lo que provoca un daño al tejido músculo esquelético, contribuyendo a la aparición de la fatiga muscular, caracterizada por la disminución de la fuerza. En consecuencia, esta condición compromete la capacidad de los individuos para realizar actividad física. La apocinina es un fármaco que además de ser un inhibidor específico de la NADPH oxidasa, presenta propiedades antioxidantes en modelos experimentales de resistencia a la insulina. Sin embargo, se desconoce el efecto de la apocinina sobre la salud del músculo esquelético durante la DM. Por lo tanto, a fin de preservar la estructura y función del músculo, el objetivo de este estudio fue evaluar el efecto del tratamiento con apocinina sobre la función muscular en un modelo de diabetes experimental. Se utilizaron ratas macho Wistar (230-250 g) a las cuales se les indujo diabetes vía intraperitoneal con estreptozotocina (45 $\mathrm{mg} / \mathrm{kg}$ ). El tratamiento con la apocinina (3 $\mathrm{mg} / \mathrm{kg} / \mathrm{día}$ ) fue administrado durante 8 semanas y al finalizar el tratamiento, los músculos extensores digitorum longus (EDL) fueron aislados y se realizó un protocolo de tensión isométrica (estimulación eléctrica repetitiva: pulsos de $100 \mathrm{~V}, 300 \mathrm{~ms}$ de duración y frecuencia de 45 y $50 \mathrm{~Hz}$, respectivamente). El tratamiento con la apocinina contribuyó a un aumento significativo en el tiempo de resistencia a la fatiga $(88.23 \%$; $p<0.05)$ y mejoró la tensión muscular máxima $(72.23 \% ; p<0.5)$ y total $(80 \% ; p<0.5)$ comparado al grupo diabético. Adicionalmente, se observó un efecto positivo sobre el peso y una disminución del nivel de glucemia. En conjunto, estos resultados nos indican que la apocinina ejerció un efecto protector sobre el tejido músculo esquelético durante la diabetes. 


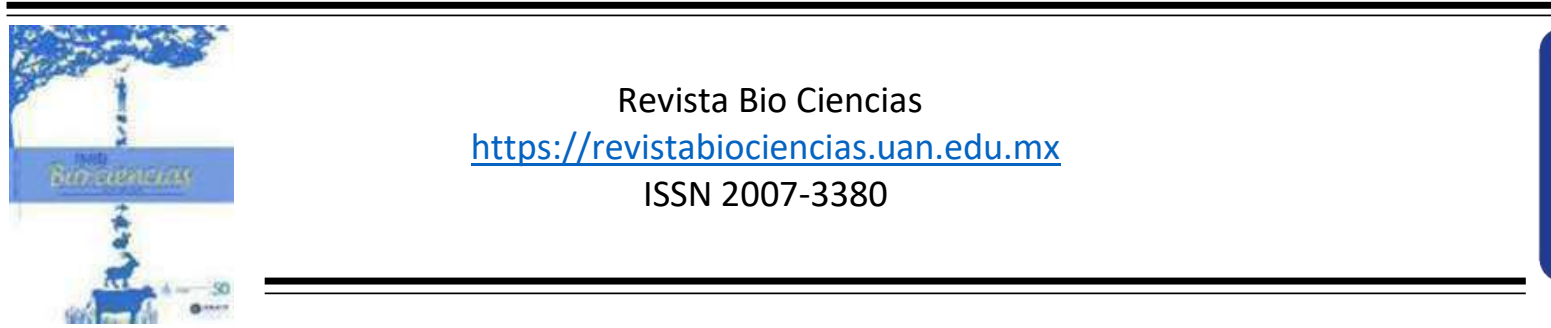

Trabajos libres: Cardiovascular y Sistema Muscular

Modalidad de Presentación: Cartel

\title{
Desorganización del sistema de túbulos $\mathrm{T}$ y desregulación del calcio intracelular en cardiomiocitos de rata ZDF-Gn, un subgrupo no diabético y obeso de las ratas ZDF
}

\author{
González Sandoval, S., Ramírez González, A., Galindo Ramírez, F., Avelino Cruz, J. E. * \\ Benemerita de la Universidad de Puebla.Instituto de Fisiología \\ *Autor Corresponsal: José Everardo Avelino Cruz. E- mail: everardo.avelino@correo.buap.mx
}

Las ratas ZDF presentan una mutación en el receptor de leptina que las predispone a desarrollar obesidad y diabetes mellitus tipo 2, sin embargo, un subgrupo de estas, las ZDF-Gn, solo desarrolla obesidad. Datos previos de nuestro laboratorio muestran que los cardiomiocitos de las ratas ZDF presentan disminución de la contracción, alteraciones en la regulación de calcio y desorganización del sistema de túbulos T (STT). En este trabajo evaluamos si las ratas ZDF-Gn presentan alteraciones estructurales del STT y en la regulación de calcio intracelular. Utilizamos microscopia confocal para estudiar los sparks, transitorios de calcio y el arreglo del STT en cardiomiocitos ventriculares aislados de ratas macho ZDF Gn y Lean, portadora asintomática de la mutación, de 13 semanas de edad. Al comparar con el grupo Lean, las ratas ZDF-Gn presentan una desorganización del STT en ambos ventrículos según los valores del TT index (v. izquierdo:74.7 \pm 0.6 ; v. derecho:73.9 $\pm 1 \%$ en ratas ZDF $G n$ vs $80.5 \pm 0.6 \%$ y $83.7 \pm 0.7 \%$, respectivamente, en ratas Lean). En el ventrículo izquierdo, aumentó la masa de los sparks de calcio debido a un incremento de $\approx 100 \%$ en su amplitud y frecuencia $(p<0.05)$. En el ventrículo derecho, la amplitud de los sparks aumentó, pero el tamaño disminuyó y su masa no presentó cambios significativos. Con respecto a los transitorios de calcio, en el ventrículo izquierdo, encontramos una disminución de $\approx 10 \%$ del nivel diastólico de calcio y un aumento de $\approx 30 \%$ en la tau de decaimiento. Del lado derecho, la amplitud del transitorio aumento un $\approx 17 \%$, el calcio medio un $\approx 15 \%$ y el tiempo al pico $\approx 5 \%$. En conclusión, las ratas ZDF no diabéticas presentan una desorganización del STT, una mayor fuga de calcio en el ventrículo izquierdo y una disminución de la velocidad de liberación del calcio en el derecho, lo que podría alterar el acople excitación-contracción. 


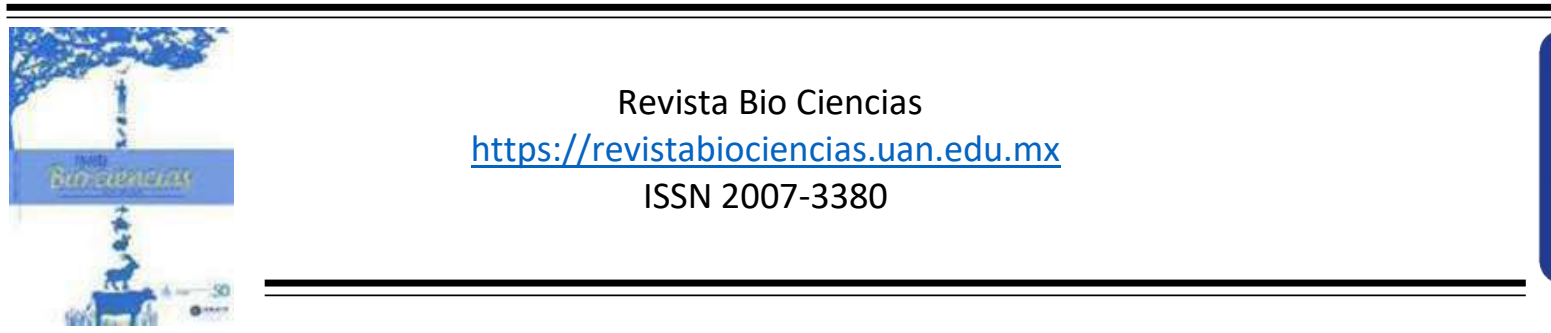

Trabajos libres: Cardiovascular y Sistema Muscular

Modalidad de Presentación: Oral

\section{Cambios en el electrocardiograma en crías de madres con una dieta alta en carbohidratos}

Mitre Velasco, Y., Jacome Torres, J., Gil Rodriguez, J., Arroyo Carmona., R., Albarado Ibañez A. *

Benemerita de la Universidad de Puebla. Fisiología.

*Autor Corresponsal: Alondra Albarado Ibañez. E- mail: a100102@hotmail.com

La nutrición durante el embarazo tiene un impacto en la salud de la progenie, tanto al momento de nacer como a largo plazo, predisponiendo a la progenie a padecer enfermedades durante su edad adulta, si la dieta durante el embarazo no es adecuada. Este trabajo tiene por hipótesis que la obesidad infantil inicia desde el embarazo, y por consecuencia incrementa el riesgo a padecer enfermedades cardiovasculares. Para este estudio se usaron crías de madres con una dieta alta en carbohidratos y control. Se tomaron dos registros de electrocardiograma de cada camada, el primero a los dos meses de edad, con una dieta normal y el segundo se realizó a los tres meses con un mes de dieta alta en sacarosa. Se calcularon los intervalos R-
$R$ de cada registro y con esto la frecuencia y variabilidad (SD1 y SD2) cardiaca de cada individuo. Los resultados mostraron que en machos los hijos de madres sanas disminuyeron su frecuencia cardiaca al engordar, cosa que no sucedió con los hijos de madres obesas, sin embargo, estos últimos disminuyeron su variabilidad. En el caso de las hembras el único cambio significativo entre el primer y segundo registro fue de la variabilidad en SD2, aun cuando su incremento de peso sí fue significativo. A partir de los datos obtenidos, se puede concluir que el estado de nutrición de la madre afecta la actividad eléctrica del corazón a lo largo de la vida de las crías sólo en el caso de los machos. R., Albarado Ibañez A. (2020). Cambios en el electrocardiograma en crías de madres con una dieta alta en carbohidratos. Bio Ciencias 7: (Suppl) Memorias de Congreso. LXIII Congreso Nacional de la Sociedad Mexicana de Ciencias Fisiologicas, A. C. e1097. 


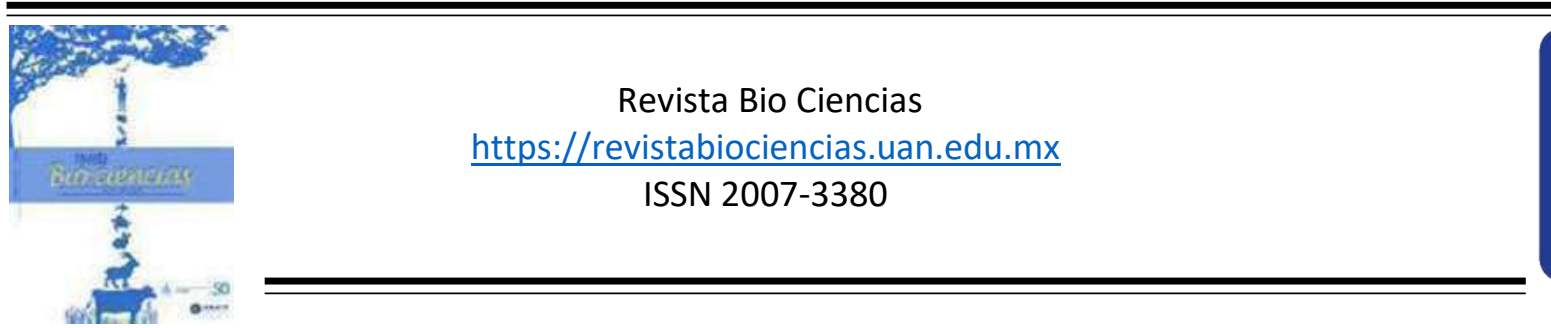

Trabajos libres: Cardiovascular y Sistema Muscular

Modalidad de Presentación: Cartel

\title{
Efecto del agonista Isoproterenol en la variabilidad de la actividad eléctrica del nodo sinoatrial aislado de rata
}

\author{
Huanosta Gutiérrez, A. ${ }^{1}$, González Gómez, G. H. ${ }^{2}$, Echeverría Arjonilla, J. C. ${ }^{1}$, Godínez Fernández, \\ R. $^{{ }^{*}}$ \\ ${ }^{1}$ Universidad Autónoma Metropolitana. Departamento de Bioingeniería. ${ }^{2}$ Facultad de Ciencias
UNAM
}

*Autor Corresponsal: Rafael Godínez Fernández. E- mail: gfjr@xanum.uam.mx

Las células del nodo seno atrial (NSA), también llamadas células marcapaso del corazón, determinan la frecuencia cardiaca (FC). La regulación de la FC se produce por la descarga sincrónica de un grupo de células y aún se desconocen los mecanismos de sincronización de estos grupos celulares. Por otro lado, la FC también está regulada por los sistemas simpático y parasimpático, la interacción entre los estímulos de éstos se refleja en la variabilidad de la frecuencia cardiaca (VFC). Una técnica para caracterizar señales complejas como la VFC en el NSA es el Análisis de Fluctuaciones Sin Tendencia (DFA) que proporciona una estimación de las correlaciones a largo plazo que son medidas con un exponente de escalamiento llamado $\alpha$. En este proyecto, se realizó una caracterización electrofisiológica de la actividad eléctrica poblacional del NSA aislado en condiciones control y en presencia del agonista simpático isoproterenol. Las señales fueron analizadas en tres programas: Uno para la captura de los datos y despliegue de la señal completa. Otro para el análisis de los periodos. Finalmente, uno para el análisis de la variabilidad de los periodos con la técnica de DFA. De acuerdo con las propiedades de correlación fractal descritas por el exponente $\alpha$ en el DFA, nuestros resultados muestran que en la actividad eléctrica espontánea de NSA (control) obtuvimos un valor de $\alpha=0.671 \pm 087$ y en presencia de Isoproterenol $\alpha=0.903 \pm 0.376 \quad(n=7)$. Estos resultados indican que, en general, ocurre una disminución en la irregularidad de la señal eléctrica en el NSA, es decir que la actividad tiende a volverse menos aleatoria en presencia del agonista isoproterenol comparada con el control. Esto concuerda bien con resultados previos de VFC reportados en personas y modelos animales, en que se observa que ante un incremento de la actividad simpática, se reduce la irregularidad y la VFC. 


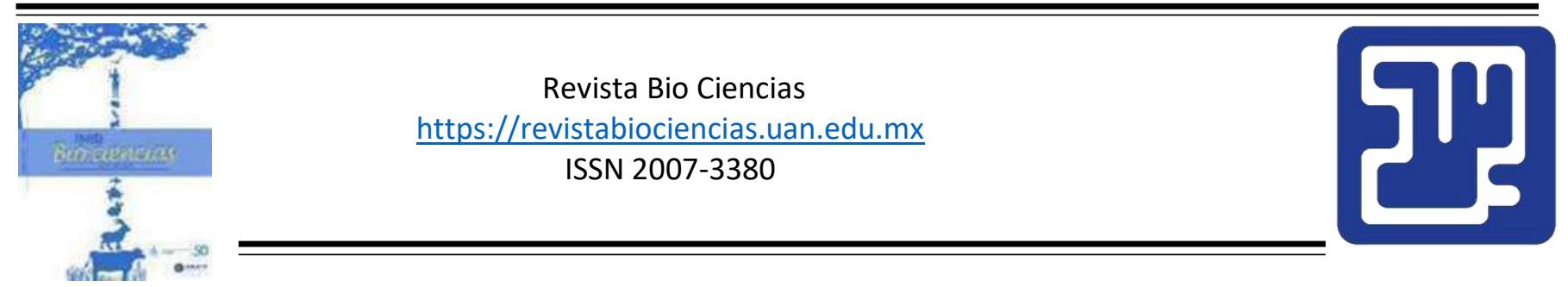

Cite this paper/Como citar este artículo: Terrazas L. I., Peón A. N. (2019). Expresión de receptores dopaminérgicos y serotoninérgicos de pacientes con esquizofrenia tratados con risperidonaRevista Bio Ciencias 6: (Suppl) Memorias IV Congreso de la Sociedada Mexicana de Neuroinmunoendocrinología. e841. http://doi.org/10.15741/revbio.06.Suppl.e841 


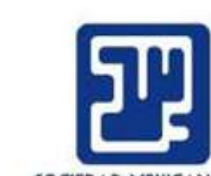

SOCIEDAD MEXICANA DE CIENCIAS FISIOLOGICAS, A.C

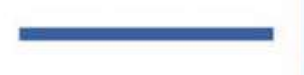

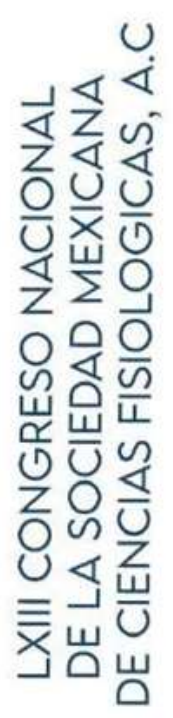
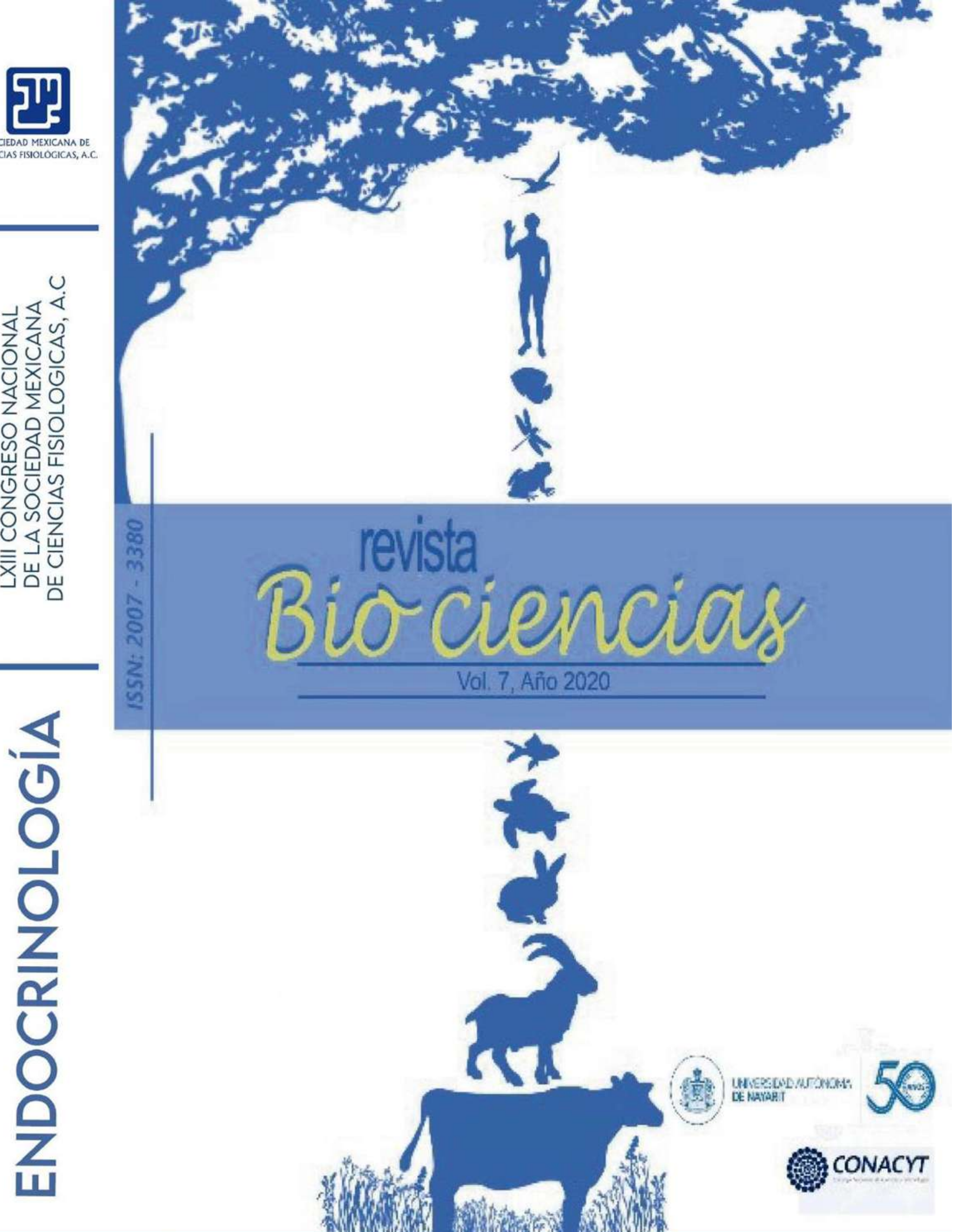


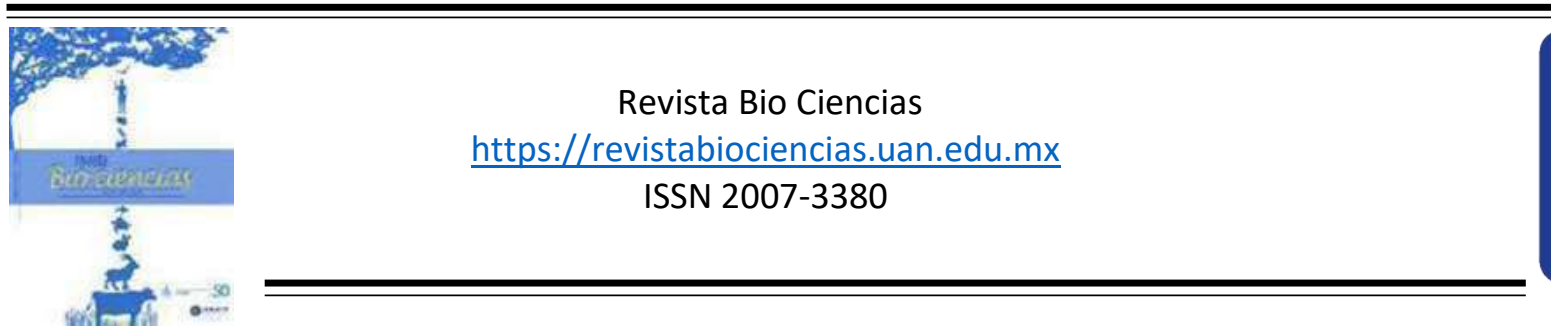

Trabajos libres: Biología: Endocrinología

Modalidad de Presentación: Cartel

\title{
Efecto de la sección unilateral del nervio vago sobre la fertilidad en ratas con síndrome de ovario poliquístico
}

\author{
${ }^{1}$ Chaparro Ortega, A., Martínez Hernández, E. ${ }^{1}$ Espinoza Moreno, J. A. ${ }^{2}$, Linares Culebro, R. ${ }^{1}$, \\ Morales Ledesma, L. ${ }^{\text {* }}$ \\ 1 Universidad Nacional Autónoma de México Facultad De Estudios Superiores Zaragoza. \\ Laboratorio de Fisiología Reproductiva. ${ }^{2}$ Benemerita Universidad Autonoma de Puebla \\ *Autor Corresponsal: Leticia Morales Ledesma. E- mail: moralesledesma@yahoo.com.mx
}

El nervio vago (NV) es una vía neural que regula las funciones del ovario y que participa en el desarrollo y mantenimiento del síndrome de ovario poliquístico (SOPQ). Esta patología se caracteriza por: alteración en la secreción de gonadotropinas, hiperandrogenismo, formación de quistes y oligo-anovulación. Un modelo experimental que reproduce mejor estas características es la inyección de una dosis de valerato de estradiol (VE). En la rata prepúber 0 adulta con SOPQ por administración de VE, la sección unilateral del NV restablece la ovulación, sin embargo, desconocemos si estos ovocitos son fértiles. Para probarlo, se inyectó a ratas hembra de la cepa CII-ZV de 10 días de edad, $0.1 \mathrm{ml}$ de aceite de sésamo (Vh), o 2 mg de VE. 50 días después fueron sometidas a la sección del NV izquierdo (SNVI) o derecho (SNVD) y a los 70 días de edad en proestro, se colocaron con un macho de fertilidad probada. Presentaron espermas el $100 \%$ de los animales inyectados con $\mathrm{Vh}$ y vagotomizados, en las ratas VE+SNVI el $66 \%$ y el $75 \%$ con VE+SNVD. A pesar de la presencia de espermatozoides no todos los animales quedaron preñados. La tasa de fertilidad fue del $83 \%$ en los animales $V h+S N V I$ y del $100 \%$ en las ratas $V h+S N V D$, en las ratas VE+SNVI fue del $11 \%$ y en el grupo VE+SNVD del $12.5 \%$. De los animales con el SOPQ y que no quedaron preñados, el análisis de la morfología ovárica reveló la presencia de quistes, pero también de cuerpos lúteos, indicativo de ovulación. Los datos obtenidos hasta el momento indican que en la rata con SOPQ la vagotomía unilateral restablece la ovulación, sin embargo, es posible que se haya alterado la calidad del ovocito lo que no permitió la fecundación. Investigación apoyada por los programas: UNAM-DGAPA-PAPIIT IN216519 y Becas Posdoctorales en la UNAM. Linares Culebro, R., Morales Ledesma, L. (2020). Efecto de la sección unilateral del nervio vago sobre la fertilidad en ratas con síndrome de ovario poliquístico. Revista Bio Ciencias 7: (Suppl) Memorias de Congreso. LXIII Congreso Nacional de la Sociedad Mexicana de Ciencias Fisiologicas, A. C. e1097. http://doi.org/10.15741/revbio.07Suppl.e1097 


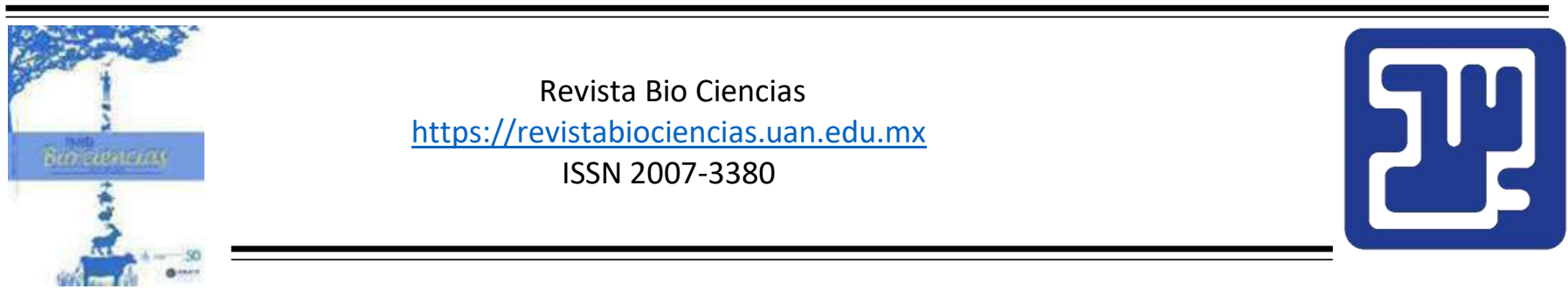

Trabajos libres: Endocrinología

Modalidad de Presentación: Cartel

\title{
Los estudiantes hombres del nivel medio superior expresan mayores niveles de cortisol durante el periodo de exámenes
}

\author{
Silva Gómez, A. B. ${ }^{* 1}$, Castelán Martínez, S. ${ }^{2}$, Hernández Mendez, B. ${ }^{2}$, Molina Hernández, J.2, \\ Rubalcaba Silva, M. X.2, Saavedra Cortés, K. E. ${ }^{2}$ \\ ${ }^{1}$ Benemerita Universidad Autonoma de Puebla. Facultad de Ciencias Biologicas. ${ }^{2}$ Instituto \\ Mexicano Madero \\ *Autor Corresponsal: Adriana Berenice Silva Gómez. E- mail: berenice71@yahoo.com
}

El estrés es un estado fisiológico alterado en respuesta a un "estimulo estresante". Dicha tensión provoca manifestaciones cognitivas, emocionales y conductuales para la búsqueda de la adaptación a las condiciones que enfrenta. El cortisol es una hormona que se libera como respuesta a los estímulos estresantes. Durante la adolescencia, el ámbito académico puede generar estrés debido a la sobrecarga académica por la entrega de trabajos, la participación oral frente al grupo, el hacinamiento y los exámenes provocando alteraciones fisiológicas, psicológicas 0 de comportamiento. Se cuantificó los niveles de cortisol en sangre de alumnos de tercer año de bachillerato del Instituto Mexicano Madero Plantel Centro, para conocer sus niveles de estrés durante una semana de clases (actividades regulares) y en el tercer día de la semana de evaluaciones finales del semestre. Se tomaron muestras de sangre a 27 voluntarios (14 mujeres y 13 hombres) de 17 a 18 años de edad, para cuantificar la concentración de cortisol y de glucosa. Los niveles promedio de glucosa se encontraron dentro de los valores normales en ambos muestreos. Los niveles de cortisol de los hombres son altos en ambos momentos respecto de los niveles de cortisol en las mujeres (que expresan niveles en el rango de referencia "nomal") y significativamente más altos durante el periodo de exámenes respecto del periodo de clases. Sugerimos que las mujeres, muestran un adecuado manejo de sus emociones en ambos momentos mientras que nuestros resultados sugieren que los estudiantes hombres se estresan de manera significativa ante las actividades académicas, siendo el periodo de exámenes un detonante en la liberación de cortisol. Sugerimos que los niveles de glucosa no influyeron en los resultados encontrados de cortisol y de acuerdo a algunos estudios, sugerimos un efecto neuroprotector de los estrógenos, lo que nos deja nuevas preguntas de investigación. 


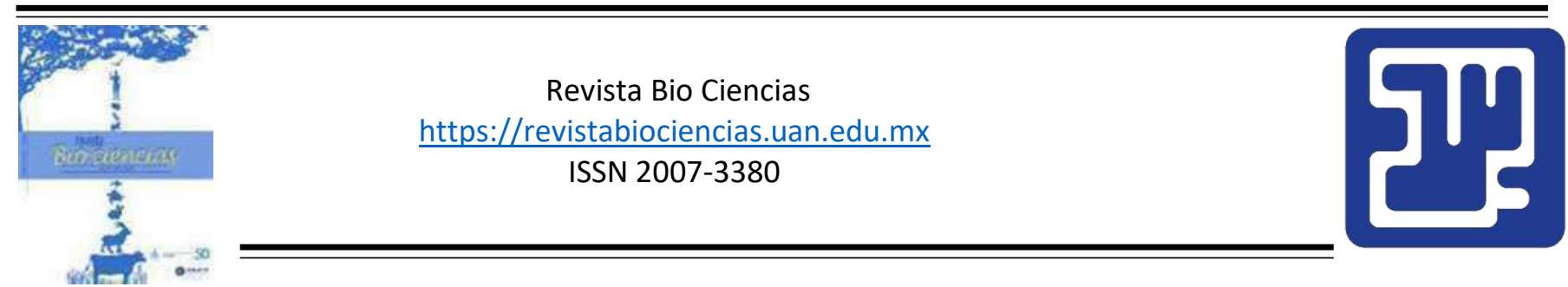

Trabajos libres: Endocrinología

Modalidad de Presentación: Oral

\section{El efecto del desarrollo puberal sobre el razonamiento espacial}

Guerra Flores, G., Coronado López, K. B., González González, J. A., Ramírez Tule, M. C. García García, M. A. Valdez Ramírez, P., Borrani Valdés, J. B. *

Universidad Autonoma de Nuevo León. Laboratorio de Psicofisiología, Facultad de Psicología *Autor Corresponsal: Jorge Benjamín Borrani Valdés. E- mail: jorgeborrani@gmail.com

El razonamiento espacial es la capacidad de manipular la información visual que ha sido percibida. La ejecución en tareas de razonamiento espacial mejora con mayores niveles de testosterona, cuya producción aumenta durante la pubertad. Sin embargo, no se ha analizado si hay una mejora en el razonamiento espacial relacionada al desarrollo puberal, únicamente se ha observado con la edad y el grado escolar. Es importante analizar el efecto de la pubertad sobre el razonamiento espacial independientemente de la edad y la escolaridad. Participaron 36 niñas y 28 niños de 10 a 12 años de edad (10.28 \pm 0.98 años) desde 4to hasta 6to grado de primaria (5.13 \pm 1.0 años escolares). Los grupos de alto y bajo desarrollo puberal se formaron con participantes sin diferencias en edad $y$ escolaridad, pero con puntajes por encima o por debajo de la media grupal en la Escala de Desarrollo Puberal (que mide el desarrollo de los caracteres sexuales secundarios). Para evaluar el razonamiento espacial se midió tiempo y aciertos en la tarea de Habilidades Espaciales; en la cual se presenta una figura irregular con otras cuatro figuras, el participante elige la figura que completa un cuadrado al unirse a la figura irregular. Los niños con alto desarrollo puberal tuvieron más aciertos (11.71 \pm 2.64 aciertos) en la tarea $(\mathrm{U}=32.50, p<0.01)$ que los de bajo desarrollo puberal (9.14 \pm 2.24 aciertos) y ambos tardaron lo mismo. Las niñas con alto desarrollo puberal tardaron menos tiempo $(2.03 \pm 0.7$ minutos) en contestar $(U=99.00, p<0.05)$ que las de bajo desarrollo puberal (2.58 \pm 1.0 minutos) y ambas tuvieron los mismos aciertos. En conclusión, el desarrollo puberal mejora el razonamiento espacial de niños y niñas, independientemente de la edad y la escolaridad. Esto implica que niños y niñas de la misma edad tienen diferente capacidad para manipular información visual, la cual es crucial para realizar actividades académicas y deportivas. 


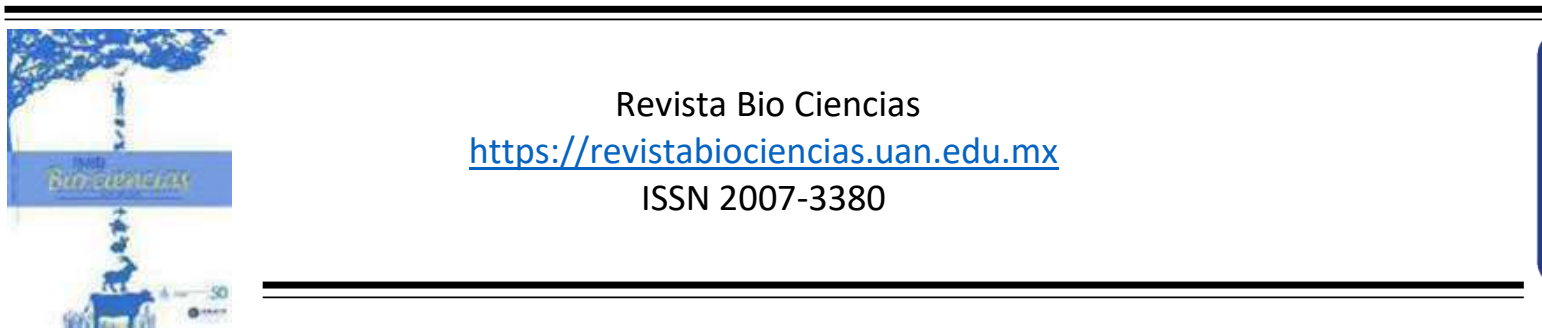

Trabajos libres: Endocrinología

Modalidad de Presentación: Cartel

\section{Efecto del estrés sobre la memoria de procedimiento en ratas macho adrenalectomizadas}

Alanís González, M., González López, M. R. Z., García Saldívar, N. L., Cruz Morales, S. A. *

Universidad Nacional Autónoma de México. Facultad de Estudios Superiores Iztacala. Laboratorio de Psicofarmacología

*Autor Corresponsal: Sara Eugenia Cruz Morales. E- mail: saracruz@unam.mx

Existen diversos estudios que demuestran que las fases de la memoria pueden ser modificadas por el estrés o por la concentración de glucocorticoides en plasma. Hay pocos estudios que analizan los efectos producidos en diferentes tipos de memoria cuando se elimina la producción de glucocorticoides por adrenalectomia. En este trabajo se estudió el efecto del estrés por restricción $15 \mathrm{~min}$, o por la inyección de corticosterona $1 \mathrm{mg} / \mathrm{kg}$ pre-entrenamiento, en ratas macho adrenalectomizadas, que ejecutaron la tarea de laberinto elevado en T (LET). Mediante esta tarea se puede evaluar la memoria de procedimiento. Se utilizaron 32 ratas Wistar macho asignadas a diferentes grupos, uno sometido a LET sin adrenalectomía (LET) y tres grupos adrenalectomizados, uno expuesto a LET (ALET), otro a restricción 15 min antes de LET (AR15-LET) y otro inyectado con corticosterona $1 \mathrm{mg} / \mathrm{kg}$ antes de LET (ACORT-LET). En los sujetos adrenalectomizados se tomó glucosa en diferentes tiempos y se midió el peso de las gónadas. En la fase de adquisición no hubo diferencias significativas. En la retención hubo deterioro de la memoria entre los grupos ALET, AR15-LET contra LET y ACOR-LET. Hubo disminución del peso testicular en los sujetos adrenalectomizados y se observaron cambios en la concentración de glucosa en los diferentes intervalos. En este experimento asumimos que en sujetos adrenalectomizados no hay corticosterona o la concentración es muy baja. Cuando se inyectó corticosterona en $1 \mathrm{mg} / \mathrm{kg}$ los sujetos tuvieron buena ejecución similar al grupo sin adrenalectomía. Cuando se restringieron los sujetos adrenalectomizados hubo deterioro de la retención asociada a baja 0 nula concentración de corticosterona, es probable que otros procesos neuroquímicos participen en el deterioro de la memoria en sujetos restringidos. Por lo que se concluye que la corticosterona liberada en las glándulas suprarrenales está involucrada en la consolidación de la memoria de procedimiento. 


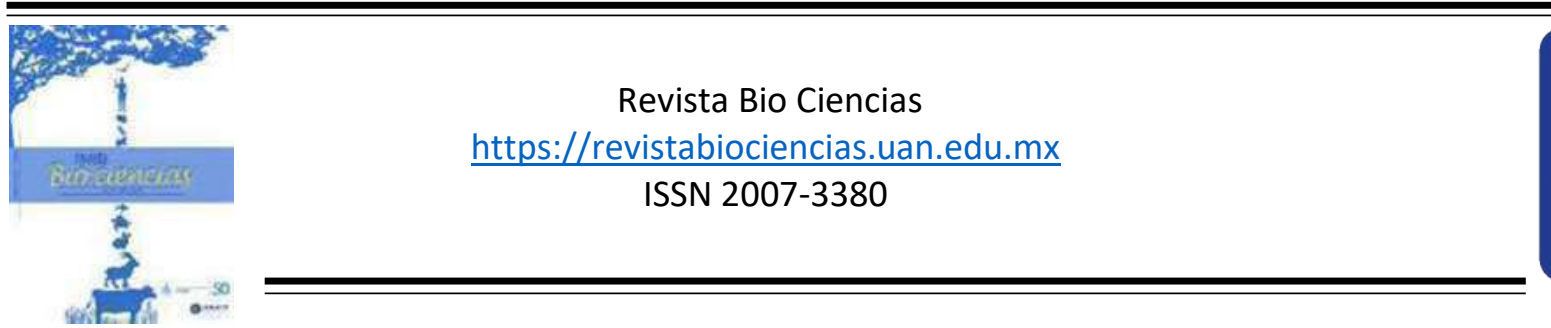

Trabajos libres: Endocrinología

Modalidad de Presentación: Cartel

\title{
The protective effect of vasopressin deficiency in liver fibrosis in rats with chronic portocaval anastomosis
}

\author{
Navarro Gonzalez, Y. D., Tinajero Ruelas, M., Gonzalez Blas, D. Ventura Juarez, J., Muñoz Ortega, \\ M. H. Quintanar Stephano. A. * \\ Universidad Autónoma De Aguascalientes. Departamento De Fisiología \\ *Autor Corresponsal: Andres Quintanar Stephano. E- mail: aquinta@correo.uaa.mx
}

Liver fibrosis occur in liver diseases and its complications is cause of the increased rate of human mortality. The disease is characterized by the gradual accumulation of scar tissue in the liver parenchyma with decrease in metabolic capacity and liver failure. It is known that arginine vasopressin (AVP) participate in the regulation of the immune responses, including the scarring. However, the effect of how AVP regulates this process is not clear. Here we study the role of the AVP deficiency induced by the neurointermediate pituitary lobectomy (NIL) in rats with chronic anastomosis portocaval (APC) model (sixteen weeks). Groups of young male Wistar rats of 8-10 each were prepared: Sham operated (SHAM), APC, LNI and APC+NIL. Blood, plasma and serum biochemical variables were assessed: prothrombin time (TP), blood NH3, transaminases (TGO and TGP), bilirubins and $Y$-Glutamyl Transpeptidase (GGT). Liver histological slides were stained with $\mathrm{H}-\mathrm{E}$, Masson, Sirius Red and PAS. Results showed that in the APC group: the TP, NH3, TGO and
TGP, bilirubins and GGT were significantly increased, whereas serum glucose levels, cholesterol, triglycerides, albumin, total proteins and the liver glycogen content where significantly augmented. Comparisons between SHAM and NIL groups did not shown significant differences in all these variables. As compared with the APC, the APC+NIL group developed a significant improvement in all these variables. The liver histopathology showed that the APC group developed a significant increase in fibrosis septa, inflammatory infiltrates and diminution of the glycogen content. The NIL group we do not have available data yet. In the NIL+APC group histology data showed a significant liver regeneration; less fibrosis, disappearance of inflammatory infiltrates and liver glycogen restoration. Conclusions. Results indicate the AVP play a role in liver fibrosis (demonstrated by the AVP deficiency). Results also suggest that AVP antagonists may be used for liver fibrosis treatment. 


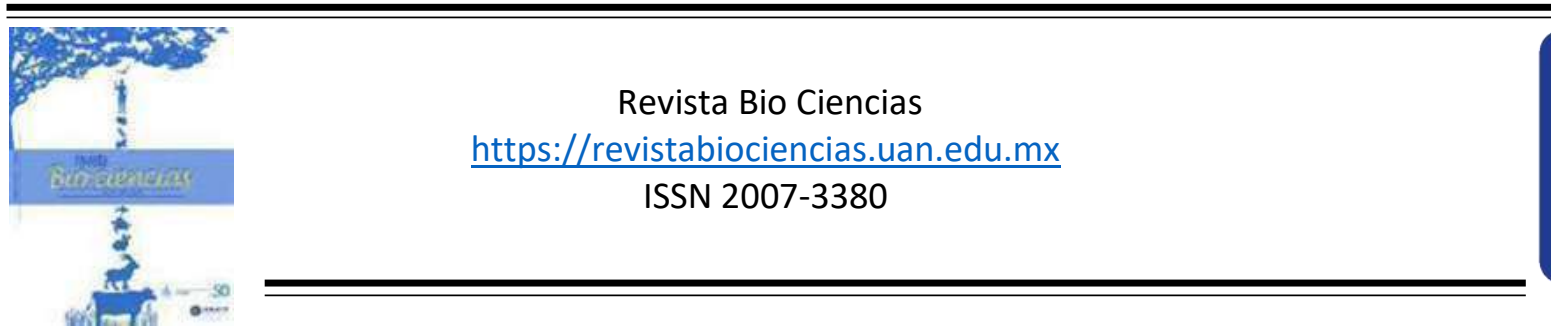

Trabajos libres: Endocrinología

Modalidad de Presentación: Cartel

\title{
Efecto del estímulo gonadotrópico, sobre la dinámica del crecimiento folicular de ratas con síndrome de ovario poliquístico
}

\author{
Cervantes Palafox, M. A., Ramírez Ramírez, A., Meza Medina, M. F., Linares Culebro, R., Morales \\ Ledesma. L. * \\ Universidad Nacional Autónoma de México. Facultad de Estudios Superiores Zaragoza. Centro De \\ Investigación en Reproducción Animal \\ *Autor Corresponsal: Leticia Morales Ledesma. E- mail: moralesledesma@yahoo.com.mx
}

El Síndrome de ovario poliquístico (SOPQ), cuya etiología es desconocida, se relaciona con una falla hipotalámica, que resulta en el detenimiento del crecimiento de los folículos, formación de quistes y alteración en la concentración de estradiol. En el presente estudio se analizó el efecto del estímulo gonadotrópico sobre el desarrollo folicular y la concentración de estradiol en animales con SOPQ, inducido por la inyección de valerato de Estradiol (VE). A ratas hembra de la cepa CII-ZV, de 10 días de edad se les inyectó $2 \mathrm{mg}$ de VE, disuelto en $0.1 \mathrm{~mL}$ de aceite de sésamo que fungió como el vehículo (Vh). A los 72 días de edad algunos animales fueron estimulados con $8 \mathrm{UI}$ de gonadotropina coriónica equina (eCG), otros con $8 \mathrm{UI}$ eCG y 56 horas después con $10 \mathrm{Ul}$ de gonadotropina coriónica humana (hCG). Los animales se sacrificaron al estro inmediato al estímulo gonadotrópico. La inyección de VE resultó en el incremento del número de quistes respecto al grupo
Vh (VE: $9.7 \pm 2.4$ vs. Vh: 1.0 ), ausencia de cuerpos lúteos y pocos folículos sanos. En animales con SOPQ y estímulo gonadotrópico aumentó el número de cuerpos lúteos, respecto a los animales inyectados sólo con el VE (VE+eCG: $5.6 \pm 0.8, V E+e C G+h C G: 7.3 \pm 1.6$ vs. VE: $0)$; así como el número de folículos sanos

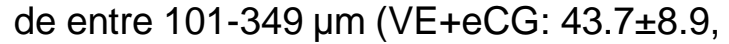
VE+eCG+hCG: $78.7 \pm 15.6$ vs. VE: $33 \pm 14.1)$, y se observaron pocos folículos de entre 350-449 $\mu \mathrm{m}$ (VE+eCG: $3 \pm 1.2$, VE+eCG+hCG: $3.3 \pm 0.9$ vs. VE: 3.0) y 500 $\mu \mathrm{m}$ (VE+eCG: 2 $\pm 0.6, \quad \mathrm{VE}+\mathrm{eCG}+\mathrm{hCG}$ : $1.5 \pm 0.5$ vs. VE: 3.0). El estímulo gonadotrópico no modificó la concentración de estradiol. Estos resultados nos permiten sugerir que en el modelo de la rata con SOPQ, las gonadotropinas favorecen la reactivación del crecimiento folicular, así como los mecanismos de liberación del ovuló y la subsecuente formación del cuerpo lúteo. Estudio apoyado por DGAPA-PAPIIT, clave IN216519. 


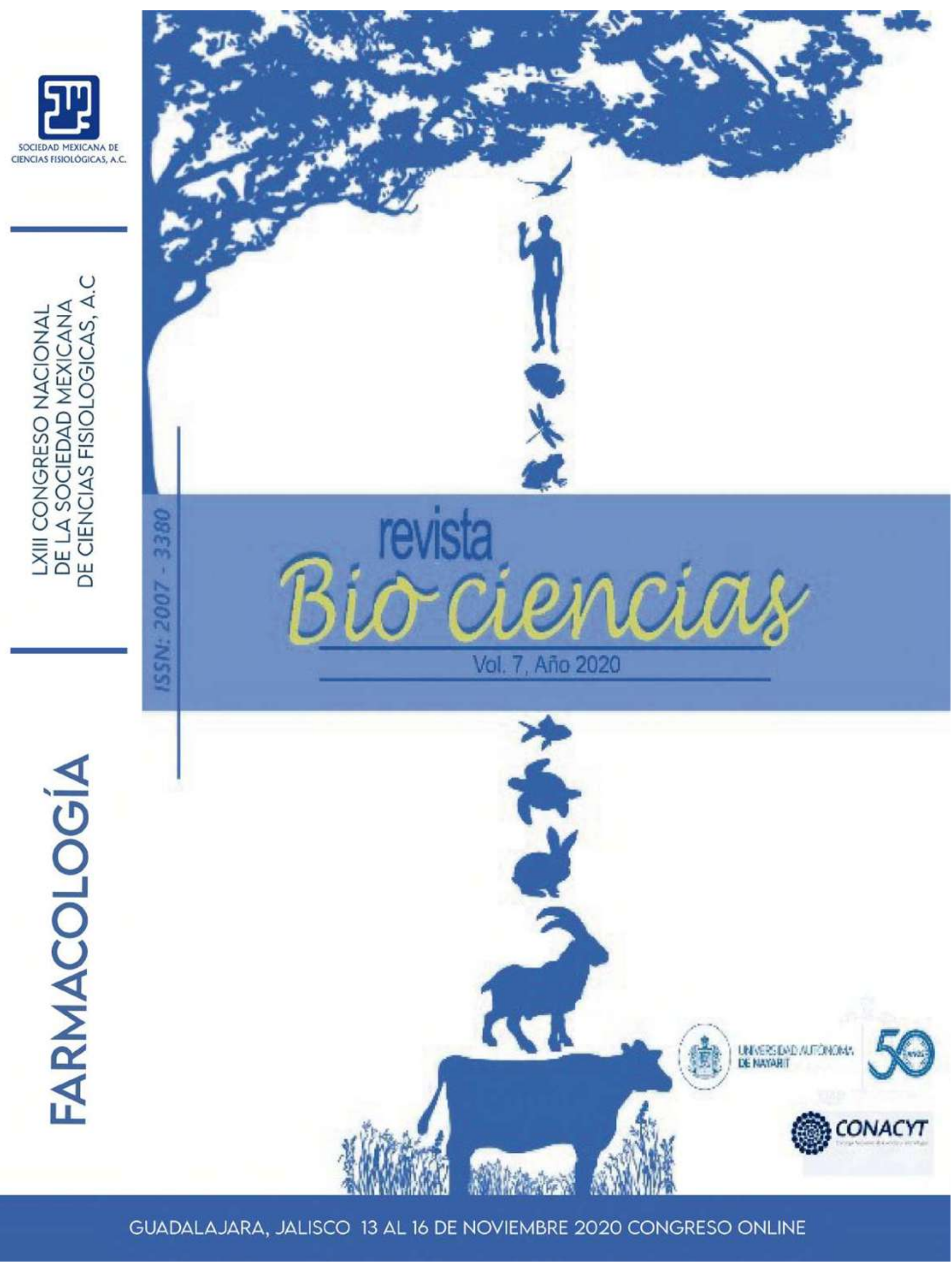




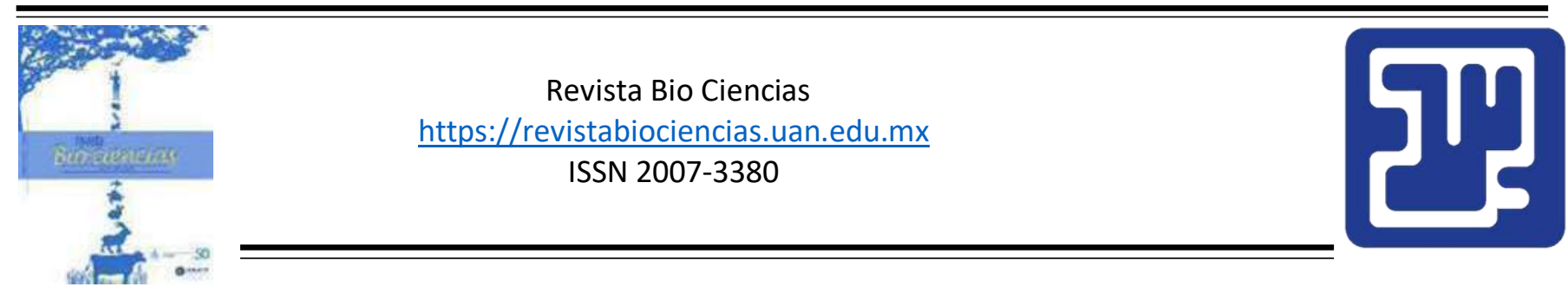

Trabajos libres: Farmacología

Modalidad de Presentación: Oral

\section{La ficoeritrina previene el estrés oxidativo renal provocado por la intoxicación con $\mathrm{HgCl} 2$}

Chao Vázquez, A., Rojas Franco, P., García Pliego, E., Blas Valdivia, V., Cano Europa, E., Franco Colín, $M . *$

Escuela Nacional de Ciencias Biológicas, IPN

*Autor Corresponsal: Margarita Franco Colín. E- mail: $\underline{\text { mfc22405@yahoo.com.mx }}$

El mercurio es un metal que se bioacumula en los riñones provocando una lesión renal aguda (LRA) ya que causa eventos de estrés oxidante y daño celular. Por otro lado, la ficoeritrina es un pigmento accesorio de cianobacterias rojas con acción antioxidante in vitro.

Bajo este contexto, el presente trabajo tuvo como objetivo determinar si la ficoeritrina previene el estrés oxidativo renal ocasionado por la intoxicación con $\mathrm{HgCl}$.

Para ello, se emplearon 24 ratones albinos macho de 20-25 g los cuales fueron divididos en seis grupos: 1 ) solución salina (SS) $0.9 \%$ ip + SS $0.9 \%$ ig, 2) $\mathrm{HgCl} 25 \mathrm{mg} / \mathrm{Kg}$ dosis única (DU) ip + SS 0.9\% ig, 3) (SS) $0.9 \%$ ip + ficoeritrina $100 \mathrm{mg} / \mathrm{Kg} / \mathrm{d}$ ig, 4) DU + ficoeritrina $25 \mathrm{mg} / \mathrm{Kg}$ por día, 5) DU + ficoeritrina 50 $\mathrm{mg} / \mathrm{Kg}$ por día y 6) $\mathrm{DU}$ + ficoeritrina $100 \mathrm{mg} / \mathrm{Kg}$ por día.
Los animales fueron eutanizados a los 5 días y se disecó el riñón para determinar marcadores de estrés oxidativo como peroxidación de lípidos, cuantificación de nitritos, especies reactivas del oxígeno (ROS) y glutatión oxidado.

Así mismo, se determinó la actividad de las caspasas 3 y 9 como marcadores de muerte celular.

Los resultados muestran que el mercurio incrementa los marcadores de estrés oxidante y la actividad de las caspasas 3 y 9 . Mientras que, los animales intoxicados con mercurio y tratados con ficoeritrina sólo disminuyeron la peroxidación de lípidos, ROS, glutatión oxidado, y la actividad de las caspasas. En conclusión, la ficoeritrina previene el estrés oxidativo inducido por la intoxicación aguda con $\mathrm{HgCl} 2$. estrés oxidativo renal provocado por la intoxicación con $\mathrm{HgCl}$. Revista Bio Ciencias 7: (Suppl) Memorias de Congreso. LXIII Congreso Nacional de la Sociedad Mexicana de Ciencias Fisiologicas, A. C. e1097. http://doi.org/10.15741/revbio.07Suppl.e1097 


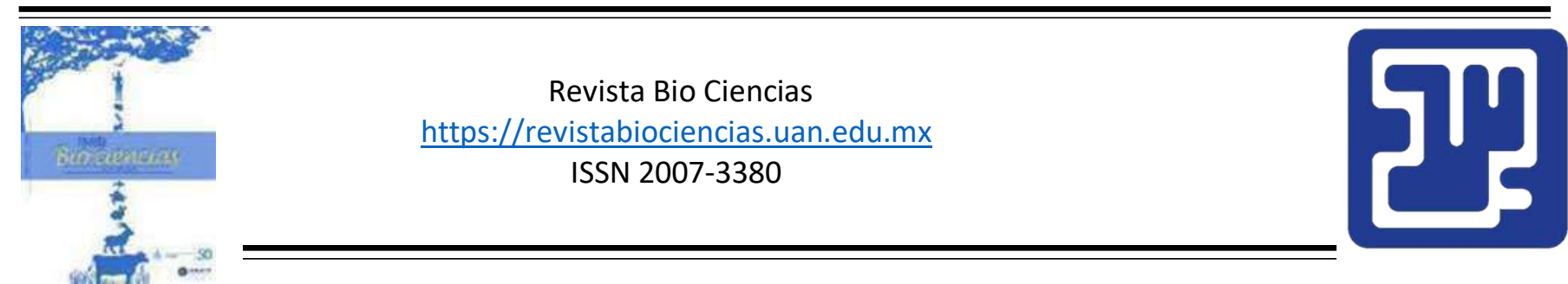

Trabajos libres: Farmacología

Modalidad de Presentación: Cartel

\begin{abstract}
Efecto antialodínico de 4 nuevos alcaloides sintéticos análogos de 3-OH-paroxetina en ratas neuropáticas
\end{abstract}

\author{
Godínez Chaparro, B. ${ }^{*}$, Salgado Moreno, G. ${ }^{1}$, Chamorro Arenas, $D .^{2}$, Sartillo Piscil, $P .^{2}$ \\ ${ }^{1}$ Universidad Autónoma Metropolitana Unidad Xochimilco \\ ${ }^{2}$ Benemerita Universidad Autonoma de Puebla
}

*Autor Corresponsal: Beatriz Godínez Chaparro. E- mail: betty godcha@yahoo.com.mx

El dolor neuropático es causado por una lesión o enfermedad del sistema nervioso somatosensorial, generando respuestas espontaneas como alodinia e hiperalgesia. El tratamiento farmacológico incluye el uso de antiepilépticos (gabapentina) y antidepresivos (paroxetina). El objetivo del presente estudio fue evaluar el efecto antialodínico inducido por 4 análogos de 3-hidroxiparoxetinas (3HPX) [(R, R)-3HPX, (R, S)-3HPX, (S, R)-3HPX y (S, $\mathrm{S})-3 \mathrm{HPX}$ ] en ratas neuropáticas. Para generar la alodínia táctil, a los animales se les ligaron los nervios espinales L5-L6. La alodínia táctil fue evaluada con los filamentos de von Frey por el método de up-down. Catorce días después de la cirugía, la administración intraperitoneal de paroxetina $(0.1-10 \mathrm{mg} / \mathrm{Kg})$ incrementó el umbral de respuesta de retiro de la pata de dosis-dependiente. El efecto antialodínico de paroxetina se observó $2 \mathrm{~h}$ después de la administración y la dosis de 10 $\mathrm{mg} / \mathrm{kg}$ alcanzó un porcentaje máximo de efecto posible (MEP) del $75 \%$ con una duración de $6 \mathrm{~h}$.
Asimismo, la administración intraperitoneal de $(\mathrm{R}, \mathrm{R})-3 \mathrm{HPX}$ y (S, R)-3HPX mostró un incremento en el umbral de retiro de la pata dosis-dependiente.Cabe destacar que $(R, R)$ $3 \mathrm{HPX}$ produjo el mejor efecto antialodínico a una dosis de $1 \mathrm{mg} / \mathrm{kg}$ alcanzando el $73.9 \%$ del MEP a las $2 \mathrm{~h}$. La DE50 de este análogo de paroxetina es $0.70 \mathrm{mg} / \mathrm{mg}$ mientras que la DE50 de paroxetina es de $1.7 \mathrm{mg} / \mathrm{kg}$, por lo tanto, $(R, R)-3 H P X$ es 2.5 más potente que la paroxetina in vivo. Por otro lado, $(R, S)-3 H P X$ y (S, R)-3HPX mostraron un efecto antialodínico modesto $34.6 \%$ y $41.5 \%$, respectivamente. Desafortunadamente, el análogo de paroxetina (S, S)-3HPX no mostró efecto antialodínico en ninguna dosis probada. Estos datos sugieren que la posición y orientación del grupo hidroxilo colocado en la posición C-3 desempeña un papel crucial en el efecto antialodínico inducido por los $3-\mathrm{OH}$ análogos de paroxetina, siendo el análogo $(R$, R)-3HPX el más que mostró mejor efecto antialodínico en ratas neuropáticas.

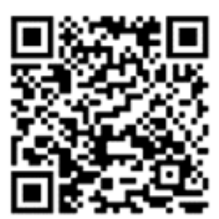

Cite this paper/Como citar este artículo: Godínez Chaparro, B., Salgado Moreno, G., Chamorro Arenas, D., Sartillo Piscil, P. (2020). Efecto antialodínico de 4 nuevos alcaloides sintéticos análogos de 3-OH-paroxetina en ratas neuropáticas. Revista Bio Ciencias 7: (Suppl) Memorias de Congreso. LXIII Congreso Nacional de la Sociedad Mexicana de Ciencias Fisiologicas, A. C. e1097. http://doi.org/10.15741/revbio.07Suppl.e1097 


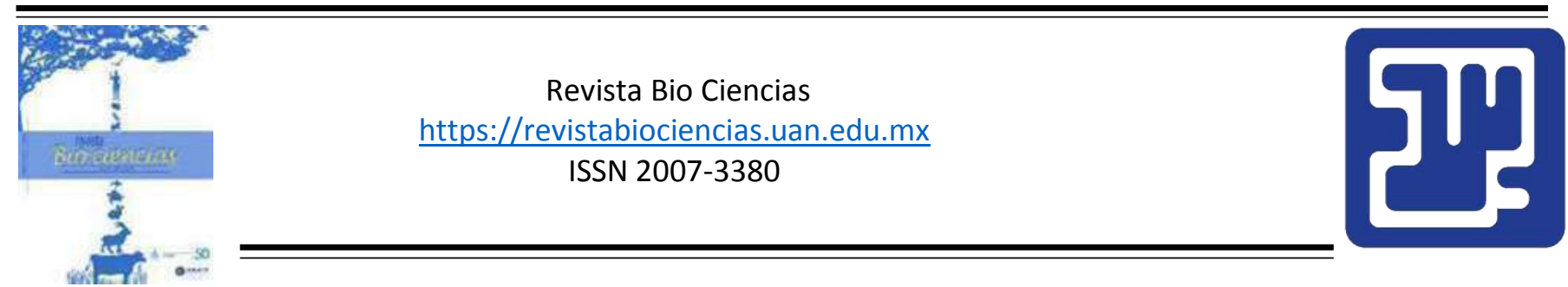

Trabajos libres: Farmacología

Modalidad de Presentación: Catel

\title{
El efecto antialodínico y antihiperalgésico producido por la combinación L-DOPA + celecoxib es mediado por la vía NO-GMPc-canales de K+ sensibles a ATP en ratas parkinsonianas.
}

\author{
Rodríguez Ramos, C., Godínez Chaparro, B.* \\ Universidad Autónoma Metropolitana Unidad Xochimilco
}

*Autor Corresponsal: Beatriz Godínez Chaparro. E- mail: bgodinez@correo.xoc.uam.mx

El dolor es uno de los síntomas no-motores más comunes y molestos de la enfermedad de Parkinson (EP), afectando negativamente la calidad de vida del paciente. La prevalencia del dolor en la EP alcanza hasta el $82 \%$. En la $E P$, el dolor se clasifica de acuerdo con el esquema de Ford como musculoesquelético, distónico, neuropático y dolor central. Actualmente, el tratamiento para el manejo del dolor en la EP no es claro. Algunos estudios sugieren optimizar el tratamiento dopaminérgico (L-DOPA) para mejorar el dolor, sin embargo, es eficaz sólo en aproximadamente el $30 \%$ de los pacientes con la EP. Además, un estudio reveló que el $81 \%$ de los pacientes con la EP toman analgésicos para mitigar el dolor y los antiinflamatorios no esteroideos (AINE) se utilizan con mayor frecuencia $(60 \%)$. Un estudio reciente determinó que la combinación de L-DOPA + celecoxib $(6.09+8.72 \mathrm{mg} / \mathrm{kg} / \mathrm{i}$. p.) produce una interacción sinérgica antialodínica y antihiperalgésica a nivel sistémico.
Por lo que el objetivo del presente estudio fue determinar si el efecto sinérgico antialodínico y antihiperalgésico inducido por la combinación de L-DOPA + celecoxib (6.09 +8.72 mg/kg/i.p.) es mediado por la vía del NO-GMPc-canales de K+ sensibles a ATP en ratas lesionadas unilateralmente con 6-OHDA en la sustancia nigra pars compacta (SNpc). La alodinia táctil y la hiperalgesia mecánica fueron evaluadas usando filamentos de von Frey. El efecto sinérgico antialodínico y antihiperalgésico inducido por la combinación L-DOPA + celecoxib fue bloqueado por la inyección intratecal de L-NAME (100 $\mu \mathrm{g} / \mathrm{rata})$, ODQ $(10 \mu \mathrm{g} / \mathrm{rata})$ y glibenclamida (50 $\mu \mathrm{g} / \mathrm{rata})$. Por lo tanto, estos resultados sugieren que uno de los mecanismos responsables de modular el efecto sinérgico antialodínico y antihiperalgésico de la combinación L-DOPA + celecoxib es a través de la activación de la vía NO-GMPc-canales de K+ sensibles a ATP, a nivel central, en ratas con la EP.

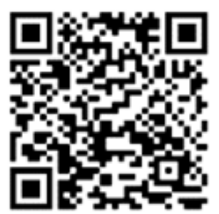

Cite this paper/Como citar este artículo: Rodríguez Ramos, C., Godínez Chaparro, B. (2020). El efecto antialodínico y antihiperalgésico producido por la combinación L-DOPA + celecoxib es mediado por la vía NO-GMPc-canales de $\mathrm{K}+$ sensibles a ATP en ratas parkinsonianas. Revista Bio Ciencias 7: (Suppl) Memorias de Congreso. LXIII Congreso Nacional de la Sociedad Mexicana de Ciencias Fisiologicas, A. C. e1097. http://doi.org/10.15741/revbio.07Suppl.e1097 


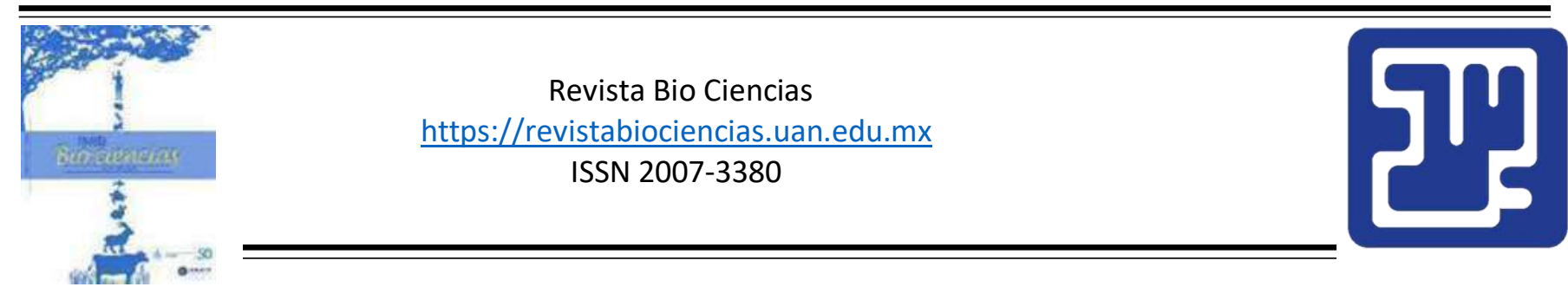

Trabajos libres: Farmacología

Modalidad de Presentación: Oral

\section{Interacción farmacológica en pacientes con diabetes tipo 2 en una población tabasqueña}

Ramírez González, D. ${ }^{1}$, Nolasco Rosales, G. A. ${ }^{1}$, Pérez Lopez, N. R. ${ }^{1}$, Suarez Méndez, S. ${ }^{1}$, Rodríguez Sánchez, . $^{2}$, Juárez Rojop, I. E. ${ }^{1 *}$

${ }^{1}$ Universidad Juarez Autonoma de Tabasco

${ }^{2}$ Hospital de Alta Especialidad Gustavo A. Rovirosa Perez

*Autor Corresponsal: Isela Esther Juarez Rojop. E- mail: iselajuarezrojop@hotmail.com

Los pacientes con DT2 requieren coadministración de fármacos para controlar su padecimiento además de otras comorbilidades, por lo que la polifarmacia ocurre frecuentemente. El riesgo de interacción farmacológica genera consecuencias y efectos adversos en pacientes con DT2. El resultado de esta interacción induce efectos variables en el tratamiento, consiguiendo ser positivos 0 negativos, y en consecuencia indeseables en su mayoría. La finalidad de este trabajo fue determinar la interacción farmacológica potencial en pacientes con diabetes tipo 2 en una población tabasqueña. En este estudio participaron 109 pacientes con DT2 de la Clínica de Diabetes del Hospital "Dr. Gustavo A. Rovirosa Pérez". Se registró características clínicas, parámetros bioquímicos, comorbilidades y régimen farmacológico. Se utilizó el sistema de revisión Drug Interaction Checker ${ }^{\circledR}$ para detectar interacción farmacológica. Los resultados fueron obtenidos por medio test T de Student y la $x^{2}$ de Pearson en frecuencia, porcentaje, media y derivación estándar. Los pacientes con DT2 estudiados utilizaba insulina y el $92.7 \%$ (101) empleaba otro medicamento antidiabético; el $38.5 \%$ de los pacientes usaba fármacos relacionados a enfermedades cardiovasculares. Se encontraron 227 interacciones farmacológicas con insulina de tipo moderado. La presencia de la interacción fármaco-fármaco de insulina con linagliptina $(p=0.016)$, telmisartán $(p=0.005)$, y diltiazem $(p=0.008)$ tiene mejor efecto de control glucémico. La interacción con hidroclorotiazida $(p=0.012)$ aumenta el peso de los pacientes. Nosotros sugerimos que existe un elevado número de interacción moderada fármaco-fármaco y se encontraron asociaciones entre la $\mathrm{HbA} 1 \mathrm{c}$ y la interacción insulina-linagliptina, y de la glucosa en ayuno con insulina con telmisartán y diltiazem. Esto demuestra que, aunque la interacción farmacológica puede ocasionar efectos adversos potenciales no deseados, también puede ser apoyo para el manejo de pacientes con la presencia de comorbilidades. Además, este estudio nos permite sugerir la importancia del uso de sistemas de revisión en pacientes con enfermedades crónicas.

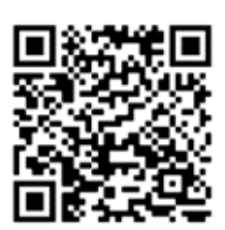

Cite this paper/Como citar este artículo: Ramírez González, D., Nolasco Rosales, G. A., Pérez Lopez, N. R., Suarez Méndez, S., Rodríguez Sánchez, E., Juárez Rojop, I. E. (2020). Interacción farmacológica en pacientes con diabetes tipo 2 en una población tabasqueña. Revista Bio Ciencias 7: (Suppl) Memorias de Congreso. LXIII Congreso Nacional de la Sociedad Mexicana de Ciencias Fisiologicas, A. C. e1097. http://doi.org/10.15741/revbio.07Suppl.e1097 


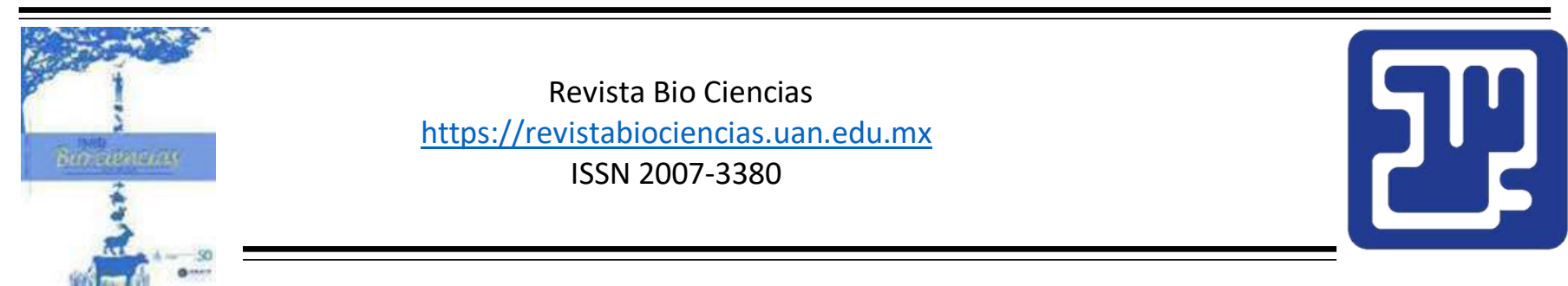

Trabajos libres: Farmacología

Modalidad de Presentación: Cartel

\author{
Potenciación analgésica de la coadministración de metamizol+hesperidina en el modelo de \\ estiramiento abdominal en ratón \\ González Ugalde, D. ${ }^{1}$, Mares Sánchez, J. J. ${ }^{2}$, Avilés Herrera, J.2 Ángeles López, G. E. ${ }^{2}$, Déciga \\ Campos, M. ${ }^{1}$, Ventura Martínez, R. $^{2 *}$ \\ ${ }^{1}$ Instituto Politécnico Nacional \\ ${ }^{2}$ Universidad Nacional Autónoma de México
}

*Autor Corresponsal: Rosa Ventura Martínez. E- mail: venturam7@hotmail.com

El modelo de estiramiento abdominal o "writhing", es un modelo preclínico que reproduce un dolor de tipo visceral. Uno de los tratamientos de elección en la clínica para este tipo de dolor es el metamizol; sin embargo, sus efectos adversos limitan su uso. Una estrategia para tratar de disminuir los efectos adversos de los AINEs es combinarlos con metabolitos de plantas medicinales como la hesperidina, la cual ha demostrado también actividad antinociceptiva en modelos preclínicos. Por lo anterior, el objetivo de este trabajo fue determinar el tipo de interacción analgésica entre hesperidina y metamizol en un modelo de dolor visceral. Para ello se utilizaron ratones machos CD-1 a los que se les administró metamizol, hesperidina o varias combinaciones de ambos fármacos, 30 minutos antes de la administración intraperitoneal de ácido acético (1\%). Se determinó el número de estiramientos abdominales inducidos por el ácido acético durante 30 minutos en los animales con los diferentes tratamientos.
Los resultados muestran que la combinación de metamizol+hesperidina (27.22+21.12 $\mathrm{mg} / \mathrm{kg}$ ) indujo un efecto antinociceptivo similar que la dosis de metamizol de $100 \mathrm{mg} / \mathrm{kg}$ en administración individual. Por otro lado, la combinación de metamizol+hesperidina $(54.4+42.2 \mathrm{mg} / \mathrm{kg})$ indujo un efecto mayor al compararlo con el efecto esperado de esta combinación, que se obtuvo con la suma del efecto de las dosis respectivas de los fármacos en administración individual. Estos resultados sugieren un efecto de potenciación analgésica de la coadministración de metamizol+hesperidina. Es necesario determinar los mecanismos de acción involucrados en la interacción de la hesperidina con el metamizol; sin embargo, nuestros resultados sugieren que esta combinación puede ser utilizada como una alternativa terapéutica para el tratamiento del dolor visceral con menor riesgo de efectos adversos, sobre todo los inducidos por el metamizol a dosis altas. Este estudio fue apoyado por PAPIIT (IN201820).

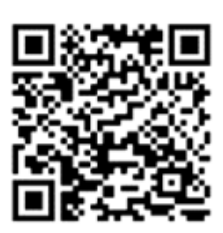

Cite this paper/Como citar este artículo: González Ugalde, D., Mares Sánchez, J. J., Avilés Herrera, J., Ángeles López, G. E., Déciga Campos, M., Ventura Martínez, R. (2020). Potenciación analgésica de la coadministración de metamizol+hesperidina en el modelo de estiramiento abdominal en ratón. Revista Bio Ciencias 7: (Suppl) Memorias de Congreso. LXIII Congreso Nacional de la Sociedad Mexicana de Ciencias Fisiologicas, A. C. e1097. http://doi.org/10.15741/revbio.07Suppl.e1097 


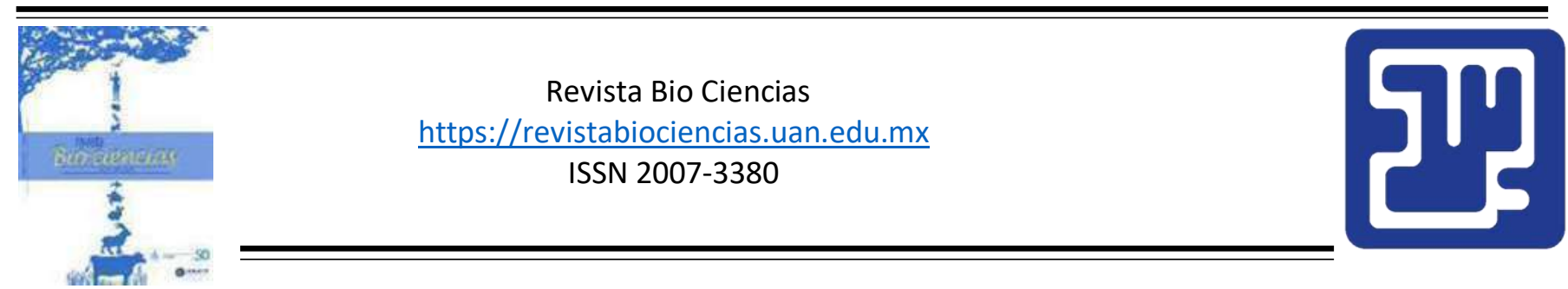

Trabajos libres: Farmacología

Modalidad de Presentación: Oral

\begin{abstract}
Efecto de la sertralina en ratas de alto y bajo bostezo en la prueba de nado forzado
\end{abstract}
Adriana Bravo Durán, D., Cortés Sánchez, M. C., Eguibar Cuenca, J. R. *

Benemerita Universidad Autónoma de Puebla

*Autor Corresponsal: José Ramón Eguibar Cuenca. E- mail: jose.eguibar@correo.buap.mx

Los altos niveles de estrés se han relacionado con una mayor susceptibilidad para desarrollar ansiedad y depresión. Las sublíneas de alto- (HY) y bajo- bostezo (LY) han mostrado diferencias conductuales al ser sometidas a pruebas que evalúan su respuesta ante distintos estresores. Al exponerlas a un campo abierto, las ratas HY deambulan más que las LY siendo menos reactivas emocionalmente y por lo tanto se consideran resilientes.

El objetivo del presente trabajo fue determinar el efecto de la sertralina en la inmovilidad y la actividad motora de las ratas LY, HY y Sprague-Dawley en la prueba de nado forzado (PNF). Se emplearon ratas macho de tres meses de edad.

Los sujetos recibieron inyecciones intraperitoneales de sertralina a las dosis de 2.5 y $5 \mathrm{mg} / \mathrm{Kg}$ y al control se le administró solución salina. La PNF consiste en una preprueba de $15 \mathrm{~min}$; posteriormente se administran tres dosis de sertralina, a las 23,19 y 0.5 horas antes de la prueba que tiene una duración de $5 \mathrm{~min}$. Se evaluaron las conductas de inmovilidad, nado, escalamiento y buceo. Nuestros resultados muestran que a la dosis de $2.5 \mathrm{mg} / \mathrm{Kg}$ de sertralina disminuyó en un $91.7 \%$ el tiempo de inmovilidad en las ratas HY respecto del grupo control, pero tan solo un $28.2 \%$ en las ratas LY y un $22 \%$ en las SD. Sólo el nado se incrementó con un $28 \%$ en las ratas HY, un $21 \%$ en las ratas LY y un $23.4 \%$ en las SD.

La sertralina en una dosis baja es más efectiva en las ratas HY disminuyendo el tiempo de inmovilidad e incrementando el de nado.

En conclusión, estos resultados muestran que las ratas HY no solo son resilientes, sino que también dosis bajas de sertralina tienen un mayor efecto antidepresivo respecto a lo obtenido en las LY y SD.

Cite this paper/Como citar este artículo: Adriana Bravo Durán, D., Cortés Sánchez, M. C., Eguibar Cuenca, J. R. (2020). Efecto de la sertralina en ratas de alto y bajo bostezo en la prueba de nado forzado. Revista Bio Ciencias 7: (Suppl) Memorias de Congreso. LXIII Congreso Nacional de la Sociedad Mexicana de Ciencias Fisiologicas, A. C. e1097. http://doi.org/10.15741/revbio.07Suppl.e1097 


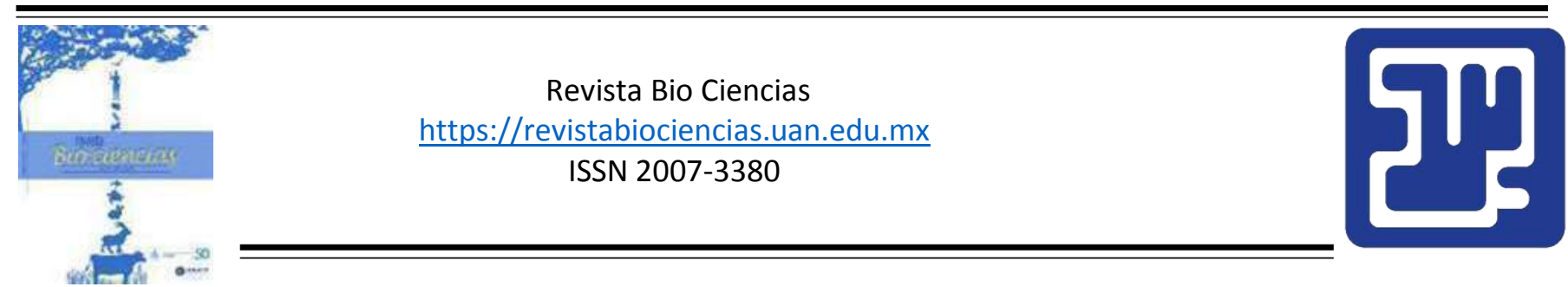

Trabajos libres: Farmacología

Modalidad de Presentación: Oral

\title{
Etanercept reduce el infiltrado inflamatorio y el daño tubular renal en un modelo de enfermedad renal crónica
}

\author{
Villaseñor Tapia, E. C. ${ }^{1}$, Gálvez Gastelum, F. J. ${ }^{1}$, Yáñez Sánchez, I. ${ }^{1}$, Mendieta Condado, R. ${ }^{2}$, \\ Márquez Aguirre, A. L. ${ }^{1 *}$ \\ ${ }^{1}$ Centro de Investigación y Asistencia en Tecnología y Diseño del Estado de Jalisco \\ ${ }^{2}$ Instituto de Diagnóstico y Referencia Epidemiológicos-SSA
}

*Autor Corresponsal: Ana Laura Márquez Aguirre. E- mail: amarquez@ciatej.mx

La enfermedad renal crónica (ERC) se define como la pérdida progresiva de la función renal; el tratamiento actual, se basa en el control de la etiología y fisiopatología de la enfermedad. Sin embargo, en etapas avanzadas, se pueden llegar a emplear terapias más invasivas como la diálisis o el trasplante renal.

Etanercept (ETA) es un agente anti-TNF-a ampliamente utilizado en el tratamiento de enfermedades autoinmunes, como la artritis reumatoide $(A R)$.

ETA es una proteína de fusión que se une específicamente al Factor de Necrosis Tumoral alfa (TNF-a), la principal citocina involucrada en la respuesta inflamatoria. Se ha demostrado que la administración de ETA es capaz de remover el TNF-a de la circulación en la AR.

Sin embargo, existe poca evidencia de su eficacia en otras enfermedades que cursan con inflamación crónica, como la ERC.
El objetivo del presente trabajo fue determinar el efecto de ETA en un modelo de ERC. Para ello previamente se confirmó la unión de ETA al TNF- $\alpha$ de rata.

Una vez confirmada esta unión, se realizó la inducción de ERC por administración de Adenina vía oral $(100 \mathrm{mg} / \mathrm{kg} / \mathrm{día})$ a ratas Wistar por 28 días y se administró de manera simultánea ETA (Enbrel®) a una dosis de 2 $\mathrm{mg} / \mathrm{kg}$ de peso cada tercer día vía s.c. Se determinaron parámetros hematológicos y bioquímicos, así como las concentraciones de TNF-a en suero por medio de ELISA.

Finalmente, se realizaron análisis histopatológicos con tinciones de $\mathrm{H} \& \mathrm{E}$ y Massón. Se encontró que el tratamiento con ETA retrasa la perdida de la Tasa de Filtración Glomerular (TFG) y reduce el infiltrado inflamatorio, así como la atrofia tubular, pero no tiene un impacto en la disminución de la fibrosis renal en las ratas con ERC.

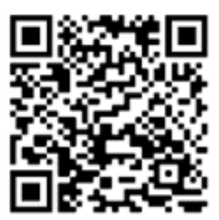

Cite this paper/Como citar este artículo: Villaseñor Tapia, E. C., Gálvez Gastelum, F. J., Yáñez Sánchez, I., Mendieta Condado, R., Márquez Aguirre, A. L. (2020). Etanercept reduce el infiltrado inflamatorio y el daño tubular renal en un modelo de enfermedad renal crónica. Revista Bio Ciencias 7: (Suppl) Memorias de Congreso. LXIII Congreso Nacional de la Sociedad Mexicana de Ciencias Fisiologicas, A. C. e1097. http://doi.org/10.15741/revbio.07Suppl.e1097 


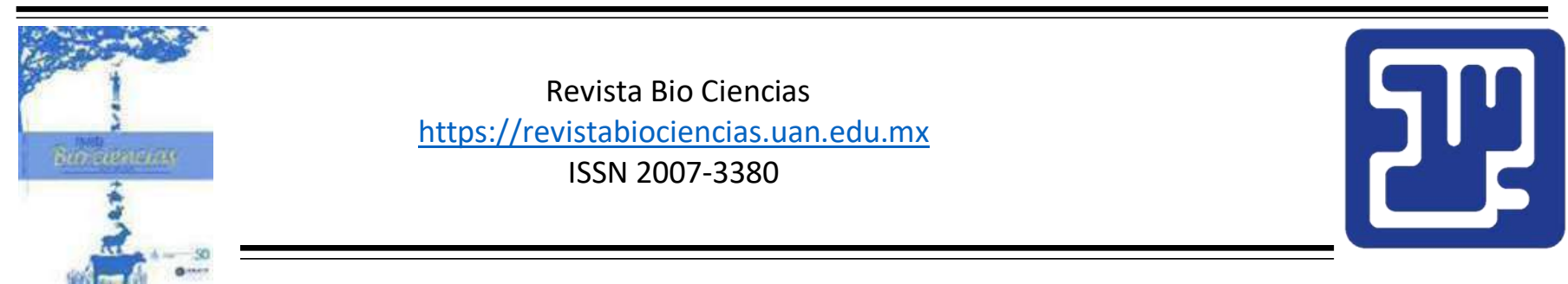

Trabajos libres: Farmacología

Modalidad de Presentación: Cartel

\begin{abstract}
La quercetina disminuye el efecto antinociceptivo de la indometacina en un modelo de dolor tipo artritis gotosa en rata

Avilés Herrera, J., González Ugalde, D., Ángeles López, G. E., Deciga Campos, M., Ventura Martinez., $R$. $^{*}$
\end{abstract}

Universidad Nacional Autónoma de México

*Autor Corresponsal: Rosa Ventura Martinez. E- mail: rventuram7@hotmail.com

La quercetina es un flavonoide con actividad antinociceptiva presente en muchos alimentos, el cual, actualmente se comercializa como suplemento alimenticio.

El objetivo de este trabajo fue determinar cómo afecta la quercetina al efecto antinociceptivo de la indometacina, un analgésico antiinflamatorio en uso clínico para enfermedades artríticas.

Para ello se utilizaron ratas machos Wistar a las que se les administró $50 \mu \mathrm{l}$ de ácido úrico en la articulación fémur-tibio-rotular de la pata posterior derecha.

Se determinó el índice de funcionalidad de cada animal y cuando presentaron una disfunción total de la extremidad con ácido úrico se les administró a diferentes grupos de animales indometacina $(10 \mathrm{mg} / \mathrm{Kg})$ por vía oral, quercetina $(100 \mathrm{mg} / \mathrm{Kg})$ por vía intraperitoneal o la combinación de ambos fármacos.
Los resultados muestran que la indometacina induce un efecto antinociceptivo de cerca del $60 \%$ a partir de la primera hora de su administración; mientras que, la quercetina en administración individual no produjo prácticamente ningún efecto analgésico (menos del 10\%).

Por otro lado, cuando la quercetina se administró junto con la indometacina, el efecto antinociceptivo de éste disminuyó a cerca del $30 \%$ a partir de la primera hora de su administración. Estos resultados sugieren un efecto de antagonismo analgésico de la quercetina sobre la indometacina. Es necesario determinar los mecanismos de acción involucrados en la interacción de la quercetina con la indometacina; sin embargo, nuestros resultados sugieren que en pacientes con un tratamiento con indometacina para el alivio del dolor inflamatorio debe evitarse el uso de suplementos alimenticios que contengan quercetina.

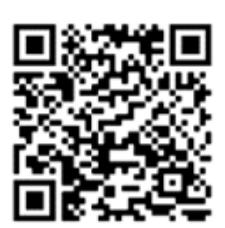

Cite this paper/Como citar este artículo: Avilés Herrera, J., González Ugalde, D., Ángeles López, G. E., Deciga Campos, M., Ventura Martinez., R. (2020). La quercetina disminuye el efecto antinociceptivo de la indometacina en un modelo de dolor tipo artritis gotosa en rata. Revista Bio Ciencias 7: (Suppl) Memorias de Congreso. LXIII Congreso Nacional de la Sociedad Mexicana de Ciencias Fisiologicas, A. C. e1097. http://doi.org/10.15741/revbio.07Suppl.e1097 


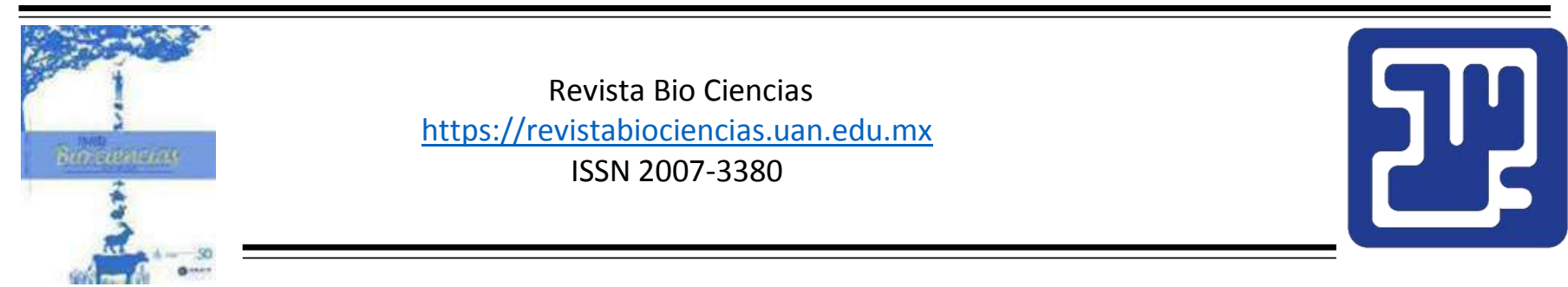

Trabajos libres: Farmacología

Modalidad de Presentación: Cartel

\title{
Hidroclorotiazida bloquea las corrientes de los canales Kir4.1
}

Marmolejo Murillo, L. G. ${ }^{1 *}$, Guardado Mendoza, R. ${ }^{1}$, Delgado Ramírez, M. ${ }^{2}$, Aréchiga Figueroa, I. A. ${ }^{3}$, Sánchez Duarte, E. ${ }^{1}$, Ferrer Villada, T. ${ }^{2}$, Azmar Rodríguez Menchaca., A. ${ }^{3}$

\author{
1 Universidad de Guanajuato \\ 2 Universidad de Colima \\ ${ }^{3}$ Universidad Autónoma de San Luis Potosí
}

*Autor Corresponsal: Leticia Gabriela Marmolejo Murillo. E- mail: Igmm83@hotmail.com

La hidroclorotiazida es un fármaco utilizado como diurético en el tratamiento de múltiples patologías, el cual actúa en el túbulo contorneado proximal y distal inhibiendo el cotransportador unidireccional de sodio y cloro.

Es una estructura cíclica, al igual que otros fármacos que han demostrado ser capaces de bloquear a los canales Kir4.1. Los canales Kir4.1 son canales de rectificación entrante, los cuales se caracterizan por una asimetría en su conductancia al potasio, generando una corriente entrante mayor a potenciales más negativos respecto al potencial de equilibrio para el ion potasio en comparación a la corriente observada a potenciales más positivos que este potencial, dando lugar a una rectificación de la corriente aun cuando las concentraciones de potasio en ambos lados de la membrana sean iguales. Los canales Kir4.1 se encuentran en diversos tipos celulares, entre ellos en la nefrona, por lo que resulta interesante explorar el efecto de este fármaco sobre las corrientes de los canales Kir4.1.
Se realizaron registros electrofisiológicos en canales Kir4.1 expresados en células HEK293 con la técnica de fijación de voltaje en la configuración de parche escindido con la cara interna de la membrana hacia afuera (insideout).

Exploramos el efecto de diferentes concentraciones de hidroclorotiazida sobre las corrientes de los canales Kir4.1 aplicando un protocolo de voltaje con un pulso despolarizante $\mathrm{a}+100 \mathrm{mV}$ seguido de otro hiperpolarizante $(-140 \mathrm{mV})$.

La hidroclorotiazida es capaz de modificar las corrientes de los canales Kir4.1. Al aplicar 1 $\mu \mathrm{M}$, se observa una disminución de la corriente en un $58 \%$, mientras que cuando se aplican 10 y $100 \mu \mathrm{M}$ se disminuye un 67 y 71 $\%$, respectivamente.

Es probable que la interacción de hidroclorotiazida con los canales Kir4.1 explique los efectos de este fármaco en las células.

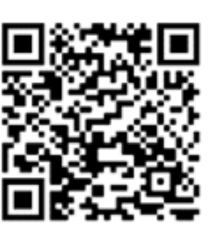

Cite this paper/Como citar este artículo: Marmolejo Murillo, L. G., Guardado Mendoza, R., Delgado Ramírez, M., Aréchiga Figueroa, I. A., Sánchez Duarte, E., Ferrer Villada, T., Azmar Rodríguez Menchaca., A. (2020). Hidroclorotiazida bloquea las corrientes de los canales Kir4.1. Revista Bio Ciencias 7: (Suppl) Memorias de Congreso. LXIII Congreso Nacional de la Sociedad Mexicana de Ciencias Fisiologicas, A. C. e1097. http://doi.org/10.15741/revbio.07Suppl.e1097 


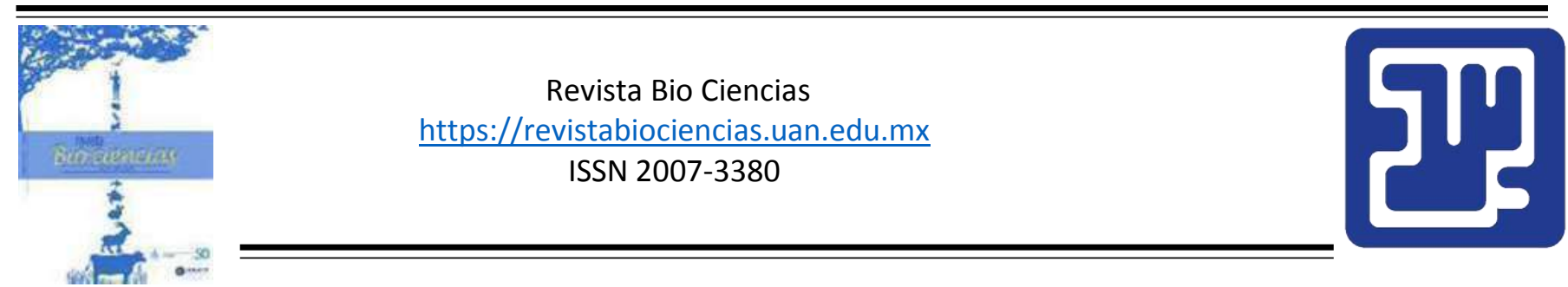

Trabajos libres: Farmacología

Modalidad de Presentación: Cartel

\title{
Estudio etnobotánico y evaluación de la actividad diurética del extracto acuoso de Eryngium heterophyllum Engelm en la rata
}

\author{
Esqueda Balcázar, J. J. *, Meléndez Camargo, M. E. \\ Escuela Nacional De Ciencias Biológicas IPN
}

*Autor Corresponsal: Joshua Jarim Esqueda Balcázar. E- mail: josh.jj@hotmail.com

Existe gran variedad de plantas que producen algún efecto terapéutico, entre ellas Eryngium heterophyllum Engelm, conocida comúnmente como hierba del sapo, empleada en la Medicina Tradicional por sus beneficios en la función renal.

El objetivo fue evaluar la probable actividad diurética del extracto acuoso Eryngium heterophyllum en la rata.

Se realizó el estudio etnobotánico en la comunidad Los Amoles, en el municipio de Moroleón, Guanajuato.

Se recolectó e identificó la especie y se llevó a cabo el análisis fitoquímico preliminar. Para la evaluación diurética se utilizaron ratas Wistar, hembra, adultas de $200 \pm 20 \mathrm{~g}$ de peso corporal (p.c.), se distribuyeron en 5 grupos, el testigo (vehículo), la furosemida (4 $\mathrm{mg} / \mathrm{kg}$ de p.c.) y 3 tratados con el extracto acuoso a las dosis de 200, 400 y $800 \mathrm{mg} / \mathrm{kg}$ de p.c., per os.

Se colocaron en jaulas metabólicas por 6 horas, al término de este tiempo se obtuvieron muestras de orina y suero, para medirles las concentraciones de sodio, potasio y creatinina, en orina además el volumen total.

Con estos datos se calcularon el flujo urinario y la depuración de creatinina, $\mathrm{Na}+$ y $\mathrm{K}+$, las excreciones y carga filtrada de los iones. Se determinó la dosis letal 50 en ratones $\mathrm{NIH}$ hembra, adultas de $25 \pm 5 \mathrm{~g}$ de p.c., tratados con el extracto (1, 2, 4 y $8 \mathrm{~g} / \mathrm{kg}$ de p.c.). Es utilizada como decocción para padecimientos renales, se detectaron alcaloides, flavonoides, taninos y saponinas.

En la evaluación diurética se observó un incremento en el flujo urinario, en la excreción urinaria y depuración de iones en los grupos tratados con furosemida y a las diferentes dosis del extracto. La DL50 es mayor a $8 \mathrm{~g} / \mathrm{kg}$ de p.c.

Estos hallazgos avalan el uso diurético de Eryngium heterophyllum Engelm en la Medicina Tradicional Mexicana. 


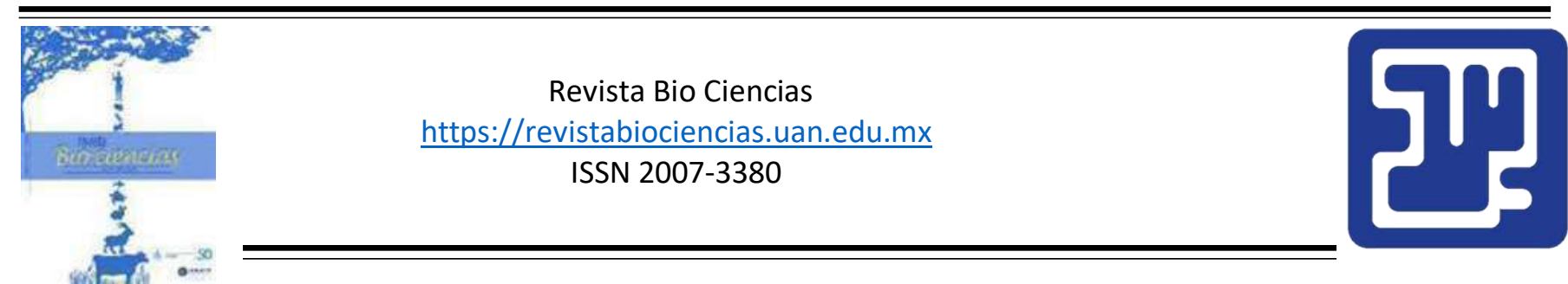

Trabajos libres: Farmacología

Modalidad de Presentación: Cartel

\title{
Efecto del 17- $\beta$ estradiol y/o progesterona sobre los despertares intermitentes de ratas ovariectomizadas
}

\author{
Carrasco Núñez, N. ${ }^{1}$, Cabeza Salinas, M. ${ }^{1}$, Romano Pardo, M. ${ }^{2}$, Lopez Avila, A. ${ }^{1}$ \\ 1 Universidad Autónoma Metropolitana Unidad Xochimilco \\ ${ }^{2}$ Centro de Investigación y de Estudios Avanzados
}

*Autor Corresponsal: Nayely Carrasco Nuñez.E- mail:nellybonita@hotmail.com

Antecedentes. En el síndrome climatérico se presentan un conjunto de síntomas, debidos al cese de la función ovárica; entre otros trastornos la incapacidad para dormir. La terapia de sustitución disminuye esta sintomatología; sin embargo, el efecto de la progesterona y/o 17ß-estradiol en dosis crecientes no ha sido evaluado.

Objetivo. Determinar el efecto del tratamiento con $17 \beta$-estradiol y/o progesterona en dosis escalonadas sobre los despertares intermitentes en un modelo de rata adulta ovariectomizada. Método. Se realizo una ovariectomía bilateral (OVX) en rata Winstar bajo anestesia; se mantuvieron en condiciones de bioterio, bajo ciclos de luz / oscuridad de 12/12 h con agua y comida ad libitum durante todo el experimento. Se formaron 5 grupos (6 ratas). Se administraron $17 \beta$-estradiol y/o progesterona cada 24 horas por un periodo de 7 días para cada dosis incrementada semanalmente e inyectada por vía subcutánea. Un grupo de ratas OVX se mantuvo como control y otro control (SHAM).
EL monitoreo del número de despertares se realizó por medio de un circuito cerrado.

Resultados. Los resultados mostraron que existe una diferencia significativa $(P<0.05)$ en la frecuencia de despertares entre los grupos control (OVX) y SHAM. Estas diferencias se observaron desde la primera semana. Los datos indicaron que existe una diferencia significativa $(P<0.05)$ en la frecuencia de despertares entre los grupos control (OVX) y los inyectados con 17ß-estradiol y/o progesterona a la mayor dosis. Además, en la tercera semana se observa una diferencia significativa entre los grupos control (OVX) y los grupos de $17 \beta$-estradiol (tercera dosis) y progesterona (tercera dosis), pero no de su combinación en la misma semana.

Conclusiones. La evaluación mostró que la terapia de sustitución combinada mejora significativamente la calidad del sueño en dosis de $0.33 \mathrm{mg} / \mathrm{Kg}$ de $17 \beta$-estradiol y 2.4 $\mathrm{mg} / \mathrm{Kg}$ de progesterona en ratas OVX.

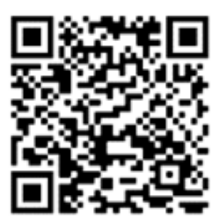

Cite this paper/Como citar este artículo: Carrasco Núñez, N., Cabeza Salinas, M., Romano Pardo, M., Lopez Avila, A. (2020). Efecto del 17- $\beta$ estradiol y/o progesterona sobre los despertares intermitentes de ratas ovariectomizadas. LXIII Congreso Nacional de la Sociedad Mexicana de Ciencias Fisiologicas, A. C. e1097. http://doi.org/10.15741/revbio.07Suppl.e1097 


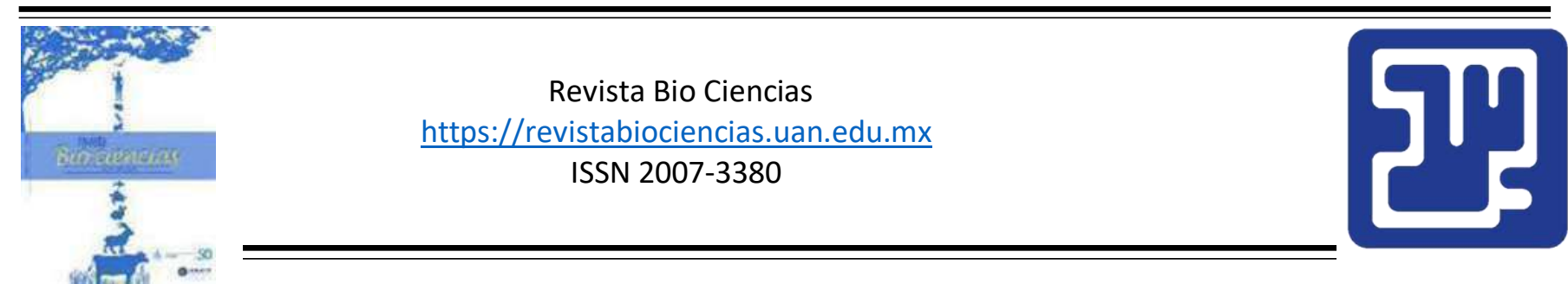

Trabajos libres: Farmacología

Modalidad de Presentación: Oral

\section{Efectos del extracto etanólico de Brugmansia arbórea en la respuesta aversiva a la temperatura del caracol de jardín (Helix aspersa)}

Ríos Cano, A. A., Pérez Romano, J. E., Méndez Martínez, E., Itha Amador, A. L. *

Benemerita Universidad Autonoma de Puebla

*Autor Corresponsal: Martha Lucia Itha Amador. E- mail: martha.ita@correo.buap.mx

La herbolaria es una fuente primaria para el estudio de plantas medicinales. En Teziutlán Puebla México, juega un papel preponderante. Un ejemplo es la Brugmansia (Solanaceae), conocidas como "Floripondio", "campanchu", "yerba del diablo", (De Feo, 2003). Cuyo uso es como analgésico (De Smet, 1983). El uso del caracol de jardín (Helix aspersa) como modelo animal para el estudio de la nocicepción resulta útil ya que presenta una conducta de aversión ante estímulos, como la temperatura, ya descrita en la literatura (Kavaliers, et al., 1983, Kavaliers, 1988; Dyakonova et al., 1995; Kavaliers y Perrot-Sinal, 1996; Zakharov et al., 1995). A la fecha no existen estudios de los mecanismos del efecto anestésico de los extractos de Floripondio.

Por lo que nos planteamos describir el efecto del extracto de etanholico de Florufundio en la conducta de aversión a la temperatura en el caracol $\mathrm{H}$. aspersa.
Los caracoles $\mathrm{H}$. aspersa se recolectaron y se mantuvieron en condiciones de laboratorio y se utilizó el protocolo de estimulación termonociceptivo descrito en la literatura (León-Olea, et al., 2001).

Se exploró la latencia de la conducta de aversión a $45^{\circ} \mathrm{C}$ (Miller-Pérez, 2008), en condiciones control y en presencia de las distintas concentraciones del extracto de Floripondio $\quad(1 \mathrm{mg} / 100 \mathrm{~mL}, \quad 3 \mathrm{mg} / 100 \mathrm{~mL}$, $10 \mathrm{mg} / 100 \mathrm{~mL}, 30 \mathrm{mg} / 100 \mathrm{~mL}, 100 \mathrm{mg} / \mathrm{mL}$.).

El extracto etanólico de las hojas de Brugmansia arborea se obtuvo al colocar la planta por 10 díass en etanol al 96\%, a temperatura ambiente. Se secó a presión reducida, dando $10 \mathrm{~g}$ de extracto acuoso. El extracto produjo un acortamiento relacionado con la dosis en la latencia de respuesta aversiva al estímulo termonocíptico, del $47 \%$ y $50.8 \%$, para las dosis 10 y $30 \mathrm{nmg} / \mathrm{ml}$ respectivamente, efecto que se desvaneció 45 minutos después.

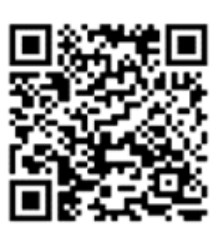

Cite this paper/Como citar este artículo Ríos Cano, A. A., Pérez Romano, J. E., Méndez Martínez, E., Itha Amador, A. L. (2020). Efectos del extracto etanólico de Brugmansia arbórea en la respuesta aversiva a la temperatura del caracol de jardín (Helix aspersa). Revista Bio Ciencias 7: (Suppl) Memorias de Congreso. LXIII Congreso Nacional de la Sociedad Mexicana de Ciencias Fisiologicas, A. C. e1097. http://doi.org/10.15741/revbio.07Suppl.e1097 


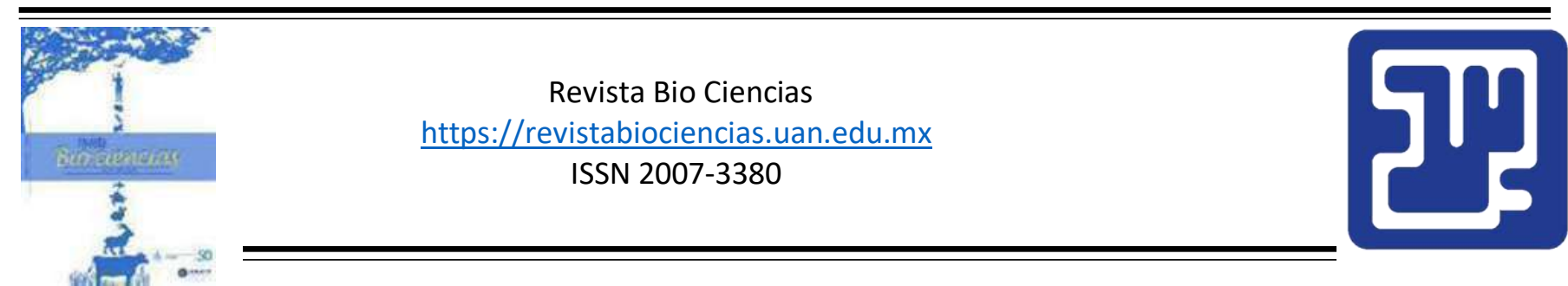

Trabajos libres: Farmacología

Modalidad de Presentación: Cartel

\section{La infusión intravesical de lidocaína o lidocaína-epinefrina genera cambios cistométricos diferenciales durante la micción en ratas hembra anestesiadas}

Muñoz Toscano, A. *, Palacios Galicia, J. L., Luquin de Anda, M.S.

Centro Universitario del Norte, Universidad de Guadalajara

*Autor Corresponsal: Alvaro Munoz Toscano. E- mail: alvaro.munoz@academicos.udg.mx

La aplicación intravesical de lidocaína se ha utilizado para mejorar síntomas en pacientes con síndrome de vejiga dolorosa, una condición caracterizada por dolor pélvico originado desde la vejiga urinaria. Sin embargo, los efectos urodinámicos causados por lidocaína intravesical durante cistometría abierta no han sido plenamente caracterizados experimentalmente.El efecto potenciador propuesto para la co-aplicación de epinefrina también fue evaluado cistométricamente. Utilizamos 12 ratas hembra, de la cepa Wistar, anestesiadas con uretano (1.2 g/kg i.p.).

Se colocó un catéter suprapúbico conectado a una bomba de infusión y un transductor de presión mediante una llave de 3 vías. Los experimentos constaron de tres etapas: a) infusión con salina, b) lidocaína $(2 \mathrm{mg} / \mathrm{ml}$; $\mathrm{N}=6)$ o lidocaína-epinefrina (2 $\mathrm{mg} / \mathrm{ml}$ $0.5 \mathrm{microg} / \mathrm{ml} ; \mathrm{N}=6$ ) y c) lavado con salina. Los cambios en presión intravesical fueron digitalizados y analizados con el software WinDaq y Prism. Análisis de grupos muestran que la lidocaína no afecta el intervalo intercontráctil, la presión umbral de micción o la presión máxima de contracción, sin embargo, disminuye el volumen de micción $(p<0.05$ vs salina/lavado) y promueve la desaparición de las oscilaciones de alta frecuencia (OAF) conduciendo a un goteo durante la infusión ( $p<0.01$ vs salina/lavado).

Por otra parte, la infusión de la mezcla lidocaína-epinefrina reduce el intervalo contráctil ( $p<0.05$ vs salina), sin afectar la presión umbral o la presión máxima de contracción. El volumen de micción también fue reducido significativamente $(p<0.01$ vs salina/lavado). En contraste al efecto causado con lidocaína sola, las OAF fueron observables y medibles, aunque su duración fue reducida por lidocaína-epinefrina $(p<0.05$ vs salina/lavado).

Estos resultados sugieren que la aplicación intravesical de lidocaína o lidocaína-epinefrina generará efectos diferenciales que podrían conducir a una situación de incontinencia urinaria en el segundo caso.

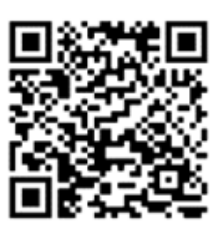

Cite this paper/Como citar este artículo Muñoz Toscano, A., Palacios Galicia, J. L., Luquin de Anda, M.S. (2020). La infusión intravesical de lidocaína o lidocaína-epinefrina genera cambios cistométricos diferenciales durante la micción en ratas hembra anestesiadas. Revista Bio Ciencias 7: (Suppl) Memorias de Congreso. LXIII Congreso Nacional de la Sociedad Mexicana de Ciencias Fisiologicas, A. C. e1097. http://doi.org/10.15741/revbio.07Suppl.e1097 


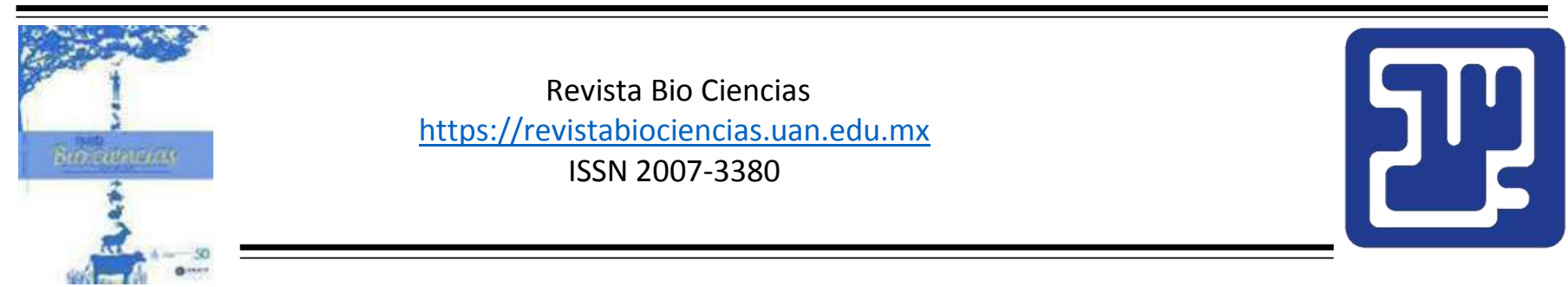

Trabajos libres: Farmacología

Modalidad de Presentación:Oral

\section{Regulación de canales KV 10.1 involucrados en cáncer de mama por extractos de Passiflora subpeltata}

Puente Guzmán, E. I. ${ }^{1}$, Rodríguez Zamora, A. ${ }^{1}$, Arregui Mena, A. L. ${ }^{1}$, Gómez Lagunas, F. ${ }^{2}$, Rivera Becerril, E. ${ }^{\text {* }}$

1 Universidad Autónoma Metropolitana Cuajimalpa

2 Universidad Autonoma De Mexico

*Autor Corresponsal: Ernesto Rivera Becerril. E- mail: e.rivera@dcniuamc.com

El cáncer de mama se caracteriza por un descontrolado ciclo celular, entre los factores involucrados se encuentra el potencial de membrana que a su vez es regulado por canales de potasio sensibles a voltaje (KV). La desregulación y la sobre expresión de estos canales provocan oncocanalopatías y el desarrollo de la enfermedad. Actualmente, los productos naturales son utilizados en tratamientos contra el cáncer, debido a su eficacia, bajo costo y pocos o nulos efectos secundarios. El género Passiflora ha sido estudiado muy poco, pero se han resaltando metabolitos secundarios que regulan canales iónicos, por lo que este género es de interés farmacológico.

El presente trabajo evalúa la actividad anticancerígena de los extractos de tallos y hojas de Passiflora subpeltata en una línea celular de carcinoma de mama humano (MDAMB-231), además de evaluar electrofisiológicamente las corrientes iónicas en canales KV 10.1 de células HEK.

Los extractos metanólico $(\mathrm{MeOH})$, acetónico
(Me2CO), clorofórmico ( $\mathrm{CHCl} 3)$ y hexánico (Hex) de Hojas y Tallos de P. Subpeltata, se caracterizaron por cromatografía en capa fina y empleando reveladores fitoquímicos, mostrando la presencia de diversos polifenoles. Los extractos se evaluaron en la línea celular MDA-MB-231 mediante una técnica colorimétrica empleando el colorante MTT (8 ensayos). Las hojas, del extracto $\mathrm{MeOH}$ inhibió el crecimiento celular en $58.54 \%$, el CHCl3 70.57\%, el Me2CO 79.85\%. En Tallos, el extracto MeOH inhibió $91.57 \%$, CHCl3 $82.93 \%$ y Hex $51.37 \%$. Las células tratadas se tiñeron con loduro de Ipratropio y anexina $\mathrm{V}$ para determinar la muerte celular vía apoptosis.

Además, se observó que el extracto metanólico de tallos redujo las corrientes iónicas de potasio KV10.1 en un 96.24\%, (5 ensayos). Los resultados obtenidos sugieren que los extractos de $P$. subpeltata, principalmente conteniendo polifenoles, inhiben la proliferación celular en líneas de cáncer de mama induciendo apoptosis vía la inhibición de canales KV 10.1.

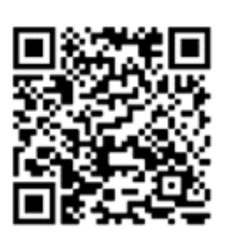

Cite this paper/Como citar este artículo: Puente Guzmán, E. I., Rodríguez Zamora, A., Arregui Mena, A. L., Gómez Lagunas, F., Rivera Becerril, E. (2020). Regulación de canales KV 10.1 involucrados en cáncer de mama por extractos de Passiflora subpeltata. Revista Bio Ciencias 7: (Suppl) Memorias de Congreso. LXIII Congreso Nacional de la Sociedad Mexicana de Ciencias Fisiologicas, A. C. http://doi.org/10.15741/revbio.07Suppl.e1097 


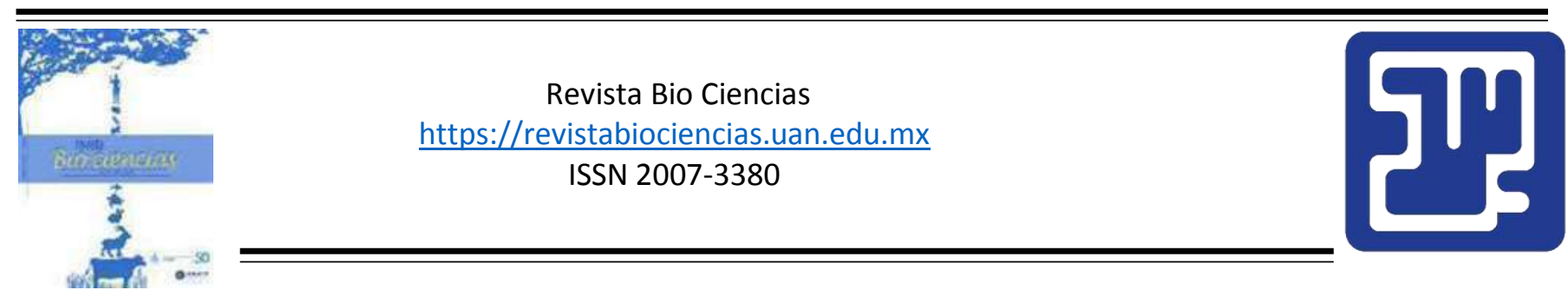

Trabajos libres: Farmacología

Modalidad de Presentación: Cartel

\section{Efectos de Hibiscus Sabdariffa y sus Antocianinas en la Salud Reproductiva de Ratas Hembras Sanas}

Hernández Hernández, A., Bañuelos Pineda, J., Aguirre López, L. O., Lorenzana Martínez, G., Gómez Rodiles, C. C., Cuéllar Pérez, J. R.*

Centro Universitario de Ciencias Biológicas y Agropecuarias (CUCBA), Universidad de

Guadalajara.

*Autor Corresponsal: José Ricardo Cuéllar Pérez. E- mail: ricardo.cuellarp@academicos.udg.mx

Las antocianinas (Ant's) son fitopigmentos con propiedades nutracéuticas encontrados en alimentos funcionales como berries, maíz morado y cálices de la flor de Jamaica. Infusiones de estos cálices presentan efectos antioxidantes, diuréticos, colesterolémicos, hipotensivos, entre otros. La retención de líquidos e hipertensión generada en el embarazo promueve el consumo de infusiones de Jamaica en mujeres mexicanas con el propósito de disminuir dichos síntomas; aunque, el riesgo por consumir estos extractos provoca complicaciones durante el embarazo hasta abortos espontáneos.

Este estudio evaluó el extracto de antocianinas de flor de Jamaica $(50 \mathrm{mg} / \mathrm{Kg}$ ) en la salud reproductiva de ratas gestantes. Cincuenta ratas hembras se dividieron en 5 grupos: Preñez+Ant's, Preñez+SinAnt's, SinPreñez+Ant's, SinPreñez+SinAnt's y Preñez+ExtractoCrudo. Las ratas preñadas fueron diseccionadas al día 19 de gestación, y los cuernos uterinos fueron removidos. Se registraron anormalidades o cualquier cambio morfológico, peso y talla de los fetos, y su longitud encefálica.
Muestras sanguíneas se recolectaron para cuantificar lípidos en suero y medir la concentración de progesterona. El número de crías de las ratas preñadas no fue diferente entre ellas, pero, el peso de las crías fue menor en ratas que consumieron el extracto crudo comparado con los grupos preñez+Ant's y preñez+sinAnt's $\quad(P<0.05$ ambos). Además, la talla de las crías fue más pequeñas de ratas que consumieron el extracto crudo ( $P<0.01$ ambos). La longitud encefálica fue más pequeña en las crías de los grupos de preñez+Ant's y preñez+extractocrudo comparados con ratas preñez+sinAnt's ( $P<0.05$ ambos). Finalmente, las glucemias durante la gestación no fueron diferentes entre grupos, tampoco presentaron diferencias en el análisis de lípidos séricos, ni en los niveles de progesterona de ratas preñadas y sin preñez.

Todos estos resultados indican que el extracto de antocianinas no muestra efectos adversos en la salud reproductiva de ratas hembras. Aunque, el consumo de un extracto crudo provoca ligeros cambios antropométricos.

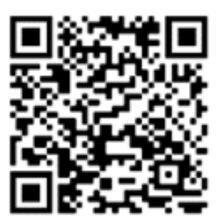

Cite this paper/Como citar este artículo: Hernández Hernández, A., Bañuelos Pineda, J., Aguirre López, L. O., Lorenzana Martínez, G., Gómez Rodiles, C. C., Cuéllar Pérez, J. R. (2020). Efectos de Hibiscus Sabdariffa y sus Antocianinas en la Salud Reproductiva de Ratas Hembras Sanas. Revista Bio Ciencias 7: (Suppl) Memorias de Congreso. LXIII Congreso Nacional de la Sociedad Mexicana de Ciencias Fisiologicas, A. C. e1097. http://doi.org/10.15741/revbio.07Suppl.e1097 


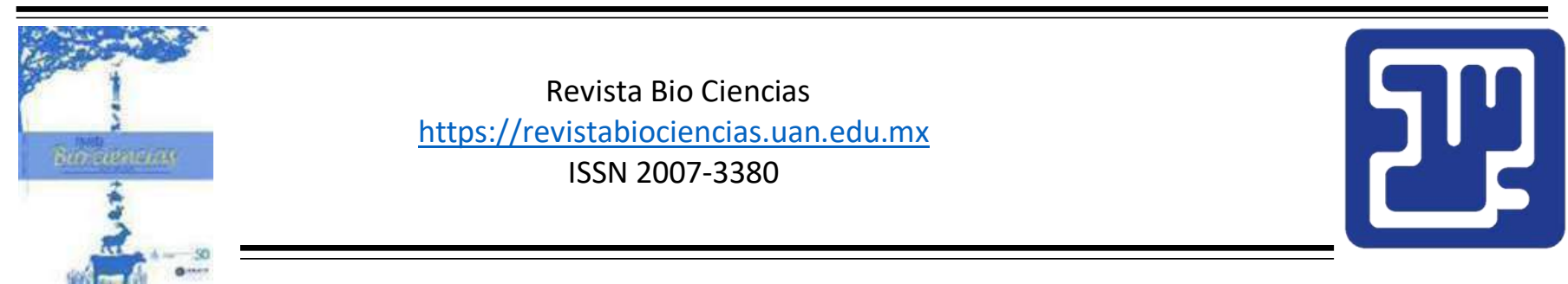

Trabajos libres: Neurociencias

Modalidad de Presentación: Oral

\title{
Evaluación entre la calidad de vida y el deterioro cognitivo en pacientes con esquizofrenia en una población tabasqueña
}

\author{
Ovando Rodríguez, A. P., Ramos Olán, C. A., Ramos Rodriguez, L. A., Medrano Hernández, J. I., \\ Aguilar Mariscal, H., Juárez Rojop, I. E. *
}

Universidad Juarez Autonoma de Tabasco. Ciencias de la salud.

*Autor Corresponsal: Isela Esther Juárez Rojop. E- mail: iselajuarezrojop@hotmail.com

Las personas con esquizofrenia tienen un nivel de calidad vida más bajo que las demás personas. Se encuentran distintos factores que interfieren en la calidad de vida de los pacientes, sin embargo, se ha reportado que el déficit cognitivo está relacionado al pronóstico de la enfermedad. El objetivo fue determinar la relación de la calidad de vida y el deterioro cognitivo en pacientes con esquizofrenia en una población tabasqueña. El presente estudio fue de tipo descriptivotransversal, en pacientes con esquizofrenia de acuerdo a los criterios de la CIE-10, edad de 18-60 años. El deterioro cognitivo se evaluó por la escala cognitiva de Montreal y la evaluación de la calidad de vida por el cuestionario de salud FS-36. Se realizó frecuencias y porcentajes para las variables categóricas, con medias y desviaciones estándar, así como análisis de varianza (ANOVA). Los resultados obtenidos fue un total de pacientes con esquizofrenia fue 66 , de estos 46 pertenecen al género masculino. Se observó relación entre la calidad de vida, el nivel educativo y el nivel socioeconómico. Además, se encontró que el $59.1 \%$ de los pacientes con esquizofrenia presentan deterioro severo. Nosotros sugerimos que los pacientes con esquizofrenia tienen una menor calidad de vida, la cual surge debido a un conjunto de componentes, sociales, económicos, educativos, psicológicos y biológicos. También, el deterioro cognitivo influye en la calidad de vida de la población tabasqueña. 


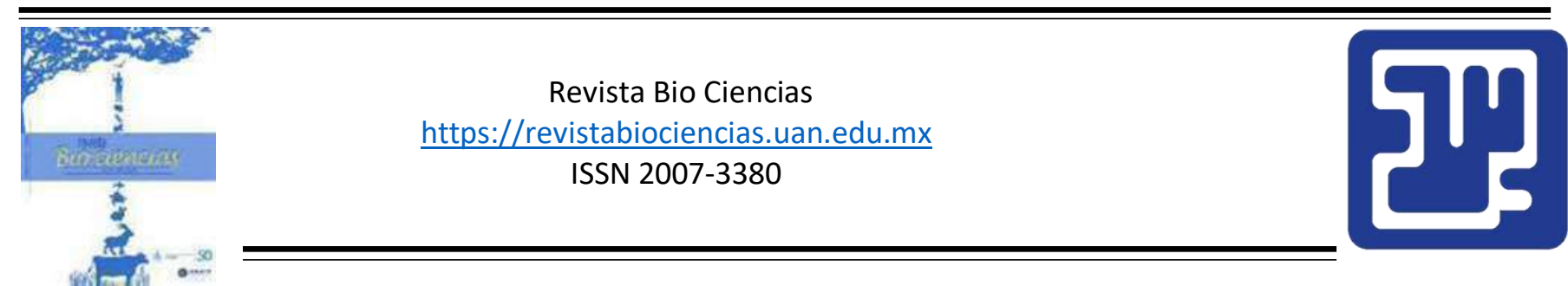

Trabajos libres: Neurociencias

Modalidad de Presentación: Cartel

\title{
Videolaboratorio Sensaciones Somáticas
}

\author{
Limón Mendoza, A., Muñoz Tabares, J. N., Quintanar Stephano, A. * \\ Universidad Autonoma de Aguascalientes. Departamento de fisiología.
}

*Autor Corresponsal: Andrés Quintanar Stephano. E- mail: aquinta@correo.uaa.mx

Por motivo de la emergencia sanitaria por el COVID19, que interrumpió la realización presencial de las sesiones de laboratorio y por la gran importancia que la observación directa de los fenómenos fisiológicos tiene sobre la comprensión de los mecanismos fisiológicos, aquí presentamos el video Sensaciones Somáticas. El video está dividido en las siguientes secciones: Fundamentos, objetivos, material, métodos y resultados. En cada maniobra experimental se analizan y discuten los resultados y las conclusiones más importantes de cada maniobra. El conocimiento del medio ambiente, la relación entre el propio cuerpo y el medio externo, e incluso la percepción del estado y situación de las diferentes partes de nuestro propio cuerpo, corren a cargo del sistema nervioso somatosensorial. Las sensaciones somáticas tienen su origen en receptores sensoriales especializados localizados en la piel, o inmediatamente debajo de ella, o en los tejidos profundos (fascias, músculos, periostio y articulaciones), y en los órganos viscerales. Las sensaciones exteroceptivas son mediadas por los receptores de tacto, temperatura, dolor, cosquillas y comezón de la superficie de la piel. Las sensaciones propioceptivas se originan en tejidos profundos que informan del estado de contracción de los músculos, y la posición y velocidad con que se mueven las articulaciones de los miembros y otras partes del cuerpo, así como de las fuerzas o presiones que soportan. La percepción de las vísceras da lugar a las sensaciones viscerales, que son transmitidas por fibras nerviosas sensoriales que siguen la misma trayectoria periférica del sistema nervioso autónomo. Todas estas sensaciones conforman las sensaciones somáticas. Mucho se puede aprender acerca de la función de las sensaciones exteroceptivas como las de tacto, temperatura, dolor, cosquillas y comezón de la superficie de la piel mediante experimentos sencillos. Estos ejercicios pueden aplicarse inclusive durante los exámenes clínicos neurológicos.

Vídeo disponible en: https://youtu.be/LOJ75q6H3ts

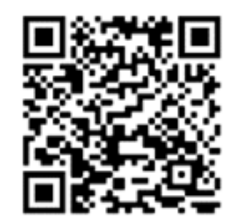

Cite this paper/Como citar este artículo: Limón Mendoza, A., Muñoz Tabares, J. N., Quintanar Stephano, A. (2020). Videolaboratorio Sensaciones Somáticas. Revista Bio Ciencias 7: (Suppl) Memorias de Congreso. LXIII Congreso Nacional de la Sociedad Mexicana de Ciencias Fisiologicas, http://doi.org/10.15741/revbio.07Suppl.e1097

A. C. e1097. 


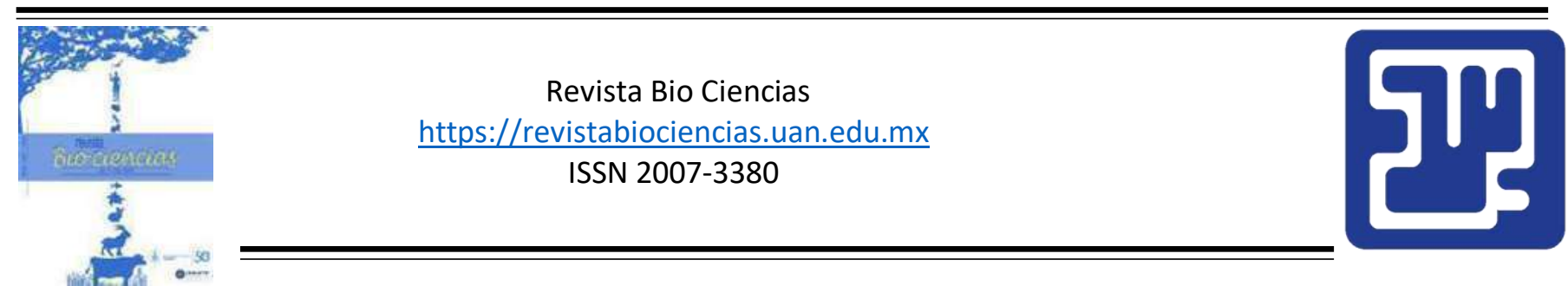

Trabajos libres: Neurociencias

Modalidad de Presentación: Cartel

\section{El más eficiente: Aprendizaje y memoria en el acocil}

González Valdéz, A., Pérez Hernández, S. A., Jáuregui Durán, S., Mendoza Angeles, K., De la O Martínez, A., Hernández Falcón, J.*

\section{Universidad Nacional Autonoma de Mexico. Facultad de Medicina. Laboratorio de Fisiología. *Autor Corresponsal: Jesús Hernández Falcón. E- mail: jesushf@unam.mx}

El aprendizaje y la memoria ocurren en invertebrados cuando se aplica el paradigma adecuado. En el acocil es posible obtener condicionamiento clásico y aversivo, pero la caracterización completa de estos tipos de aprendizaje requiere demostrar que ellos son sensibles a los agentes amnésicos. El condicionamiento clásico en el acocil se obtiene al asociar un estímulo no condicionado, un destello de prueba, con uno condicionado (una perturbación en el acuario), mientras se mide la frecuencia cardiaca. La perturbación del acuario provoca una bradicardia transitoria. Después de varias repeticiones, se obtiene la bradicardia pese a la exclusión de la perturbación. El condicionamiento aversivo se obtiene al colocar a un acocil en una caja cuyo piso se puede electrificar. Se entrena al acocil a salir de la caja para evitar la descarga eléctrica. Posteriormente se asocia un estímulo luminoso que precede al eléctrico.
El acocil aprende a evitar este último cuando se enciende la luz. Cuando acociles desconocidos entre sí se encuentran en un mismo acuario, establecen interacciones de dominancia sumisión y forman un orden jerárquico con un animal dominante y dos sumisos. Esta organización brinda diversas ventajas al acocil dominante. El propósito de este trabajo fue demostrar que los animales dominantes aprenden mejor los paradigmas clásico y aversivo que los animales sumisos. Usamos triadas de acociles machos, adultos P. clarkii en intermuda. Una vez obtenida la organización jerárquica, condicionamos a los tres integrantes de cada triada, en uno de los dos paradigmas. Los animales dominantes aprendieron más rápido y mejor en los dos paradigmas. Ambos aprendizajes son sensibles a agentes amnésicos.

Cite this paper/Como citar este artículo: González Valdéz, A., Pérez Hernández, S. A., Jáuregui Durán, S., Mendoza Angeles, K., De la O Martínez, A., Hernández Falcón, J. (2020). El más eficiente: Aprendizaje y memoria en el acocil. Revista Bio Ciencias 7: (Suppl) Memorias de Congreso. LXIII Congreso Nacional de la Sociedad Mexicana de Ciencias Fisiologicas, A. C. e1097. http://doi.org/10.15741/revbio.07Suppl.e1097 


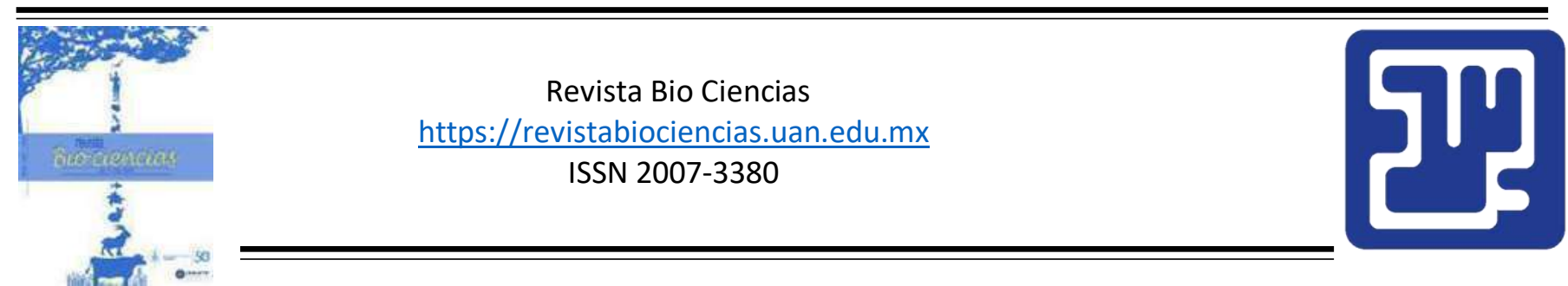

Trabajos libres: Neurociencias

Modalidad de Presentación: Oral

Evaluación del incentivo sexual olfatorio en las ratas hembras de alto y de bajo bostezo

Mora Bolaños, A., Cortés Sánchez, M. C., Eguibar Cuenca, J. R. *

Benemerita Universidad Autonoma de Puebla. Instituto de Fisiología.

*Autor Corresponsal: José Ramón Eguibar Cuenca. E- mail: jose.eguibar@correo.buap.mx

Para entender el mecanismo de la atracción sexual en roedores, es importante identificar los estímulos relevantes como son el olfato, la audición, y la visión, que activan la atención, la aproximación y el despliegue de la cópula. El objetivo del presente trabajo fue evaluar la discriminación que realizan las hembras de alto bostezo (HY, de sus siglas en inglés) y de bajo bostezo (LY, de sus siglas en inglés) hacia los olores presentes en las camas de aserrín, provenientes de machos sexualmente expertos Sprague-Dawley, HY y LY. Se utilizó la prueba de campo abierto en forma de cubo de $60 \times 60 \times 50 \mathrm{~cm}$, de madera pintada de negro y una pared frontal de cristal oscuro para la observación de la conducta de olfacción. Como incentivos olfatorios, se colocaron en las esquinas, de forma aleatoria, tres porciones de viruta utilizadas como cama por los machos SD, LY o HY, y en otra se colocó viruta de madera presurizada limpia (Beta chip, USA). En el centro del campo abierto se introdujo a una hembra con esto inducido y se midió la frecuencia y duración de los olfateos, la latencia para el primer episodio de olfateo y el intervalo de retorno a cada área incentivo. Los resultados mostraron que las ratas hembra prefieren los olores de los machos SD y HY, ya que ejecutaron un mayor número de episodios de olfateo y pasaron más tiempo olfateando, 20 segundos en las hembras $\mathrm{HY}$ y 30 segundos en las LY $(P<0.05)$. En conclusión, las feromonas masculinas producen un "adorno químico sexual" que transmiten información a distancia capaz de atraer constantemente a las hembras, independientemente de la compatibilidad genética, $y$, en consecuencia, aumentan el potencial de éxito reproductivo. Financiado por el apoyo al CA en NeuroendocrinologíaBUAP-CA-288. AMB es becario de CONACyT No. 662091 por Doctorado en Ciencias Fisiológicas.

Cite this paper/Como citar este artículo: Mora Bolaños, A., Cortés Sánchez, M. C., Eguibar Cuenca, J. R. (2020). Evaluación del incentivo sexual olfatorio en las ratas hembras de alto y de bajo bostezo. Revista Bio Ciencias 7: (Suppl) Memorias de Congreso. LXIII Congreso Nacional de la Sociedad Mexicana de Ciencias Fisiologicas, A. C. e1097. http://doi.org/10.15741/revbio.07Suppl.e1097 


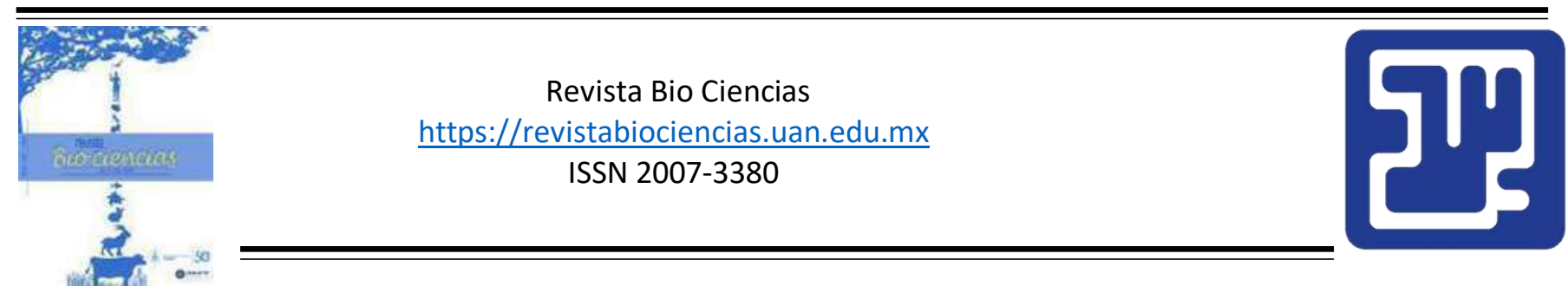

Trabajos libres: Neurociencias

Modalidad de Presentación: Cartel

\begin{abstract}
Dieta con $6 \%$ de moras azules (Vaccinium corymbosum L.) atenúa trastornos motores en ratas Wistar hemiparkinsonianas
\end{abstract}

\author{
Dawn Ojeda, A. A., Granados Patrón, D .A., Marín Canul, J. E., Cuevas Carbonell, S. G., Góngora \\ Alfaro, J. L. *
}

Universidad Autonoma de Yucatan. Facultad de Medicina.

*Autor Corresponsal: José Luis Góngora Alfaro. E- mail: jlgongoralf@gmail.com

La enfermedad de Parkinson se caracteriza por pérdida de neuronas dopaminérgicas nigroestriatales, lo que causa trastornos motores. Alimentación con $3 \%$ de mora azul atenúa la denervación dopaminérgica unilateral y disminuye los giros inducidos con apomorfina en ratas. Aquí reportamos el efecto de una dosis mayor de moras para atenuar los trastornos motores inducidos con 6-hidroxidopamina (6-OHDA). Un grupo de ratas Wistar $(n=5)$ recibió una cantidad fija de alimento LabDiet5001, y otro $(n=5)$ recibió dicho alimento suplementado con $6 \%$ de moras azules liofilizadas. Dos semanas después se les inyectó $8.75 \mu \mathrm{g}$ de 6-OHDA (día 0) en el cuerpo estriado derecho ( $\mathrm{AP}=$ $+0.2 \mathrm{~mm}, \mathrm{~L}=-3.5 \mathrm{~mm}$ y $\mathrm{DV}=-5 \mathrm{~mm}$ ) y se continuó la dieta tres semanas más. Antes y posterior a la lesión, en intervalos semanales se evaluó el número de errores cometidos en la pasarela elevada y la asimetría motora en el uso de las patas delanteras en el cilindro. Análisis: ANOVA de 2 factores (Tiempo y tratamiento) y ANOVA de medidas repetidas (MR) con post hoc de Bonferroni. Con el ANOVA-2, el factor tiempo mostró diferencias significativas en ambas pruebas, mientras que el tratamiento sólo en la asimetría $(p<0.05)$. El grupo control cometió más errores al día 21 en comparación con el grupo que recibió moras y su propio valor basal del día -1 ( $p<0.05)$. En el día 7, la asimetría del grupo de moras fue menor que el grupo control $(p<0.05)$. Según el ANOVA-MR, la asimetría motora del grupo control incrementó todas las semanas postlesión vs. el día -1 $(p<0.0001)$, caracterizada por mayor uso de la pata ipsilateral y menor uso de la pata contralateral $(p<0.05)$, lo cual no ocurrió en el grupo tratado con moras. El consumo de $6 \%$ de moras azules atenúa los trastornos motores, posiblemente por su contenido en antioxidantes.

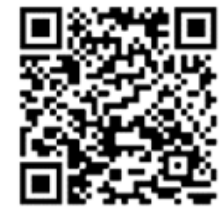

Cite this paper/Como citar este artículo: Dawn Ojeda, A. A., Granados Patrón, D .A., Marín Canul, J. E., Cuevas Carbonell, S. G., Góngora Alfaro, J. L (2020). Dieta con 6\% de moras azules (Vaccinium corymbosum L.) atenúa trastornos motores en ratas Wistar hemiparkinsonianas. Revista Bio Ciencias 7: (Suppl) Memorias de Congreso. LXIII Congreso Nacional de la Sociedad Mexicana de Ciencias Fisiologicas, A. C. e1097. http://doi.org/10.15741/revbio.07Suppl.e1097 


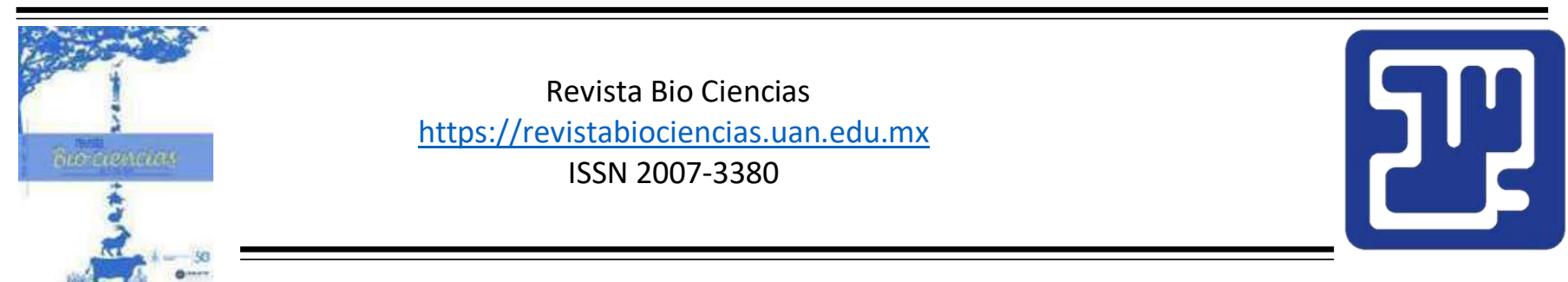

Trabajos libres: Neurociencias

Modalidad de Presentación: Cartel

Evaluación del acicalamiento en ratas estresadas tratadas con fluoxetina

Limón Vázquez, A. K. *, Bernal Morales, B., Rodríguez Landa, J. F., Guillén Ruiz, G., Ayala Saavedra, D. A., Valenzuela Limón, O. L.

\section{Universidad Veracruzana. Instituto de neuroetología.}

*Autor Corresponsal: Ana Karen Limón Vázquez. E- mail: zs19019718@estudiantes.uv.mx

El acicalamiento es una conducta dirigida al mantenimiento de la higiene, su importancia biológica se basa en el cuidado de la salud, previniendo el desarrollo de infecciones y malos olores. En las ratas el acicalamiento se caracteriza por presentarse como una serie de movimientos secuenciales y organizados, sin embargo, en situaciones estresantes se altera en forma y cantidad y es desconocido si la acción antidepresiva de fluoxetina, evidente por el aumento de la motivación en situaciones de conflicto, también restablece el acicalamiento en ratas adultas estresadas crónicamente. El objetivo del presente estudio fue analizar el efecto de fluoxetina sobre el acicalamiento en ratas macho adultas estresadas por restricción de espacio y nado forzado. El presente estudio estuvo integrado por tres grupos de ratas, un grupo control y dos grupos que fueron sometidos a la restricción de espacio durante 21 días
(Vehículo; Restricción de espacio (60 min); Restricción de espacio + Fluoxetina). Todas las ratas fueron forzadas a nadar una vez a la semana por tres semanas. El acicalamiento se registró en campo abierto los días 7, 14 y 21. Los resultados revelaron una disminución notable del tiempo de acicalamiento rostral y total, con mayor número de patrones de acicalamiento interrumpidos en las ratas con restricción de espacio $(p<0.05)$. La fluoxetina impidió el efecto del estrés sobre el acicalamiento, alcanzando valores de acicalamiento semejantes al grupo sin restricción de espacio. Se concluye que la fluoxetina ejerce un efecto protector contra los efectos negativos de la restricción de espacio crónica sobre el acicalamiento, lo que podría ser de utilidad para el desarrollo de estrategias de cuidado emocional en animales en cautiverio.

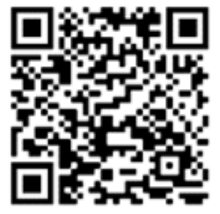

Cite this paper/Como citar este artículo: Limón Vázquez, A. K., Bernal Morales, B., Rodríguez Landa, J. F., Guillén Ruiz, G., Ayala Saavedra, D. A., Valenzuela Limón, O. L. (2020). Evaluación del acicalamiento en ratas estresadas tratadas con fluoxetina. Revista Bio Ciencias 7: (Suppl) Memorias de Congreso. LXIII Congreso Nacional de la Sociedad Mexicana de Ciencias Fisiologicas, A. C. e1097. http://doi.org/10.15741/revbio.07Suppl.e1097 


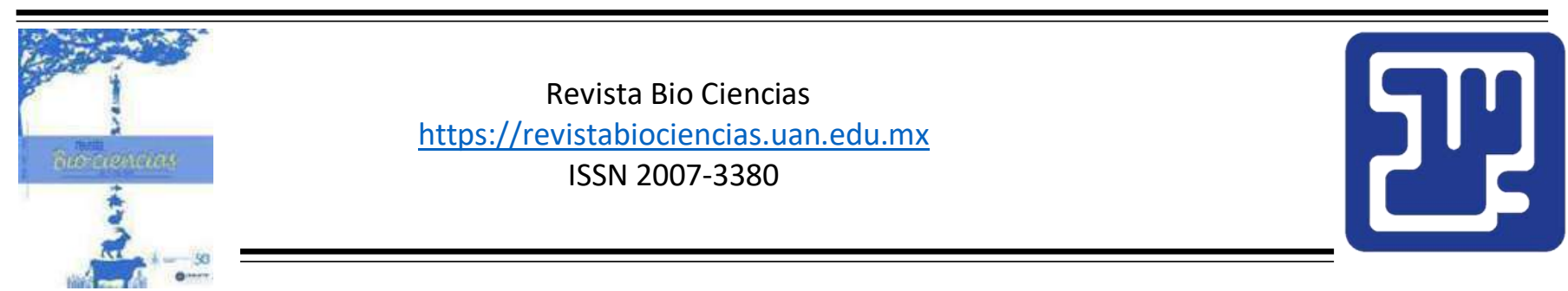

Trabajos libres: Neurociencias

Modalidad de Presentación: Cartel

\begin{abstract}
La administración de EPOrh promueve la restauración del tejido hipocampal, ante el daño excitotóxico
\end{abstract} inducido por GMS en ratas neonatas

García Juárez, A., Carrillo Gonzalez, N., Gasca Martínez, Y., Rivera Cervantes, M. C., Ureña Guerrero, M. E., Beas Zarate, C., Cabrera Gudiño, G. *

Universidad de Guadalajara. Departamento de Biologia Celular y Molecular. *Autor Corresponsal: Graciela Cabrera Gudiño. E- mail: graciela.gudino@cucba.udg.mx

El ácido L-glutámico (Glu) es el principal neurotransmisor excitatorio del sistema nervioso central, sin embargo, la acumulación excesiva de Glu en el espacio extracelular produce un ambiente excitotóxico que promueve muerte neuronal en regiones susceptibles como el hipocampo, así como un incremento de astrocitos. Dado que se ha considerado a la excitotoxicidad como la base celular del daño en diversos padecimientos, es de interés la búsqueda de estrategias farmacológicas para atenuar la muerte de las células neurales. Una alternativa es el uso de eritropoyetina (EPO), una citocina que se ha asociado a neuroprotección. Por lo anterior resulta importante determinar si la administración de la EPO recombinante humana (EPOrh) promueve la neuroprotección y neurorestauración en la excitotoxicidad inducida por GMS. Se utilizaron 4 grupos de ratas macho de la cepa Wistar recién nacidas $(n=4)$ : Control, GMS (animales tratados con 1 dosis de GMS de 4 $\mathrm{mg} / \mathrm{g}$ de peso corporal, vía subcutánea los días 1, 3, 5 y 7 de edad posnatal), GMS + EPO (EPOrh de $1000 \mathrm{UI} / \mathrm{kg}$ al día $8 \mathrm{PN}$ ) y EPO. Se realizó un estudio inmunocitoquímico con NeuN (Millipore)/Alexa 488 y GFAP (Dako)/Alexa 594 En individuos tratados con GMS se detectó alteración de la citoarquitectura, hipertrofia celular y desorganización de los estratos neuronales, un aumento de expresión de GFAP con respecto al intacto y al GMS+EPO y EPO. Además, disminuyó la expresión de NeuN nuclear, mientras que la isoforma citoplasmática permanece, a diferencia de los grupos GMS+EPO y EPO que no presentan esta alteración evidente en el patrón de NeuN. La expresión de NeuN es necesaria para la función sináptica y la sinaptogénesis en el giro dentado del hipocampo, la disminución de NeuN nuclear podría estar relacionada con la susceptibilidad a las crisis convulsivas que presentan los individuos en edad adulta en este modelo.

Cite this paper/Como citar este artículo: García Juárez, A., Carrillo Gonzalez, N., Gasca Martínez, Y., Rivera Cervantes, M. C., Ureña Guerrero, M. E., Beas Zarate, C., Cabrera Gudiño, G. (2020). La administración de EPOrh promueve la restauración del tejido hipocampal, ante el daño excitotóxico inducido por GMS en ratas neonatas. Revista Bio Ciencias 7: (Suppl) Memorias de Congreso. LXIII Congreso Nacional de la Sociedad Mexicana de Ciencias Fisiologicas, A. C. e1097. http://doi.org/10.15741/revbio.07Suppl.e1097 


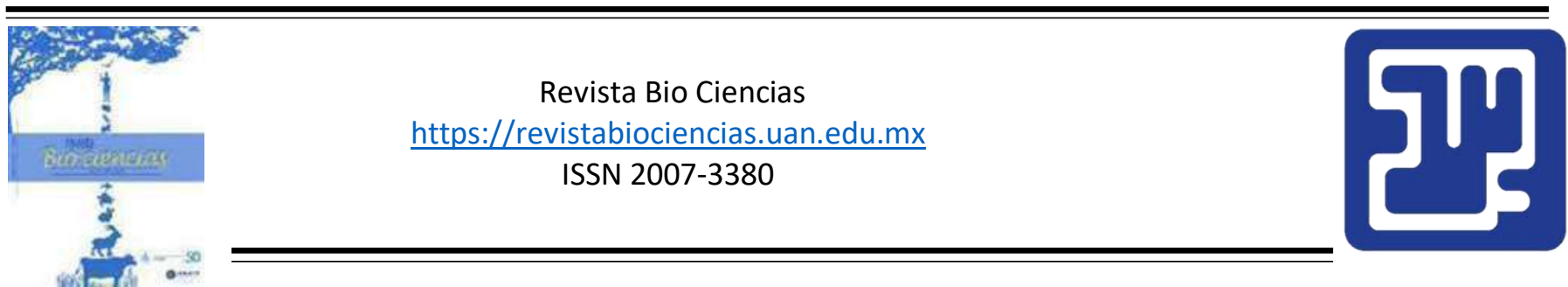

Trabajos libres: Neurociencias

Modalidad de Presentación: Oral

Bloqueo de la amnesia producida por un inhibidor de la síntesis de proteínas de novo en las ventanas temporales de consolidación de la memoria empleando un aprendizaje incrementado

Medina Fragoso, A. C., Bello Medina, P. C., Arboleyda Fibela, A. O., Quirarte Quirarte, G. L., Prado Alcalá, R. A. *

Universidad Nacional Autónoma de México. Departamento de Neurobiología Conductual y Cognitiva.

*Autor Corresponsal: Roberto A. Prado Alcalá. E- mail: prado@servidor.unam.mx

Se ha propuesto que hay diferentes periodos de consolidación de la memoria después de una experiencia de aprendizaje, los cuales son dependientes de mecanismos de transcripción y traducción. Se ha demostrado que un aprendizaje incrementado protege a la memoria de tratamientos amnésicos, pero no se sabe si bloqueando los mecanismos de traducción en los periodos de consolidación, se mantiene el efecto protector. Se usaron ratas macho Wistar y se entrenaron en la tarea de evitación inhibitoria con 0.34 o $1.0 \mathrm{~mA}$. Treinta minutos antes del entrenamiento se administró cicloheximida (CXM), inhibidor de la síntesis de proteínas, $(3.0 \mathrm{mg} / \mathrm{kg}$, s.c.) o vehículo. A otros grupos se les administró el mismo tratamiento, $1,2.5$ o $5.5 \mathrm{~h}$ después del entrenamiento. Se agregó un par de grupos con la administración de vehículo o CXM tanto antes como después del entrenamiento (30 min y $2.5 \mathrm{~h}$ ) pero entrenados con $1 \mathrm{~mA}$. En todos los casos la prueba de retención se realizó 48 horas después del entrenamiento. Se encontró que la administración de CXM antes del entrenamiento con $0.34 \mathrm{~mA}$ o $2.5 \mathrm{~h}$ después produjo amnesia, pero cuando los sujetos fueron entrenados con un choque eléctrico alto se bloqueó la amnesia. El efecto se repitió en el grupo en el que se administró el tratamiento en los dos periodos de consolidación. Por lo tanto, los resultados nos permiten proponer que la memoria generada ante un aprendizaje incrementado está sustentada probablemente por mecanismos independientes a la producción de nuevas proteínas. Agradecemos el apoyo técnico a Norma Serafín, Bernardino Osorio, Martín García, Alejandra Castilla, Omar González y Ramón Martínez. PAPIIT (IN203918).

Cite this paper/Como citar este artículo: Medina Fragoso, A. C., Bello Medina, P. C., Arboleyda Fibela, A. O., Quirarte Quirarte, G. L., Prado Alcalá, R. A. (2020). Bloqueo de la amnesia producida por un inhibidor de la síntesis de proteínas de novo en las ventanas temporales de consolidación de la memoria empleando un aprendizaje incrementado. Revista Bio Ciencias 7: (Suppl) Memorias de Congreso. LXIII Congreso Nacional de la Sociedad Mexicana de Ciencias Fisiologicas, A. C. e1097. http://doi.org/10.15741/revbio.07Suppl.e1097 


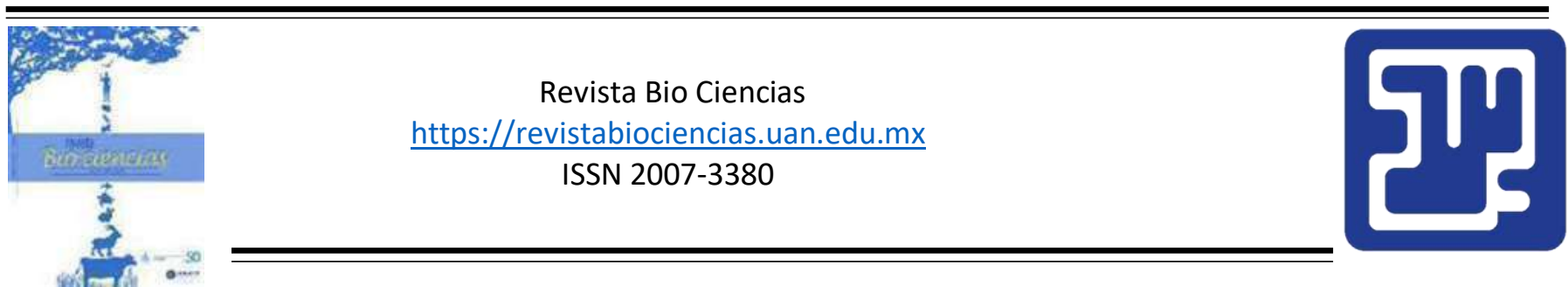

Trabajos libres: Neurociencias

Modalidad de Presentación: Cartel

Impacto sobre la expresión de c-Fos en el tallo cerebral de ratas con lesión espinal

Laureani Fierro, A. J., Morgado Valle, C., García Hernández, L. I., Rojas Durán, F., Hernández

Aguilar, M. E., Pérez Estudillo, C. A. *

Universidad Veracruzana

*Autor Corresponsal: César Antonio Pérez Estudillo. E-mail: cesperez@uv.mx

La médula espinal comunica información desde la periferia del cuerpo hasta el encéfalo y viceversa; su daño produce pérdida parcial o total de funciones motoras y sensoriales. Investigaciones previas han reportado que la lesión de la médula espinal (LME) en segmentos torácicos afectan la función del hipotálamo, formación reticular y cerebelo, mientras que la LME cervical afecta a los núcleos respiratorios del tallo cerebral (TC). Sin embargo, no se sabe si la LME torácica afecta la función de núcleos respiratorios y de otros núcleos del TC. Se investigó si 6 y 24 horas posteriores a la LME completa transversal torácica (T8) modifica la actividad celular en distintos núcleos del TC de ratas. Se utilizaron ratas macho adultas Wistar (300$400 \mathrm{~g}$ ) divididas en grupos de intactas, sham y LME. Usando la prueba de Tarlov-Bohlman se corroboró el grado de deterioro motor inducido por la LME. Por inmunohistoquímica se cuantificó el número de células inmunorreactivas a c-Fos en 7 núcleos del TC. A las 24 horas, el grupo de LME mostró un aumento significativo de células inmunoreactivas a c-Fos en el complejo preBötzinger, el complejo Bötzinger, los grupos respiratorios ventral dorsal y ventral caudal, el núcleo motor del vago, el núcleo del tracto solitario y la oliva inferior. A las 6 horas, también se observó un aumento de estos núcleos en el grupo de LME, aunque este incremento fue menor a lo observado a las 24 horas. El número de células c-Fos positivas entre intactas y sham fue similar. Los cambios en la expresión de c-Fos en el TC después de la LME podrían deberse por la afectación de las vías de esos núcleos que conectan directa o indirectamente con la médula espinal torácica; así mismo, estarían relacionados a los procesos bioquímicos del daño primario y secundario que ocurren posteriormente al trauma medular. 


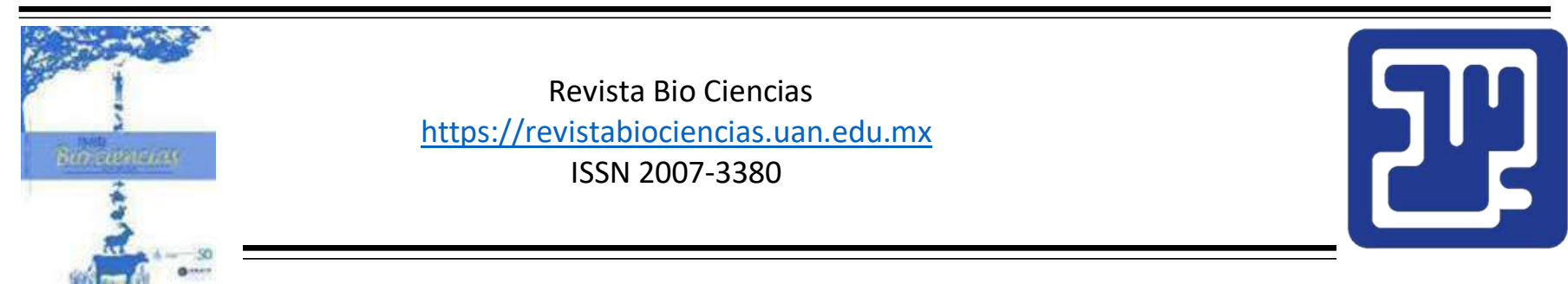

Trabajos libres: Neurociencias

Modalidad de Presentación: Cartel

\title{
La eyaculación rápida que presenta la rata macho en la Arena de Selección Múltiple de Pareja no se debe a la ansiedad
}

\author{
Cruz Benites, A. ${ }^{1}$, Morales Otal, $A .{ }^{1}$, Torner Aguilar, $C^{3}{ }^{3}$, Gomora Arrati, ${ }^{3}{ }^{3}$, Ferreira Nuño, $A .{ }^{{ }^{*}}$ \\ 'Universidad Autónoma Metropolitana Iztapalapa \\ ${ }^{2}$ Universidad Autónoma Metropolitana Unidad Xochimilco \\ ${ }^{3}$ Universidad Autónoma de Tlaxcala
}

*Autor Corresponsal: Armando Ferreira Nuño. E- mail: fena@xanum.uam.mx

La Arena de Selección Múltiple de Pareja (ASMP), consta de 4 redondeles de acrílico colocados de forma circular, en la que se coloca una rata macho en cada redondel y a una rata hembra sexualmente receptiva (HSR) en el centro de la arena, para que pueda elegir al macho con el que desea copular. En estas condiciones hemos demostrado que la hembra copula con mayor frecuencia con el macho que visita en primer lugar, esto genera que los machos no preferidos (MNP) eyaculen con menos intromisiones y en menor tiempo. Para demostrar si la eyaculación rápida que presentan los MNP en la ASMP se debe a la ansiedad, evaluamos la conducta que presentan dos grupos de ratas macho sexualmente expertos en el laberinto elevado en cruz, en un ambiente competitivo (grupo C, $\mathrm{n}=7$ ) y en un ambiente no competitivo (grupo NoC, $n=6$ ). En el ambiente competitivo se colocó un macho en cada redondel de la ASMP y una HSR en el área central. La prueba terminó cuando el primer MNP realizó las primeras 3 intromisiones, enseguida se evaluó su conducta en el laberinto elevado durante $5 \mathrm{~min}$. En el ambiente no competitivo se colocó a un sólo macho, en uno de los redondeles de la ASMP y la prueba terminó cuando el macho realizó tres intromisiones y enseguida se evaluó su conducta en el laberinto elevado durante $5 \mathrm{~min}$. El número de entradas en brazos abiertos y el tiempo pasado en brazos abiertos fue muy semejante en ambos grupos. Por lo tanto, la eyaculación rápida que presentan los MNP en la ASMP, no se debe a un incremento en la ansiedad por la competencia copulatoria. 


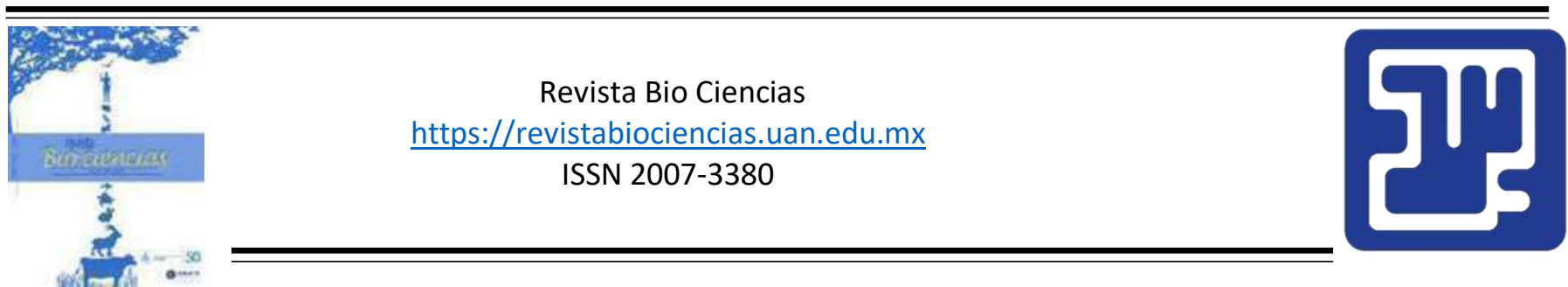

Trabajos libres: Neurociencias

Modalidad de Presentación: Oral

\title{
Efecto del status socioeconómico percibido sobre EEG en reposo, cortisol en cabello y rendimiento cognitivo en adultos mayores sanos
}

\author{
Villada Rodriguez, C. ${ }^{1 *}$, Lopez Gonzalez, M. ${ }^{2}$, Aguilar Zavala, H. ${ }^{1}$, Fernández Harmony, $T^{1}$. \\ ${ }^{1}$ Universidad de Guanajuato. Departamento de psicología \\ ${ }^{2}$ Universidad Nacional Autónoma de México
}

*Autor Corresponsal: Carolina Villada Rodriguez. E- mail: c.villada@ugto.mx

El envejecimiento satisfactorio depende de factores externos e internos que influyen en el proceso general de envejecimiento. Algunos de esos factores externos son la percepción subjetiva y objetiva del status socioeconómico, emergiendo como potenciales factores psicosociales en la etiopatofisiología de los trastornos relacionados con la edad. Se considera que un estatus socioeconómico bajo puede actuar como un estresor psicosocial afectando a mecanismos psiconeuroendocrinos, que, a su vez, pueden afectar a la fisiología cerebral. En el electroencefalograma en reposo, se ha visto que un exceso de actividad theta y delta se relacionan con deterioro cognitivo y demencia. El principal objetivo de este estudio fue analizar el efecto de estatus socioeconómico subjetivo y objetivo (SES) sobre la cognición y la actividad eléctrica cerebral (EEG). treinta adultos mayores (61-82 años) fueron separados en dos grupos: alto (HS) y bajo (LS) estatus socioeconómico. Se les evaluó el rendimiento cognitivo mediante la batería de pruebas del WAIS-IV, la actividad eléctrica cerebral en reposo mediante EEG, y las concentraciones de cortisol en cabello (HCC) en los últimos 3 meses. Los resultados mostraron que un bajo SES está relacionado con un peor rendimiento cognitivo en tareas de memoria de trabajo, mayor potencia de theta y delta y menor actividad de alfa. Sin embargo, parece que el SES no afectó al HCC en esta población. Estos resultados enfatizan el papel de los factores psicosociales en el envejecimiento desde una perspectiva integradora, la cual nos permitirá implementar mejores programas de intervención dirigidos al deterioro cognitivo en adultos. 


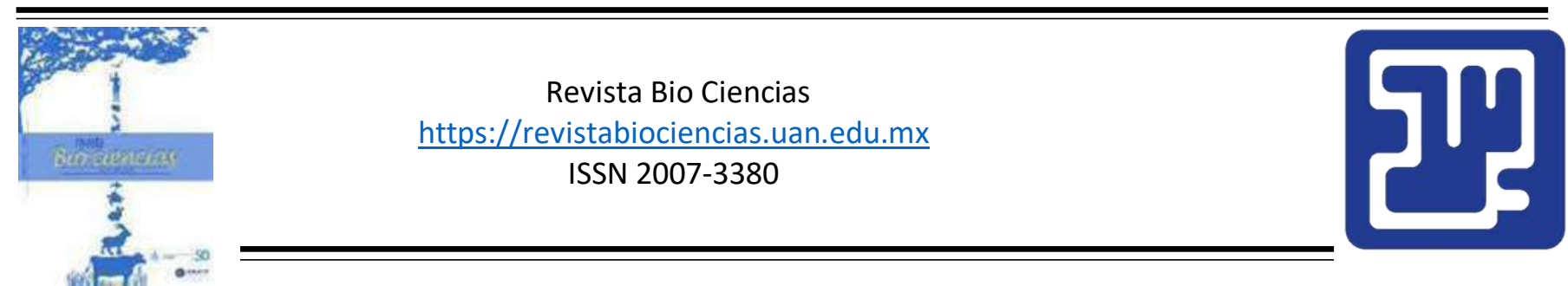

Trabajos libres: Neurociencias

Modalidad de Presentación: Cartel

\title{
Impacto de las hormonas ováricas sobre la ansiedad y la expresión de la proteína Fos en el área CA1 del hipocampo de la rata Wistar
}

\author{
Sobrino Flores, C. ${ }^{1}$, Puga Olguín, A. ${ }^{2}$, Flores González, A. ${ }^{1}$, Rovirosa Hernández, M. J. ${ }^{3}$, Rodríguez \\ Landa, J. F. ${ }^{3 *}$ \\ 1 Universidad Veracruzana, Facultad de Química Farmacéutica Biológica \\ ${ }^{2}$ Instituto Interdisciplinario de Investigaciones de la Universidad De Xalapa \\ ${ }^{3}$ Instituto de Neuroetología de la Universidad Veracruzana
}

*Autor Corresponsal: Juan Francisco Rodríguez Landa. E- mail: juarodriguez@uv.mx

La menopausia quirúrgica aumenta la vulnerabilidad para presentar trastornos psiquiátricos como la ansiedad y la depresión, entre otras alteraciones emocionales y fisiológicas, debido a la reducción de las concentraciones plasmáticas y cerebrales de hormonas ováricas, que afectan la actividad neuronal de estructuras cerebrales como el hipocampo. Para el estudio de esas alteraciones se utiliza a la rata ovariectomizada, pero se desconoce el efecto de la ovariectomía sobre la ansiedad y su relación con la actividad neuronal del área CA1 del hipocampo. Se evaluaron los efectos de la ovariectomía sobre la ansiedad en el modelo de laberinto de brazos elevados y la expresión de Fos en el hipocampo. Se incluyeron tres grupos de ratas Wistar ovariectomizadas a los tres meses de edad y fueron evaluadas a 3, 9 y 15 semanas postovariectomía, respectivamente; más dos grupos controles, uno en fase de proestroestro $(P-E)$ y otro en fase de metaestro-diestro
(M-D). Los efectos fueron evaluados en el laberinto de brazos elevados (ansiedad) y en la prueba de campo abierto (actividad locomotora). Al finalizar las pruebas se obtuvieron los cerebros para cuantificar, por inmunohistoquímica, la proteína Fos en el área CA1 del hipocampo. Los resultados fueron analizados mediante ANOVA de una vía y post hoc de Student-Newman-Keuls. En el laberinto de brazos elevados, los grupos ovariectomizados y el grupo M-D tuvieron mayores indicadores de ansiedad, respecto al grupo en $P-E(p<0.01)$, efectos que no fueron relacionados por alteraciones en la actividad motora. La ansiedad estuvo asociada con la disminución de Fos en el área CA1 del hipocampo, un efecto no observado en los grupos controles $(p<0.001)$. Se concluye que la ausencia hormonal a largo plazo aumenta la ansiedad, lo cual podría estar asociado con la disminución de la activación neuronal en el área CA1 del hipocampo.

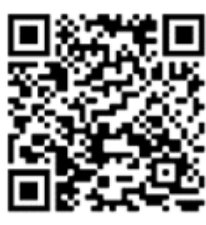

Cite this paper/Como citar este artículo: Sobrino Flores, C., Puga Olguín, A., Flores González, A., Rovirosa Hernández, M. J., Rodríguez Landa, J. F. (2020). Impacto de las hormonas ováricas sobre la ansiedad y la expresión de la proteína Fos en el área CA1 del hipocampo de la rata Wistar. Revista Bio Ciencias 7: (Suppl) Memorias de Congreso. LXIII Congreso Nacional de la Sociedad Mexicana de Ciencias Fisiologicas, A. C. e1097 http://doi.org/10.15741/revbio.07Suppl.e1097 


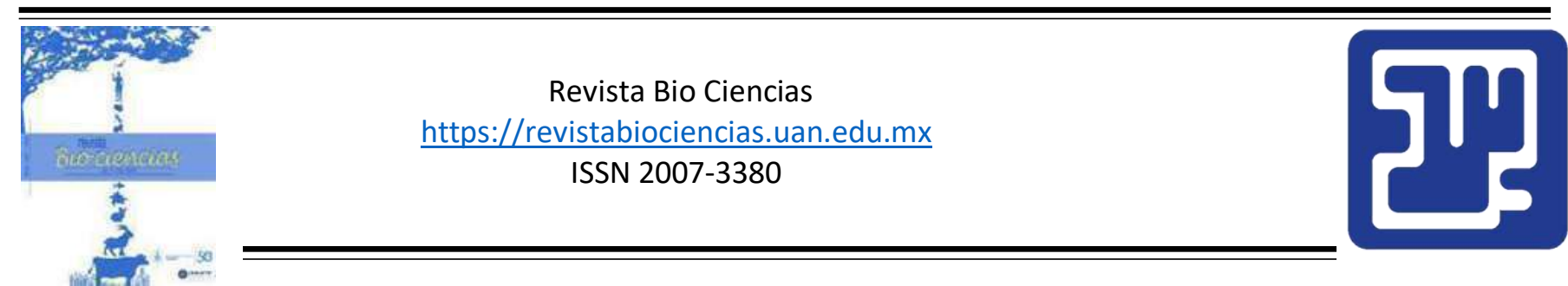

Trabajos libres: Neurociencias

Modalidad de Presentación: Cartel

La exposición prenatal al alcohol incrementa la expresión de genes de intercambiadores de guanina Rho en la CPF de ratas Wistar y el MPH lo revierte

Cobian Pacheco, C. G. ${ }^{1}$, Juárez Rodríguez, P. ${ }^{1}$, Guzmán Brambilla, $C .^{2}$, Godínez Rubí, J. M. ${ }^{1}$, Orozco Barocio, A. ${ }^{1}$, Ortuño Sahagún, D. ${ }^{1}$, Rojas Mayorquín, A. E. ${ }^{1 *}$

${ }^{1}$ Centro Universitario de Ciencias Biológicas y Agropecuarias (CUCBA), Universidad De

Guadalajara

${ }^{2}$ Tecnológico de Monterrey

*Autor Corresponsal: Argelia Esperanza Rojas Mayorquín. E- mail: argelia.rojas@gmail.com

La exposición prenatal al alcohol (PAE) está asociada con defectos en el neurodesarrollo que derivan en alteraciones de la conducta y la cognición de la descendencia. El principal órgano blanco del etanol es el cerebro, siendo la corteza prefrontal (CPF) una región especialmente vulnerable. El metilfenidato (MPH) es un psicoestimulante con efectos positivos en la atención, funciones cognitivas y la conducta en trastornos neuropsiquiátricos. Los intercambiadores de nucleótido de guanina (GEF) regulan los estados de activación e inactivación de las proteínas GTPasas, cruciales en el desarrollo sináptico y la plasticidad de las redes neuronales. En el presente trabajo se determinaron los niveles de expresión génica de tres GEF de la familia Rho en la CPF de ratas con PAE y su modificación por el tratamiento posnatal con MPH. Se realizó un modelo de PAE por vía intragástrica en ratas Wistar hembras preñadas (8-20 DEG). Las crías macho recibieron MPH o solución vehículo (26-38 DEP). Se disecó la CPF de cada rata, se obtuvo el RNA total para su retro-transcripción y amplificación por qPCR, los resultados se analizaron por método de comparación de $\triangle \triangle C T$. En la CPF, Mcf2 y Net1 reducen su expresión bajo todas las condiciones experimentales. Por su parte Vav1 aumento su expresión en la CPF por el tratamiento con $\mathrm{MPH}$, así como por el $\mathrm{OH} / \mathrm{MPH}$. La desregulación de la actividad de los GEF se ha asociado con un rango amplio de enfermedades, incluidas neurodegenerativas y del neurodesarrollo. No obstante, no se había vinculado con la PAE, en la que la remodelación del citoesqueleto de actina en las espinas dendríticas parece jugar un papel relevante. Palabras clave: Exposición Prenatal al Alcohol, Intercambiadores de nucleótido de guanina Rho, Metilfenidato.

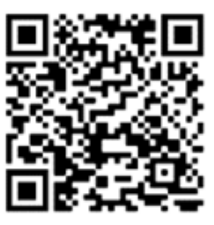

Cite this paper/Como citar este artículo: Cobian Pacheco, C. G., Juárez Rodríguez, P., Guzmán Brambilla, C., Godínez Rubí, J. M., Orozco Barocio, A., Ortuño Sahagún, D., Rojas Mayorquín, A. E. (2020). La exposición prenatal al alcohol incrementa la expresión de genes de intercambiadores de guanina Rho en la CPF de ratas Wistar y el MPH lo revierte. Revista Bio Ciencias 7: (Suppl) Memorias de Congreso. LXIII Congreso Nacional de la Sociedad Mexicana de Ciencias Fisiologicas, A. C. e1097. http://doi.org/10.15741/revbio.07Suppl.e1097 


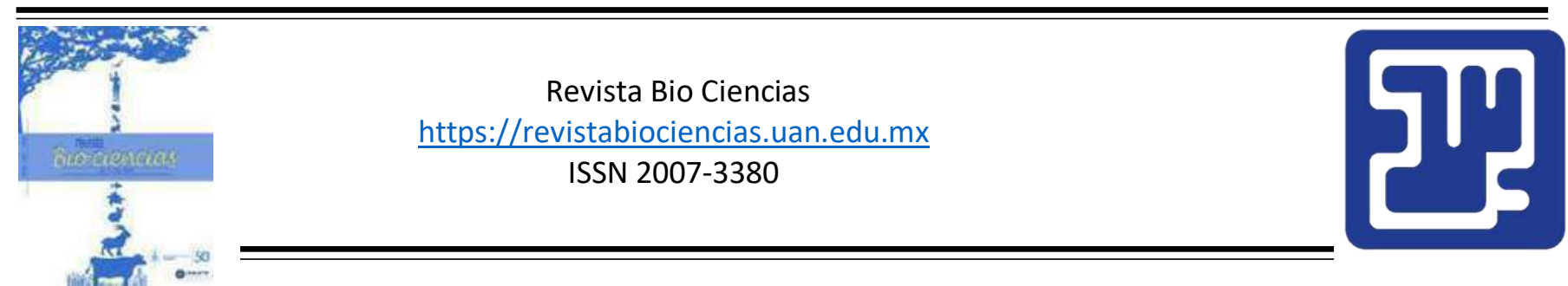

Trabajos libres: Neurociencias

Modalidad de Presentación: Oral

\author{
Participación del sistema gabaérgico del SCN en la síntesis de vip y la inhibición de la ovulación \\ Ramos Puga, D. A. ${ }^{1}$, Calderón Ramos, . $^{2}$, Vieyra Valdez, E. ${ }^{2}$, Domínguez Casalá, $R^{2}{ }^{2}$, Morales \\ Ledesma, L. ${ }^{*}$
}

*Autor Corresponsal: Leticia Morales Ledesma. E- mail: moralesledesma@yahoo.com.mx

\begin{abstract}
El Núcleo Supraquiasmático (SCN) regula los ritmos biológicos como la liberación circadiana de las hormonas hipotalámicas relacionadas con la reproducción. EI SCN se comunica con núcleos GnRHérgicos a través del péptido intestinal vasoactivo (VIP) y la vasopresina (AVP). Previamente mostramos que los receptores colinérgicos del SCN participan en la regulación de la ovulación y que podría ser mediada por la liberación del ácido gammaaminobutírico (GABA) en el SCN. Para analizar esta posibilidad, se procedió a realizar en la mañana del proestro, la microinyección de GABA en el SCN izquierdo o derecho y se evaluaron sus efectos sobre la ovulación y la síntesis del mRNA de VIP por RT-PCR en tiempo real. Para ello, ratas cíclicas de la cepa CII-ZV fueron anestesiadas a las 09:00 h del proestro y microinyectadas en el SCN izquierdo o derecho con $0.3 \mu \mathrm{L}$ de solución salina (vehículo, Vh) o GABA [10 $\mathrm{mM}$ ]. Los animales fueron sacrificados $1 \mathrm{~h}$ después de la cirugía para obtener el SCN y
\end{abstract}

realizar la extracción del RNA total. Otro grupo fue sacrificado $24 \mathrm{~h}$ para evaluar la respuesta ovulatoria. La microinyección de GABA en el SCN no modificó el porcentaje de animales ovulantes (GABA SCN-izquierdo 7/8 vs. Vh SCN-izquierdo 8/8; GABA SCN-derecho 6/8 vs. Vh SCN-derecho 8/8). En comparación con su respectivo grupo $\mathrm{Vh}$, la microinyección de GABA resultó en la disminución del número de ovocitos liberados (GABA SCN-izquierdo $5.4 \pm 2.58$ vs. Vh SCN-izquierdo $11.08 \pm 2.55$; GABA SCN-derecho $7.3 \pm 2.58$ vs. Vh SCNderecho 12.25 $\pm 1.76 ; \quad p<0.05)$. No se observaron diferencias en la cuantificación del mVIP entre los grupos tratados. Resultados que permiten sugerir que en la mañana del proestro, el sistema GABAérgico del SCN regula de manera inhibitoria los mecanismos que desencadenan la liberación del ovocito y que esta respuesta no es mediada por VIP, en las primeras horas del incremento de GABA en el SCN.

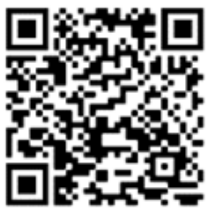

Cite this paper/Como citar este artículo: Ramos Puga, D. A., Calderón Ramos, R., Vieyra Valdez, E., Domínguez Casalá, R., Morales Ledesma, L. (2020). Participación del sistema gabaérgico del SCN en la síntesis de vip y la inhibición de la ovulación. Revista Bio Ciencias 7: (Suppl) Memorias de Congreso. LXIII Congreso Nacional de la Sociedad Mexicana de Ciencias Fisiologicas, A. C. e1097. http://doi.org/10.15741/revbio.07Suppl.e1097 


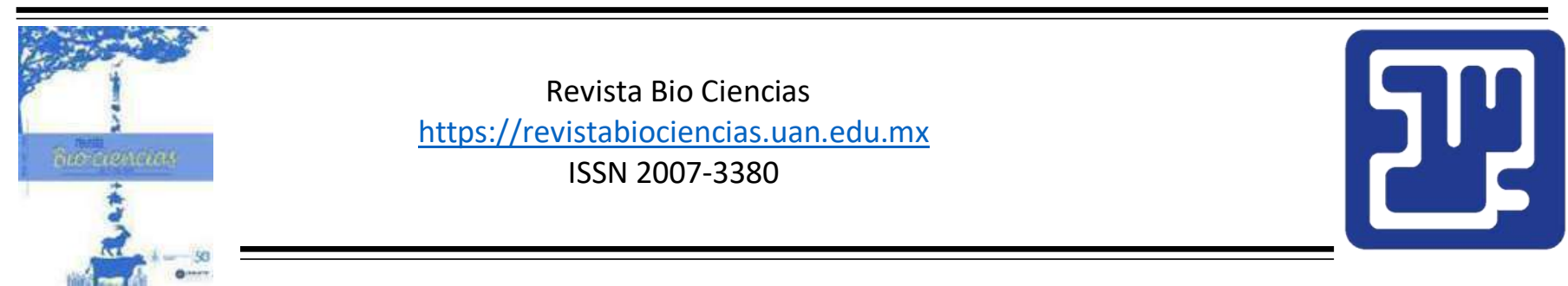

Trabajos libres: Neurociencias

Modalidad de Presentación: Cartel

\author{
Efecto del estrés prenatal sobre el trasportador de serotoina en el hipocampo dorsal de la rata \\ Mendez Guerrero, D. ${ }^{1}$, Jiménez Vásquez, F. J. ${ }^{1}$, Rubio Osornio, M. ${ }^{2}$, Rubio Osornio, M. C. ${ }^{2}$, Orozco \\ Suárez, S. ${ }^{3}$, Retana Márquez, M. S. I. ${ }^{1 *}$ \\ ${ }^{1}$ Universidad Autónoma Metropolitana Iztapalapa \\ ${ }^{2}$ Instituto Nacional de Neurología y Neurocirugía Manuel Velasco Suárez \\ ${ }^{3}$ Centro Médico Nacional Siglo XXI
}

*Autor Corresponsal: Maria del Socorro Imelda Retana Márquez. E- mail: sretanam@gmail.comx

En trabajos previos hemos demostrado que la liberación de serotonina en el hipocampo dorsal disminuye en animales estresados prenatalmente (EP) que presentan deficiencias cognitivas. Dado que la Serotonina se une a sus receptores posinápticos y de esa manera podría modificar la actividad de neuronas posinápticas, En este trabajo se evaluó el contenido del transportador de serotonina (SERT) en el hipocampo dorsal de animales adultos EP en condiciones basales y durante los días de aprendizaje y memoria. Para ello, se utilizaron machos control y EP de 3 meses, de los cuales se obtuvieron los hipocampos dorsales en condiciones basales y de otros animales se obtuvo esta estructura después de realizar pruebas de aprendizaje y memoria, utilizando el laberinto acuático de Morris (LAM). Se confirmaron las deficiencias cognitivas en los machos EP en comparación con los controles. Se observó que el contenido basal del SERT es mayor en los animales EP que en los machos control, lo que explica la baja concentración extracelular de serotonina observada en los animales EP. Durante las pruebas cognitivas, no se observaron cambios significativos en el contenido del SERT, en los animales EP, lo que sugiere que la recaptura de serotonina durante los procesos cognitivos podría mantenerse aumentada en los animales EP. EI SERT en los animales control parece incrementarse, probablemente debido a la elevada concentración extracelular de serotonina. En conclusión la elevada concentración basal del SERT grupo EP es mayor, incrementando así la recaptura de serotonina, disminuyendo así la comunicación con neuronas posinápticas en el circuito hipocampal relacionado con el aprendizaje y la memoria.

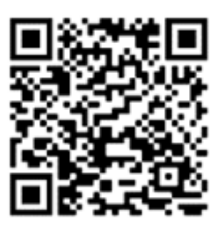

Cite this paper/Como citar este artículo: Mendez Guerrero, D., Jiménez Vásquez, F. J., Rubio Osornio, M., Rubio Osornio, M. C., Orozco Suárez, S., Retana Márquez, M. S. I.(2020). Efecto del estrés prenatal sobre el trasportador de serotoina en el hipocampo dorsal de la rata. Revista Bio Ciencias 7: (Suppl) Memorias de Congreso. LXIII Congreso Nacional de la Sociedad Mexicana de Ciencias Fisiologicas, A. C. e1097. http://doi.org/10.15741/revbio.07Suppl.e1097 


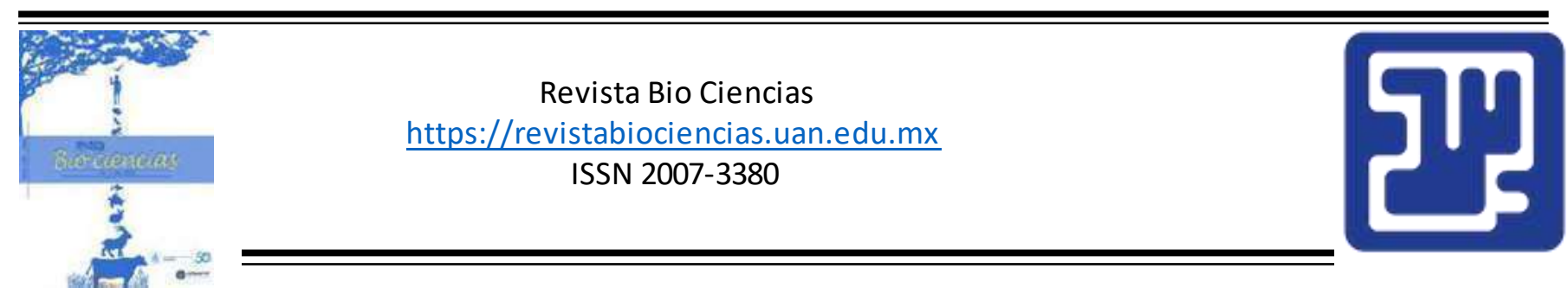

Trabajos libres: Neurociencias

Modalidad de Presentación: Oral

\section{La prolactina modifica las crisis de ausencia en la rata taiep hembra adulta}

Hernández Alvarado, E. S., Eguibar Cuenca, J. R., Cortés Sánchez, M. C. *

Instituto de Fisiologia, Benemerita Universidad Autonoma de Puebla

*Autor Corresponsal: Ma. Del Carmen Cortés Sánchez.E-mail: carmen.cortes@correo.buap.mx

Las crisis de ausencia son un tipo de epilepsia generalizada caracterizada por descargas espiga-onda en el electroencefalograma (EEG). En modelos animales de crisis de ausencia durante la lactancia se incrementan las crisis, cuando la prolactina alcanza su máxima concentración, ya que esta hormona afecta el circuito talamo-cortical, sitio de origen de estas crisis. El objetivo fue determinar el efecto de la administración central de prolactina sobre las descargas espiga-onda en ratas taiep hembras adultas. Se implantó una cánula i.c.v. y electrodos en la corteza cerebral, el hipocampo, los músculos de la nuca y la órbita ocular izquierda de ratas taiep hembra de 6 meses. Se realizó ovariectomía bilateral y reemplazo hormonal con $2 \mu \mathrm{g}$ de $17-\beta$ estradiol vía s.c. diariamente. Se realizaron 4 registros de EEG de 12 horas de duración con 48 horas de separación entre estos; el primero en condiciones control y los siguientes tras administrar prolactina de rata vía i.c.v a dosis de $0.5,1$ y $2 \mu \mathrm{g}$, respectivamente. La prolactina no incrementó la frecuencia de las descargas espiga-onda con las 3 dosis administradas $(P>0.05)$. Para las dosis de 0.5 y $1 \mu \mathrm{g}$ la prolactina incrementó en $210 \%$ y $189 \%$, respectivamente, la duración de las crisis 7 h después $(P<0.001)$. La dosis de 2 $\mu \mathrm{g}$ incrementó en $205 \%$ la duración de las crisis 8 h después $(P<0.001)$. En conclusión, la prolactina fue capaz de modificar la duración, pero no la frecuencia de las crisis de ausencia en ratas taiep hembra. Se requiere la realización de más estudios para determinar el mecanismo de acción de esta hormona sobre el circuito talamo-cortical. Parcialmente financiado por VIEP-BUAP para el Cuerpo Académico en Neuroendocrinología BUAPCA-288. ESHA es becario CONACYT CVU No. 952483. J. R., Cortés Sánchez, M. C. (2020). La prolactina modifica las crisis de ausencia en la rata taiep hembra adulta. Revista Bio Ciencias 7: (Suppl) Memorias de Congreso. LXIII Congreso Nacional de la Sociedad Mexicana de Ciencias Fisiologicas, A. C. e1097. http://doi.org/10.15741/revbio.07Suppl.e1097 


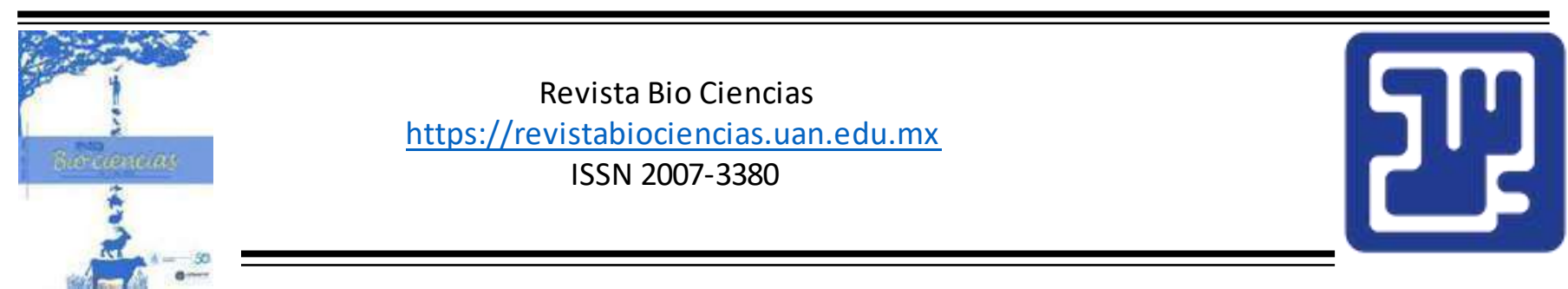

Trabajos libres: Neurociencias

Modalidad de Presentación: Cartel

\begin{abstract}
Efecto del aceite de pescado vs aceite de krill sobre la actividad eléctrica del CA1 del Hipocampo durante una tarea de memoria en ratas posterior a convulsiones
\end{abstract}

Rivera Rojas, G. N., Martínez Arteaga, P., Gaytán Pacheco, N., Martínez Acuña, M. R., Flores

Mancilla, L. E. *

Universidad Autónoma De Zacatecas

*Autor Corresponsal: Leopoldo Eduardo Flores Mancilla. E-mail: mansileo1@yahoo.com.mx

Existe bajo rendimiento en tareas de memoria en niños epilépticos, evidencias indican que grasas omega-3 pudieran atenuar crisis convulsivas, poco se conoce de productos con omega-3 que pudieran contrarrestar el efecto adverso de convulsiones sobre funciones cognitivas. Objetivo: Comparar el efecto de la suplementación de aceite de krill vs la de aceite de pescado (abundantes en omega-3) sobre la actividad eléctrica (EEG) de CA1 en Hipocampo de ratas adultas durante la ejecución de una tarea de memoria antes y después de convilsiones. Materiales y Métodos: 4 grupos ( $n=6 x g r u p o$ ), Grupo Krill (Krill) ratas suplementadas con aceite de krill (300mg/kg), Grupo Pescado (PES) ratas suplementadas con aceite de Pescado (300mg/kg), Grupo Palma (Palm) ratas suplementadas con aceite de Palma (300mg/kg), Grupo Control (CTRL) ratas suplementadas con vehículo (300 ul agua bidestilada). Los tratamientos se suministraron desde la etapa fetal (a través de la madre) y hasta la edad de 152 días, se implantaron electrodos bilaterales en CA1 del hipocampo, se capturó el EEG durante adquisición y ejecución de una tarea de memoria en laberinto radial (LR) , posteriormente se les indujo una primera convulsión de la cual se evaluó EEG y severidad, 48 hrs posteriores se evaluaron errores por reingreso, omisión y duración así como potencia absoluta (PA) y relativa del EEG durante la prueba, el procedimiento se repitió luego de una segunda convulsión. Resultados se observó que PES registró significativamente menor número de errores por reingreso, omisión y duración de la prueba y mayor PA del EEG durante la ejecución, no así durante las convulsiones en donde registró significativamente menor PA mayor latencia y menor severidad al comparar con Palm , Krill y CTRL $(p<0.05)$ Conclusión: Se sugiere que la suplementación de PES se puede asociar a un menor deterioro cognitivo producido por convulsiones que la suplementación de aceite de krill.

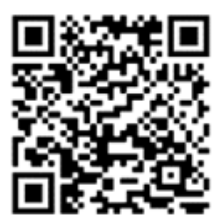

Cite this paper/Como citar este artículo: Rivera Rojas, G. N., Martínez Arteaga, P., Gaytán Pacheco, N., Martínez Acuña, M. R., Flores Mancilla, L. E. (2020). Efecto del aceite de pescado vs aceite de krill sobre la actividad eléctrica del CA1del Hipocampo durante una tarea de memoria en ratas posterior a convulsiones. Revista Bio Ciencias 7: (Suppl) Memorias de Congreso. LXIII Congreso Nacional de la Sociedad Mexicana de Ciencias Fisiologicas, A. C. e1097. http://doi.org/10.15741/revbio.07Suppl.e1097 


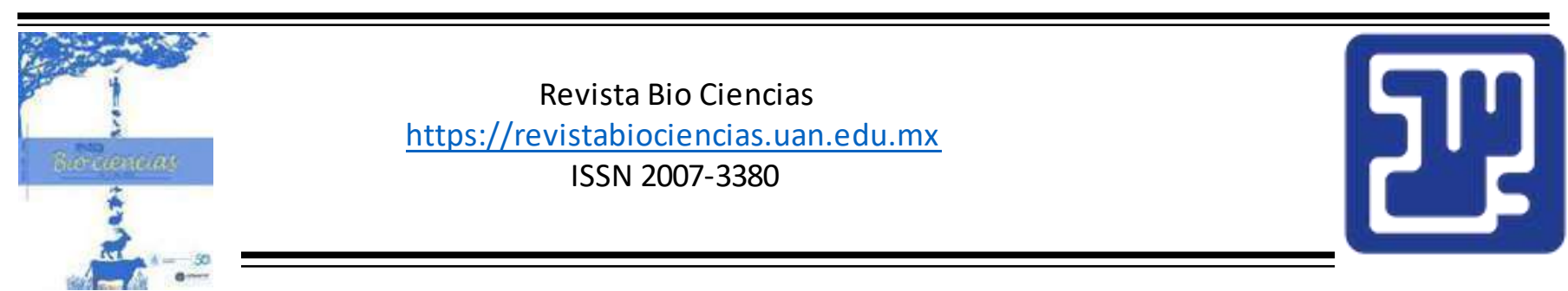

Trabajos libres: Neurociencias

Modalidad de Presentación: Oral

\title{
Análisis de agrupación de conducta sexual masculina en ratas de alto y bajo bostezo y en las Sprague-Dawley
}

\author{
Cepeda Freyre, H. A., Eguibar Cuenca, J. R., Cortés Sánchez, M. C. *
}

Benemerita Universidad Autonoma De Puebla

*Autor Corresponsal: Ma.del Carmen Cortés Sánchez carmen.E-mail: cortes@correo.buap.mx

La conducta sexual es uno de los comportamientos más diversos y complejos que se pueden encontrar en el reino animal. Sin embargo, es posible encontrar similitudes en los patrones de apareamiento entre las diversas especies. Asimismo, se han observado patrones cualitativamente similares entre miembros de una misma especie, gracias a lo cual se han creado algunas clasificaciones de "tipos de copulador". El objetivo del presente trabajo fue detectar e identificar la posible existencia de agrupaciones de comportamiento sexual en ratas de bajo bostezo (LY), alto bostezo (HY), y Sprague-Dawley utilizando aprendizaje por máquina, que mediante algoritmos identifican patrones de datos para realizar predicciones. Se utilizaron ratas macho HY, LY, y SpragueDawley de 90 días de edad $(n=160)$, con libre acceso a alimento balanceado y agua; bajo una temperatura constante de $22 \pm 1^{\circ} \mathrm{C}$. Las ratas fueron expuestas a 4 sesiones de cópula con una duración de 30 minutos cada una; durante las cuales se midieron 8 tipos diferentes de conducta sexual. Se promediaron las mediciones de conducta sexual a través de las 4 sesiones, y los registros de sesiones en las que no se presentó cópula fueron descartados. Adicionalmente, dos ratas fueron descartadas al ser detectadas como casos atípicos. Inicialmente, se llevó a cabo un análisis de agrupación por jerarquías evaluando similitudes en las conductas sexuales, seguido de la elaboración de un dendograma. Empleando un algoritmo de agrupación, se detectaron 4 agrupaciones de ratas en función de los distintos comportamientos sexuales. A pesar de que todos los grupos mostraron diferencias significativas entre sí con respecto a sus centroides $(P<0.05)$, sólo dos de los grupos generados difirieron significativamente $(P<0.05)$. En conclusión, en las ratas que difieren en su desempeño copulatorio, también se detectan diferencias cuando se consideran todos los componentes de la conducta sexual masculina.

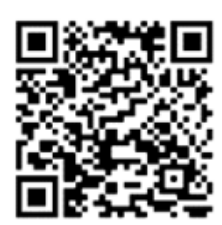

Cite this paper/Como citar este artículo: Cepeda Freyre, H. A., Eguibar Cuenca, J. R., Cortés Sánchez, M. C. (2020). Análisis de agrupación de conducta sexual masculina en ratas de alto y bajo bostezo y en las Sprague-Dawley. Revista Bio Ciencias 7: (Suppl) Memorias de Congreso. LXIII Congreso Nacional de la Sociedad Mexicana de Ciencias Fisiologicas, A. C. e1097. http://doi.org/10.15741/revbio.07Suppl.e1097 


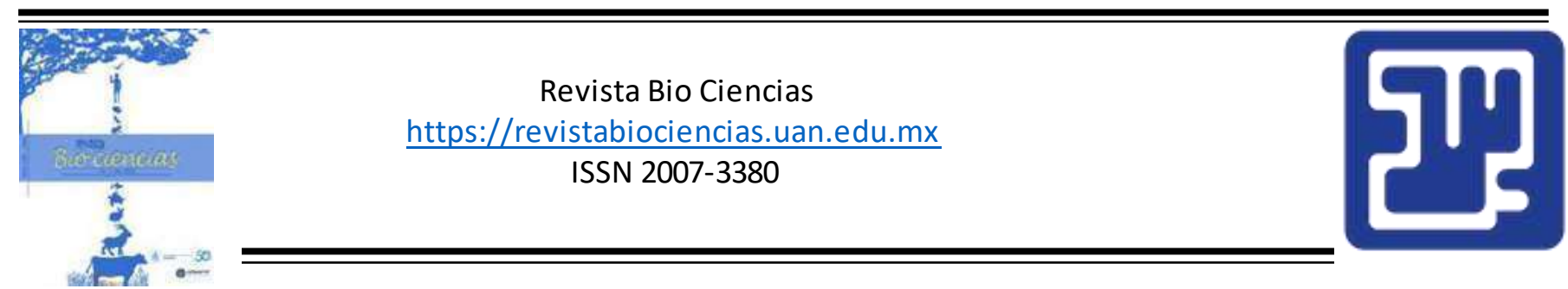

Trabajos libres: Neurociencias

Modalidad de Presentación: Cartel

\title{
El estrés crónico por aislamiento social no afecta la morfología de neuronas CA3 del hipocampo
}

\author{
Martínez López, I. D., Gazga Valencia, K. A., Barreda Guzmán, S. J., Santos Morales, M., Silva \\ Gómez, A. B. *
}

Benemerita Universidad Autonoma De Puebla

*Autor Corresponsal: Adriana Berenice Silva Gómez. E- mail: berenice71@yahoo.com

Se sabe que el estrés es una condición fisiológica que tiene profundo efecto sobre la morfología de algunas estructuras del SNC como es el hipocampo. Varios estudios han demostrado que el estrés por restricción de movimiento, provoca remodelación dendrítica principalmente en cuanto a la densidad de espinas dendríticas. Estos estudios han sido realizados principalmente en rata macho debido a las complicaciones experimentales que se tienen en cuanto a la expresión del ciclo estral. En el presente trabajo se analizó la morfología de neuronas CA3 de hipocampo dorsal y de hipocampo ventral de ratas hembra después de un periodo de aislamiento social con el cual se provoca estrés crónico. Se trabajó con dos lotes de ratas a los cuales se les mantuvo en condiciones de grupos intactos y con monitoreo del ciclo estral. En cada lote se tuvo un grupo de organismos sociales y un grupo de organismos que fueron criados desde el día 28 de edad en aislamiento social por 56 días. Inmediatamente después del periodo de aislamiento, a las ratas se les sacrificó para obtener el cerebro y el cual fue procesado mediante la técnica de Golgi-Cox. Se analizó la longitud dendrítica total y la densidad de espinas dendríticas tanto de las neuronas CA3 del hipocampo dorsal como de las neuronas CA3 del hipocampo ventral. De los resultados obtenidos observamos que, el estrés crónico generado por el aislamiento social en ratas hembra a partir del destete, no promueve cambios en la morfología de neuronas de la región CA3 del hipocampo. Previos estudios han sugerido que los estrógenos tienen un efecto neuroprotector, lo cual puede ser apoyado con los resultados obtenidos en el presente estudio. social no afecta la morfología de neuronas CA3 del hipocampo. Revista Bio Ciencias 7: (Suppl) Memorias de Congreso. LXIII Congreso Nacional de la Sociedad Mexicana de Ciencias Fisiologicas, A. C. e1097. http://doi.org/10.15741/revbio.07Suppl.e1097 


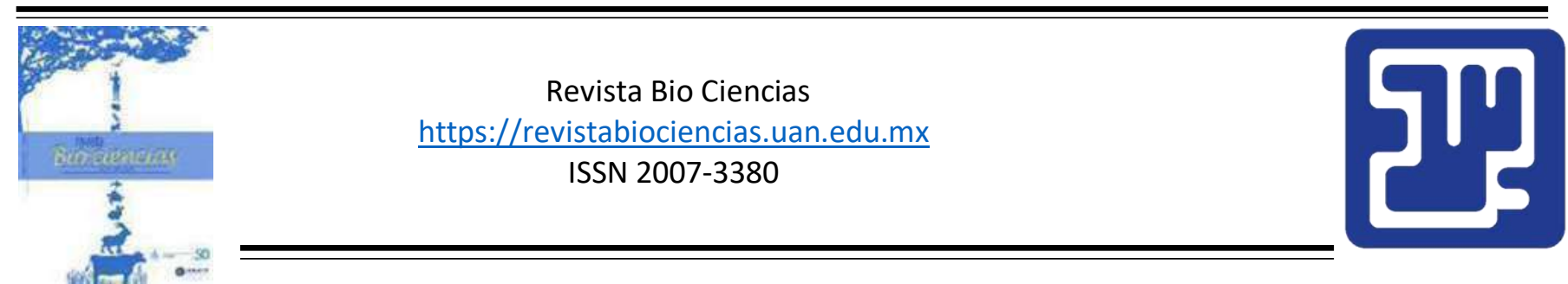

Trabajos libres: Neurociencias

Modalidad de Presentación: Oral

\begin{abstract}
Efectos diferenciales del LPS y la 6-OHDA en la morfología de la microglía en ratas: implicaciones para el modelo inflamatorio en la Enfermedad de Parkinson
\end{abstract}

Parra Becerra, I. M. ${ }^{1}$, Martínez García, I. ${ }^{1}$, Ramírez García, G. ${ }^{2}$, Tizabi, Y. ${ }^{3}$, Martínez Mendieta, L. ${ }^{*}$

\author{
${ }^{1}$ Benemérita Universidad Autónoma de Puebla \\ 2 Instituto Nacional de Neurología y Neurocirugía Manuel Velasco Suárez \\ ${ }^{3}$ Howard University College of Medicine
}

*Autor Corresponsal: Liliana Martínez Mendieta. E- mail: liliana.martinezmen@correo.buap.mx

La Enfermedad de Parkinson (EP) es una enfermedad neurodegenerativa idiopática y progresiva caracterizada por la pérdida del $\sim 80 \%$ de las neuronas dopaminérgicas en la sustancia negra pars compacta (SNpc). Debido a que la activación de la respuesta inmune celular innata, mediada por microglía, se ha relacionado con la neurodegeneración en la EP, en el presente estudio evaluamos los efectos del lipopolisacárido (LPS) y la 6hidroxidopamina (6-OHDA) sobre los cambios morfológicos de la microglía (que está relacionada con su actividad) así como las neuronas tirosina hidroxilasa (TH) positivas en SNpc y la conducta motora. Se inyectaron estereotáxticamente ratas macho Wistar adultas con LPS o 6-OHDA en el cuerpo estriado dorsolateral izquierdo. Los grupos de control recibieron el vehículo apropiado. Se examinaron los cambios morfológicos de las células microgliales y los efectos neurotóxicos 1, 7 y 14 días después de la inyección. Tanto el LPS como la 6-OHDA provocaron la activación y e indujeron cambios morfológicos en las células microgliales, así como pérdida de neuronas dopaminérgicas en SNpc. Estos efectos fueron máximos a los 14 días después de la inyección, donde también fueron evidentes las alteraciones motoras. Sin embargo, nuestros hallazgos indican que la 6OHDA causa un bajo grado de activación de la microglía en comparación con el LPS. Por lo tanto, se puede concluir que el modelo del LPS para la EP podría ser una mejor representación de la participación inflamatoria en esta devastadora enfermedad.

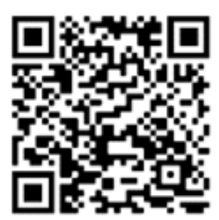

Cite this paper/Como citar este artículo: Parra Becerra, I. M., Martínez García, I., Ramírez García, G., Martínez Mendieta, Y. T. L (2020). Efectos diferenciales del LPS y la 6-OHDA en la morfología de la microglía en ratas: implicaciones para el modelo inflamatorio en la Enfermedad de Parkinsons. Revista Bio Ciencias 7: (Suppl) Memorias de Congreso. LXIII Congreso Nacional de la Sociedad Mexicana de Ciencias Fisiologicas, A. C. e1097. http://doi.org/10.15741/revbio.07Suppl.e1097 


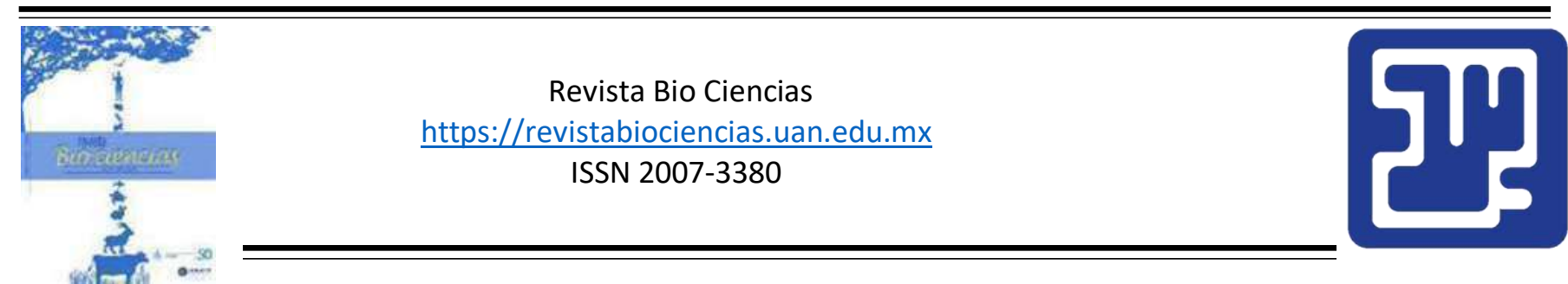

Trabajos libres: Neurociencias

Modalidad de Presentación: Cartel

\begin{abstract}
Marcadores de inhibición sináptica (GAD y SOM) en la formación hipoacmpal del modelo transgénico para la enfermedad de alzhéimer
\end{abstract}

Poblano Páez, I., Díaz Miranda, S. Y.*

Instituto de Neurobiología, UNAM

*Autor Corresponsal: Sofía Yolanda Díaz Miranda. E- mail: yoldi@unam.mx

La enfermedad de Alzheimer (EA) es la más común de las demencias, se caracteriza por un declive progresivo de la memoria y otras funciones cognitivas. Los mecanismos del deterioro de la memoria en este proceso neurodegenerativo son extensas y han generado diferentes propuestas de posibles mecanismos que incluyen múltiples factores; estrés oxidativo, disfunción sináptica, muerte neuronal (por oligómeros tóxicos del péptido $\beta$-amiloideo), excitotoxicidad por fallas en la recaptación de glutamato, taupatía, neuroinflamación y de manera importante se propone la hiperexcitabilidad ocasionada por la disminución o pérdida de la función inhibitoria. Dentro del funcionamiento sináptico del tejido cerebral la modulación entre los sistemas de excitación-inhibición tiene un papel fundamental, ya que las alteraciones de dicha regulación, pueden desencadenar cambios en las funciones cognitivas y motoras. El objetivo de este estudio se centró en caracterizar los cambios en la disminución de la densidad de las interneuronas, inhibitorias GABAérgicas (IG) que sintetizan y señalizan a partir del ácido $y$ amino butírico (GABA) en la formación hipocampal $(\mathrm{FH})$ estructura involucrada en la regulación de la memoria. Se emplearon ratones transgénicos $3 \times T g-A D$, como modelo de la patología tipo Alzheimer, en dos edades sintomáticas (12 y 18 meses). Se cuantificaron las IG positivas a somatostatina (IG-SOM+), y a la enzima glutamato descarboxilasa (IGGAD67+) en el Subiculum (Sub) y en la región del CA1 en sus 3; estratos: Oriens (EO), Pyramidalis (EP) y Radiatum (ER) de la FH. Los resultados en ambas edades, mostraron reducciones significativas del número de interneuronas IG-SOM+ en el Sub y en los 3 estratos de la FH con respecto a los controles. Lo que abunda acerca de que la alteración anatómica puede repercutir en los defectos sinápticos por depleción del GABA, ocasionando hiperexcitabilidad en la EA.

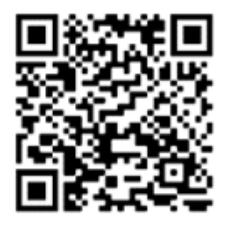

Cite this paper/Como citar este artículo: Poblano Páez, I., Díaz Miranda, S. Y. (2020). Marcadores de inhibición sináptica (GAD y SOM) en la formación hipoacmpal del modelo transgénico para la enfermedad de alzhéimer. Revista Bio Ciencias 7: (Suppl) Memorias de Congreso. LXIII Congreso Nacional de la Sociedad Mexicana de Ciencias Fisiologicas, A. C. e1097. http://doi.org/10.15741/revbio.07Suppl.e1097 


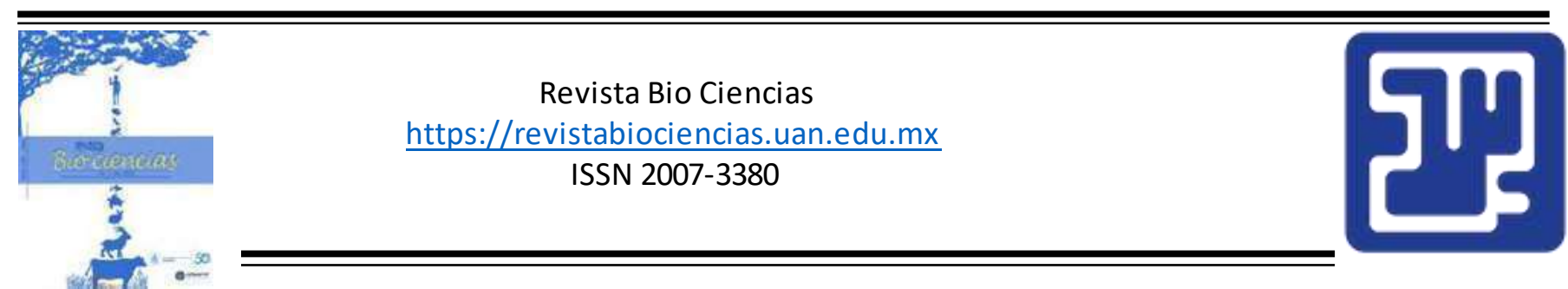

Trabajos libres: Neurociencias

Modalidad de Presentación: Oral

\title{
Efecto del bloqueo de la actividad de la familia de la proteína cinasa C (PKC) en el estriado dorsomedial de ratas sobre la consolidación de un entrenamiento moderado e intenso
}

\author{
Guillermo Montiel, I. H., Medina Fragoso, A. C., Bello Medina, P. C., Quirarte Quirarte, G. L., Prado \\ Alcalá, R. A. * \\ Instituto De Neurobiología, Universidad Nacional Autónoma de México \\ *Autor Corresponsal: Roberto A. Prado Alcalá. E- mail: prado@servidor.unam.mx
}

Se ha encontrado que los tratamientos que típicamente producen amnesia se vuelven inocuos cuando los animales son sometidos a un entrenamiento intenso en la tarea de evitación inhibitoria. Los mecanismos neurobiológicos que pudieran estar implicados en la consolidación de este tipo de memorias altamente aversivas son desconocidos. La familia de las proteínas cinasas C (PKC) participan en distintas cascadas de señalización asociadas a procesos mnemónicos y se plantea que su inhibición podría deteriorar la consolidación de este tipo de memoria. Para estudiar este planteamiento, se implantaron cánulas bilateralmente en el estriado dorsomedial de ratas macho Wistar adultas. Después de un periodo de recuperación y una fase de manipulación, se les administró bilateralmente queleritrina (inhibidor de las isoformas alfa, delta y épsilon de PKC), veinte minutos antes del entrenamiento en la tarea de evitación inhibitoria usando un choque eléctrico de 1.0 (entrenamiento moderado) o de $3.0 \mathrm{~mA}$ (entrenamiento intenso). Cuarenta y ocho horas después se realizó la prueba de retención y se encontró un deterioro significativo en la consolidación. Los resultados indican que la participación de la familia de las proteínas cinasas $C$ en el estriado dorsomedial resulta necesaria para la consolidación de memorias altamente aversivas. Agradecemos el apoyo técnico a Norma Serafín, Bernardino Osorio, Martín García, Ma. Antonieta Carbajo, Lourdes Lara, Nydia Hernández, Nuri Aranda, Omar González y Ramón Martínez. PAPIIT (IN203918). 


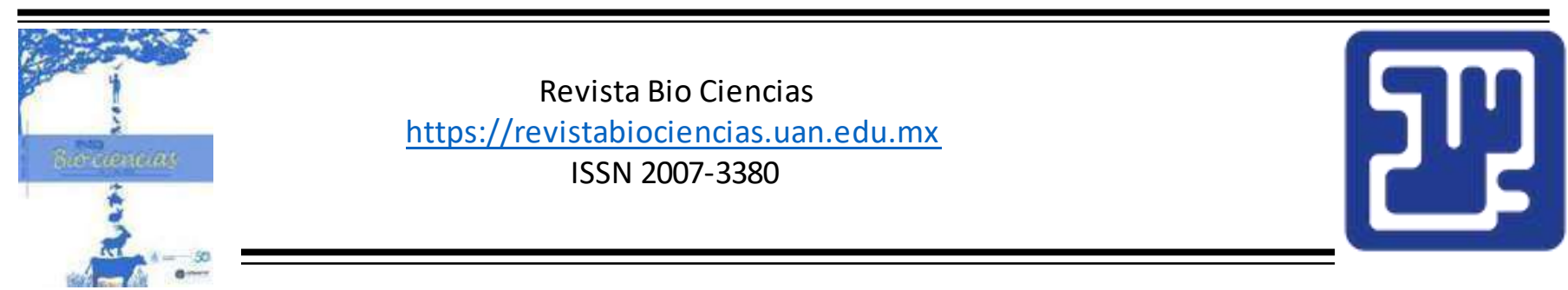

Trabajos libres: Neurociencias

Modalidad de Presentación: Oral

\title{
Cambios en los componentes de la atención durante las etapas hipnagógicas
}

\author{
Borrani Valdés, J. B*., Perez Castro, J., Isaias García, A. M., López Barrios, I. E., Ramírez, M. C., \\ García García, M. A., Valdez Ramírez, P. \\ Universidad Nacional Autónoma de Nuevo León
}

*Autor Corresponsal: Jorge Benjamín Borrani Valdés. E- mail: jorgeborrani@yahoo.com.mx

El objetivo de este estudio fue analizar los componentes de la atención, alerta tónica, alerta fásica y atención selectiva, durante las etapas hipnagógicas. Las etapas hipnagógicas $(\mathrm{EH})$ son períodos de actividad cerebral con características específicas que suceden durante el proceso de inicio del dormir y se obtienen mediante el análisis visual del EEG. En la EH1 predominan ondas alfa, en la EH2 decrementan, en la EH3 se hacen intermitentes, en la $\mathrm{EH} 4$ desaparecen y la señal se aplana, en la EH5 aparecen ondas theta, de la EH6 a la EH8 incrementan las ondas vertex y en la EH9 aparecen complejos K. Once participantes $(19.72 \pm 2.49$ años de edad, 5 mujeres) fueron registrados dentro del laboratorio, acostados en un cubículo oscuro. Los componentes de la atención se evaluaron mediante una tarea de ejecución continua mientras se registraba el EEG. Durante este registro solo aparecieron $\mathrm{EH}$ entre la 1 y la 5 . En alerta tónica, las EH1 $(97.10 \%)$, EH2 $(97.35 \%)$ y $\mathrm{EH} 3(95.71 \%)$ mostraron un alto porcentaje de respuestas correctas, comparadas con la $\mathrm{EH} 4$ (85.17\%) ( $\mathrm{U}=2204.5$, $\mathrm{p}<0.001)$ y la $\mathrm{EH} 5 \quad(68.12 \%) \quad(\mathrm{U}=207$, $\mathrm{p}<0.001)$. En alerta fásica también hubo buena ejecución en las EH1 (81.57\%), EH2 $(88.04 \%)$ y EH3 $(96.25 \%)$, comparadas con la EH4 (67.36\%) $(U=389, p<0.001)$ y la EH5 $(60 \%) \quad(U=24.5, \quad p<0.05) . \quad E n$ atención selectiva, en la $\mathrm{EH} 1$ hubo una mala ejecución $(57.89 \%)(\mathrm{U}=622.5, p<0.01)$, pero en las $\mathrm{EH} 2$ (77.83\%) y EH3 (82.65\%) mejoró la ejecución, comparada con la EH4 (55.31\%) (U=1719.5, $\mathrm{p}<0.001)$ y la $\mathrm{EH} 5(51.56 \%)(U=192, p<0.01)$. Esto indica que las capacidades para responder en general (alerta tónica), tras una señal de aviso (alerta fásica), y de manera específica (atención selectiva), se deterioran cuando alfa desaparece. Los errores y omisiones que las personas cometen a partir de ese momento van incrementando $y$ aumentan el riesgo de sufrir accidentes automovilísticos o laborales. 


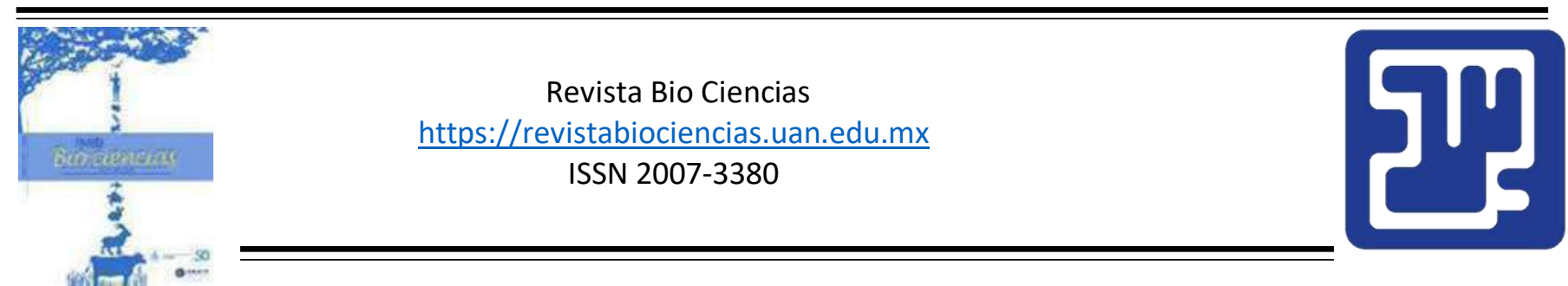

Trabajos libres: Neurociencias

Modalidad de Presentación: Oral

La dosificación continua de acetato de leuprolida facilita la recuperación de circuitos espinales y funcionalidad del tracto urinario inferior en ratas macho con lesión medular

\author{
Palacios Galicia, J. L. ${ }^{1}$, Luquín de Anda, M. S. ${ }^{1}$, Quintanar Stephano, J. L. ${ }^{2}$, Munoz Toscano, A. ${ }^{*}$ \\ 1 Universidad de Guadalajara \\ 2 Universidad Autónoma de Aguascalientes
}

*Autor Corresponsal: Alvaro Munoz Toscano. E- mail: alvaro.munoz@vunorte.udg.mx

Una prioridad para pacientes con lesión de médula espinal (LME) es recuperar la continencia urinaria. Se sabe que el acetato de leuprolida ( $A L)$, un agonista del GnRHR, presenta propiedades neuroregenerativas. Nuestro objetivo fue determinar si la administración continua de $\mathrm{AL}$ promueve neuroregeneración de la médula espinal dañada y funcionalidad del tracto urinario inferior en ratas con LME. Se llevó a cabo una laminectomía en T8/T9 (ratas macho Wistar, 3-4 meses; $n=10)$. Posteriormente se comprimió la médula espinal por $30 \mathrm{~s}$ (grupo LME). En 5 animales se colocó una bomba osmótica (Alzet 2002) con AL (10 micro-g/kg por 15 días; grupo $L M E+A L)$. Seis ratas intactas sirvieron como control. Se realizaron estudios conductuales de función urinaria, locomoción y sensibilidad táctil (Von-Frey) semanalmente. En la cuarta semana se evaluó la contracción vesical y electromiografía del esfínter externo de la uretra (EEU). Previo a LME, las ratas expulsan orina en la orilla de la caja. Esta conducta normal fue abolida en ambos grupos. Sin embargo, en ratas LME las expulsiones de orina anormales fueron asociadas a conductas de esfuerzo como toser y husmear en los días 7 y 14, y en reposo en el día 21. En ratas $L M E+A L$, las expulsiones de orina fueron asociadas a contracciones rítmicas de la musculatura perineal y erecciones peneanas en el día 28. El umbral de sensibilidad en $\mathrm{LME}+\mathrm{AL}$ fue significativamente menor en comparación con ratas LME. La presión máxima de contracción vesical fue mayor en ratas $L M E+A L$ vs ratas LME. La actividad fásica del EEU durante micciones fue abolida en LME, pero no en $\mathrm{LME}+\mathrm{AL}$. La actividad motora de las patas traseras en ratas $L M E+A L$ también fue mayor que en LME. Estos resultados sugieren que la administración continua de AL facilita el proceso de micción promoviendo la regeneración de circuitos espinales y función del tracto urinario inferior.

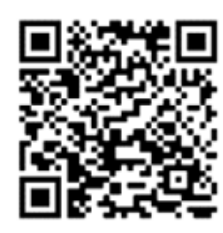

Cite this paper/Como citar este artículo: Palacios Galicia, J. L., Luquín de Anda, M. S., Quintanar Stephano, J. L., Munoz Toscano, A. (2020). La dosificación continua de acetato de leuprolida facilita la recuperación de circuitos espinales y funcionalidad del tracto urinario inferior en ratas macho con lesión medular. Revista Bio Ciencias 7: (Suppl) Memorias de Congreso. LXIII Congreso Nacional de la Sociedad Mexicana de Ciencias Fisiologicas, A. C. e1097. http://doi.org/10.15741/revbio.07Suppl.e1097 


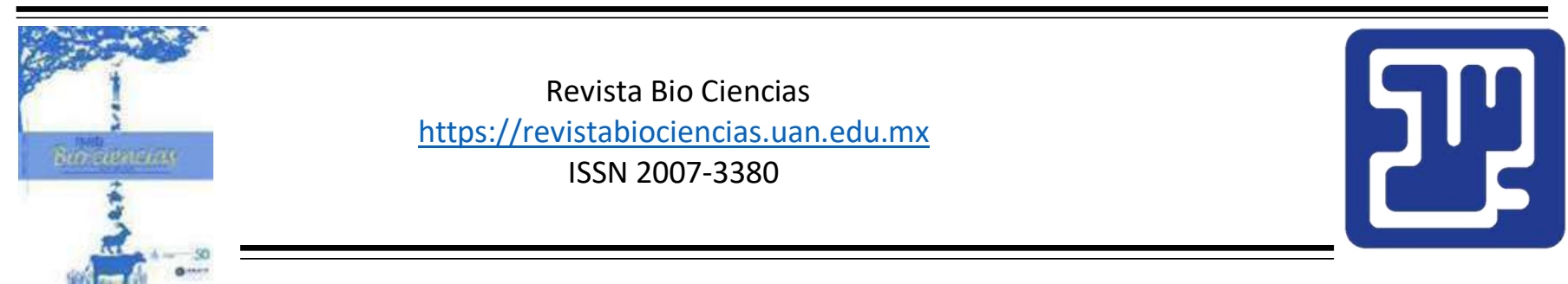

Trabajos libres: Neurociencias

Modalidad de Presentación: Cartel

Preservación neuronal en el hipocampo de ratas sometidas a hipoperfusión cerebral crónica, por progesterona

\author{
García Meza, J. L. ${ }^{1}$, Reyes Tolentino, E. ${ }^{1}$, Vázquez Espadín, A. M. ${ }^{1}$, Orozco Suárez, S. A. ${ }^{1}$, \\ Cervantes Alfaro, J. M. ${ }^{2}$, Moralí de la Brena, G. ${ }^{3^{*}}$ \\ ${ }^{1}$ Universidad Autónoma Metropolitana Iztapalapa \\ ${ }^{2}$ Universidad Michoacana de San Nicolás de Hidalgo \\ ${ }^{3}$ Instituto Mexicano del Seguro Social \\ *Autor Corresponsal: Gabriela Moralí de la Brena. E- mail: gmorali@hotmail.com
}

La Hipoperfusión Cerebral Crónica (HCC), reducción moderada pero persistente del flujo sanguíneo cerebral por alteraciones cerebrovasculares, desencadena fenómenos que provocan daño o muerte selectiva de neuronas piramidales de la corteza cerebral y del área CA1 del hipocampo. Esto da lugar al deterioro del aprendizaje y la memoria y, en humanos, a la demencia vascular. La progesterona (P4) ejerce efectos neuroprotectores en modelos de daño agudo al cerebro y a la médula espinal, pero no se han estudiado estos efectos en modelos experimentales de HCC. El objetivo del estudio fue evaluar la preservación de neuronas piramidales del área $\mathrm{CA} 1$ del hipocampo en ratas sometidas a HCC, por progesterona. Se utilizaron ratas macho Sprague Dawley en 3 condiciones experimentales: SHAM, cirugías simuladas; $\mathrm{HCC}+\mathrm{VEH}$, oclusión permanente de las arterias carótidas comunes (ACC) y tratamiento con vehículo $(0.5 \mathrm{ml} / \mathrm{kg} / \mathrm{d})$ por 7 días; $\mathrm{HCC}+\mathrm{P} 4$, oclusión permanente de las ACC y tratamiento con P4 $(8 \mathrm{mg} / \mathrm{kg} / \mathrm{d})$ por 7 días. A los 90 o 180 días de iniciada la HCC se fijaron los cerebros por perfusión intracardíaca y se realizó su procesamiento histológico (cortes coronales de $10 \mu \mathrm{m}$, tinción de Nissl). Se hicieron conteos de neuronas piramidales en CA1 y se compararon mediante ANOVA y pruebas de Tukey. A 90 y 180 días, el número de neuronas en los grupos HCC+VEH (213.4 $\pm 13.2 ; 200.4 \pm$ 19.6), fue significativamente menor $(p<0.05)$ en comparación con el de los grupos SHAM (273.8 $\pm 5.7 ; 275.4 \pm 5.2)$. En los grupos HCC+P4 el número de neuronas (261.4 \pm 2.6 ; $252.3 \pm 8.0$ ) fue similar al de los grupos Sham y significativamente mayor $(p<0.05)$ al de los grupos HCC+VEH. La administración de progesterona en los primeros 7 días de HCC contrarrestó fenómenos de daño inducidos en CA1 por HCC que, sin este tratamiento, ocasionaron pérdida neuronal a 90 y 180 días.

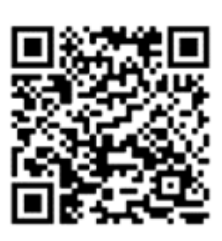

Cite this paper/Como citar este artículo: García Meza, J. L., Reyes Tolentino, E., Vázquez Espadín, A. M., Orozco Suárez, S. A., Cervantes Alfaro, J. M., Moralí de la Brena, G. (2020). Preservación neuronal en el hipocampo de ratas sometidas a hipoperfusión cerebral crónica, por progesterona. Revista Bio Ciencias 7: (Suppl) Memorias de Congreso. LXIII Congreso Nacional de la Sociedad Mexicana de Ciencias Fisiologicas, A. C. e1097. http://doi.org/10.15741/revbio.07Suppl.e1097 


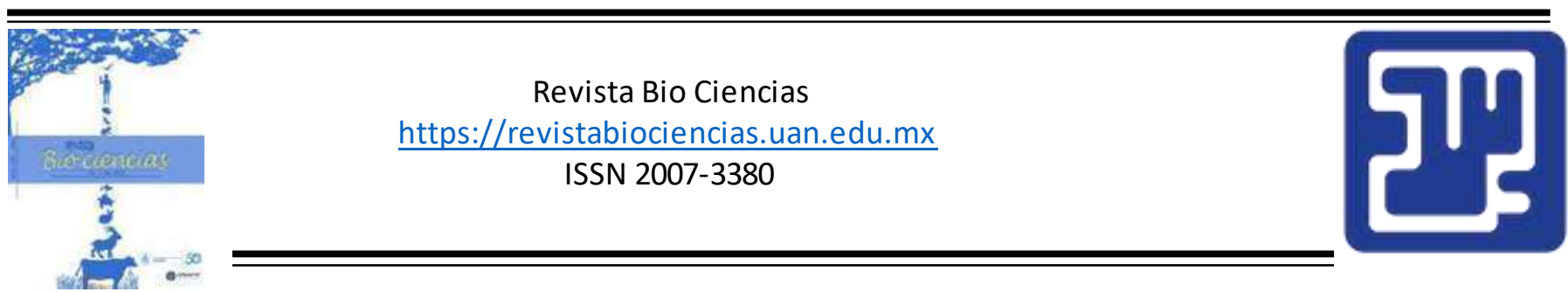

Trabajos libres: Neurociencias

Modalidad de Presentación: Cartel

\title{
Videolaboratorio fisiología ocular
}

\author{
Muñoz Tabares, J. N., Limón Mendoza, A., Quintanar Stephano, A.* \\ Universidad Autónoma De Aguascalientes
}

*Autor Corresponsal: Andrés Quintanar Stephano.E-mail: aquinta@correo.uaa.mx

Por motivo de la emergencia sanitaria por el COVID19, que interrumpió la realización presencial de las sesiones de laboratorio y por la gran importancia que la observación directa de los fenómenos fisiológicos tiene sobre la comprensión de los mecanismos de la visión, aquí presentamos el video FISIOLOGÍA OCULAR. El video está dividido en las siguientes secciones: Modelo óptico de la visión, agudeza visual y campimetría. Cada sección se subdivide en: Fundamentos, objetivos, material, métodos y resultados. En cada maniobra experimental se analizan y discuten los resultados y se señalan las conclusiones más importantes de cada maniobra. En el modelo óptico se representan la fuente de luz, la imagen a observar, el globo ocular, la retina y el sistema óptico del ojo. La colocación de las lentes convexas y cóncavas en el modelo permite observar los fenómenos de la refracción de la luz, divergencia y convergencia de las lentes. Permite observar la inversión de la imagen proyectada en la retina. Así mismo, permite reproducir lo errores de refracción más frecuentes; como miopía, hiperopía y astigmatismo y su corrección con las lentes adecuadas. EI modelo también permite apreciar el efecto que tiene el diámetro pupilar sobre la profundidad de foco. Agudeza visual. Se describe el fundamento y la metodología para evaluarla clínicamente utilizando la carta de Snellen. Se describen los fundamentos de la campimetría, fabricación del campímetro y su utilización para la evaluación de los campos visuales, ubicación del escotoma fisiológico y diagnóstico y evolución de enfermedades de la reina como: retinitis pigmentosa, desprendimientos de retina retinitis alérgica, efectos tóxicos de algunos medicamentos, así como patologías de la vía visual, como lesiones en el quiasma óptico y cudantanopsias por lesiones a diversos niveles de la vía visual. 


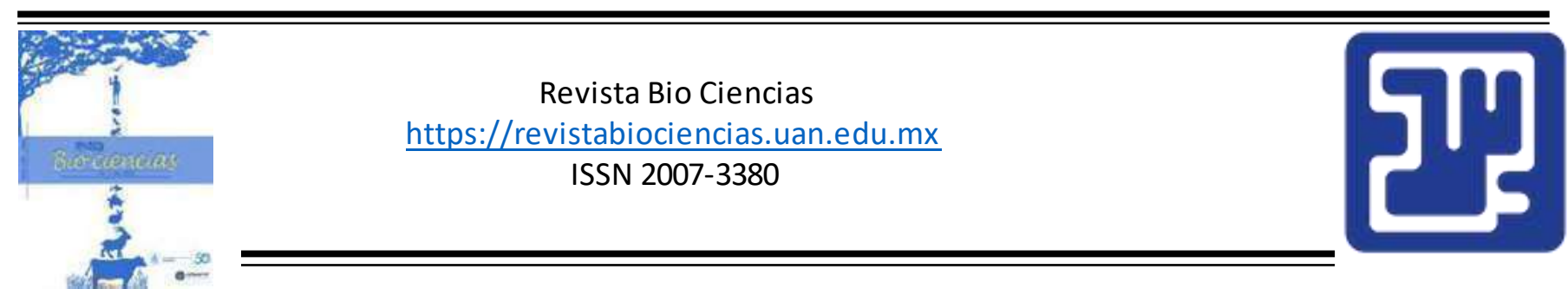

Trabajos libres: Neurociencias

Modalidad de Presentación: Cartel

\title{
Efecto de la quipacina en el patrón de la marcha de la rata taiep: un modelo de tubulinopatía
}

\author{
Ahumada Juárez, J. C., Eguibar Cuenca, J. R.* \\ Benemérita Universidad Autónoma De Puebla
}

*Autor Corresponsal: Jose Ramón Eguibar Cuenca. E- mail: jose.eguibar@correo.buap.mx

Las tubulinopatías son un grupo de enfermedades que afectan a las tubulinas, las mutaciones del gen TUBB4A producen hipomielinización con atrofia de los ganglios basales y cerebelo. La ataxia, parálisis espástica y las alteraciones motoras son algunos de los signos clínicos en esta patología debido a la hipomielinización y afectación en la función del cerebelo y los ganglios basales. La rata mutante de mielina taiep es un modelo de esta patología que cursa con desmielinización progresiva, su nombre es el acrónimo de los signos motores que la caracterizan: temblor, ataxia, inmovilidad, epilepsia y parálisis. El objetivo de este estudio fue el de evaluar los cambios en el patrón de la marcha antes y después de la administración de la quipacina un agonista serotoninérgico 5 -HT2A. Se utilizaron 6 ratas taiep macho de tres meses de edad, con un registro de la marcha control $(\mathrm{NaCl}$ al $0.9 \%)$ y después de la administración de quipacina a las dosis de $0.125,0.25$ y $0.5 \mathrm{mg} / \mathrm{Kg}$ por vía i.p. El registro de la marcha se realizó mediante el equipo CatWalk ${ }^{\text {TM }}$ (Noldus Technologies) y el análisis de datos con el programa CatWalk 9.1 ${ }^{\mathrm{TM}}$ los cuales fueron: longitud de zancada, fase de apoyo, fase de balanceo, área máxima de contacto, índice de regularidad y velocidad. La administración sistémica de quipacina a $0.25 \mathrm{mg} / \mathrm{Kg}$ mejoró la coordinación entre las extremidades (ANOVA, $\mathrm{H}=9.9, \mathrm{gl}=3, \mathrm{P}<0.05$ ), aumentó el área de contacto y aumento la velocidad de la marcha (ANOVA, $\mathrm{H}=11.16, \mathrm{gl}=3, \mathrm{P}=0.014$ ). En conclusión, la quipacina mejoró la velocidad de la marcha y la coordinación entre las extremidades. Este estudio muestra que un agonista serotoninérgico es capaz de mejorar la marcha en un modelo que cursa con un proceso desmielinizante. En experimentos futuros analizaremos el efecto de la administración crónica.

Cite this paper/Como citar este artículo: Ahumada Juárez, J. C., Eguibar Cuenca, J. R. (2020). Efecto de la quipacina en el patrón de la marcha de la rata taiep: un modelo de tubulinopatía. Revista Bio Ciencias 7: (Suppl) Memorias de Congreso. LXIII Congreso Nacional de la Sociedad Mexicana de Ciencias Fisiologicas, A. C. e1097. http://doi.org/10.15741/revbio.07Suppl.e1097 


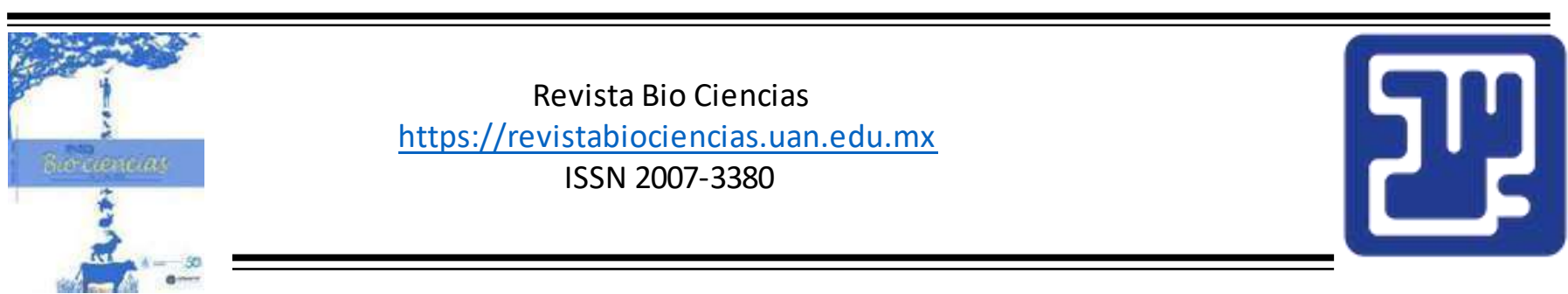

Trabajos libres: Neurociencias

Modalidad de Presentación: Oral

\title{
La inhibición del núcleo reticular del tálamo anula la aparición de las crisis de ausencia en la rata taiep
}

\author{
Ibarra Hernández, J. M., Eguibar Cuenca, J. R., Cortés Sánchez, M. C.*
}

Benemérita Universidad Autónoma De Puebla

\section{*Autor Corresponsal: Ma.del Carmen Cortés Sánchez.E-mail: carmen.cortes@correo.buap.mx}

Las crisis de ausencia son un tipo de epilepsia generalizada con pérdida de la conciencia y descargas espiga-onda en el electroencefalograma (EEG). Las ausencias se deben a un decremento en la actividad del receptor gamma-aminobutírico tipo a (GABAa) en la corteza somatosensorial y a un aumento concomitante en la inhibición mediada por los receptores GABAa en el circuito tálamo-cortical regulada por el núcleo reticular del tálamo (NRT). El objetivo de este trabajo fue el analizar el efecto de un agonista del receptor GABAa en el NRT de ratas taiep, y de esta forma determinar el rol de este núcleo en las crisis de ausencia. Se implantaron electrodos en el NRT, corteza cerebral, músculos de la nuca y en la órbita del ojo en ratas taiep macho adultas. Se les administró gaboxadol localmente en el NRT en dosis de 7.5, 15 y $30 \mu \mathrm{g} / \mu \mathrm{L}$. Se les realizó un registro de EEG control, seguido de tres registros tras la administración de dosis crecientes de la droga cada 48h. La administración de gaboxadol en el NRT abolió las crisis de ausencia durante las primeras dos horas los registros con las dosis de 7.5 y 15 $\mu \mathrm{g} / \mu \mathrm{L}(\mathrm{P}<0.001)$, y hasta cuatro horas con la dosis de $30 \mu \mathrm{g} / \mu \mathrm{L}$ de gaboxadol $(P<0.001)$, respecto al registro control el cual presentó una frecuencia de $23 \pm 10$ crisis/h con una duración de $3.5 \pm 0.2 \mathrm{~s}$ con una latencia para la primera crisis de $300 \pm 140 \mathrm{~s}$. En conclusión, el gaboxadol es capaz de reducir significativamente las crisis de ausencia en la rata taiep mediante la inhibición mediada por el receptor GABAa. Estos resultados sustentan que el NRT juega un rol primordial en la aparición de las crisis de ausencia de la rata taiep por cambios en la actividad de la red tálamo-cortical. Parcialmente financiado por VIEP-BUAP. JMIH es becario CONACYT.

Cite this paper/Como citar este artículo: Ibarra Hernández, J. M., Eguibar Cuenca, J. R., Cortés Sánchez, M. C (2020). La inhibición del núcleo reticular del tála mo anula la aparición delas crisis de ausencia en la rata taiep. Revista Bio Ciencias 7: (Suppl) Memorias de Congreso. LXIII Congreso Nacional de la Sociedad Mexicana de Ciencias Fisiologicas, A. C. e1097. http://doi.org/10.15741/revbio.07Suppl.e1097 


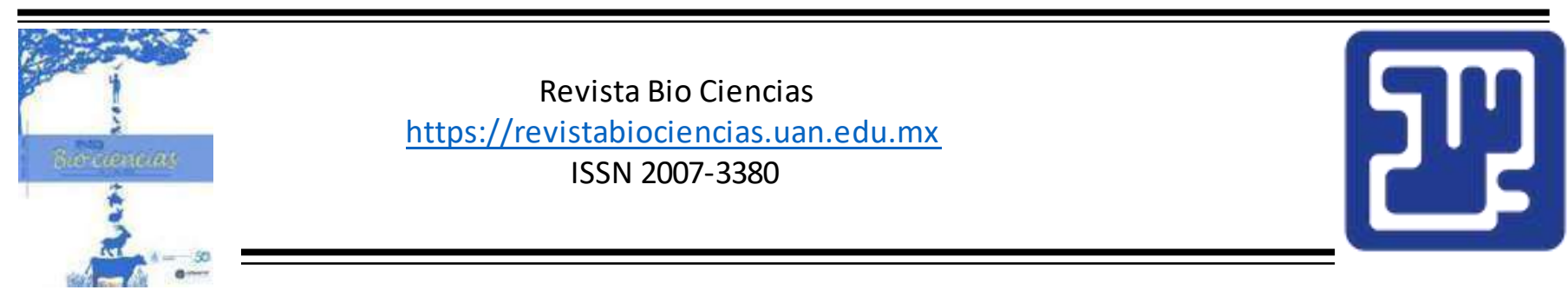

Trabajos libres: Neurociencias

Modalidad de Presentación: Oral

\section{Evaluación del resultado durante el aprendizaje inverso en la toma de decisiones: un estudio EEG}

García Hernández, J. P., Cortes Esparza, P. M., Iribe Burgos, F. A., Hernández González, M., Guevara Pérez, M. A. *

Instituto De Neurociencias, CUCBA, Universidad De Guadalajara

*Autor Corresponsal: Migue Angel Guevara Pérez. E- mail: miguel.guevara@academicos.udg.mx

La toma de decisiones (TD) como proceso adaptativo requiere del aprendizaje de las asociaciones entre estímulo y recompensa que ocurre durante la retroalimentación. Este aprendizaje permite la adaptación a los cambios en la relación estímulo-recompensa $y$, por ende, permite efectuar respuestas con base en las nuevas contingencias establecidas para lograr la meta en curso. Las tareas de aprendizaje inverso se basan en cambios de la retroalimentación y permiten estudiar estas respuestas adaptivas. En este sentido, se ha relacionado la actividad de las cortezas prefrontales medial y orbital con la inhibición de la respuesta aprendida. Sin embargo, otras cortezas como las prefrontales frontopolar y dorsolateral, parietal y temporal podrían estar participando en la detección del cambio de la asociación estímulorecompensa. El objetivo del presente trabajo fue comparar los cambios entre una condición de aprendizaje inicial y una de aprendizaje inverso en la potencia absoluta (PA) de las bandas electroencefalográficas (EEG) registradas en las cortezas prefrontal (frontopolar y dorsolateral), parietal y temporal durante la fase de retroalimentación en una tarea de TD. En la condición de aprendizaje inverso, en comparación con la de aprendizaje inicial, se presentó un aumento de la PA de delta en temporal izquierdo; theta en temporal tanto izquierdo como derecho; y en alpha1 en prácticamente todas las derivaciones registradas (para ambos hemisferios). Estos resultados EEG muestran un diferente patrón de activación cortical durante la retroalimentación, lo cual podría asociarse a la detección del cambio de la relación estímulorecompensa que ocurre durante la condición de aprendizaje inverso. 


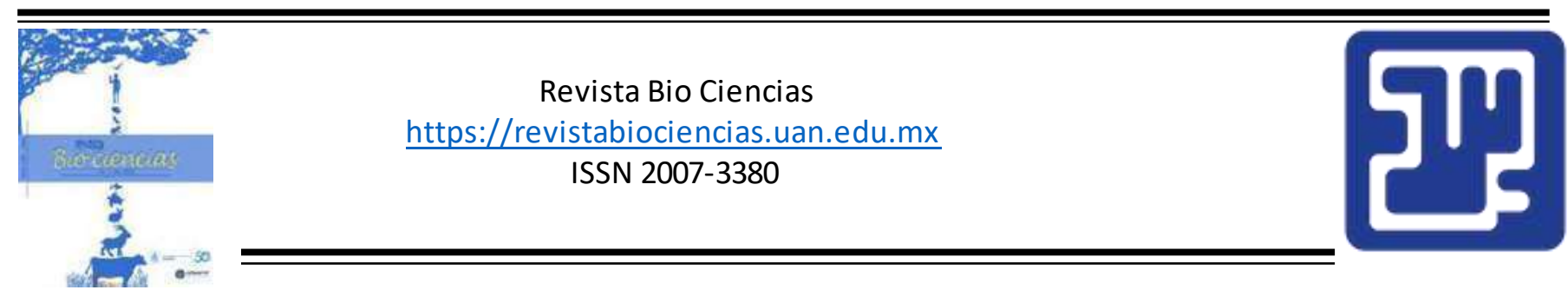

Trabajos libres: Neurociencias

Modalidad de Presentación: Oral

\title{
Efecto de la diabetes mellitus tipo 2 en el status epilepticus inducido con dos modelos experimentales en ratas
}

\author{
Ramos Riera, K. P., Mérida Portilla, C. V., Montiel Gómez, S. K., Beltrán Parrazal, L., López Meraz, \\ M. L.* \\ Centro De Investigaciones Cerebrales, Unviersidad Veracruzana \\ *Autor Corresponsal: María Leonor López Meraz. E-mail: leonorlopez@uv.mx
}

La diabetes mellitus (DM) es un desorden metabólico que cursa con hiperglicemia crónica. Estudios clínicos y experimentales muestran que la DM se relaciona con la presencia de status epilepticus (SE) de mayor severidad. Hasta el momento no se han realizado investigaciones detalladas sobre la relación entre la DM tipo 2 (DM2) y el SE. El objetivo de este trabajo fue evaluar el efecto de la DM2 en la severidad del SE inducido con los modelos de litio-pilocarpina $y$ pentilentetrazol (PTZ) en ratas adultas. Para inducir la DM2, ratas macho Wistar se administraron con $100 \mathrm{mg} / \mathrm{kg}$, s.c. de estreptozotocina (STZ, disuelta en buffer de citratos $0.1 \mathrm{M} \mathrm{pH} \mathrm{4.5)} \mathrm{en} \mathrm{el} \mathrm{día} \mathrm{postnatal}(P) 3$; las ratas control (CTRL) se inyectaron con vehículo. La glucosa sérica se determinó los días P30, P60 y P90 y solo las ratas STZ que presentaron niveles $\geq 200 \mathrm{mg} / \mathrm{dl}$ se incluyeron en este estudio. En el día P90, un grupo de ratas STZ y otro CTRL se sometieron al modelo de litio-pilocarpina ( $3 \mathrm{mEq} / \mathrm{kg}$,i.p., LiCl; $30 \mathrm{mg} / \mathrm{kg}$,s.c., clorhidrato de pilocarpina). Otro grupo de ratas STZ y CTRL se sometieron al modelo de PTZ (inyección i.p. inicial de 20 $\mathrm{mg} / \mathrm{kg}$, seguida de inyecciones cada $10 \mathrm{~min}$ de $10 \mathrm{mg} / \mathrm{kg}$ ). Los resultados mostraron que la latencia a la primera crisis generalizada y al SE generado con litio-pilocarpina fue mayor en las ratas STZ comparadas con las ratas CTRL; las ratas STZ también presentaron un mayor número y duración de las crisis generalizadas en comparación al grupo CTRL. El grupo STZ no mostró diferencias en la dosis de PTZ necesaria para producir las convulsiones, ni en la latencia o frecuencia de las mismas, en comparación con el CTRL. En conclusión, la DM2 aumenta la severidad del SE inducido con el modelo de litio-pilocarpina, pero no el causado con PTZ en ratas adultas. 


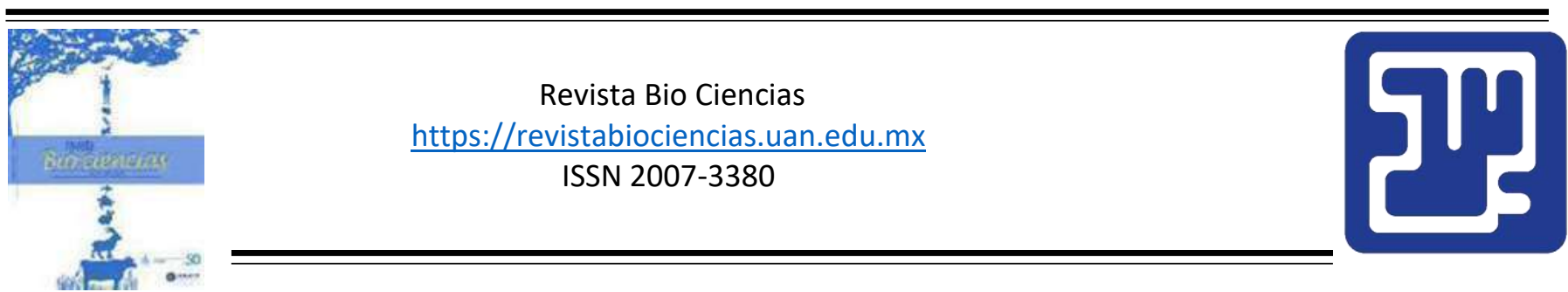

Trabajos libres: Neurociencias

Modalidad de Presentación: Cartel

\begin{abstract}
Efecto de la ablación unilateral del ganglio pélvico mayor sobre la morfometría de la próstata de ratas
\end{abstract}

\author{
Zamora Sánchez, K., Arellano Hernández, J., Hernández Aguilar, M. E., Cruz Gómez, Y.*
}

\title{
*Autor Corresponsal: Yolanda Cruz Gómez. E- mail: cruzgomezy@yahoo.com.mx
}

En este estudio se determinó el efecto de la ablación unilateral (izquierdo) del GPM (AGPM) sobre las características morfométricas de los lóbulos ventrales prostáticos de rata. Se estudiaron ratas adultas de la cepa Wistar asignadas a los siguientes grupos: A) intactos $(n=2), B)$ dos semanas después de la AGPM $(n=5)$ y C) 20 semanas después de la AGPM $(n=5)$. Los lóbulos ventrales izquierdo y derecho fueron seccionados a $5 \mu \mathrm{m}$ y teñidos con la técnica tricrómica de Masson. Se midió el área de los alvéolos y la altura de las células epiteliales. No hubo diferencias estadísticamente significativas en el área de los alvéolos o la altura del epitelio de los lóbulos ventrales izquierdo y derecho de los animales del Grupo A. En el Grupo B no hubo diferencias significativas en el área de los alvéolos de los lóbulos derecho e izquierdo, pero sí hubo una disminución en la altura del epitelio del lóbulo prostático ipsilateral a la AGPM ( $p<0.05)$. En el Grupo C, tanto el área de los alvéolos como la altura del epitelio del lóbulo ventral izquierdo (ipsilateral al AGPM) fueron menores ( $p$ $<0,01)$ a los observados en el lado intacto. Se concluye que la AGPM denerva a la próstata, lo que aumenta gradualmente el área de los alvéolos y disminuye la altura del epitelio prostático. Los resultados indican que el GPM contribuye a la regulación de la secreción del epitelio prostático y a mantener la citoestructura del epitelio alveolar. Así también que, aunque el plexo pélvico de la rata contiene ganglios pélvicos bilaterales interrelacionados a través de los nervios comisurales, el lóbulo prostático ipsilateral a la ablación no es reinervado contralateralmente, por lo que la AGPM conduce a una disfunción funcional progresiva y permanente. CONACYT-1011072; DEGESU, UATLX-CA 226.

Cite this paper/Como citar este artículo: Zamora Sánchez, K., Arellano Hernández, J., Hernández Aguilar, M. E., Cruz Gómez, Y. (2020). Efecto de la ablación unilateral del ganglio pélvico mayor sobre la morfometría de la próstata de ratas. Revista Bio Ciencias 7: (Suppl) Memorias de Congreso. LXIII Congreso Nacional de la Sociedad Mexicana de Ciencias Fisiologicas, A. C. e1097. 


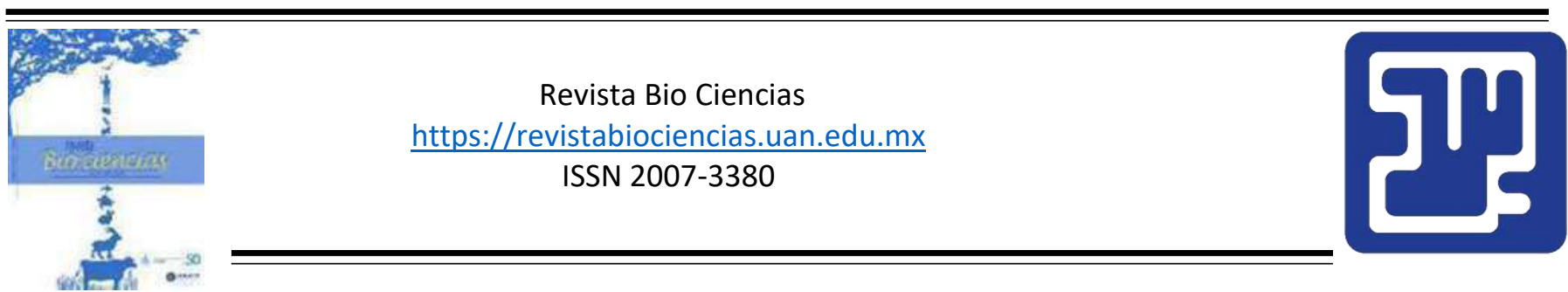

Trabajos libres: Neurociencias

Modalidad de Presentación: Cartel

\title{
La lesión cortical con hierro aumenta el estrés oxidativo y déficit de las enzimas antioxidantes pontinas y cerebelares
}

\author{
García García, K. I., Avila Luna, L. A., Gálvez Rosas, A., Pérez Aguirre, A., Wences Chirino, T. Y., \\ Cruz Castro, E.R., Bueno Nava, A. * \\ Instituto Nacional De Rehabilitación Luis Guillermo Ibarra Ibarra, Dirección De Investigación \\ Biomédica/ Neurociencias
}

*Autor Corresponsal: Antonio Bueno Nava. E- mail: ton631@hotmail.com

La enfermedad vascular cerebral (EVC) de tipo hemorrágico es la de mayor tasa de mortalidad $(90 \%)$ y altamente discapacitante. El puente y el cerebelo son estructuras que están conectadas con la corteza cerebral a través de las vías córtico-ponto-cerebelotálamo-cortical, y la lesión cortical puede alterar su función, contribuyendo a las secuelas discapacitantes. Nuestro objetivo fue determinar el daño oxidativo pontino y cerebelar después de la lesión intracortical con hierro. Utilizamos ratas macho Wistar de $250 \mathrm{~g}$ entrenadas en la viga elevada y divididas en 2 grupos: un grupo experimental lesionado con hierro ( $\mathrm{FeCl} 2 ; 50 \mathrm{nM})$ y un grupo sham (vehículo). Ambos grupos fueron evaluados en la viga elevada para medir el déficit motor. Para determinar el daño oxidativo se utilizó el método de las especies reactivas de oxígeno (ROS) y el índice glutatión, tanto para la forma reducida (GSH) como la forma oxidada (GSSG). La lesión con hierro produce un aumento significativo del $80 \%(\mathrm{P}<0.05)$ de déficit motor en los primeros 4 días post lesión, alcanzando su recuperación después del día 10 post lesión. Con respeto a las ROS pontinas, el grupo lesionado presentó un aumento $(P<0.05)$ a los 20 días post lesión. El cerebelo tuvo un aumento significativo $(P<0.05)$ de las ROS del grupo lesionado tanto a los 3 días como a los 20 días, en comparación al grupo sham. El análisis de la GSSG presentó una reducción significativa a nivel cerebelar en ambos hemisferios a los 3 y 20 días post lesión, mientras que para GSH encontramos una reducción pontina ipsilateral a los 3 y 20 días post lesión. Concluimos que la lesión cortical con hierro aumenta el estrés oxidativo y déficit de las enzimas antioxidantes pontinas y cerebelares. cerebelares. Revista Bio Ciencias 7: (Suppl) Memorias de Congreso. LXIII Congreso Nacional de la Sociedad Mexicana de Ciencias Fisiologicas, A. C. e1097. 


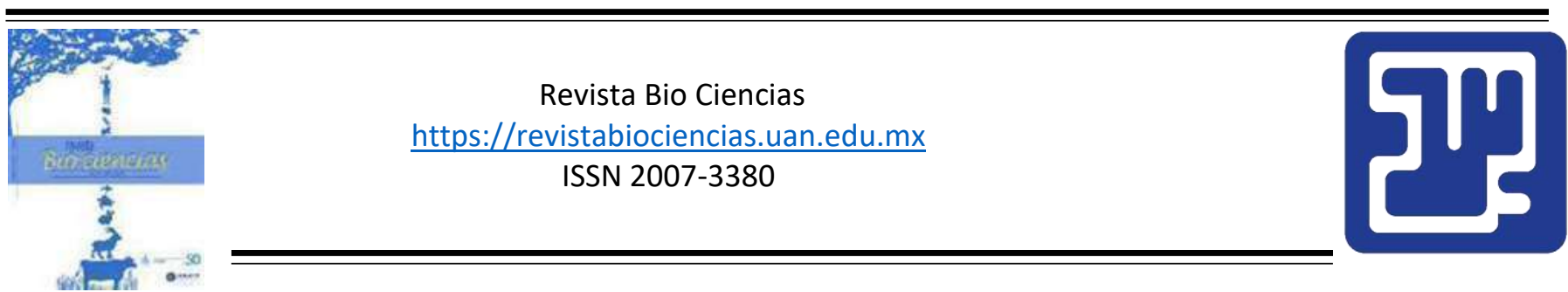

Trabajos libres: Neurociencias

Modalidad de Presentación: Cartel

\title{
Las neuronas CA1 del hipocampo de la rata hembra no se afectan por estrés crónico inducido por aislamiento social
}

\author{
Gazga Valencia, K. A., Barreda Guzmán, S. J., Santos Morales, M., Martínez López, I. D., Silva \\ Gómez, A. B.*
}

Benemérita Universidad Autónoma De Puebla

*Autor Corresponsal: Adriana Berenice Silva Gómez. E- mail: berenice71@yahoo.com

La neurona CA1 del hipocampo ha recibido mucha atención por parte de la comunidad científica debido a su capacidad de expresar potenciación a largo plazo y participar activamente en los procesos de aprendizaje. El hipocampo se divide en la porción dorsal directamente relacionada con funciones cognitivas y en la porción ventral que participa en procesamiento de información emocional. En ratas macho, las neuronas CA1 del hipocampo ventral sufren retracción dendrítica del árbol basilar y de sus espinas dendríticas por efecto de aislamiento social. Con el presente trabajo se estudió el efecto que tiene el estrés crónico inducido por aislamiento social en neuronas CA1 de hipocampo dorsal e hipocampo ventral de ratas hembra. Se utilizaron ratas intactas y ratas a las cuales se les monitoreó el ciclo estral criadas bajo una condición social y una condición estrés crónico inducido por aislamiento social por 56 días. Se analizó la morfología neuronal mediante la técnica de Golgi-Cox y análisis de Sholl, específicamente se determinó la longitud dendrítica total y la densidad de espinas dendríticas. Nuestros resultados muestran que, el estrés crónico al cual fueron sometidas las ratas hembra por el aislamiento social a partir del destete, no tiene ningún efecto en la longitud dendrítica de los árboles basilares y apicales de las neuronas CA1 y tampoco tiene efecto sobre la densidad de las espinas dendríticas. Estos resultados son contrarios a los observados en ratas macho, lo que sugiere la rata hembra expresa neuroprotección a partir de los estrógenos tal y como se ha mencionado previamente por algunos autores. Además, estos resultados están relacionados con observaciones de nuestro laboratorio respecto de que la capacidad de aprendizaje y memoria espacial no se ve afectada por el aislamiento social. la rata hembra no se afectan por estrés crónico inducido por aislamiento social. Revista Bio Ciencias 7: (Suppl) Memorias de Congreso. LXIII Congreso Nacional de la Sociedad Mexicana de Ciencias Fisiologicas, A. C. e1097. http://doi.org/10.15741/revbio.07Suppl.e1097 


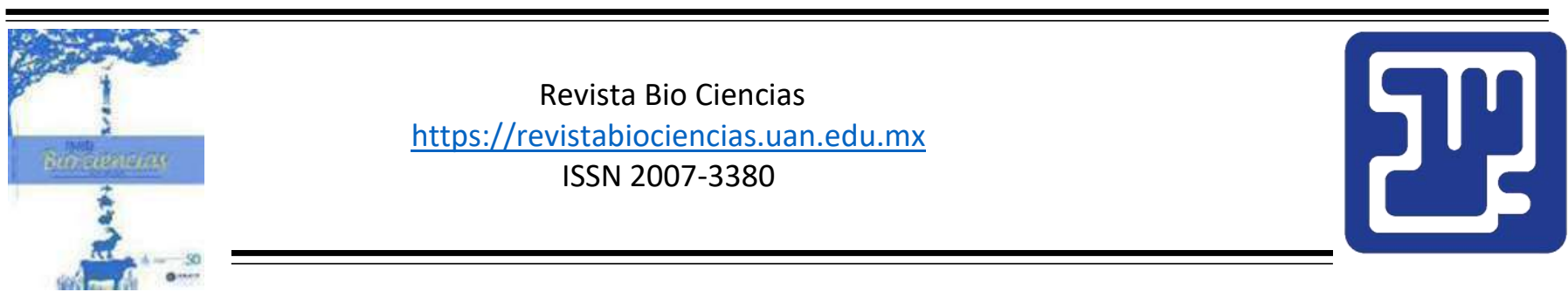

Trabajos libres: Neurociencias

Modalidad de Presentación: Oral

\title{
Estrategias no farmacológicas para el rescate de las alteraciones cognitivas asociadas al consumo de dietas hipercalóricas
}

\author{
Guzmán Ramos, K. R*., Peña Reyes, J. G., Hernández Ramírez, S.
}

Universidad Autónoma Metropolitana

*Autor Corresponsal: Kioko Rubí Guzmán Ramos. E-mail: k.guzman@correo.ler.uam.mx

La obesidad y enfermedades metabólicas relacionadas constituyen un factor de riesgo para el desarrollo de deterioro cognitivo. Paralelamente al estudio de los mecanismos que subyacen a las afectaciones a nivel central causadas por la exposición crónica a dietas hipercalóricas; la búsqueda de estrategias no farmacológicas para prevenir o disminuir los efectos adversos ha proporcionado alternativas para compensar los efectos de los ambientes obesogénicos. Dentro de las más comunes se encuentra el ejercicio físico voluntario, que además de mejorar el perfil metabólico, mejora la función cognitiva a través de diferentes mecanismos que tienen como consecuencia el fortalecimiento de los contactos sinápticos y el incremento de la plasticidad sináptica. Otra estrategia ampliamente utilizada como modulador positivo de la función cognitiva es el enriquecimiento ambiental, que muchas veces incluye, en los modelos animales, elementos para realizar ejercicio, así como objetos y congéneres para interactuar. Aunque la actividad física frecuente es parte de las recomendaciones para mejorar la salud y disminuir la adiposidad corporal, es de difícil apego; de esta forma, en el presente estudio evaluamos el efecto de la estimulación cognitiva constante que no involucrara un aumento considerable de la actividad física con el fin de revertir las afectaciones producidas por la exposición crónica a una dieta alta en grasa y azúcar. Los resultados indican un incremento en la actividad catecolaminérgica durante la exploración de objetos novedosos y la inducción constante de esta actividad rescata la función hipocampal evaluada a través de tareas de memoria espacial. Se propone que los mecanismos involucrados incluyen la preservación de las terminales catecolaminérgicas y sus efectos neuromoduladores, restituyendo la pérdida de la función sináptica causada por los daños celulares que desencadena el consumo de dietas hipercalóricas 


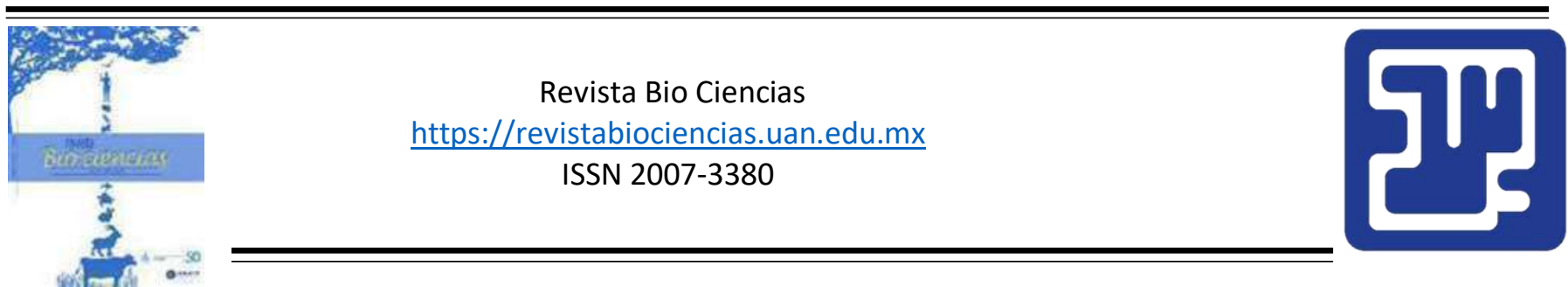

Trabajos libres: Neurociencias

Modalidad de Presentación: Oral

Influencia de la respuesta innata al estrés sobre la flexibilidad cognitiva

Díaz Espinosa, L., Ugarte Rojano, A., Cortés Sánchez, M. C., Eguibar Cuenca, J. R. *

Benemérita Universidad Autónoma de Puebla

*Autor Corresponsal: José Ramón Eguibar Cuenca. E- mail: jose.eguibar@correo.buap.mx

Las respuestas al estrés y la memoria espacial son funciones que permiten al sujeto sobrevivir en un ambiente cambiante. En este contexto, la capacidad del individuo de ajustar su comportamiento a las demandas medioambientales se denomina flexibilidad cognitiva, ésta al igual que la consolidación de la memoria espacial pueden verse afectadas por respuestas exageradas al estrés. Las sublíneas de ratas de alto y bajo bostezo (high-yawning: HY y low-yawning: LY, respectivamente) presentan respuestas resilientes la HY y ansiosas ante estresores la LY. El objetivo de este estudio fue evaluar la memoria espacial y la flexibilidad cognitiva en machos HY, LY y Sprague-Dawley empleando el laberinto de Barnes y siete días después se les aplicó una prueba reversa, en la cual la posición de la caja de escape cambió $180^{\circ}$ al entrenamiento. Al término de la evaluación conductual se determinó la concentración de corticosterona plasmática en todos los sujetos. Nuestros resultados muestran que la memoria espacial de largo plazo fue mejor en los sujetos HY y SD respecto de la sublínea LY (ANOVA $P<0.01$ ). La flexibilidad cognitiva de ambas sublíneas es menor, ya que invirtieron más tiempo y visitaron más la zona donde se ubicó la caja de escape durante el entrenamiento, respecto de lo mostrado en las ratas SD (ANOVA $P<0.05$ ). La secreción de corticosterona 15 minutos después de la recuperación de la memoria fue significativamente mayor en los machos LY respecto del grupo HY (ANOVA $\mathrm{P}<0.05$ ). Concluimos que el fenotipo ansioso de la sublínea LY influye negativamente en su memoria y flexibilidad cognitiva. Adicionalmente proponemos que la resiliencia influye diferencialmente sobre dos procesos relacionados en la sublínea HY; la cual mostró una memoria espacial intacta, pero flexibilidad cognitiva deficiente. Financiamiento: VIEPBUAP al CA en Neuroendocrinología BUAPCA-288. LD es becaria del CONACyT No. 850282 por Doctorado en Ciencias Fisiológicas. cognitiva. Revista Bio Ciencias 7: (Suppl) Memorias de Congreso. LXIII Congreso Nacional de la Sociedad Mexicana de Ciencias Fisiologicas, A. C. e1097. 


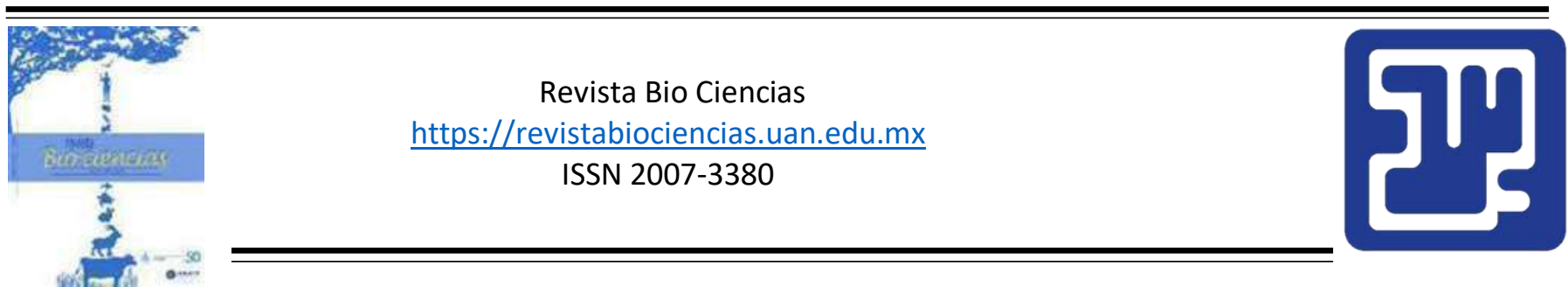

Trabajos libres: Neurociencias

Modalidad de Presentación: Oral

Functional study at the very early disease stage in the $\operatorname{rg} 4510$ mouse model of tauopathy

Xolalpa Cueva, L., Peña Ortega, F., Orta Salazar, E., Díaz Cintra, S., Mondragón Rodríguez, S. *

Instituto De Neurobiología UNAM

*Autor Corresponsal: Siddhartha Mondragón Rodríguez. E- mail: sidmonrod@gmail.com

Tau hyperphosphorylation at several sites, including those close to their microtubule domain (MD), is considered a key pathogenic event in the development of tauopathies. Nevertheless, we recently demonstrated, that at the very early disease stage, phosphorylation increases in MD sites of tau protein (pTau) promotes neuroprotection by preventing induced like seizures. To further explore the hypothesis, that very early pTau is not detrimental, the present work explores the young $r$ Tg4510 mouse model of tauopathy as a case study. First, we tested, at one month of age (p30), the locomotor and spatial memory functional performance. Then, we tested the hippocampal network activity, and finally, we evaluated the increase of pTau within the hippocampal area. Our results showed that a very young $\mathrm{rTg} 4510$ model has no detectable changes in either, locomotor activity or spatial memory. In contrast, the very young rTg4510 exhibited a higher discrimination index value of discrimination learning. Interestingly, the pyramidal neurons from p30 rTg4510 accumulate pTau protein and that this accumulation correlates with changes in oscillatory activity. Collectively, this study provides new insights into the pathogenesis of tauopathies. Acknowledgments: We thank the following facilities from INB: Proteogenomic Facility Unit, Behavioral Analysis Core Facility, and Vivarium Facility. Benito Ordaz and Azucena Aguilar Vázquez for technical support. 


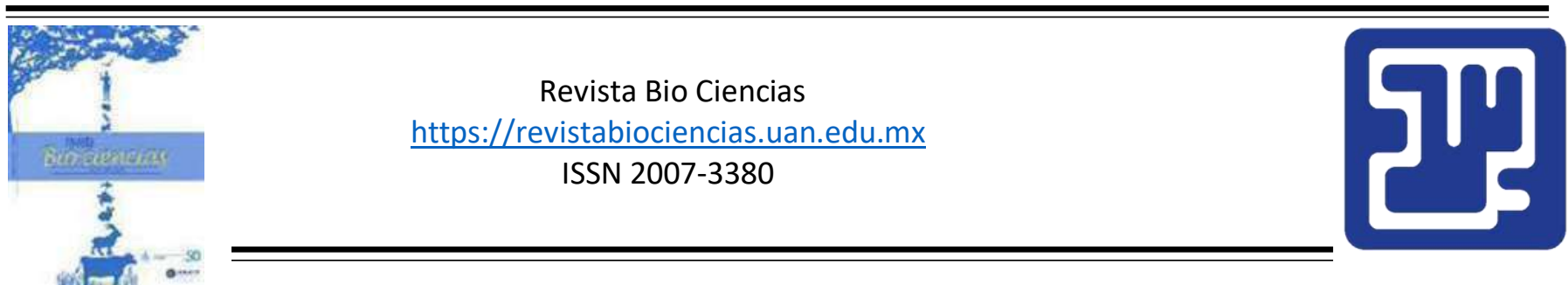

Trabajos libres: Neurociencias

Modalidad de Presentación: Cartel

\title{
Análisis de la expresión de las neuronas Kisspeptidérgicas y GnRHérgicas del hipotálamo de la rata taiep en estro como modelo animal de desmielinización
}

\author{
Muñoz De La Torre, L. P. ${ }^{1}$, Trujillo Hernández, $A .{ }^{2}$, Eguivar Cuenca, J. R. ${ }^{2}$, Cortés Sánchez, M. C. ${ }^{2}$, \\ Morales Ledesma, L. ${ }^{1 *}$ \\ ${ }^{1}$ Universidad Autónoma de México \\ 2 Benemérita Universidad Autónoma de Puebla \\ *Autor Corresponsal: Leticia Morales Ledesma. E- mail: moralesledesma@yahoo.com.mx
}

Las mujeres con enfermedades desmielinizantes presentan problemas reproductivos como: disminución en las concentraciones de la hormona folículo estimulante, la hormona luteinizante, disminución de la reserva folicular e infertilidad. El eje Hipotálamo-HipófisisGónadas regula la función reproductiva, uno de sus componentes son las neuronas kisspeptidérgicas (NKiss), localizadas en el área anteroventral periventricular (AVPV) y el núcleo arcuato (ARC). Las NKiss participan en la liberación de la hormona liberadora de gonadotropinas $(\mathrm{GnRH})$ por las neuronas GnRHérgicas localizadas en la eminencia media(eM). Al desconocer la relación desmielinización-problemas reproductivos, nosotros usamos a la rata taiep, que presenta desmielinización y problemas reproductivos y analizamos si la distribución y número de las NKiss y/o las neuronas GnRHérgicas de la hembra en estro se encuentran afectadas. Obtuvimos los cerebros de hembras en estro taiep y Sprague-Dawley(SD), fueron cortados a $10 \square \mathrm{m}$, se localizó el AVPV, ARC y eM. Se realizó inmunofluorescencia contra kisspeptina y GnRH (bs-0749r-cy5, bs-
10369R-A488; Bioss Antibodies). Se analizó intensidad de fluorescencia y número de neuronas usando el programa ImageJ1.50i. Las NKiss de las ratas taiep presentaron menor intensidad de fluorescencia comparado con las SD (AVPV: $0.469 \pm 0.026$ vs $0.571 \pm 0.042 ; \quad$ ARC: $0.427 \pm 0.026$ vs $0.567 \pm 0.028, p<0.01)$. Aumentó el número de NKiss en AVPV de las ratas taiep comparado con las SD (136 \pm 6.58 vs $87.8 \pm 17.41 ; p<0.05)$, sin cambios en el ARC. No se observaron cambios significativos en ningún parámetro evaluado de las neuronas GnRHérgicas. La disminución en la presencia de kisspeptina en la rata taiep podría deberse a la baja concentración de estrógeno, previamente reportado, mientras que, el aumento en el número de NKiss en el AVPV actúa como mecanismo compensatorio permitiendo mantener la expresión de $\mathrm{GnRH}$ durante esta etapa del ciclo estral en este modelo animal. Parcialmente financiado por: proyecto VIEP clave 100274222-VIEP2019; apoyo DGAPAPAPIIT clave IN216519. LPMT becario CONACyT No.736730. Se agradece el apoyo del Biol. José Luis Córdova, Lab. Microscopía, Instituto de Fisiología, BUAP

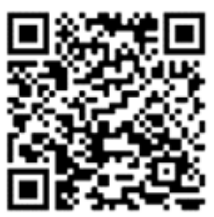

Cite this paper/Como citar este artículo: Muñoz De La Torre, L. P, Trujillo Hernández, A., Eguivar Cuenca, J. R., Cortés Sánchez, M. C., Morales Ledesma, L. (2020). Análisis de la expresión de las neuronas Kisspeptidérgicas y GnRHérgicas del hipotálamo de la rata taiep en estro como modelo animal de desmielinización. Revista Bio Ciencias 7: (Suppl) Memorias de Congreso. LXIII Congreso Nacional de la Sociedad Mexicana de Ciencias Fisiologicas, A. C. e1097. http://doi.org/10.15741/revbio.07Suppl.e1097 


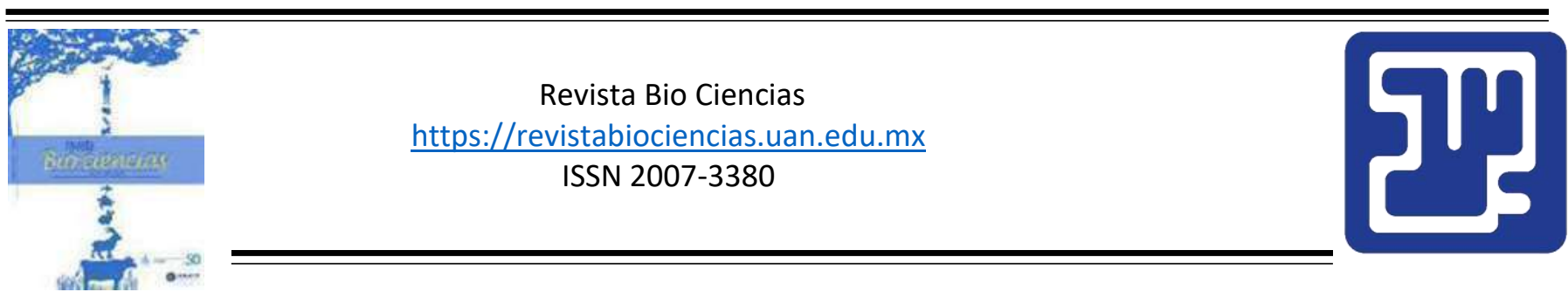

Trabajos libres: Neurociencias

Modalidad de Presentación: Cartel

\author{
El aislamiento social en ratas hembras con y sin monitoreo del ciclo estral no afecta la capacidad \\ de memoria en el laberinto acuático de Morris
}

\author{
Santos Morales, M., Martínez López, I. D., Gazga Valencia, K. A., Barreda Guzmán, S. J., Silva \\ Gómez, A. B. *
}

Benemerita Universidad Autonoma De Puebla

*Autor Corresponsal: Adriana Berenice Silva Gómez. E- mail: berenice71@yahoo.com

\begin{abstract}
El estrés es una condición metabólica natural de los organismos que le permite enfrentar un ambiente cambiante o que se percibe como amenaza. En su condición aguda, facilita la capacidad de respuesta mientras que, en la condición crónica, puede alterar la capacidad de respuesta a situaciones desafiantes. En los organismos hembra, el factor hormonal favorece mecanismos de neuroprotección de las capacidades cognitivas. Se determinó el efecto del estrés crónico en la capacidad de aprendizaje y memoria de ratas hembra maduras sexualmente. Se utilizaron ratas hembra Wistar de 28 días de edad, se le sometió a aislamiento social por 56 días y se les monitoreo el ciclo estral a partir de los 45 días de edad. Después del periodo de aislamiento, a las ratas se les aplicó la prueba del laberinto acuático de Morris. Observamos que las ratas aisladas intactas tienen una
\end{abstract}

latencia de escape menor que las ratas sociales intactas en tres días de la prueba, no obstante, solo hay una diferencia significativa en el día tres de la prueba. Las ratas aisladas monitoreadas del ciclo estral, no muestran cambios en la capacidad de aprendizaje excepto en el tercer día de la prueba, en donde el tiempo de latencia de escape es mayor. Tanto los organismos aislados intactos como los aislados con monitoreo del ciclo estral expresan un tiempo de permanencia en el cuadrante blanco menor sin embargo no es significativa la diferencia, lo que sugiere que la condición de aislamiento no promueve déficit en la capacidad de memoria. Se ha sugerido que cualquier estimulo ambiental repetitivo puede provocar plasticidad neuronal, no obstante, la manipulación constante para monitorear el ciclo estral no afecta la capacidad de aprendizaje y memoria.

Cite this paper/Como citar este artículo: Santos Morales, M., Martínez López, I. D., Gazga Valencia, K. A., Barreda Guzmán, S. J., Silva Gómez, A. B. (2020). El aislamiento social en ratas hembras con y sin monitoreo del ciclo estral no afecta la capacidad de memoria en el laberinto acuático de Morris. Revista Bio Ciencias 7: (Suppl) Memorias de Congreso. LXIII Congreso Nacional de la Sociedad Mexicana de Ciencias Fisiologicas, A. C. e1097. http://doi.org/10.15741/revbio.07Suppl.e1097 


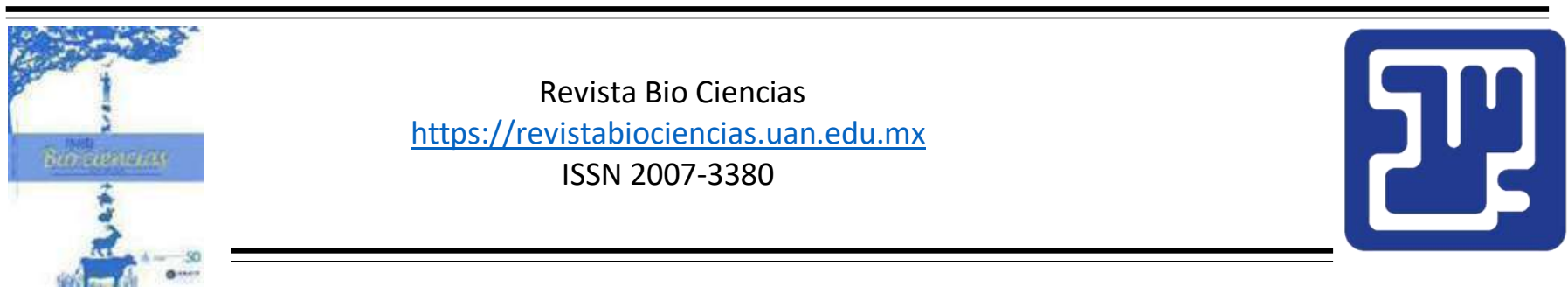

Trabajos libres: Neurociencias

Modalidad de Presentación: Cartel

La experiencia materna disminuye el efecto de un estímulo distractor sobre una tarea de memoria de trabajo: un estudio EEG

Pérez Hernández, M., Hidalgo Aguirre, R. M., Guevara Pérez, M. A., Hernández González, M. *

Universidad De Guadalajara

*Autor Corresponsal: Marisela Hernández González. E- mail: marisela.hgonzalez@academicos.udg.mx

La experiencia materna es adquirida a largo plazo durante la crianza de uno o más hijos. Este proceso es acompañado de cambios conductuales y neurobiológicos, que modulan la forma en que una mujer codifica y responde a las señales afectivas infantiles. Se sabe que el procesamiento cognitivo de madres primerizas es afectado por el llanto de bebé; sin embargo, existe poca información acerca del efecto de este estímulo auditivo sobre el desempeño cognitivo y funcionamiento cerebral en madres multíparas. Este estudio caracteriza el grado de correlación electroencefalográfica ( $\mathrm{rEEG}$ ) entre áreas prefrontales y parietales en madres multíparas $(\mathrm{MM})$ y madres primerizas (MP), mientras resuelven una tarea de memoria de trabajo visoespacial (MTv) y simultáneamente escuchan un distractor emocional (llanto de bebé) o neutro (ruido blanco). En la condición MTv con llanto únicamente las madres MM necesitaron menos tiempo para resolver la tarea cognitiva. Además, presentaron una menor rEEG prefronto-parietal izquierda y mayor rEEG inter-parietal durante la tarea de MTV mientras escuchaban ambos estímulos distractores respecto a la MP. El acoplamiento inter e intrahemisférico observado en MM se asoció con un bajo efecto del estímulo distractor sobre el desempeño en la tarea MTv, lo que podría ser una adaptación para el control de la situación (tarea cognitiva con distractor) y así lograr un mejor desempeño en la tarea cognitiva.

Cite this paper/Como citar este artículo: Pérez Hernández, M., Hidalgo Aguirre, R. M., Guevara Pérez, M. A., Hernández González, M. (2020). La experiencia materna disminuye el efecto de un estímulo distractor sobre una tarea de memoria de trabajo: un estudio EEG. Revista Bio Ciencias 7: (Suppl) Memorias de Congreso. LXIII Congreso Nacional de la Sociedad Mexicana de Ciencias Fisiologicas, A. C. e1097. http://doi.org/10.15741/revbio.07Suppl.e1097 


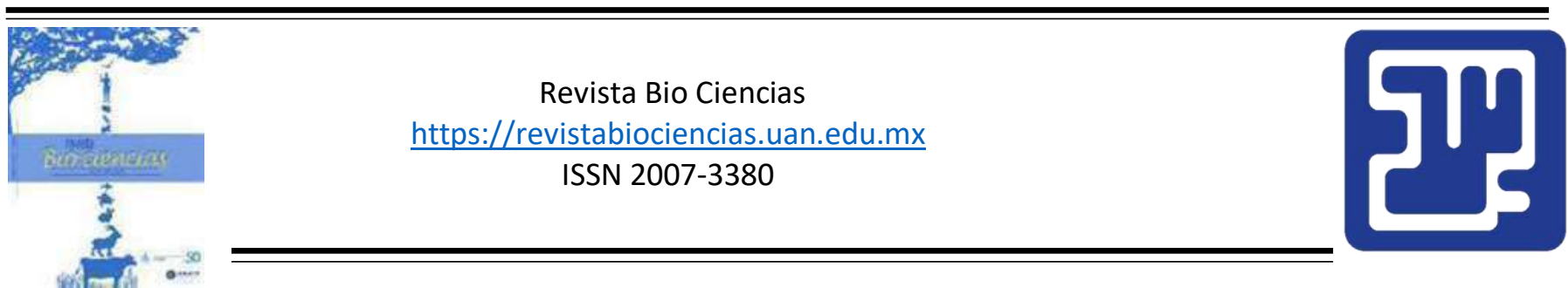

Trabajos libres: Neurociencias

Modalidad de Presentación: Oral

Transportador de serotonina en el hipocampo ventral de ratas estresadas prenatalmente Retana Marquéz, M. S. ${ }^{1}$, Méndez Guerrero, D. ${ }^{1}$, Rubio Osornio, M. C. ${ }^{2}$, Rubio Osornio, M. ${ }^{2}$, Orozco Suarez, S. ${ }^{3}$, Jiménez Vásquez, F. J. ${ }^{1^{*}}$

${ }^{1}$ UAM Iztapalapa

${ }^{2}$ Instituto Nacional de Neurología y Neurocirugía Manuel Velasco Suárez

${ }^{3}$ Unidad de Investigación Médica en Enfermedades Neurológicas. Hospital de Especialidades, C.M.N. Siglo XXI.

*Autor Corresponsal: Felipe de Jesús Jiménez Vásquez. E- mail: iimenez felipe89@hotmail.com

En estudios previos, hemos demostrado que el estrés prenatal modifica el funcionamiento del sistema serotoninérgico, disminuyendo la liberación de serotonina en el en el hipocampo ventral después de la prueba conductual de nado forzado en la edad adulta. Es importante continuar con el estudio de los cambios en la neurotransmisión serotoninérgica, por lo que el objetivo de este trabajo fue evaluar el contenido del transportador de serotonina en el hipocampo ventral de ratas estresados prenatalmente (anhedónicas y no anhedónicas) después de la prueba de sacarosa y después de la prueba de nado forzado. En ratas macho estresados prenatalmente, de tres meses de edad se evaluó el consumo de sacarosa y la prueba de nado forzado. Al finalizar las pruebas sacarosa o de nado forzado, las ratas se eutanizaron, se diseccionó el hipocampo ventral para evaluar el contenido del transportador de serotonina mediante la técnica de western blot, tanto en los animales control como en los estresados prenatalmente, anhedónicas y no anhedónicas. Los resultados muestran que el contenido del transportador de serotonina en hipocampo ventral aumentó en las ratas control después de la prueba de nado forzado. En las ratas anhedónicas y no anhedónicas no se observaron cambios en el contenido del transportador después de la prueba de nado forzado. Estos datos muestran que, como parte de las afectaciones que el estrés prenatal causa en el sistema serotoninérgico en el hipocampo ventral, el transportador de serotonina no se modifica ni después de la prueba de sacarosa, ni después de la prueba de nado forzado.

Cite this paper/Como citar este artículo Retana Marquéz, M. S., Méndez Guerrero, D., Rubio Osornio, M. C., Rubio Osornio, M., Orozco Suarez, S., Jiménez Vásquez, F. J.(2020). Transportador de serotonina en el hipocampo ventral de ratas estresadas prenatalmente. Revista Bio Ciencias 7: (Suppl) Memorias de Congreso. LXIII Congreso Nacional de la Sociedad Mexicana de Ciencias Fisiologicas, A. C. e1097. http://doi.org/10.15741/revbio.07Suppl.e1097 


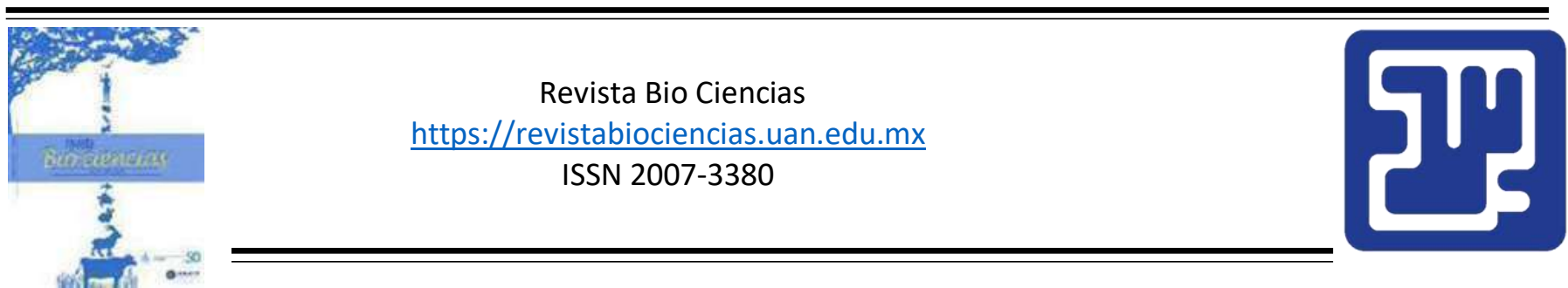

Trabajos libres: Neurociencias

Modalidad de Presentación: Cartel

\title{
Correlatos cerebrales de la estrategia postléxica de integración semántica a través de priming indirecto
}

\author{
Núñez Soria, M. ${ }^{1}$, Arias Trejo, N.. ${ }^{2}$, Marrufo Meléndez, O. ${ }^{3}$, Carrillo Mezo, R. ${ }^{3}$, Silva Pereyra, J.4, \\ Rodríguez Camacho, M. A. ${ }^{4}$, Robles Aguirre, F. A. ${ }^{\text {* }}$ \\ ${ }^{1}$ Centro Universitario del Norte, Universidad de Guadalajara \\ ${ }^{2}$ Facultad de Psicología UNAM \\ ${ }^{3}$ Instituto Nacional de Neurología y Neurocirugía \\ ${ }^{4}$ Facultad de Estudios Superiores Iztacala, UNAM
}

*Autor Corresponsal: Francisco Abelardo Robles Aguirre. E- mail: franciscoara@live.com

En una tarea de decisión léxica (DL) se utilizó priming semántico indirecto para investigar las regiones de activación relacionadas con la estrategia postléxica de integración semántica. Para ello se utilizó una asincronía de inicio de estímulos prime-target (SOA) larga $(800 \mathrm{~ms})$, permitiendo la activación de estrategias postléxicas de procesamiento (expectativa y pareo semántico). Con la finalidad de disminuir la estrategia de expectativa, se utilizó una proporción de pares de palabras no relacionadas (NOREL, 40 ensayos) que de pseudopalabras (NOPAL, 20 ensayos) y de palabras relacionadas (REL, 20 ensayos), así como la utilización de priming mediado o indirecto ("león"-"rayas" relacionadas a través de "tigre"). Se encontraron diferencias en la velocidad de respuesta entre las condiciones $(F=304.65$, $\mathrm{p}=.0001)$. Al comparar las condiciones, encontramos diferencias entre REL ( $M=917.4$,
$\mathrm{DE}=187.1)$ y $\mathrm{NOPAL}(\mathrm{M}=1025.4, \mathrm{DE}=181.6$; $\mathrm{p}=.015)$ y entre NOREL $(\mathrm{M}=919.4, \mathrm{DE}=165.8)$ y NOPAL $(p=0.14)$, con un aumento del tiempo de respuesta para la condición NOPAL. Se encontró una mayor activación BOLD en pars orbitalis del giro frontal inferior izquierdo para las condiciones REL y NOREL con respecto a la condición NOPAL. Así mismo, se encontró una mayor activación en las regiones posteriores del surco temporal medio y en el giro temporal inferior izquierdos para las condiciones de NOPAL en comparación con las condiciones de REL y NOREL. Estos datos sugieren la existencia de circuitos diferenciales en el procesamiento semántico controlado para las palabras y pseudopalabras involucrando el giro frontal inferior en la búsqueda de relaciones primetarget, y las regiones temporales inferiores en la lexicalidad de los ítems atendidos.

Cite this paper/Como citar este artículo: Núñez Soria, M., Arias Trejo, N., Marrufo Meléndez, O., Carrillo Mezo, R., Silva Pereyra, J., Rodríguez Camacho, M. A., Robles Aguirre, F. A.(2020). Correlatos cerebrales de la estrategia postléxica de integración semántica a través de priming indirecto. Revista Bio Ciencias 7: (Suppl) Memorias de Congreso. LXIII Congreso Nacional de la Sociedad Mexicana de Ciencias Fisiologicas, A. C. e1097. 


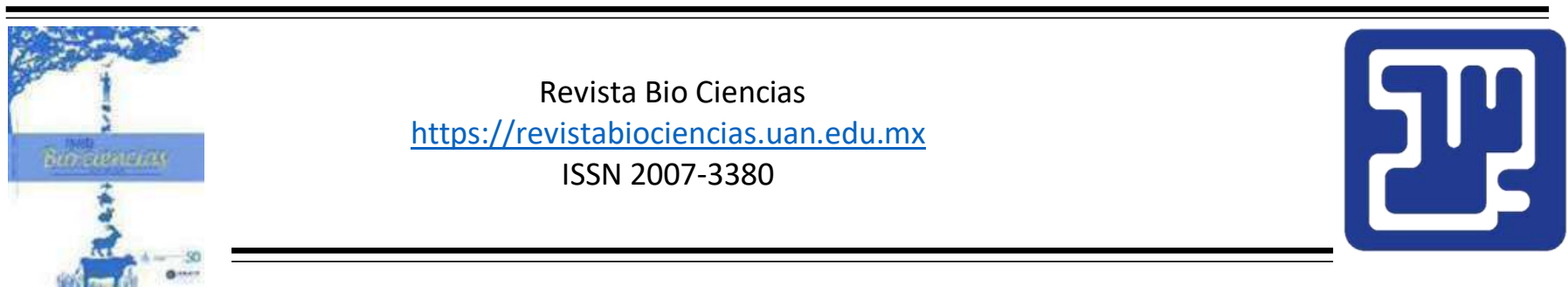

Trabajos libres: Neurociencias

Modalidad de Presentación: Oral

\begin{abstract}
Estudio del efecto de una dieta hiperproteínica sobre el eje microbiota-intestino-cerebro, y el desarrollo de conductas relacionadas a la ansiedad y depresión en un modelo murino.
\end{abstract}

\author{
Sánchez Cisneros, M. S. ${ }^{1}$, Bárcena Lozano, L. ${ }^{1}$, Serna Saldívar, S. R. O. ${ }^{1}$, Morales Medina, J. C. ${ }^{2}$, \\ Santacruz López, $A .^{1^{*}}$ \\ ${ }^{1}$ ITESM \\ ${ }^{2}$ Centro de Investigación y de Estudios Avanzados
}

*Autor Corresponsal: Arlette Santacruz López. E- mail: asantacruz@tec.mx

El eje intestino-cerebro es un complejo sistema de comunicación bidireccional que permite establecer una conexión íntima entre ambos órganos, a través de distintos mecanismos. La evidencia científica reciente acerca del importante papel que juega el microbiota que reside en el tracto intestinal en la modificación del comportamiento y otros patrones cognitivos, ha suscitado un creciente interés por estudiar diversas estrategias dietéticas para modificar dichas comunidades microbianas para modular el comportamiento, así como el desarrollo de trastornos de la conducta como la ansiedad y la depresión. Las dietas altas en proteína, tanto de origen vegetal como animal, se han popularizado como intervención dietética por sus efectos beneficiosos en el metabolismo; no obstante, en altas cantidades, pueden producirse efectos dañinos en el microbiota intestinal, por lo que este tipo de dietas aún es cuestión de debate. Dada la atención que ha recibido este enfoque, el presente trabajo tiene como objetivo el estudio de un modelo murino para investigar si las dietas altas en proteína de origen vegetal y animal, son capaces de inducir cambios en el comportamiento y en el microbiota intestinal. Treinta ratones C57/BL6 fueron asignados a tres grupos de tratamiento ( $\mathrm{n}=10$ por grupo) y fueron alimentados con una dieta normal control (NC) o dietas híper proteínicas de origen vegetal (HPV) o animal (HPA) por 8 semanas, siendo monitoreados por peso, comportamiento y composición del microbiota. El análisis de comportamiento se realizó al finalizar la intervención dietética haciendo uso de tres pruebas de conducta: laberinto elevado en forma de cruz, laberinto en forma de ' $Y$ ', y prueba de nado forzado, en las cuales diferentes niveles de actividad fueron registrados para cada grupo. Los resultados de esta investigación permitirán hacer recomendaciones más cuidadosas en el emprendimiento de intervenciones dietéticas con un mayor aporte de proteína en relación a otros macronutrientes.

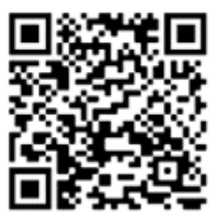

Cite this paper/Como citar este artículo: Sánchez Cisneros, M. S., Bárcena Lozano, L., Serna Saldívar, S. R. O., Morales Medina, J. C., Santacruz López, A. (2020). Estudio del efecto de una dieta hiperproteínica sobre el eje microbiota-intestino-cerebro, y el desarrollo de conductas relacionadas a la ansiedad y depresión en un modelo murino. Revista Bio Ciencias 7: (Suppl) Memorias de Congreso. LXIII Congreso Nacional de la Sociedad Mexicana de Ciencias Fisiologicas, A. C. e1097. http://doi.org/10.15741/revbio.07Suppl.e1097 


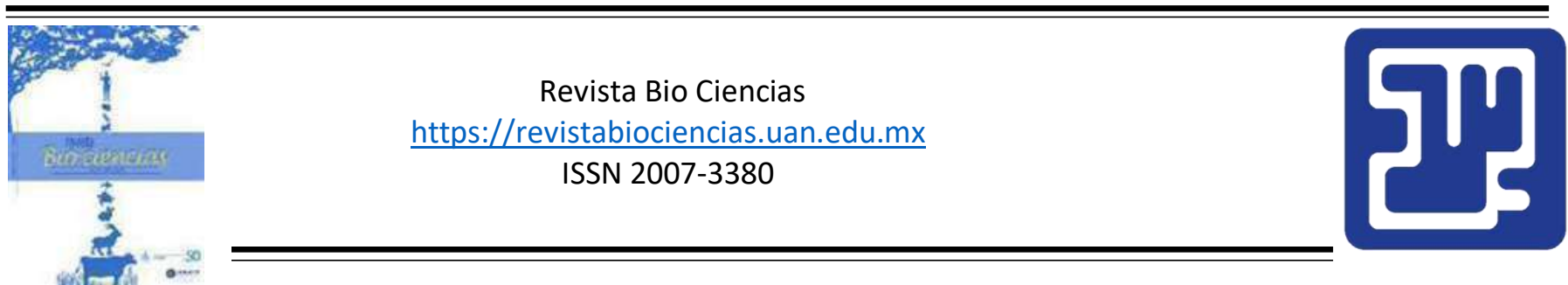

Trabajos libres: Neurociencias

Modalidad de Presentación: Oral

\title{
Uso de pirofosfato de tiamina como tratamiento neuroprotector en un modelo animal para la enfermedad de Alzheimer (3xTg-AD)
}

\author{
Pastén Castrejón, N. J. ${ }^{1}$, Díaz Miranda, S. Y. ${ }^{2 *}$ \\ ${ }^{1}$ Universidad Autónoma de Querétaro \\ 2 Instituto Nacional de Neurobiología
}

*Autor Corresponsal :Sofía Yolanda Díaz Miranda. E- mail:yoldi@unam.mx

La enfermedad de Alzheimer (EA) es resultado de la combinación de factores genéticos y epigenéticos, siendo la pérdida de la homeostasis del metabolismo energético, la neuroinflamación y la agregación de la proteína $\beta$-amiloide $(\beta A)$, características patológicas que afectan áreas cerebrales relacionadas con el aprendizaje y la memoria. En la EA se ha observado que existe un estado de hipometabolismo a nivel cerebral que puede contribuir a la agregación anómala de la proteína $\beta A$ lo que ocasiona reacciones metabólicas oxidantes, y que podría estar relacionado con el aumento de células microgliales y neuroinflamación. Se ha propuesto que el metabolismo de la glucosa, dependiente del pirofosfato de tiamina (PPT), es afectado por la disminución de las enzimas encargadas de su forma funcional. Existen fármacos capaces de suplir el déficit de PPT como es el X-2 (clorhidrato de PPT), agente neuroprotector valorado a nivel cognitivo y neurometabólico. Se administró PPT por bomba de infusión subdérmica en el modelo de ratón 3xTg-AD y se evaluó el desempeño conductual en una tarea dependientes del hipocampo (anidación). Se evaluó inmunohistoquímicamente, la cantidad de células microgliales y $\beta A$ total (Iba-1, BAM10) en la formación hipocampal (FH). Se trataron dos grupos (3xTg-AD): uno con X-2 (TG PPT) y otro con vehículo (TG VHCL), comparados con dos grupos control de no transgénicos (NoTG PPT, NoTG VHCL) bajo los mismos tratamientos. Los resultados neuroanatómicos mostraron que en el grupo TG PPT hubo una menor acumulación de $\beta A$ total en la $\mathrm{FH}$ en comparación con el grupo TG VHCL, asociado a un retraso en el déficit cognitivo (anidación). Este trabajo contribuye al estudio del efecto de fármacos que pueden mejorar el estado metabólico y por consecuencia tener una función neuroprotectora. Palabras clave: Pirofosfato de tiamina, neuroprotección, microglía, enfermedad de Alzheimer, hipocampo. pirofosfato de tiamina como tratamiento neuroprotector en un modelo animal para la enfermedad de Alzheimer (3xTg-AD). Revista Bio Ciencias 7: (Suppl) Memorias de Congreso. LXIII Congreso Nacional de la Sociedad Mexicana de Ciencias Fisiologicas, A. C. e1097. http://doi.org/10.15741/revbio.07Suppl.e1097 


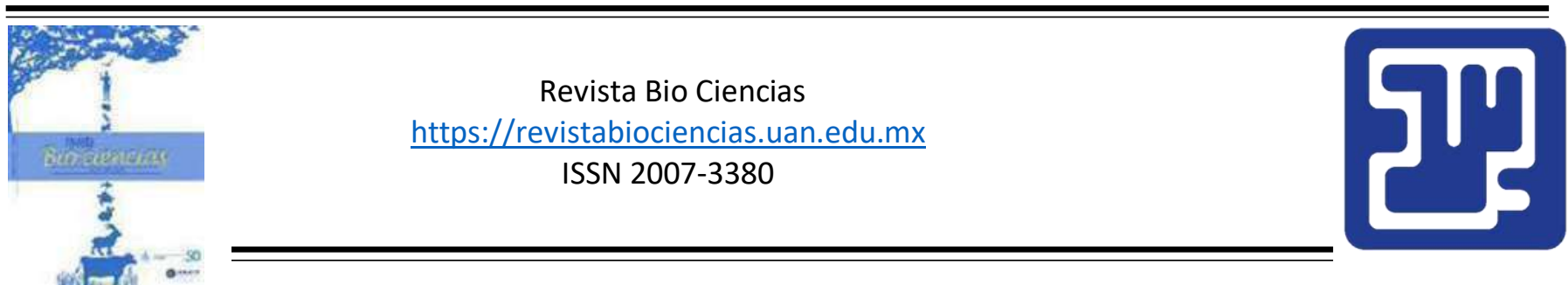

Trabajos libres: Neurociencias

Modalidad de Presentación: Oral

\begin{abstract}
Liberación de corticosterona después del aprendizaje y evocación de la memoria de un entrenamiento moderado e intenso
\end{abstract}

\author{
Bello Medina, P. C. ${ }^{1}$, Medina Fragoso, A..$^{2}{ }^{2}$, Quirarte, G. L. ${ }^{2}$, Prado Alcalá, R. A. ${ }^{2 *}$ \\ ${ }^{1}$ Universidad Autónoma Metropolitana \\ ${ }^{2}$ Universidad Nacional Autónoma de México
}

*Autor Corresponsal: Roberto Agustín Prado Alcalá. E-mail: prado@servidor.unam.mx

La administración de corticosterona (CORT) sistémica después del entrenamiento en la tarea de evitación inhibitoria (EI) facilita la consolidación de la memoria. Se desconoce si se incrementa la liberación de CORT durante la evocación. Para estudiar el efecto de la evocación de la memoria de El entrenada con un choque eléctrico moderado o incrementado sobre los niveles de CORT, tres grupos independientes de ratas macho Wistar fueron entrenados en la tarea de El (0.0, 1.0 o 3.0 $\mathrm{mA})$. Además, un grupo sin entrenamiento que recibió el choque eléctrico de $3.0 \mathrm{~mA}$ y un grupo bioterio (Bio). La retención se realizó 24 $\mathrm{h}$ después del entrenamiento. La mitad de las ratas fueron sacrificadas 15 min después del entrenamiento (grupos E-0, E-1 y E-3) y la otra mitad 15 min después de la prueba de evocación (grupos R-0, R-1 y R-3) para la medición de la CORT en suero. Los resultados muestran un aumento en la concentración de CORT en E-0, E-1 y E-3 vs. Bio, así mismo se observan diferencias significativas entre $\mathrm{E}-1$ y E-3. También observamos un aumento significativo en $\mathrm{R}-0$ vs. Bio, pero no encontramos cambios en los grupos R-1 y R3. Estos resultados sugieren que el entrenamiento en la tarea de El induce la liberación de CORT, que al unirse con los receptores a mineralocorticoides 0 glucocorticoides podrían inducir cambios estructurales durante la consolidación de la memoria; mientras que en la etapa de la evocación de la memoria de la tarea de EI no se detectó aumento en la liberación de CORT. Esto sugiere que los posibles cambios estructurales producidos en esta etapa son independientes de la activación de los receptores a glucocorticoides 0 a mineralocorticoides. Agradecemos la asistencia técnica de Norma Serafín, Bernardino Osorio, Alejandra Castilla, Lourdes Lara y Alberto Lara. Trabajo auspiciado por PAPIIT (IN203918). 


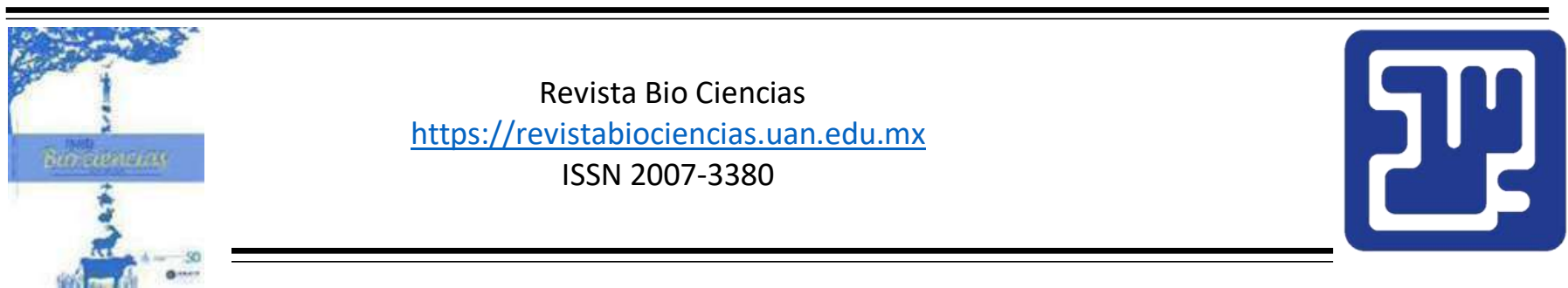

Trabajos libres: Neurociencias

Modalidad de Presentación: cartel

\begin{abstract}
El metilfenidato normaliza los niveles de expresión de enzimas de la biosíntesis de pantotenato y CoA aumentados por la PAE en el NAcc de ratas Wistar
\end{abstract}

\author{
Juárez Rodríguez, P. ${ }^{1}$, Guzmán Brambila, C. ${ }^{2}$, Yañez Esparza, $A .{ }^{1}$, Godínez Rubí, J. M. ${ }^{1}$, Orozco \\ Barocio, A. ${ }^{1}$, Ortuño Sahagún, D. ${ }^{1}$, Rojas Mayorquín, A. E. ${ }^{1 *}$ \\ ${ }^{1}$ Universidad de Guadalajara \\ ${ }^{2}$ Tecnologico de Monterrey
}

*Autor Corresponsal: Argelia Esperanza Rojas Mayorquín. E- mail:

argelia.rojas@academicos.udg.mx

El metilfenidato (MPH) es un psicoestimulante cuyos efectos a largo plazo en el cerebro son aún objeto de discusión, no obstante, es el medicamente más frecuentemente prescrito para el tratamiento del trastorno por déficit de atención e hiperactividad (TDAH), el cual presenta cierto paralelismo con la exposición prenatal al alcohol (PAE). El principal órgano blanco del alcohol es el cerebro, y el núcleo accumbens (NAcc) es una región particularmente vulnerable. Las cinasas de pantotenato producen las reacciones bioquímicas necesarias para la biosíntesis de Coenzima $A(\mathrm{Co} A)$, cofactor esencial en el funcionamiento y metabolismo del sistema nervioso. El presente trabajo buscó determinar los niveles de expresión génica de tres enzimas involucradas en la biosíntesis del pantotenato y $\mathrm{CoA}$ en el NAcc luego del tratamiento con MPH en ratas con PAE. Se administró alcohol o solución isocalórica por vía intragástrica a ratas Wistar hembras preñadas (8-20 DEG). Las crías macho recibieron MPH o solución vehículo (26-38 DEP). Se disecó el NAcc de cada rata, se obtuvo el RNA total para su retro-transcripción y amplificación por qPCR, finalmente se realizó un análisis de expresión relativa con el método de comparación de $\triangle \triangle C T$. En el NAcc, los mRNA de Pank4, Coasy y Pank1 aumentaron su expresión por la PAE, mientras que el MPH redujo su expresión hasta niveles basales. Alteraciones en la biosíntesis de la CoA se han asociado con neurodegeneración y trastornos psiquiátricos. La desregulación de estos genes ha sido reportada en el trastorno por uso de alcohol, pero no en PAE. El MPH podría funcionar como un regulador de trastornos psiquiátricos y probablemente neurodegenerativos por esta vía. metilfenidato normaliza los niveles de expresión de enzimas de la biosíntesis de pantotenato y CoA aumentados por la PAE en el NAcc de ratas Wistar. Revista Bio Ciencias 7: (Suppl) Memorias de Congreso. LXIII Congreso Nacional de la Sociedad Mexicana de Ciencias Fisiologicas, A. C. e1097. http://doi.org/10.15741/revbio.07Suppl.e1097 


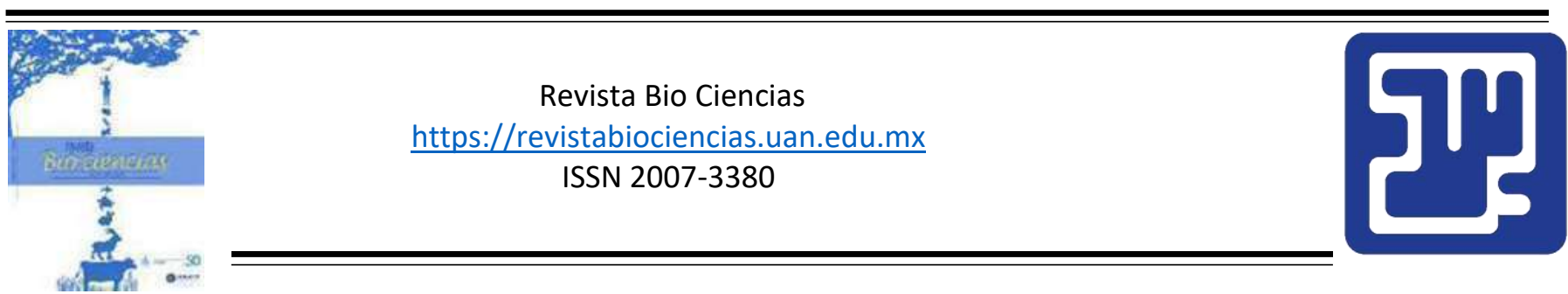

Trabajos libres: Neurociencias

Modalidad de Presentación: Oral

\section{Actividad EEG relacionada a las diferentes fases de la toma de decisiones en hombres jóvenes}

Cortes Esparza, P. M., García Hernández, J. P., Sotelo Tapia, C., Guevara Pérez, M. A., Hernández González, M. *

Instituto De Neurociencias, CUCBA, Universidad De Guadalajara

*Autor Corresponsal: Marisela Hernández González. E- mail:

marisela.hgonzalez@academicos.udg.mx

La toma de decisiones (TD) permite adaptarnos a las contingencias del medio ambiente mediante la modificación de la conducta. Se ha propuesto dividir este proceso en 3 fases temporalmente distintas: 1) formación de preferencias, 2) selección y ejecución de la acción, 3) evaluación del resultado. Sin embargo, a la fecha ha sido difícil analizar cada una de estas fases por separado. Dado lo anterior, diseñamos una tarea que permita, conductualmente, separar cada una de las 3 fases de la TD además de evaluar la adaptación conductual que se da en torno a la experiencia. En este trabajo se caracterizó la actividad electroencefalográfica (EEG) durante cada una de las fases y, además, se reportan los cambios conductuales conforme progresan los ensayos de la tarea. Participaron hombres jóvenes a los cuales se les registró la actividad EEG de las cortezas frontopolar, dorsolateral, parietal y temporal durante las 3 fases de la tarea de TD. Se analizó la ejecución conductual y la potencia absoluta (PA) de la actividad EEG. Se observó que conforme progresaban los ensayos, los participantes presentaron respuestas más rápidas y acumulaban más puntos. Respecto a la actividad EEG, las fases 1 y 3 presentaron una mayor PA en bandas rápidas en cortezas dorsolateral y parietal. La fase 2 mostró una mayor PA de la banda theta en áreas posteriores. El patrón de activación cortical de las fases 1 y 3 pudiera estar relacionado con componentes atencionales necesarios para la evaluación de los estímulos y el resultado obtenido. La actividad en la fase 2 podría asociarse al procesamiento de la información, al estado motivacional y/o al plan de respuesta motor del individuo. Estos resultados muestran que la tarea es útil para analizar los cambios conductuales relacionados con la experiencia y el funcionamiento cortical durante las fases de la toma de decisiones.

Cite this paper/Como citar este artículo: Cortes Esparza, P. M., García Hernández, J. P., Sotelo Tapia, C., Guevara Pérez, M. A., Hernández González, M. (2020). Actividad EEG relacionada a las diferentes fases de la toma de decisiones en hombres jóvenes. Revista Bio Ciencias 7: (Suppl) Memorias de Congreso. LXIII Congreso Nacional de la Sociedad Mexicana de Ciencias Fisiologicas, A. C. e1097. http://doi.org/10.15741/revbio.07Suppl.e1097 


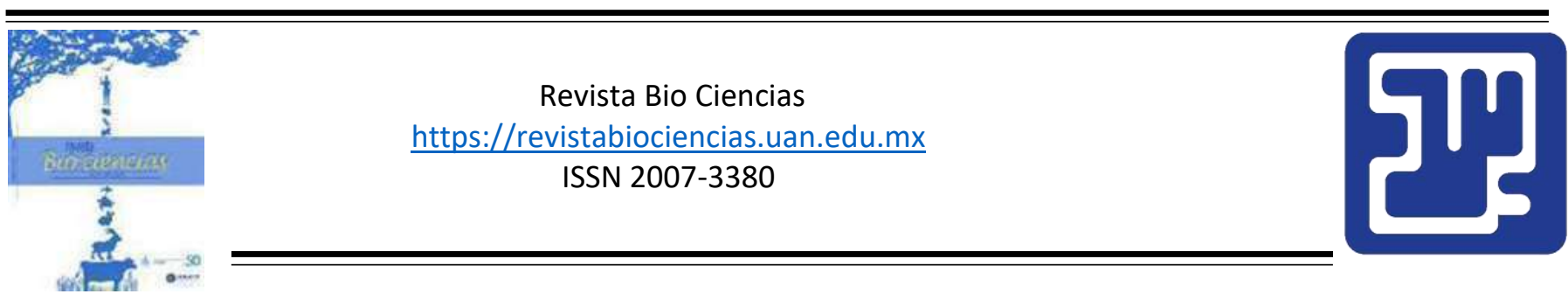

Trabajos libres: Neurociencias

Modalidad de Presentación: Cartel

\title{
Evaluación farmacológica del papel de receptores purinérgicos tipo P2X2/3 en una prueba de reconocimiento de objeto novedoso en ratas hembra
}

\author{
Lopez Dorantes, S, J., Palacios Galicia, J. L, Robles Aguirre, F. A., Muñoz Toscano, A. * \\ Centro Universitario Del Norte, Universidad De Guadalajara
}

*Autor Corresponsal: Alvaro Munoz Toscano.E-mail: alvaro.munoz@cunorte.udg.mx

Los receptores purinérgicos tipo $\mathrm{P} 2 \mathrm{X} 2 / 3$ (P2X2/3R) juegan un papel esencial en la interpretación de estímulos sensoriales. Sin embargo, investigaciones sobre el papel de P2X2/3R en tareas de aprendizaje son escasos. Utilizamos AF-353, un antagonista especifico a P2X2/3R, para determinar el papel de los receptores en una Prueba de Reconocimiento a Objeto Novedoso (PRON) en ratas hembra Wistar (12-16 semanas de edad; $\mathrm{N}=6$ ). Utilizando una arena de $60 \times 90 \mathrm{~cm}$, la actividad exploratoria fue video-grabada durante una fase de habituación (10 minutos), una etapa de entrenamiento (5 minutos con dos objetos idénticos) y una fase de PRON (5 minutos, un objeto familiar sustituido por un objeto novedoso) cada 30 minutos. Las ratas fueron inyectadas i.p. con vehículo $(0.2 \%$ DMSO/salina) o AF-353 (10 mg/kg) antes de las PRON. El antagonista se inyectó una semana después del vehículo en los mismos animales. Los efectos sensoriales del vehículo y antagonista fueron corroborados con filamentos de Von-Frey. El umbral de retirada
Von-Frey fue significativamente mayor al final de la PRON en ratas tratadas con AF-353 en comparación con vehículo $(34.8+7$ vs $107.9+17 \mathrm{gr} ; \mathrm{p}<0.001)$. El índice de actividad durante la fase de habituación fue similar en ambas condiciones $(p>0.05)$. Durante el entrenamiento, las ratas pasan tiempos similares observando objetos idénticos independientemente de condiciones vehículo $(27+10 s)$ o antagonista $(27.5+5 s ; p>0.05)$. Durante la PRON, las ratas exploraron al objeto familiar por $15.4+7 \mathrm{~s}$ y al novedoso por $31.4+8 \mathrm{~s}$ en condiciones control $(p=0.032)$. Al ser tratadas con el antagonista el tiempo fue $17.3+7 \mathrm{~s}$ explorando el objeto familiar y $45.5+4 \mathrm{~s}$ al novedoso $(\mathrm{p}<0.001)$. Estos resultados sugieren que los $\mathrm{P} 2 \mathrm{X} 2 / 3 \mathrm{R}$, además de ser importantes para la transmisión sensorial, podrían jugar un papel relevante en procesos de memoria en roedores. La inhibición de P2X2/3R con AF-353 podría despolarizar neuronas cerebrales implicadas en aprendizaje, facilitando la generación de potenciales de acción.

Cite this paper/Como citar este artículo: Lopez Dorantes, S, J., Palacios Galicia, J. L, Robles Aguirre, F. A., Muñoz Toscano, A. (2020). Evaluación farmacológica del papel de receptores purinérgicos tipo $\mathrm{P} 2 \mathrm{X} 2 / 3$ en una prueba de reconocimiento de objeto novedoso en ratas hembra. Revista Bio Ciencias 7: (Suppl) Memorias de Congreso. LXIII Congreso Nacional de la Sociedad Mexicana de Ciencias Fisiologicas, A. C. e1097. http://doi.org/10.15741/revbio.07Suppl.e1097 


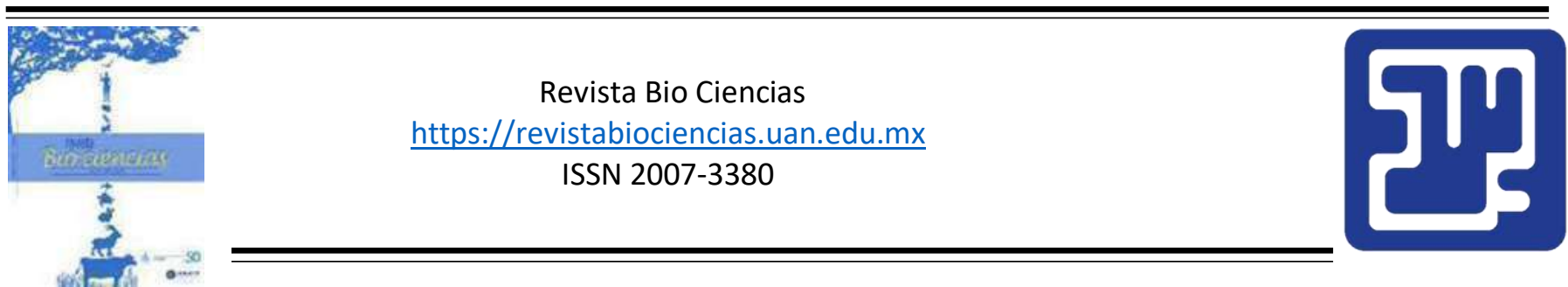

Trabajos libres: Neurociencias

Modalidad de Presentación: Cartel

\title{
Efectos de la lesión medular sobre la expresión de c-Fos en el cerebelo de ratas
}

\author{
Lara Aparicio, S. Y, Beltrán Parrazal, L., Toledo Cárdenas, M. R., Aranda Abreu, G. E., Manzo \\ Denes, J., Pérez Estudillo, C. A.* \\ Universidad Veracruzana
}

*Autor Corresponsal: César Antonio Pérez Estudillo. E- mail: cesperez@uv.mx

La lesión de la médula espinal (LME) propicia pérdida total o parcial de información sensorial, motora y autonómica. Investigaciones previas muestran que la LME no sólo afecta la locomoción, sino también la función de algunos núcleos del hipotálamo y del tallo cerebral. Asimismo, se ha demostrado que la LME modifica la actividad del cerebelo en lóbulos del vermis y del núcleo medial en ratas; sin embargo, se desconoce si también se afecta la actividad neuronal en los hemisferios del cerebelo. En el presente estudio se investigó si la actividad celular de los hemisferios cerebelares de la rata es modificada 6 y 24 horas posteriores a la LME completa transversal. Se utilizaron ratas macho adultas Wistar (300-400 g) divididas en tres grupos: intactas, sham y con LME (nivel T8). Después de la manipulación experimental se evaluó la locomoción con la escala Tarlov/Bohlman (T/B) y los hemisferios del cerebelo fueron procesados para realizar inmunocitoquímica para c-Fos. Los resultados de la escala T/B mostraron grado 0 para el grupo LME y 4 para los grupos sham e intactas. Veinticuatro horas después de la lesión, la expresión de c-Fos del grupo de LME aumentó significativamente en los 13 lóbulos de la capa granular y en 10 de los 13 lóbulos de la capa de Purkinje; así como en los dos núcleos laterales. Seis horas después de la LME también aumentó la expresión de Fos en algunos lóbulos analizados, pero no en los núcleos laterales. Los efectos fueron más sorprendentes que lo reportado en el vermis. Se sugiere que estos cambios en la expresión de c-Fos en el cerebelo después de la LME es por la afectación de las vías espinocerebelosas y de otras originadas del tallo cerebral, así como por los procesos bioquímicos del daño primario y secundario que ocurren después del daño espinal.

Cite this paper/Como citar este artículo: Lara Aparicio, S. Y, Beltrán Parrazal, L., Toledo Cárdenas, M. R., Aranda Abreu, G. E., Manzo Denes, J., Pérez Estudillo, C. A. (2020). Efectos de la lesión medular sobre la expresión de c-Fos en el cerebelo de ratas.Revista Bio Ciencias 7: (Suppl) Memorias de Congreso. LXIII Congreso Nacional de la Sociedad Mexicana de Ciencias Fisiologicas, A. C. e1097. http://doi.org/10.15741/revbio.07Suppl.e1097 


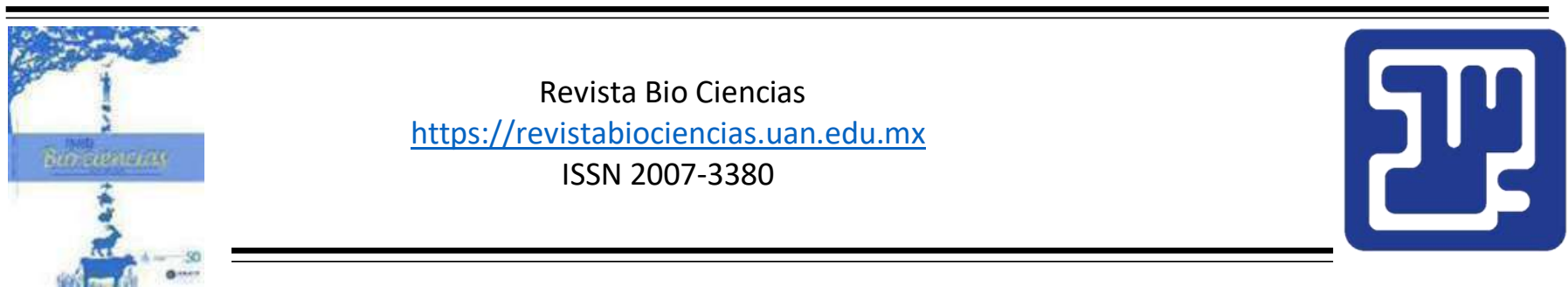

Trabajos libres: Neurociencias

Modalidad de Presentación: Oral

Efectos del hipotiroidismo sobre la neurogénesis inducida por convulsiones en ratas adultas

\author{
Mendoza Nicolás, S., Pacheco Rosado, J. * \\ Instituto Politécnico Nacional \\ *Autor Corresponsal: Jorge Pacheco Rosado. E- mail:jprosado@hotmail.com
}

Las hormonas tiroideas $(\mathrm{HT})$ intervienen de forma crítica en el desarrollo del sistema nervioso central. El hipotiroidismo ocasiona defectos de mielinización, migración y diferenciación neuronal, que originan alteraciones neurológicas irreversibles. Se ha observado que la deficiencia de HT en animales adultos prolonga las convulsiones y aumenta la susceptibilidad al kindling químico. También se ha demostrado que la neurogénesis aumenta en el hipocampo por efecto de las convulsiones, sin embargo, se desconoce si la neurogenesis provocada durante las convulsiones es mayor en las ratas hipotiroideas. El objetivo de este trabajo fue determinar si el estado hipotiroideo de las ratas modifica el número de células proliferantes en el hipocampo después de la administración crónica de pentilenotetrazol (PTZ). Se utilizaron ratas macho de la cepa Wistar $(n=15)$, que se dividieron en 2 grupos: control e hipotiroideo, empleando el metimazol $(60 \mathrm{mg} / \mathrm{kg})$ como fármaco antitiroideo. A lo largo del tratamiento antitioideo se evaluó el peso corporal y la temperatura colonal. Adicionalmente se determinó la concentración sérica de las hormonas T3 y T4 basales y al final del tratamiento mediante un ensayo ELISA. Para la inducción de convulsiones se administró PTZ cada tercer día (kindling químico) hasta conseguir dos convulsiones generalizadas. Los animales se sacrificaron una semana posterior a la última administración de PTZ por anestesia profunda y perfusión intracardiaca de solución salina y paraformaldehído. Se obtuvieron cortes coronales del hipocampo para identificar la proliferación celular por la presencia de la proteína Ki67 por inmunohistoquímica. Se observó que en el hilus del hipocampo la proliferación es mayor en las ratas hipotiroideas, mientras que en la zona subgranular no hay diferencia entre los dos grupos estudiados. Nuestros datos sugieren que la deficiencia de hormonas tiroideas favorece la neurogénesis hipocampal inducida por las convulsiones, lo que podría relacionarse con el aumento de la susceptibilidad a convulsiones. 


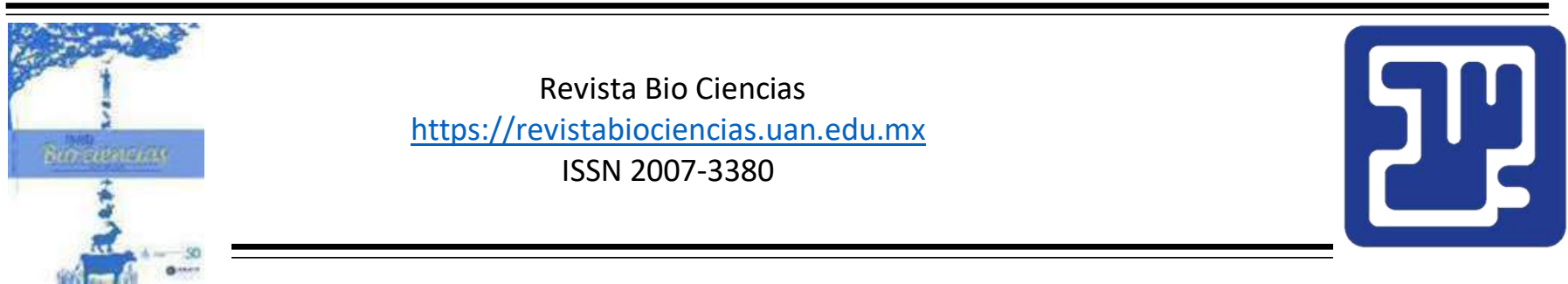

Trabajos libres: Neurociencias

Modalidad de Presentación: Oral

\title{
Epigenetic changes elicited by Maternal High Fat diet in offspring and the protective effect of Resveratrol enriched diet
}

\author{
Izquierdo Cadenas, V. ${ }^{1}$, Palomera Avalos, V. ${ }^{2}$, Griñán Ferré, $C .{ }^{1}$, Pallàs Lliberia, M. ${ }^{1 *}$ \\ 1 Universitat De Barcelona \\ ${ }^{2}$ Universidad De Guadalajara
}

*Autor Corresponsal: Merce Pallàs Lliberia. E- mail: pallas@ub.edu

Nowadays, the number of older people is increasing in parallel to the diagnosis of neurodegenerative diseases (ND). Aging is the main factor associated with ND, as Alzheimer's disease but genetic and environmental factors, such as lifestyle or diet are also implicated. However, the mechanisms by which diet modulate epigenetic inheritance are not fully understood. Resveratrol (RV) is a polyphenol with multiple beneficial properties and modulates epigenetic mechanisms. The aim of this study was to investigate the effect of maternal high fat diet (MHFD) vs. maternal control diet (MCD) and the effect RV enriched Diets (MRVD) in Senescence-accelerated mouse prone 8 (SAMP8) inheritance evaluating the epigenetic changes across generations. We found a cognitive improvement in MRVD offspring in reference to MCD and to MHFD mice evaluated by Novel Object Recognition Test. Changes in Global
DNA methylation levels and Tet1 and Tet2 gene expression were determined in hippocampus of MRVD offspring. Moreover, there were changes in histone H3K9 demethylated and $\mathrm{H} 2 . \mathrm{X}$ phosphorylated protein levels by MRVD and histone enzymes (Ehmt2 and Hdac2) gene expression in reference to HFD mothers fed group. Finally, we found significant changes in miRNAs expression levels (mmu-miR-181a, mmu-miR140-5p, mmu-miR-101b-3p, mmu-miR-98-3p and mmu-miR-106b-5p) and its target genes in offspring of MRVD mice. In conclusion, we found epigenetic changes in HFD+MRVD and a rescue of damage by HFD across generations in SAMP8. In addition, RV showed an important role in the early prevention of ND in adult offspring. ACKNOWLEDGEMENTS: PID2019106285RB (MINECO, FEDER); 2017SGR106 (AGAUR, Catalonia). University of Barcelona Predoctoral fellowship (APIF) to VI. 


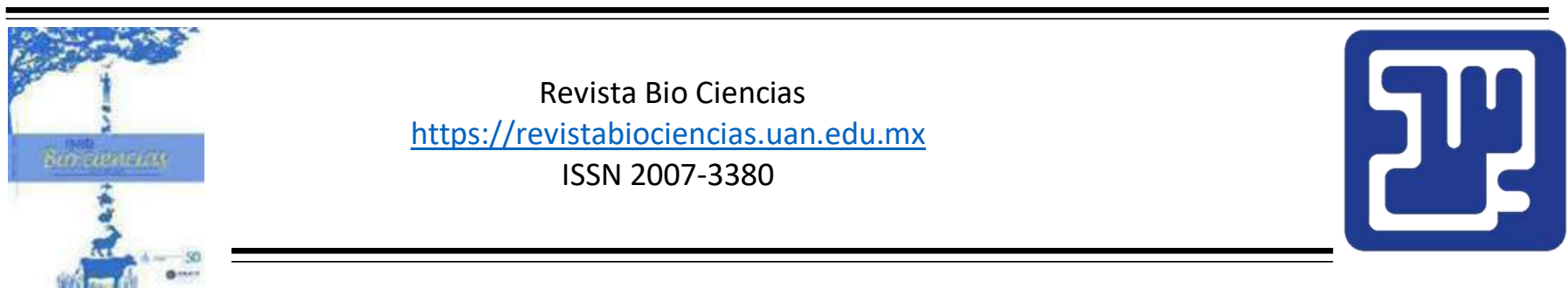

Trabajos libres: Neurociencias

Modalidad de Presentación: Oral

Efecto del estado post-epiléptico sobre la proliferación de las células precursoras y progenitoras
del hilus

García Martínez, Y. ${ }^{1}$, Sánchez Huerta, K. B. ${ }^{2}$, Pacheco Rosado, J. ${ }^{1 *}$

${ }^{1}$ Escuela Nacional de Ciencias Biológicas IPN

${ }^{2}$ Instituto Nacional de Pediatría

*Autor Corresponsal: Jorge Pacheco Rosado. E- mail: jprosado@hotmail.com

La epilepsia del lóbulo temporal (ELT) es la forma más común de epilepsia de origen focal. En modelos animales el desarrollo de la ELT consta de cuatro etapas: evento precipitante, estado epiléptico (EE), periodo de latencia y establecimiento de la epilepsia. EI EE se define como una crisis de duración prolongada o una serie de crisis sin recuperación de conciencia. Se ha reportado que el EE produce cambios morfológicos en el hipocampo que dan paso al establecimiento de la ELT, como lo es el incremento de la formación de nuevas neuronas. El hilus del hipocampo, que posee células mitóticamente activas como son las células precursoras (CP), células progenitoras de oligodendrocitos (CPO) y de neuronas (CPN), es una región poco estudiada en relación con su participación en la epilepsia. El objetivo de este trabajo fue evaluar el efecto del EE a corto y largo plazo sobre las células precursoras y CPN del hilus en el modelo litiopilocarpina. Se usaron ratas macho (Wistar), a las que se le indujo el EE con litio-pilocarpina, se sometieron a eutanasia en diferentes tiempos (1, 3 y 28 días después del EE). Se usaron marcadores específicos (Ki67, SOX2 y DCX) para identificar a las células proliferantes, precursoras y CPN. Los resultados muestran que la proliferación celular (Ki67+) del hilus aumenta en el día uno y tres después de la inducción del EE. La población de CP (Ki67+/SOX2+) aumenta el día tres, mientras que la población de CPN (Ki67+/DCX+) aumenta hasta el día 28 posterior al EE. Nuestros resultados sugieren que la neurogénesis en el hilus del hipocampo provocada por inducción de EE no es inmediata, por lo que puede ser parte del proceso de epileptogénesis. 


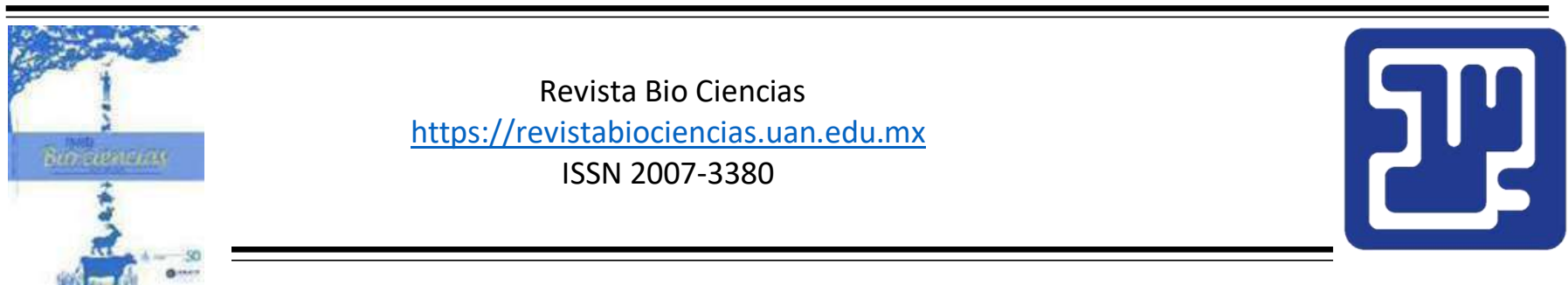

Trabajos libres: Neurociencias

Modalidad de Presentación: Oral

\title{
Caracterización de la información aferente de nervios lumbosacros en raíces dorsales de la médula espinal en la coneja doméstica
}

\author{
Flores Lozada, Z. ${ }^{1}$, Martínez Gómez, M. ${ }^{2}$, Jiménez Estrada, I. ${ }^{3}$, Zempoalteca Ramírez, R. ${ }^{1}$, Corona \\ Quintanilla, D. L. ${ }^{*}$ \\ ${ }^{1}$ Centro Tlaxcala de Biología de la Conducta \\ 2 Universidad Autonoma de Mexico \\ ${ }^{3}$ Centro de Investigación y de Estudios Avanzados
}

*Autor Corresponsal: Dora Luz Corona Quintanilla. E- mail: luzquintanilla2422@gmail.com

Se estima que a nivel mundial existen 2.5 millones de personas viven con alguna lesión en la médula espinal. Las lesiones medulares son causadas durante accidentes viales, caídas severas y/o enfermedades neurodegenerativas. Estas lesiones comprimen, estiran o rompen (avulsionan) las raíces de la médula espinal provocando disfunciones sensoriales, motoras y autonómicas. La avulsión de raíz ventral (ARV) ocurre comúnmente, a nivel lumbosacro (L6-S2), en estos segmentos se integran reflejos somáticos y viscerales, que regulan funciones de locomoción y postura, hasta del aparato urogenital inferior $y$ musculatura del piso pélvico-perineal. Etudios, previos han determinado la escasa sobrevivencia de motoneuronas. Pero, hace falta determinar si después de la ARV las vías aferentes lumbosacras se reorganizan; una forma de determinarlo es, a través, de técnicas electrofisiológicas, como es el registro de potenciales de raíz dorsal (DRP, por sus siglas en inglés). Un primer acercamiento fue caracterizar la información aferente de la región lumbosacra durante la electroestimulación de cinco nervios lumbosacros en conejas intactas. Para ello, se utilizaron 4 conejas vírgenes de la raza Chinchilla. Fueron anestesiadas con uretano al $20 \%$ y colocadas en posición dorsal para realizarles una laminectomía desde el segmento L5 hasta S3 y así descubrir la médula espinal. Después, se hizo una incisión longitudinal en la duramadre para exponer las raíces dorsales. Una de las raíces se colocó en un electrodo de plata para registrar los DRP. De la pata izquierda se identificaron 5 nervios, a cada uno se le aplicaron estímulos eléctricos. Los resultados obtenidos muestran que a nivel S1, para el nervio ciático, existe una mayor amplitud y cantidad de componentes (4 a 5); para el nervio pudendo disminuye el número de componentes, mostrando registros de sólo una dos ondas. Financiamiento: 1001233 (ZFL), 256990 (CBCQDL). 


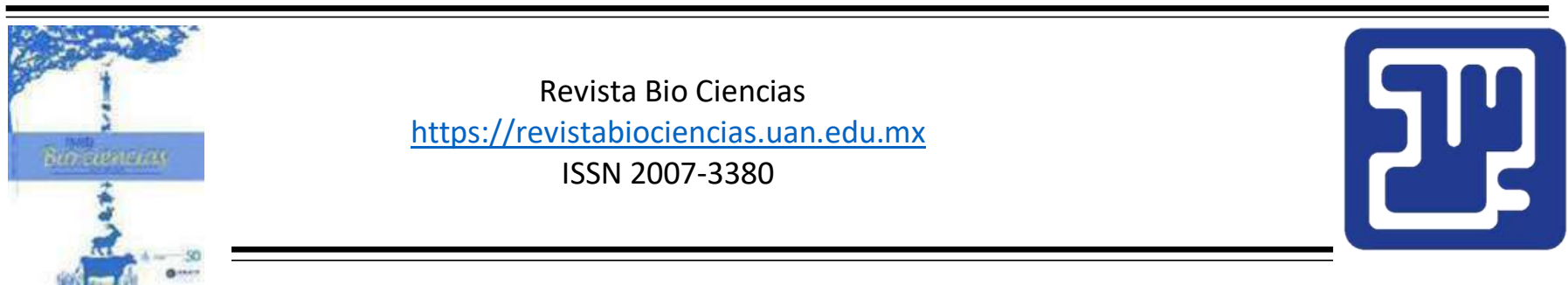

Trabajos libres: Neurociencias

Modalidad de Presentación: Oral

\section{Actividad electroencefalográfica en mujeres jóvenes durante la lectura de un texto erótico con y sin contenido agresivo}

Amezcua Gutiérrez. C. C. *, Hernández González, M., Hernández Arteaga, E.,

Guevara Pérez, M. A.

Centro Universitario de Ciencias Biológicas y Agropecuarias (CUCBA), Universidad de Guadalajara

*Autor Corresponsal: Claudia del Carmen Amezcua Gutiérrez. E- mail:

delcarmen.amezcua@academicos.udg.mx

La activación sexual (AS) es una experiencia determinante para una respuesta sexual óptima del individuo. A nivel experimental, se han utilizado diversos estímulos (audiocintas, música, videos, fotos y textos con contenido erótico) para generar un estado de AS. Frecuentemente, los textos eróticos incluyen un contenido agresivo que no ha sido evaluado en relación con la AS. El objetivo de este trabajo fue comparar la funcionalidad cortical mediante el registro de la actividad electroencefalográfica (EEG) en mujeres jóvenes ante la lectura de un texto sexualmente explicito (TSE) y un texto sexualmente explícito con agresión (TSEA). Participaron 27 mujeres de entre 20 y 30 años, sanas, diestras, con niveles promedio de lectura, a las cuales se registró la actividad EEG de zonas frontales, temporales $y$ parietales durante la lectura de ambos textos. Las participantes evaluaron el TSE como agradable en comparación con el TSEA. Ambos textos fueron calificados como generadores de activación general y de activación sexual. Durante la lectura del TSEA, se observó una mayor potencia absoluta (PA) de las bandas alfa1, alfa2 y beta 1 en áreas frontales, de theta, alfa1, alfa2 y beta1 en parietal izquierdo, así como de alfa1, alfa2, beta1 y gamma en parietal derecho respecto al TSE. En relación al grado de acoplamiento EEG, durante la lectura del TSEA las participantes presentaron una mayor correlación interhemisférica entre frontales (F3 y F4) en delta, y alfa1 y una mayor correlación intrahemisférica frontotemporal izquierda en alfa2 y beta 1 . Estos datos muestran que la funcionalidad cortical durante un estado de activación sexual en mujeres, varía dependiendo del tipo de contenido y contexto de la lectura erótica. Los resultados de este estudio amplían nuestro conocimiento acerca de los mecanismos corticales subyacentes al procesamiento $y$ asignación de valor incentivo de estímulos con connotación sexual y agresiva en mujeres jóvenes. 


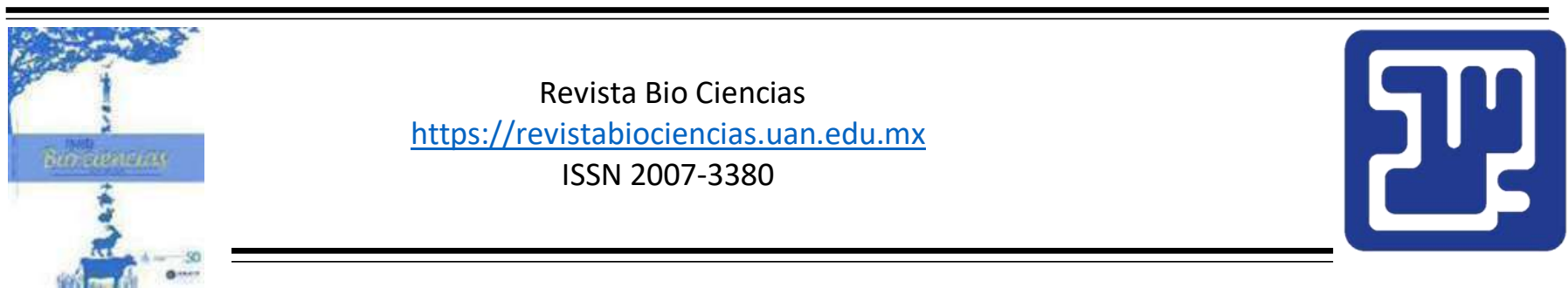

Trabajos libres: Neurociencias

Modalidad de Presentación: Oral

\title{
Efecto de la ovariectomía a largo plazo sobre la ansiedad y la expresión de Fos en el núcleo amigdalino basolateral de la rata Wistar
}

\author{
Flores González, A. ${ }^{1}$, Puga Olguín, A. ${ }^{2}$, Sobrino Flores, $C .{ }^{1}$, Rovirosa Hernández, M. J. ${ }^{1}$, Rodríguez \\ Landa, J. F. ${ }^{1 *}$ \\ ${ }^{1}$ Universidad Veracruzana \\ ${ }^{2}$ Instituto Interdisciplinario De Investigaciones de la Universidad de Xalapa
}

*Autor Corresponsal: Juan Francisco Rodríguez Landa. E- mail: juarodriguez@uv.mx

La menopausia natural o quirúrgica trae consigo la reducción de hormonas ováricas como el $17 \beta$-estradiol y la progesterona, entre otras. Lo anterior se ha asociado con la inducción de alteraciones fisiológicas, emocionales y afectivas. Particularmente en la menopausia quirúrgica, se ha observado una mayor severidad de los síntomas de ansiedad; puesto que la ausencia crónica de hormonas ováricas tiene la capacidad de ejercer cambios en la actividad y neuroquímica cerebral. Para estudiar esto a nivel preclínico se ha utilizado a la rata ovariectomizada como un modelo de menopausia quirúrgica, pero hasta el momento no se ha estudiado el efecto de esta a largo plazo sobre la ansiedad y su relación con cambios en la actividad neuronal. En este estudio se evaluó el efecto de la ovariectomía en la rata sobre la ansiedad y la expresión de la proteína Fos en la amígdala basolateral. Se incluyeron tres grupos de ratas ovariectomizadas y fueron evaluados a 3, 9, y 15 semanas postovariectomía, respectivamente. Los controles fueron un grupo en fase de proestro-estro y otro en fase de metaestro-diestro del ciclo estral. Los grupos fueron evaluados en la prueba de campo abierto (ansiedad) y al finalizar las pruebas se cuantificó la expresión de Fos mediante inmunohistoquímica en la amígdala basolateral. Los datos fueron analizados mediante ANOVA de una vía y post hoc de Student-Newman-Keuls. En la prueba de campo abierto, los grupos ovariectomizados tuvieron mayores indicadores de ansiedad respecto a los dos grupos control $(p<0.05)$, efectos que no fueron relacionados por alteraciones en la actividad locomotora. Los grupos ovariectomizados disminuyeron la expresión de Fos en la amígdala basolateral respecto a los controles $(p<0.001)$. Se concluye que la ovariectomía a largo plazo aumenta la ansiedad, lo cual se asocia con la disminución de la actividad neuronal de la amígdala basolateral. 


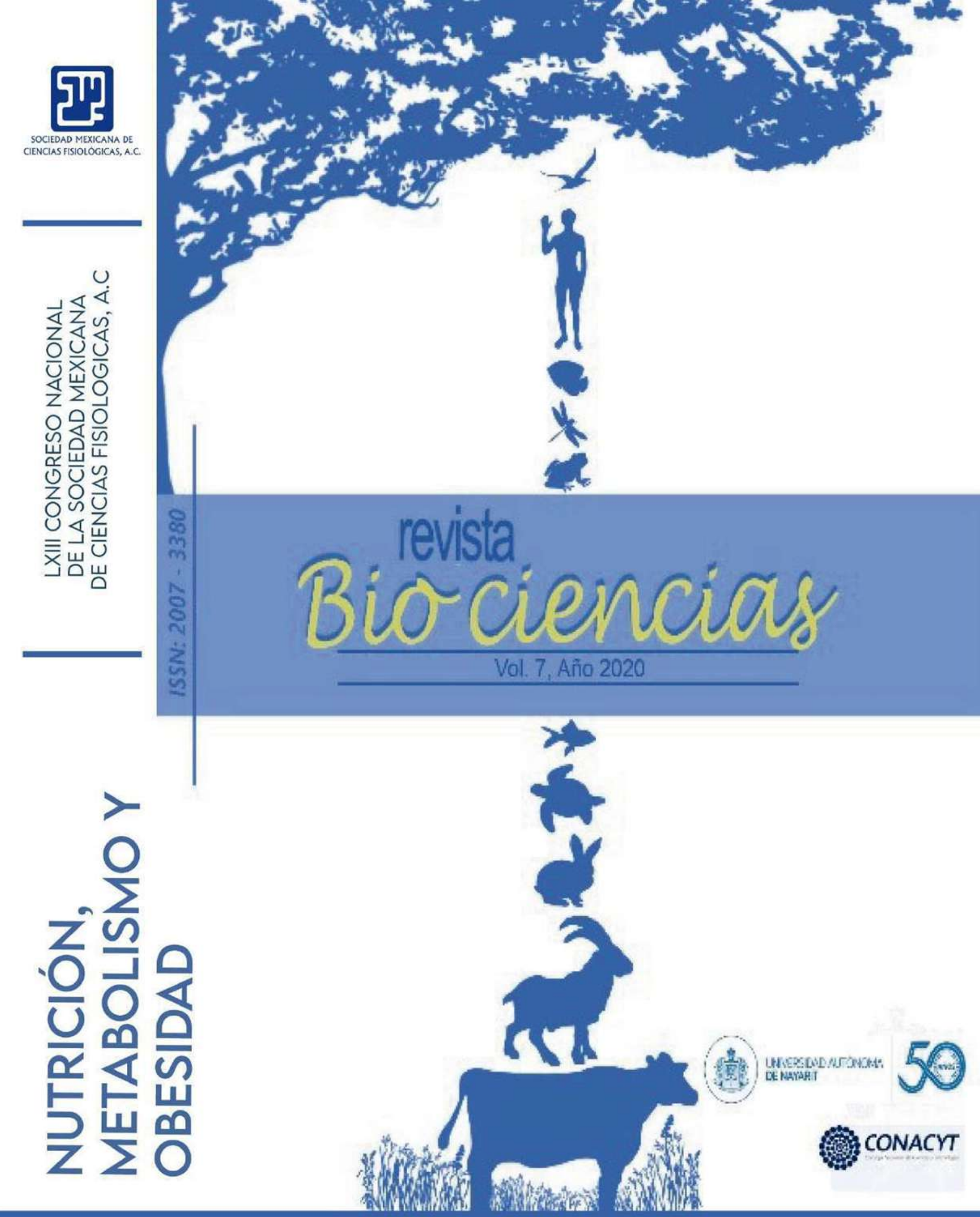

GUADALAJARA, JALISCO 13 AL 16 DE NOVIEMBRE 2020 CONGRESO ONLINE 


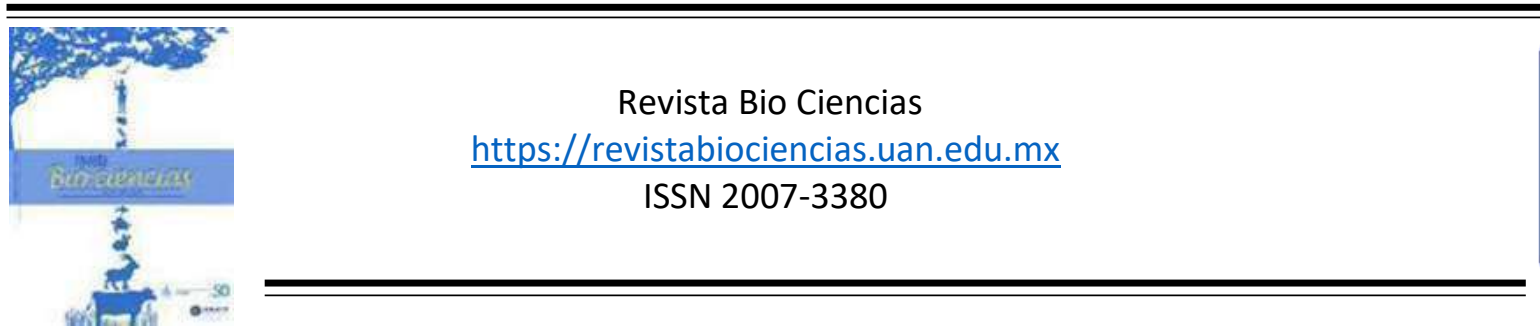

Trabajos libres: Nutrición, Metabolismo y Obesidad

Modalidad de Presentación: Cartel

\title{
Variabilidad en Frecuencia Cardiaca y Obesidad en Estudiantes Universitarias de Medicina Comunitaria en Teziutlán
}

\author{
Ita Amador, M. L. *, Rios Cano, S., Perez Romano, J. E., Méndez Martinez, E. \\ Benemerita Universidad Autonoma de Puebla. Facultad de Medicina \\ *Autor Corresponsal: Martha Lucia Ita Amador. E- mail: martha.ita@correo.buap.mx
}

Uno de los principales problemas en México es la obesidad. Con base en ENSANUT 2018 la prevalencia de obesidad y sobrepeso en el país, es del $75.2 \%$ en población mayor de 20 años. Existen factores obesigénicos como la falta de sueño, el estrés y ansiedad. Los estudiantes de medicina son sometidos continuamente a estilos de vida deficiente que contribuyen a incrementar la obesidad y con ello problemas cardiovasculares. El objetivo del trabajo fue relacionar la obesidad con el riesgo cardiovascular utilizando como biomarcador la variabilidad de frecuencia cardiaca en estudiantes de Medicina Comunitaria. Se analizaron 70 electrocardiogramas de mujeres estudiantes de Medicina General Comunitaria durante su primer año en el Complejo Regional Nororiental BUAP Teziutlán. Se evaluó la obesidad por antropometría utilizando el IMC e Índice Cadera Cintura. Se determinó la variabilidad de la Frecuencia Cardiaca midiendo los intervalos R-R. La población estuvo conformada por estudiantes de comunidades rurales de Teziutlán, con una edad promedio de 20 años. El 48\% presentan sobrepeso y obesidad con un IMC promedio de 27.8. Adicionalmente, el $63 \%$ tienen un riesgo cardiovascular en el rango moderado alto con base en su ICC. Los resultados muestran que la población estudiantil de zonas marginadas de Teziutlán modifica su variabilidad de frecuencia cardiaca en función del grado de obesidad, sugiriendo una alteración de la regulación del sistema nervioso autónomo. En conclusión, el grado de obesidad influye en la variabilidad de la frecuencia cardiaca en la población comunitaria femenina de estudiantes de medicina. 


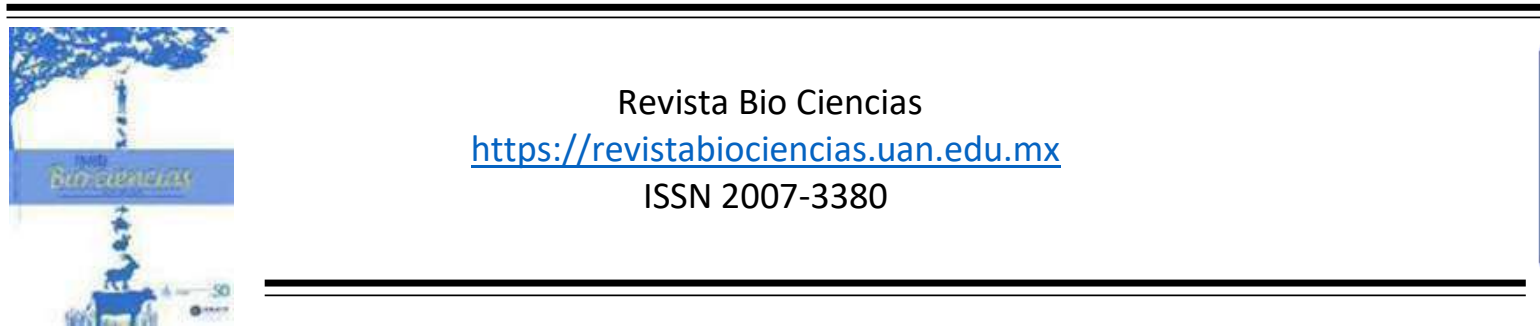

Trabajos libres: Nutrición, Metabolismo y Obesidad

Modalidad de Presentación: Oral

\title{
Efectos del extracto acuoso de Cnidoscolus chayamansa en ratas Wistar hembra bajo consumo crónico de jarabe de maíz alto en fructosa
}

\author{
Concepción López, A., Juárez Rojop, I. e., Baeza Flores, G. C., Guzmán Priego, G. G. * \\ Universidad Juarez Autonoma de Tabasco. Ciencias de la salud. \\ *Autor Corresponsal: Crystell Guadalupe Guzmán Priego. E- mail: crystell_guzman@hotmail.com
}

Las enfermedades no transmisibles, son un conjunto de patologías caracterizadas por ser prevenibles, de lenta progresión y larga duración, asociadas a diversos factores, como el sobrepeso y la obesidad que se definen como la acumulación excesiva de grasa en el cuerpo perjudicial para la salud. La ingesta de alimentos con alto contenido de azucares y carbohidratos se ha asociado con el incremento en la incidencia de sobrepeso y obesidad, principalmente aquellos que contienen jarabe de maíz alto en fructosa (JMAF). El alto consumo de fructosa se ha asociado con alteraciones metabólicas, como dislipidemia, hipertensión y resistencia a la insulina. La Cnidoscolus chayamansa se emplea como hipoglucemiante, hipolipemiante, antioxidante, antiinflamatorio y antibacteriano, así como cardioprotector y nefroprotector. El objetivo principal del presente estudio fue evaluar el efecto de un extracto acuoso de Cnidoscolus chayamansa sobre el peso y los niveles de glucosa, triglicéridos (TAG) y lipoproteínas de alta densidad (HDL), así como la actividad antinociceptiva en un modelo de síndrome metabólico inducido por ingesta crónica de jarabe de maíz alto en fructosa en ratas Wistar hembra. Se utilizaron ratas Wistar hembra (80-100g), el proceso experimental se dividió en tres fases: fase 1 o ingesta crónica de JMAF que duro 6 meses, fase 20 fase de tratamiento con el extracto acuoso de Cnidoscolus chayamansa durante 30 días y fase 3 o postratamiento, determinando peso y glucosa de forma semanal y niveles de TAG y HDL al término de cada fase experimental. Como resultado se encontró una disminución de los niveles de glucosa y HDL en las ratas con consumo de JMAF tratadas con el extracto acuoso de Cnidoscolus chayamansa, no se demostró efecto antinociceptivo del extracto acuoso. 


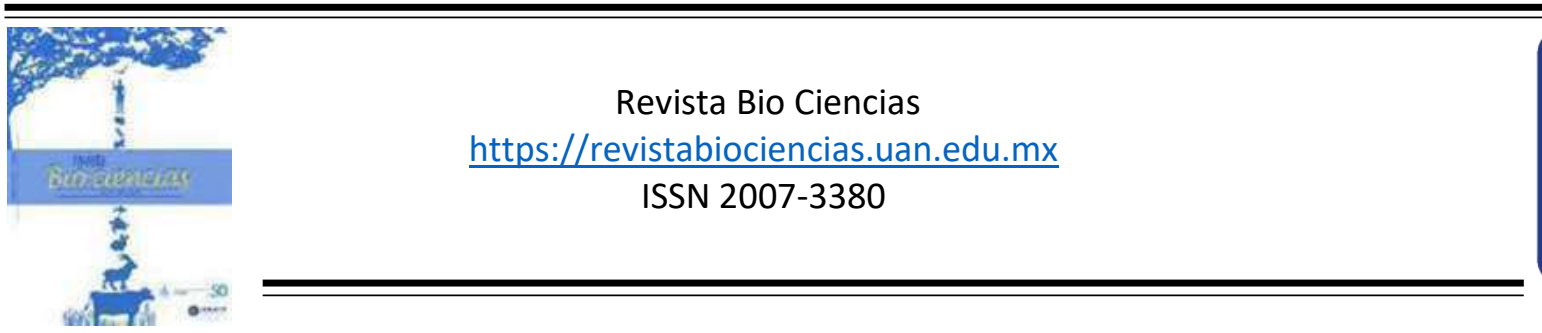

Trabajos libres: Nutrición, Metabolismo y Obesidad

Modalidad de Presentación: Cartel

\title{
Alteración de las variables cardiovasculares y de glucemia en adultos jóvenes con sobrepeso y obesidad de la UAEM
}

\author{
Cepeda Salazar, F. I. ${ }^{1}$, Hernández Alvarado, E. S. ${ }^{2}$, Cuellar Ramos, C. A. ${ }^{3}$, De Paz Garduño, I. A. ${ }^{1}$, \\ Trujillo Condes, V. E. ${ }^{1 *}$ \\ 1 Universidad Autónoma del Estado de México, Facultad de Medicina. ${ }^{2}$ Benemérita Universidad \\ Autónoma De Puebla, Instituto de Fisiología. ${ }^{3}$ Universidad Anáhuac México Centro de Investigación \\ en Ciencias de la Salud. \\ *Autor Corresponsal: Virgilio Eduardo Trujillo Condes. E- mail: eduardotc@msn.com
}

La obesidad representa uno de los problemas más graves de salud pública en México, ya que es un factor de riesgo asociado al desarrollo de enfermedades crónicodegenerativas desde edades tempranas. El objetivo de este estudio fue determinar la presencia de alteraciones de las variables cardiovasculares y de glucemia en estudiantes universitarios con exceso de peso. Se realizó un estudio observacional, correlacional, de corte transversal en una muestra de 115 alumnos (56 hombres y 59 mujeres), con una edad promedio 21 años \pm 0.2 años. A cada sujeto se le midió peso, talla, perímetro abdominal y se calculó el índice de masa corporal (IMC), así como mediciones de glucemia capilar en ayuno, presión arterial y frecuencia cardíaca. La muestra se analizó según dos variantes: presencia de obesidad central (perímetro abdominal $\geq 80 \mathrm{~cm}$ en mujeres $y \geq 90 \mathrm{~cm}$ en hombres); y exceso de peso por IMC (sobrepeso IMC $\geq 25$ a 29.9 $\mathrm{kg} / \mathrm{m} 2$ y obesidad IMC $\geq 30 \mathrm{~kg} / \mathrm{m} 2$ ). Los resultados indican que el $48.7 \%$ (56 sujetos, 19 hombres/ 37 mujeres) de la muestra estudiantil presenta obesidad central mientras que $35.7 \%$ (41 sujetos, 21 hombres/ 20 mujeres) tienen sobrepeso u obesidad por IMC. Se mostró aumento de la presión arterial sistémica tanto en sujetos con obesidad central $(p<0.01)$, como con obesidad por IMC $(p<0.001)$; así como en la frecuencia cardíaca ( $p<0.001$ y $p<0.001$, respectivamente). Además, la glucemia mostró un incremento significativo en los sujetos con obesidad central ( $p<0.01$ ) pero no en aquellos con obesidad por IMC. En conclusión, la presencia de exceso de peso, en especial en forma de obesidad central, se relacionó con alteración en los parámetros fisiológicos medidos en adultos jóvenes. Se requieren tomar medidas de intervención oportuna en población joven para disminuir los factores de riesgo que puedan desencadenar enfermedades crónicodegenerativas. 


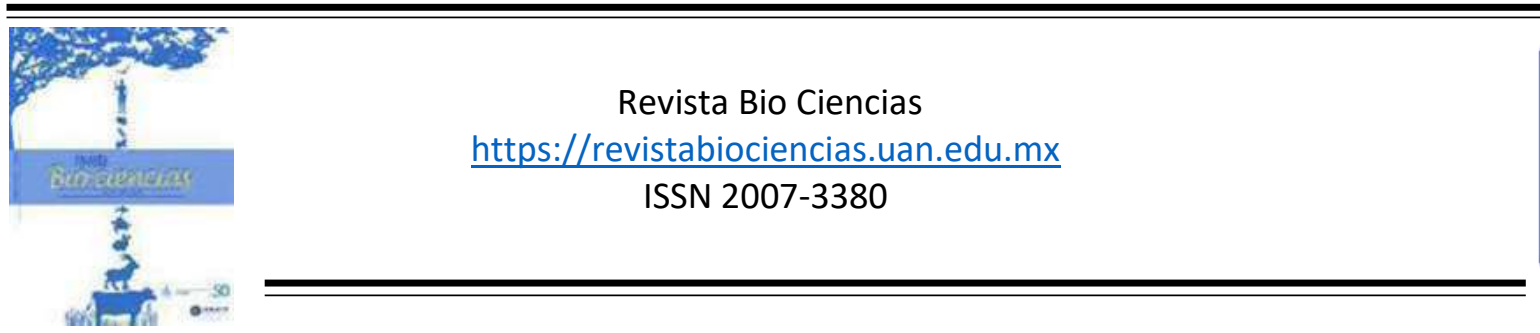

Trabajos libres: Nutrición, Metabolismo y Obesidad

Modalidad de Presentación: Cartel

\title{
Curso temporal del Sistema Renina Angiotensina en el desarrollo de Hipertensión en ratas obesas
}

\author{
Donjuán Loredo, C. E., Saderi, N., Salgado Delgado, R. C.* \\ Universidad Autónoma de San Luis Potosí. Facultad de Ciencias \\ *Autor Corresponsal: Roberto Carlos Salgado Delgado. E- mail: robertosalgado@yahoo.com
}

Aunque se sabe que la combinación de obesidad e hipertensión (HT) se asocian con incremento en la morbimortalidad, la naturaleza exacta de esta relación no es clara. Existen varios mecanismos probables: presión directa sobre el riñón por exceso de tejido adiposo (TA) abdominal, activación del sistema nervioso simpático (SNS) y sobreactivación del Sistema Renina Angiotensina (SRA). Algunos péptidos del SRA como AT2 y Ang1-7, ejercen propiedades antihipertensivas y sirven como contrapeso, modulando 0 incluso contrarrestando los efectos negativos de Angiotensina II (AnglI). Los resultados de la activación del SRA en el adiposo son controvertidos y nos generan una pregunta interesante: cómo la obesidad ocasionada por una dieta hipercalórica (DHC) resultaría en la regulación de la expresión relativamente selectiva del SRA en el TA favoreciendo el desarrollo de HT. En el presente trabajo reproducimos un modelo murino de obesidad causado por una DHC durante 12 semanas, analizando las alteraciones que se presentan durante el desarrollo de HT en diferentes tejidos. Con la hipótesis; que el consumo de una DHC, se asociará al desarrollo de HT debido a una progresiva activación del SRA local del TA, con un desbalance de los dos ejes antagónicos del SRA en el curso temporal de la enfermedad. Nuestros resultados muestran que los animales sometidos a DHC tienen exceso de TA abdominal e HT estadio 1 al final del protocolo. En tejido hepático y adiposo observamos un aumento en la expresión de Angiotensinógeno, en riñón el AT2 disminuye mientras que en adiposo el AT1 aumenta, justo cuando inicia la elevación de la PA, mostrando un claro desbalance entre los dos ejes del SRA durante el desarrollo de la HT. Los niveles séricos de Angll y 1-7 aumentan conforme se presenta la obesidad y la HT, lo que sugiere la participación del adipocito de manera directa. 


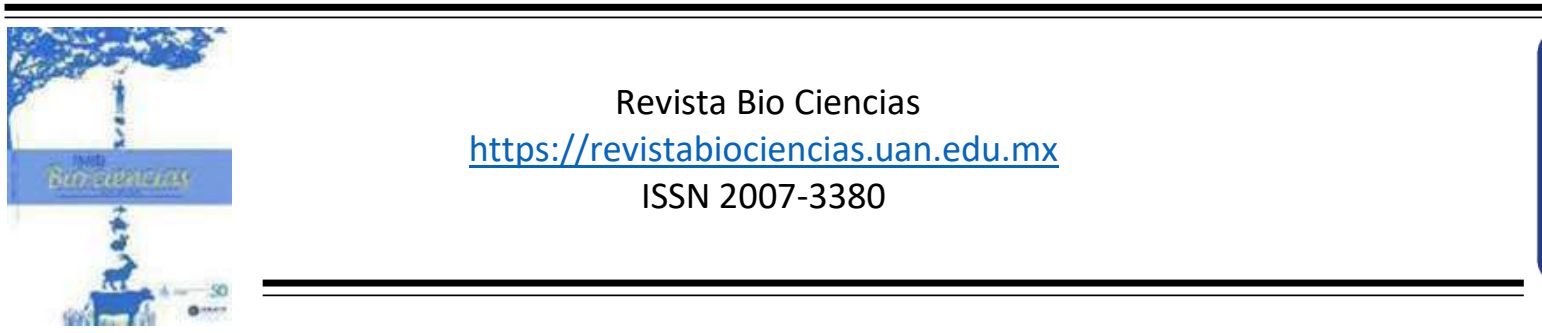

Trabajos libres: Nutrición, Metabolismo y Obesidad

Modalidad de Presentación: Cartel

\title{
Efecto de la insulina sobre el perfil inflamatorio y de inmunidad innata en la placenta humana en un modelo in vitro de diabetes mellitus gestacional
}

\author{
Jiménez Escutia, R., Ordoñez González, D., Flores Espinosa, M. P., Zaga Clavellina, V. C. Olmos \\ Ortiz, A. G. * \\ Instituto Nacional de Perinatología Isidro Espinosa de los Reyes, Departamento de \\ Inmunobioquímica \\ *Autor Corresponsal: Andrea Guadalupe Olmos Ortiz. E-mail: nut.aolmos@gmail.com
}

La diabetes mellitus gestacional (DMG) se correlaciona con el desarrollo de infecciones durante el embarazo, probablemente debido a la reducida síntesis de beta defensinas (HBDs). Además, se conoce bien que la hiperglucemia crónica induce la expresión de citocinas, adipocinas y quimiocinas que favorecen la respuesta inflamatoria local y sistémica. Sin embargo, hasta ahora no se ha evaluado el papel de la placenta como inmunomodulador de la gestación, particularmente ante el tratamiento con insulina que se indica en las pacientes con DMG. Objetivo: Evaluar el efecto de la insulina sobre el perfil inflamatorio y la síntesis de HBDs por la placenta humana en un modelo in vitro de hiperglucemia semejante el ambiente de DMG. Metodología: Se incubaron explantes placentarios durante $48 \mathrm{~h}$ en condiciones de normoglucemia $(10 \mathrm{mM})$, hiperglucemia $(25-50 \mathrm{mM})$ y en presencia de insulina (10, 50, 100, $500 \mathrm{nM})$. Se determinó por ELISA el perfil de secreción placentaria de citocinas, quimiocinas y adipocinas, así como la producción de HBDs intra-tejido.
Resultados: El modelo de hiperglucemia indujo significativamente el perfil inflamatorio (TNF-a, IL-1b, IL-6, CXCL-16 y leptina). El tratamiento con insulina $(500 \mathrm{nM})$ revirtió significativamente el efecto de la hiperglucemia sobre la secreción de estos marcadores, excepto IL-6. Ni la hiperglucemia ni el tratamiento con insulina modificaron el perfil de secreción de IL-8, quimerina, adiponectina, FABP4 0 visfatina. La hiperglucemia disminuyó significativamente la síntesis placentaria de HBD-1, HBD-2, HBD-3 y HBD-4. La presencia de insulina no modificó la producción de estos péptidos. Conclusiones: El tratamiento con insulina fue útil para atenuar el perfil inflamatorio asociado a la respuesta hiperglucémica de la DMG. Sin embargo, la insulina no restauró la producción de HBDs tras la hiperglucemia. Estos resultados experimentales contribuyen en el esclarecimiento de las propiedades inmunomoduladoras que ejerce la insulina en la unidad materno-fetal durante el desarrollo de la DMG. 


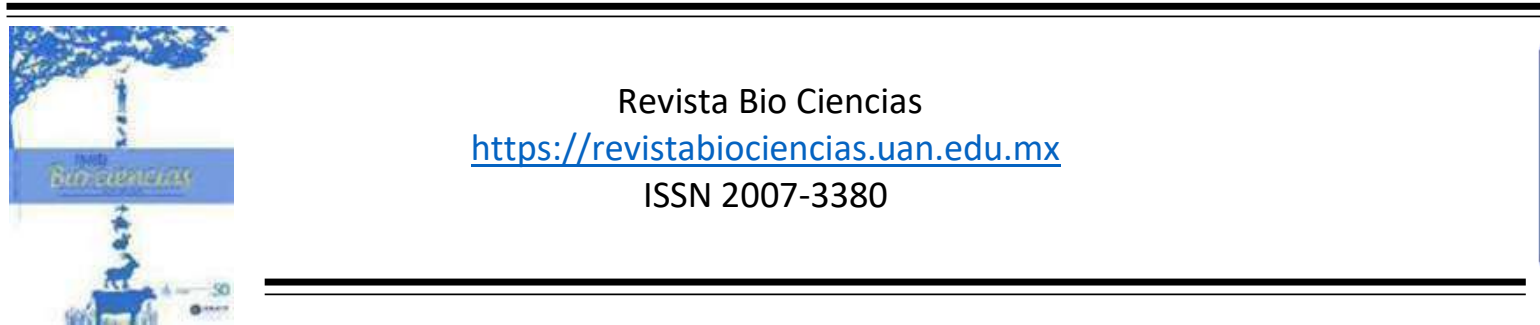

Trabajos libres: Nutrición, Metabolismo y Obesidad

Modalidad de Presentación: Oral

\title{
El aceite de krill atenúa la actividad eléctrica del núcleo arcuato en ratas adultas con restricción de crecimiento intrauterino
}

\author{
Flores Mancilla, L. E. ${ }^{1 *}$, Hernández González, M. ${ }^{2}$, Guevara Pérez, M. A. ${ }^{2}$, Martínez Arteaga, P. ${ }^{1}$, \\ Gaytán Pacheco, N. ${ }^{1}$, Rocío Martínez Acuña, M. R. ${ }^{1}$ \\ 1 Universidad Autónoma de Zacatecas. Facultad De Medicina. ${ }^{2}$ Universidad de Guadalajara. Instituto \\ de Neurociencias, CUCBA. \\ *Autor Corresponsal: Leopoldo Eduardo Flores Mancilla.E- mail: mansieduas@hotmail.com
}

La restricción de crecimiento intrauterino (RCIU), puede alterar el mecanismo de saciedad alimenticia regulado por el Núcleo Arcuato (NA), se han reportado efectos benéficos del aceite de Krill, (abundante en omega-3) sobre alteraciones cerebrales, poco se conoce del efecto de la suplementación de aceite de Krill (AK) sobre la conducta alimenticia y actividad eléctrica del NA posterior a nacimiento con RCIU.

Objetivo. -Evaluar el efecto de la suplementación de AK sobre el consumo de alimento y actividad eléctrica del NA en ratas adultas con RCIU.

Material y Métodos. - 3 grupos ( $n=8 \times g r u p o$ ), Grupo Krill integrado por ratas macho provenientes de madres suplementadas con aceite de krill (300mg/kg de peso), el Grupo Palma ratas macho provenientes de madres suplementadas con aceite de Palma (300mg/kg de peso), el Grupo Control ratas provenientes de madres suplementadas con vehículo (300 ul de agua bidestilada). Las madres progenitoras recibieron su respectivo tratamiento desde la pubertad, desarrollo, apareamiento y durante la gestación fueron intervenidas para RCIU de sus fetos, las respectivas crías continuaron con alimentación y tratamiento similar al de la madre del destete hasta los 150 días de edad, cuando se les implantaron bilateralmente electrodos en el NA, después de una semana de recuperación se evaluó la actividad eléctrica (EEG) en ayuno, durante la ingestión y posterior a saciarse del alimento, se evaluó el peso corporal, el consumo de alimento , potencia absoluta y relativa del EEG Resultados.- el grupo Krill mostró significativamente menor peso corporal, menor consumo de alimento, y menor PA en el EEG durante el periodo de ingestión y después de saciarse de alimento, en comparación con los grupos Control y Palma, $(\mathrm{p}<0.05)$.

Conclusiones. - Los resultados sugieren un efecto de la suplementación crónica de AK asociado a menor consumo de alimento y menor PA del EEG del NA bajo RCIU.

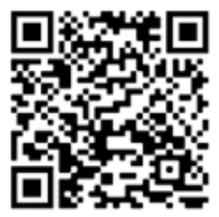

Como citar este artículo: Flores Mancilla, L. E., Hernández González, M., Guevara Pérez, M. A., Martínez Arteaga, P., Gaytán Pacheco, N., Rocío Martínez Acuña, M. R. (2020). El aceite de krill atenúa la actividad eléctrica del núcleo arcuato en ratas adultas con restricción de crecimiento intrauterino. Revista Bio Ciencias 7: (Suppl) Memorias de Congreso. LXIII Congreso Nacional de la Sociedad Mexicana de Ciencias http://doi.org/10.15741/revbio.07Suppl.e1097 


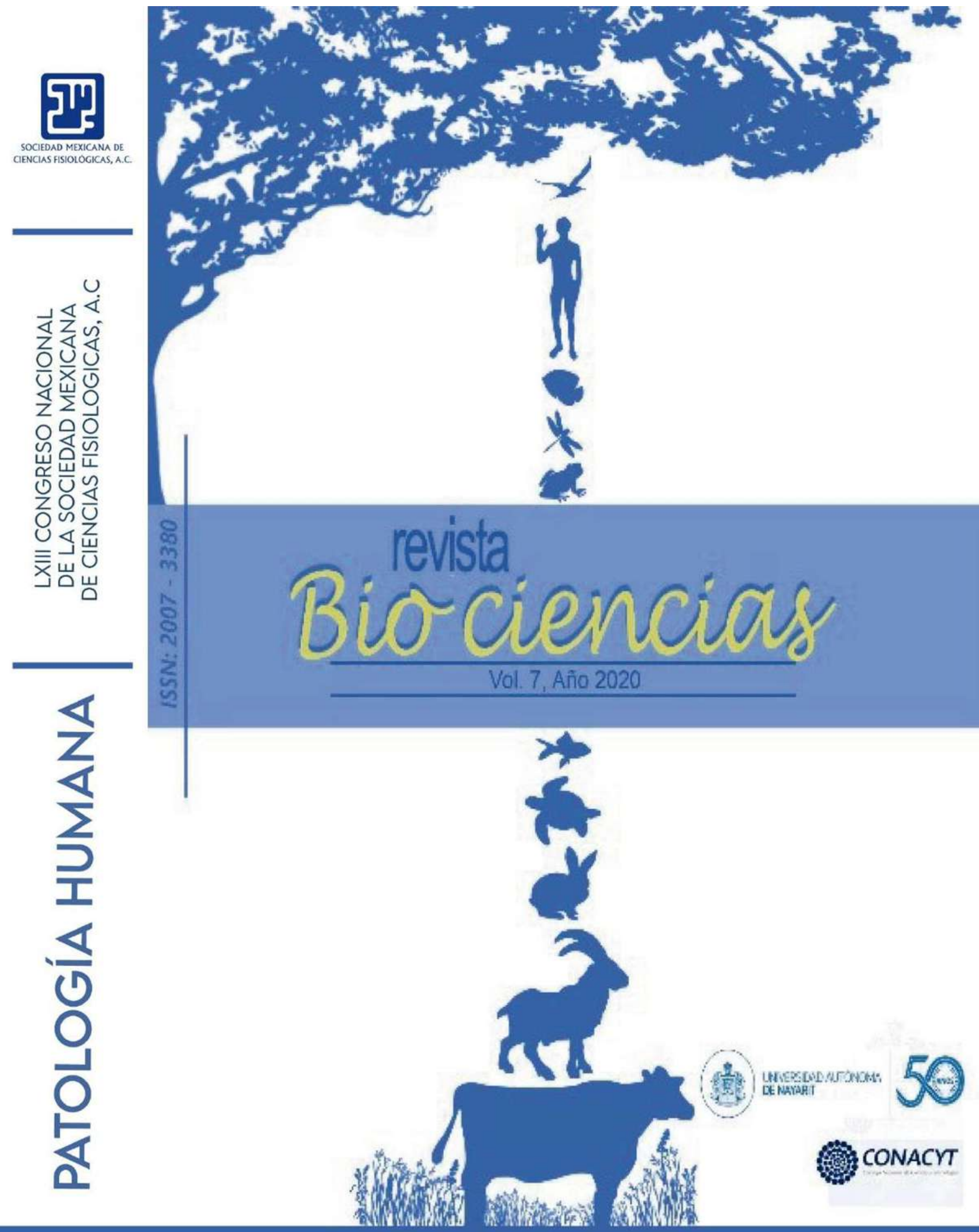




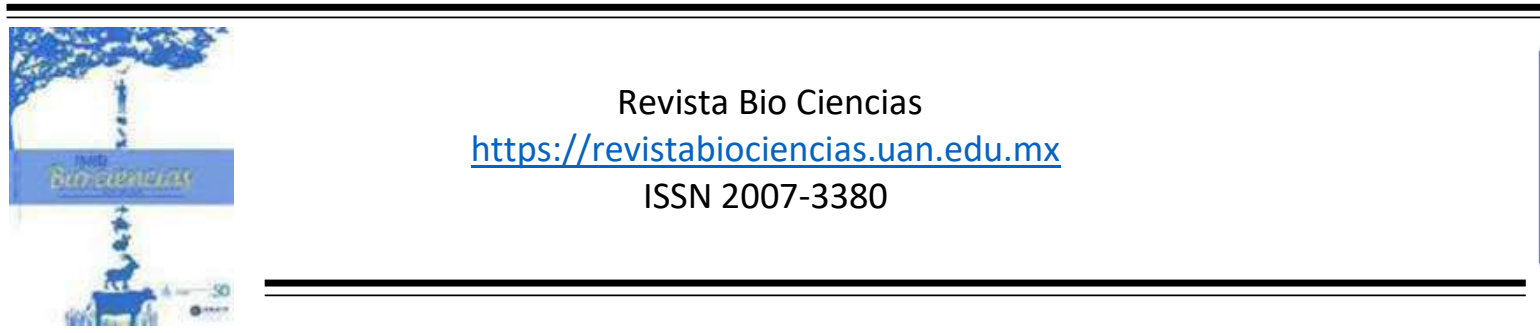

Trabajos libres: Patología Humana

Modalidad de Presentación: Cartel

\title{
Respuesta hiperglucémica diferencial en ratones C57BL/6J pre-púberes y adultos, en un modelo de diabetes tipo 2
}

\author{
Posadas Ramiro, N. A., López Pérez, S. J., Bañuelos Pineda, J., Rivas Celis, E., Ureña Guerrero, \\ M. E. * \\ Universidad de Guadalajara, Centro Universitario de Ciencias Biológicas y Agropecuarias (Cucba), \\ Departamento de Biología Celular y Molecular \\ *Autor Corresponsal: Monica Elisa Ureña Guerrero. E- mail: monica.urena@academicos.udg.mx
}

La diabetes mellitus tipo 2 (DM2) es la forma más prevalente de la enfermedad; y la aplicación de nicotinamida y estreptozotocina (NA/STZ) en roedores ha sido ampliamente usada para modelar esta condición. Los estudios que emplean al ratón C57BL/6J sólo hacen referencia al peso $(20-25 \mathrm{~g})$ para su uso, sin considerar la edad. Sin embargo, la respuesta hiperglucémica inducida por la aplicación de NA/STZ podría variar dependiendo de la edad de inicio del tratamiento. El objetivo de este trabajo fue evaluar el efecto de la edad sobre la hiperglucemia generada en ratones C57BL/6J después de la aplicación de NA/STZ. Ratones machos de 6 (pre-púberes) y 18 semanas (adultos) de edad, con un peso corporal de 20$25 \mathrm{~g}$ fueron aleatoriamente distribuidos en tres grupos experimentales: 1) intacto, 2) control NA/vehículo y 3) experimental NA/STZ. Se emplearon: $120 \mathrm{mg}$ de NA/kg de peso corporal (p.c.), disueltos en $\mathrm{NaCl} 0.9 \%$; y $100 \mathrm{mg}$ de
STZ/kg de p.c., disueltos en amortiguador de citrato de sodio, $0.1 \mathrm{M}, \mathrm{pH} 4.5$ (vehículo). Los tratamientos se administraron por vía intraperitoneal los días 0 y 2. La NA se administró 15 min antes del vehículo o la STZ. El peso corporal y los niveles de glucosa en sangre se registraron después de $4 \mathrm{~h}$ de ayuno; antes de los tratamientos y cada semana, durante 10 semanas más. Tanto en ratones pre-púberes como en adultos el tratamiento con NA/STZ disminuyó el p.c. y aumentó los niveles de glucosa en sangre de forma significativa respecto a ambos grupos control. Sin embargo, la respuesta hiperglucémica fue mayor $(\approx 250 \mathrm{mg} / \mathrm{dl})$ y duradera en los adultos, mientras que en los pre-púberes $(\approx 200 \mathrm{mg} / \mathrm{dl})$ desapareció a la semana 7 post-tratamiento. Por lo que, concluimos que en este modelo además de considerar el peso de los animales, también debe considerarse la edad 


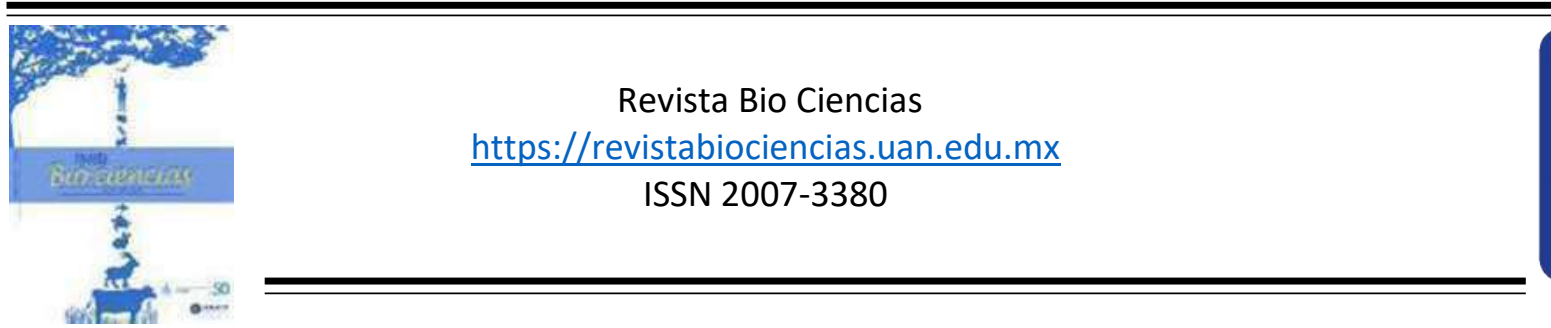

Trabajos libres: Patología Humana

Modalidad de Presentación: Oral

\title{
Diferencias entre las emociones medidas por el FaceReader durante el Cyberball de acuerdo al nivel de desconfianza social en pacientes con Trastorno Límite de la Personalidad
}

\author{
Rosales Lagarde, A. ${ }^{{ }^{*}}$, Rodríguez Torres, E. E. ${ }^{2}$, Vázquez Mendoza, E. ${ }^{2}$, Eraña Díaz, M. L. ${ }^{1}$, \\ Rodríguez Delgado, A. ${ }^{1}$, Reyes Soto, A. ${ }^{1}$, Arango de Montis, I. ${ }^{1}$ \\ ${ }^{1}$ Instituto Nacional de Psiquiatría Ramón De La Fuente Muñiz. ${ }^{2}$ Universidad Autónoma Del Estado \\ de Hidalgo \\ *Autor Corresponsal: Alejandra Rosales Lagarde. E- mail: arosalesla@conacyt.mx
}

Según la literatura, en una muestra de estudiantes, la confianza social mostró ser un factor independiente de la desconfianza social. Por ese motivo, los pacientes con Trastorno Límite de la Personalidad (TLP) fueron separados con base en sus respuestas en una escala ad hoc. A las pacientes con TLP se les administró el cyberball en sus condiciones de inclusión y exclusión. Con el software FaceReader se obtuvieron los valores de las emociones ("Happy", "Sad", "Angry", "Surprised", "Scared", "Disgusted" y "Contempt"), de "Arousal" y "Valencia", los cuales fueron promediados por minuto $y$ posteriormente cada 60 segundos. Los datos fueron agrupados de acuerdo al nivel de desconfianza media (DM, $\mathrm{n}=9$ ) y alta desconfianza $(A D, n=4)$ y se realizaron ANOVAs de dos vías para hacer las comparaciones entre el nivel de desconfianza y el tiempo para cada emoción, "valencia" y "arousal". En la condición de inclusión, los valores de "Happy" y "Contempt" fueron significativamente mayores en el grupo de $M D$, mientras que los valores de "Sad", "Angry", "Surprised" y "Scared" fueron más altos en el grupo de AD. Por otra parte, las puntuaciones de "Disgusted" fueron similares entre los grupos. En la condición de exclusión, los valores de "Happy" y "Contempt" fueron mayores en el grupo de MD; asimismo, los valores de "Angry" y "Surprised" fueron más altos en el grupo de AD. Sin embargo, los valores de "Sad" y "Disgusted" ahora fueron mayores en el grupo de MD y los valores de "Scared" fueron similares entre los grupos. En cuanto a los valores de "Valencia", estos fueron mayores en el grupo de MD en ambas condiciones. En cambio, los valores de "Arousal" fueron similares entre ambos grupos en ambas condiciones. Estos resultados reúnen evidencia conductual a favor de la independencia de esos factores ahora en pacientes con TLP. 


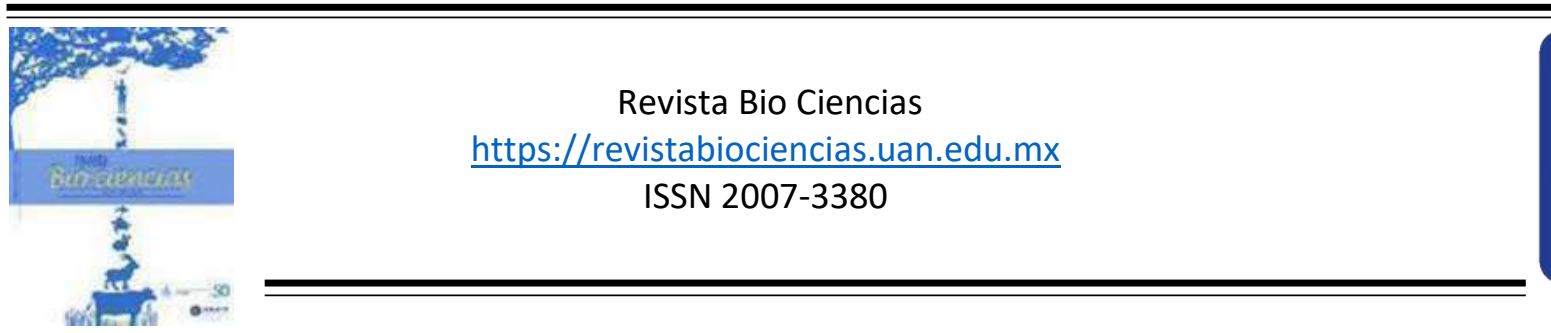

Trabajos libres: Patología Humana

Modalidad de Presentación: Cartel

\title{
Alteraciones testiculares en ratas neonatas, prepúberes y púberes con hipotiroidismo congénito experimental
}

\author{
Gómez Zúñiga, A. ${ }^{1}$, Chávez Saldaña, M. ${ }^{2}$, Rojas Castañeda, J. ${ }^{2}$, Sánchez Huerta, K. B. ${ }^{2}$, Medina \\ Granados, P. M. ${ }^{2}$, Cervantes Arias, E. ${ }^{2}$, Vigueras Villaseñor, R. M.. ${ }^{2 *}$ \\ 1 Universidad Autónoma Metropolitana Iztapalapa. Biología de la Reproducción. ${ }^{2}$ Instituto Nacional \\ de Pediatría, Laboratorio de Biología de la Reproducción. \\ *Autor Corresponsal: Rosa María Vigueras Villaseñor. E- mail: rmvigueras@yahoo.com.mx
}

El hipotiroidismo congénito $(\mathrm{HC})$ es una patología que genera múltiples trastornos en el organismo, entre ellos, afecta la función reproductiva masculina. Experimentalmente se ha inducido $\mathrm{HC}$ en rata, observándose, daños en etapa adulta, sobre la maduración de las células de Sertoli y en la morfología, viabilidad y cuenta espermática, repercutiendo en la fertilidad. Sin embargo, las alteraciones histológicas testiculares en la etapa neonatal, prepuberal y puberal de la rata con $\mathrm{HC}$ no han sido descritas. OBJETIVO. Determinar las alteraciones testiculares en ratas neonatas, prepúberes y púberes con $\mathrm{HC}$ inducido. MÉTODOS. Se formaron dos grupos de ratas, control y con $\mathrm{HC}$. EI HC fue inducido administrando Metimazol del día 16 de gestación hasta la eutanasia (días 10, 16 y 64 postnatal). Se extrajeron los testículos y se procesaron para su inclusión en EPON. Se obtuvieron cortes y se analizó el índice de diferenciación de gonocitos, el área y el índice de maduración del epitelio seminífero (IMES), así también se determinaron las alteraciones histológicas y la vitalidad, morfología y concentración espermática. Los resultados fueron analizados empleando una t-student $(p<0.05)$. RESULTADOS. Las ratas con HC de 10 y 16 días posnatal, mostraron una reducción significativa en el índice de diferenciación de gonocitos. Este hecho redundó en la etapa puberal con una disminución significativa en el peso testicular, el área del epitelio seminífero, la población de espermatocitos, el IMES, la vitalidad, morfología y la concentración espermática $(\mathrm{P}<0.05)$. Así como la presencia de alteraciones histológicas testiculares. CONCLUSIÓN. Las alteraciones observadas en ratas con $\mathrm{HC}$ muestran una posible falta de diferenciación de los gonocitos que, al verse afectado este proceso, resulta en una disminución en la cantidad de células germinales disponibles para llevar acabo la espermatogénesis y que finalmente se ve reflejado en el número total de espermatozoides funcionales para así garantizar la fertilidad masculina. Huerta, K. B., Medina Granados, P. M., Cervantes Arias, E., Vigueras Villaseñor, R. M. (2020). Alteraciones testiculares en ratas neonatas, prepúberes y púberes con hipotiroidismo congénito experimental. Bio Ciencias 7: (Suppl) Memorias de Congreso. LXIII Congreso Nacional de la Sociedad Mexicana de Ciencias Fisiologicas, A. C. e1097. http://doi.org/10.15741/revbio.07Suppl.e1097 


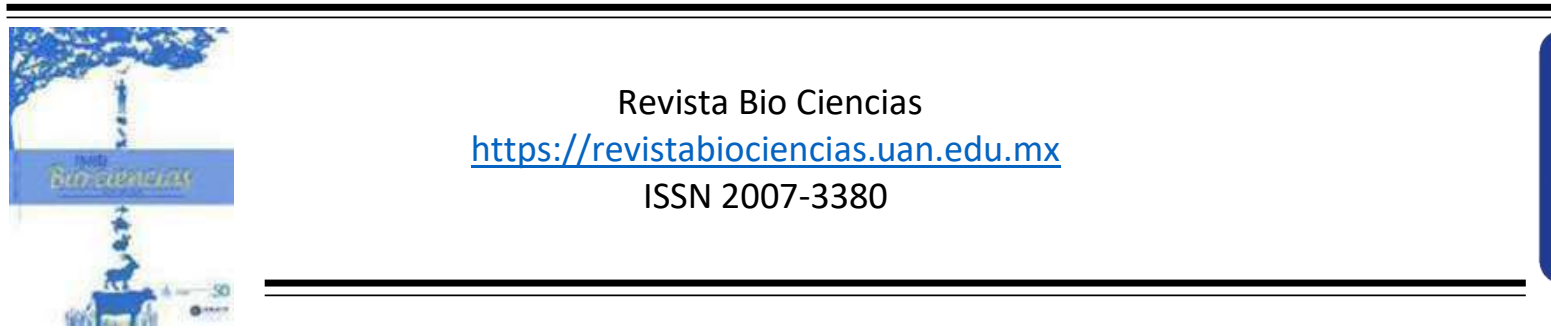

Trabajos libres: Patología Humana

Modalidad de Presentación: Cartel

\title{
Efecto de la desmopresina en la inhibición de la proliferación y migración celular de la línea OV-90 de cáncer epitelial de ovario
}

\author{
Calvillo Robledo, A., Quintanar Stephano, A. * \\ Universidad Autónoma de Aguascalientes. Departamento de Fisiología. \\ *Autor Corresponsal: Andrés Quintanar Stephano. E-mail: aquinta@correo.uaa.mx
}

El cáncer epitelial de ovario es la neoplasia ginecológica más letal, es detectado en etapas avanzadas de la enfermedad y más del $70 \%$ de las pacientes recurre a la enfermedad con poca respuesta a quimioterapia. Actualmente se desconoce del todo el efecto de la hormona neurohipofisiaria arginina vasopresina (AVP) y sus receptores en el cáncer epitelial de ovario, por lo que el presente trabajo propone evaluar la acción del análogo sintético de la AVP, la desmopresina (DDAVP) y sus receptores V1a y V2 sobre la proliferación y migración celular de la línea celular OV-90. La proliferación celular fue evaluada mediante el marcador de proliferación ki-67, mientras que el proceso de migración fue determinado mediante el ensayo de herida; para determinar la expresión de ambos receptores V1a y V2 se realizaron técnicas de inmunodetección por inmunofluorescencia. Los cultivos celulares fueron estimulados durante 12, 24, 36 y 48 horas con DDAVP (500-1500 mM), asimismo, para descartar la toxicidad del compuesto se utilizó el kit Cytotox96, cada experimento fue realizado por triplicado y doble replica cada uno. Los resultados mostraron que la línea celular OV-90 de cáncer epitelial de ovario expresa ambos receptores V1a y V2, además de que el tratamiento con 1000mM de DDAVP reflejó una disminución significativa tanto de la proliferación celular como en la migración de las células cancerosas. Estos resultados sugieren el posible rol inhibitorio de la DDAVP sobre la proliferación y migración celular de la línea OV-90 de cáncer epitelial de ovario..

Como citar este artículo: Calvillo Robledo, A., Quintanar Stephano, A. (2020). Efecto de la desmopresina en la inhibición de la proliferación y migración celular de la línea OV-90 de cáncer epitelial de ovario. Bio Ciencias 7: (Suppl) Memorias de Congreso. LXIII Congreso Nacional de la Sociedad Mexicana de Ciencias
http://doi.org/10.15741/revbio.07Suppl.e1097

Fisiologicas,

A.

C. e1097. 


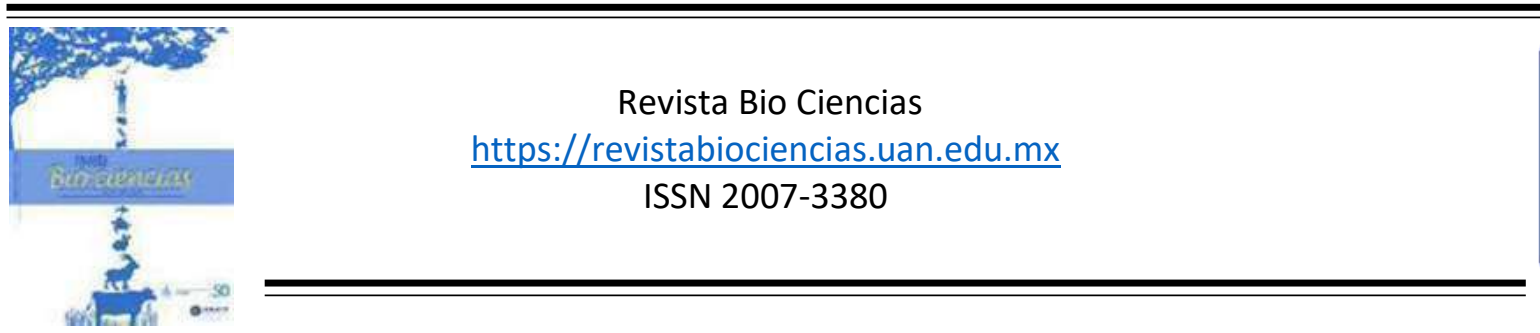

Trabajos libres: Patología Humana

Modalidad de Presentación: Oral

\title{
Expresiones faciales de emociones en pacientes con Trastorno Límite de Personalidad durante una experiencia de exclusión social
}

\author{
Reyes Soto, A. ${ }^{1}$, Rosales Lagarde, A. ${ }^{1}$, Eraña Diaz, M. L. ${ }^{2}$, Vazquez Mendoza, E. ${ }^{3}$, Rodriguez \\ Torres, E. ${ }^{3}$, Arango De Montis, I. ${ }^{\text {* }}$ \\ ${ }^{1}$ Instituto Nacional de Psiquiatría Ramón de la Fuente Muñiz. 2Universidad Autónoma del Estado de \\ Morelos. ${ }^{3}$ Universidad Autónoma de Hidalgo \\ *Autor Corresponsal: Ivan Arango De Montis. E- mail: iadmontis@gmail.com
}

La comunicación juega un papel muy importante en la búsqueda de supervivencia siendo el mecanismo más común de comunicación el lenguaje y dentro de la comunicación no verbal encontramos la expresión facial. Paul Ekman propuso seis emociones básicas: alegría, sorpresa, asco, tristeza, enojo y miedo. Un método actual para el estudio de las expresiones faciales es el software FaceReader. La forma en como evaluamos afectivamente nuestro entorno ha llevado al estudio de las emociones en el ámbito de la salud mental. Planteamiento/ objetivo: Ha sido poco estudiada la emisión de la expresión facial en personas con TLP, saber cuál expresión facial demuestran ante una situación de exclusión podrían explicar las dificultades que presentan en su medio social. El objetivo fue evaluar la relación entre frecuencia e intensidad de expresiones faciales ante una situación de exclusión social con características clínicas de pacientes con TLP. Métodos: Se realizó un estudio transversal, correlacional y comparativo, mediante consentimiento informado en pacientes con TLP ante una situación de rechazo social, mediante un juego virtual programado por medio del Cyberball, se video grabó el rostro y posteriormente se aplicaron diversas escalas. La videograbación se analizó por medio del software FaceReader versión 7.0. Resultados: La muestra final estuvo comprendida por 11 mujeres con diagnóstico de TLP. Para el total de la muestra se encontró un grado alto de desconfianza social y baja confianza social, características de pacientes con TLP. Durante el evento de inclusión predominaron expresiones faciales negativas. Durante el evento de exclusión, diversas expresiones faciales negativas disminuyeron, entre ellas el enojo, otras como la tristeza y emociones positivas como sorpresa y alegría, aumentaron. Conclusiones: Los resultados obtenidos podrían representar las distorsiones cognitivas y sociales que se presentan en este padecimiento, lo que explicaría las dificultades en su medio social e interpersonal. 


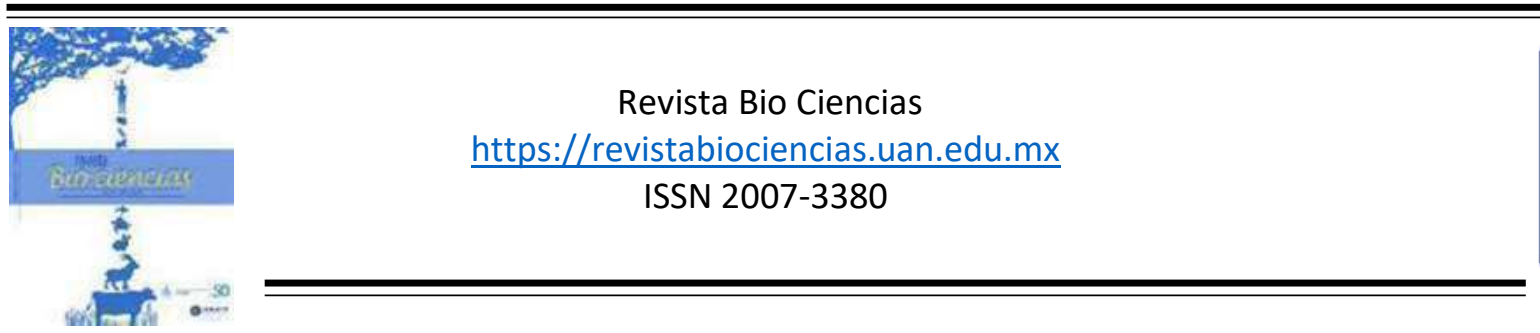

Trabajos libres: Patología Humana

Modalidad de Presentación: Oral

\title{
La inervación autonómica promueve proliferación y migración en cáncer de próstata: una aproximación matemática
}

\author{
Arellano Hernández, J. *, López Hernández, R., Cruz Gómez, Y., Martínez Cruz, R., Vázquez \\ Pérez, $E$. \\ Universidad Autónoma de Tlaxcala. Departamento de MAtematicas Aplicadas \\ *Autor Corresponsal: Jorge Arellano Hernández. E- mail: jorgeah158@hotmail.com
}

El cáncer de próstata es la segunda neoplasia maligna más frecuente en hombres y es la quinta causa de muerte en todo el mundo. Moléculas liberadas por células tumorales promueven la infiltración de inervación al tumor, esta inervación estimula la progresión, la proliferación, la angiogénesis, la invasión y la metástasis del cáncer de próstata mediante la liberación de neurotransmisores y neuropéptidos. Entender como cambios en la concentración de estas moléculas se traducen en proliferación, angiogénesis, invasión o metástasis del cáncer es fundamental para establecer mejores tratamientos para el cáncer de próstata. Sin embargo, la interacción no lineal entre las moléculas y células (tumorales o nerviosas) dificulta esta tarea. El objetivo del trabajo fue generar un modelo matemático que describa la interacción entre las moléculas liberadas por neuronas y células tumorales, y como estas promueven su proliferación y migración. El modelo consistió de un sistema de diez ecuaciones diferenciales ordinarias no lineales acopladas cuyos parámetros se calcularon a partir de bibliografía de estudios in vitro de la línea celular LNCaP. Las curvas solución del modelo mostraron que el tumor tarda aproximadamente 2 años en llegar a su límite de crecimiento $(31.5 \mathrm{cc}$ ) y que alrededor de 64000 millones de células migraron del tumor. El tumor promovió axonogénesis y neurogénesis en un 5\% respecto a la inervación control. La inhibición de sensibilidad del tumor a la inervación simpática generó una reducción en el volumen del tumor y del número de células migratorias del 81 y $88 \%$, respectivamente, mientras que la inhibición a la parasimpática ocasionó un incremento del $22 \%$ del volumen del tumor y una reducción del $78 \%$ del número de células migratorias. El modelo mostró congruencia con estudios experimentales in vivo por lo cual puede ser utilizado para mimetizar la interacción cáncer-sistema nervioso. PRODEP 511-6/2019.-14840, MODELACIÓN MATEMÁTICA: UATLX-CA-24. 


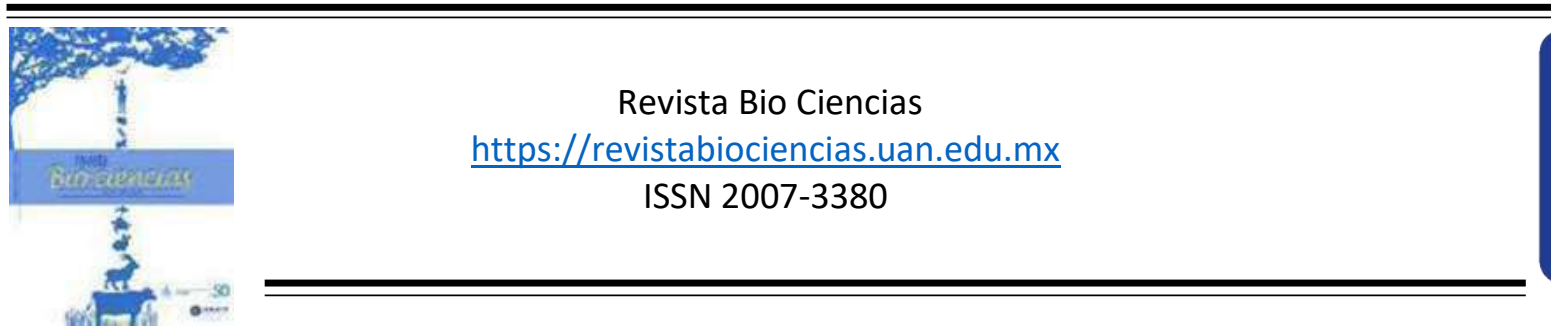

Trabajos libres: Patología Humana

Modalidad de Presentación: Cartel

\title{
Efectos del aceite esencial de Melaleuca alternifolia como tratamiento antioxidante sobre ulceraciones de pie diabético
}

\author{
González Palomares, L., Gómez Barroso, M., Peña Montes, D. J., Saavedra Molina, A., Cortés \\ Rojo, C., Montoya Pérez, $R^{*}$ \\ Universidad Michoacana de San Nicolás de Hidalgo. Laboratorio de Fisiología Muscular \\ *Autor Corresponsal: Rocío Montoya Pérez. E- mail: biochio@gmail.com
}

Actualmente la incidencia de diabetes mellitus (DM) en la población mundial se ha convertido en una de las causas cardinales de muerte. Una de las principales complicaciones de dicha enfermedad son las úlceras ocasionadas por la neuropatía y la vasculopatía diabética, llamadas úlceras de pie diabético, desencadenando en amputaciones. Recientemente se ha demostrado que el estrés oxidante, generado por las interleucinas proinflamatorias propias de las heridas es coadyuvante en la fisiopatología de DM afectando directamente en la fatiga muscular ya presente en la patología. Las úlceras de pie diabético pueden prevenirse con un adecuado seguimiento y cuidado de la lesión; la higiene, la vascularización y la cicatrización, son puntos clave para el cierre de la úlcera. Sin embargo, los tratamientos farmacológicos para dicha patología suelen ser muy costosos, largos y poco eficientes es por ello que se pretende examinar la aplicabilidad del aceite esencial obtenido de la planta Melaleuca alternifolia, indagando en su efectividad antioxidante y desinfectante. Se diseño un tratamiento que incluyó las variables: efecto antioxidante, tiempo de cicatrización, efecto en la tensión muscular y evolución clínica de las heridas inducidas en ratas Wistar macho que presentan la patología de diabetes experimental. Se observó una diferencia significativa en las ratas tratadas con aceite esencial de Melaleuca alternifolia sobre el efecto antioxidante (con una disminución del $32.12 \%$ de niveles de especies reactivas de oxígeno, por debajo de los otros tratamientos) y una evolución clínica de las heridas, (con una contracción $15 \%$ más notoria en el tratamiento con Melaleuca alternifolia) así como un daño menor en la tensión muscular afectada por la herida, (apreciándose un incremento en la contracción del $25.12 \%$ en comparación con otros tratamientos). 


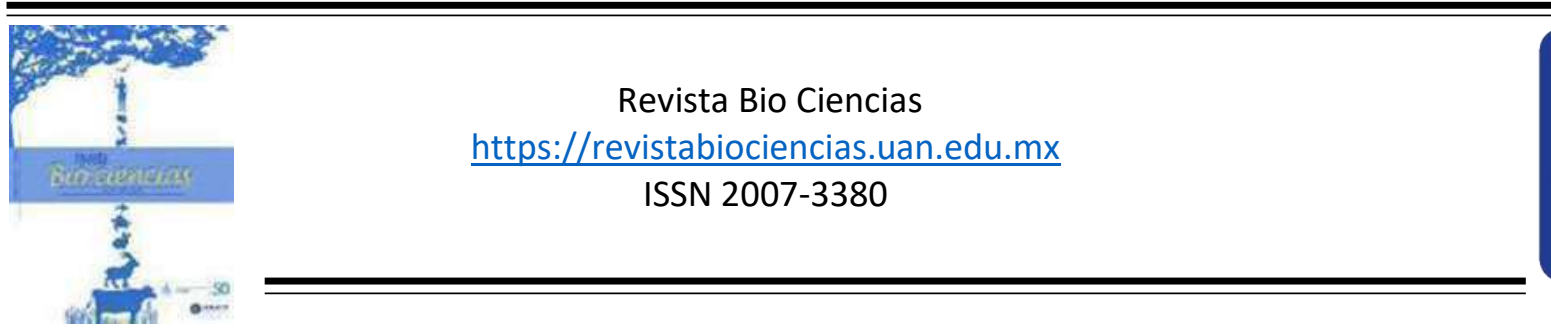

Trabajos libres: Patología Humana

Modalidad de Presentación: Oral

\section{Los niveles de Pleiotrofina en suero se asocian al sexo y al índice de masa corporal en la esclerosis múltiple remitente recurrente.}

Reyes Mata, M. P. ${ }^{1}$, Rojas Mayorquín, A. E. ${ }^{2}$, Carrera Quintanar, L. ${ }^{1}$, González Castillo, C., Mireles Ramírez, M. A. ${ }^{3}$, Guerrero García, J. J.4, Ortuño Sahagún, D. ${ }^{1 *}$

1 Universidad de Guadalajara. Centro Universitario de Ciencias de la Salud. ${ }^{2}$ Universidad de

Guadalajara, Centro Universitario de Ciencias Biológicas y Agropecuarias (CUCBA). ${ }^{3}$ Unidad

Médica de Alta Especialidad (UMAE), Hospital de Especialidades (HE), Centro Médico Nacional de

Occidente (CMNO), IMSS. ${ }^{4}$ Banco de Sangre Central, Unidad Médica de Alta Especialidad

(UMAE), Hospital de Especialidades (HE), Centro Médico Nacional de Occidente (CMNO), IMSS

*Autor Corresponsal: Daniel Ortuño Sahagún.E-mail: dortuno@cucs.udg.mx

La esclerosis múltiple (EM) remitenterecurrente (EMRR) es una enfermedad autoinmune desmielinizante propia del Sistema Nervioso Central (SNC). La Pleiotrofina (PTN) es una citocina con actividad neuroinmunomoduladora que se ha descrito en otras enfermedades autoinmunes, así como en modelos experimentales de EM. Hasta el momento la PTN no se ha estudiado en pacientes con EMRR, lo que resulta de interés por su capacidad para interaccionar con los sistemas afectados en la EM. En el presente trabajo, se cuantificaron, mediante ELISA, los niveles séricos de PTN en 57 pacientes con EMRR tratados con acetato de glatirámero o interferón beta y no tratados, así como controles pareados. Se utilizaron pruebas estadísticas no paramétricas para el análisis de los datos. Los resultados demuestran que los niveles séricos de PTN se elevan en pacientes con respecto a los controles $y$ en diferentes subgrupos clasificados por sexo e índice de masa corporal (IMC). Los pacientes y controles femeninos muestran una mayor variabilidad en los niveles de PTN, con una diferencia significativa en el grupo de pacientes según el IMC. Los pacientes masculinos presentan niveles elevados comparados con sus controles. EI IMC se correlaciona con la concentración de PTN en pacientes con menos de 8 años de evolución de la enfermedad. Los niveles de PTN tienden a correlacionarse con el IMC en mujeres. Los análisis de curvas ROC muestran que los niveles séricos de PTN tienen un mejor poder predictivo para los hombres, con un área bajo la curva de 0.824 , sensibilidad del $70.8 \%$ y especificidad del $77.8 \%$. El presente estudio demuestra que los niveles de PTN están incrementados en el suero de pacientes con EMRR respecto a controles, y se correlacionan con el sexo y el IMC. Se necesitan más estudios para determinar el papel preciso de la PTN en la EM.

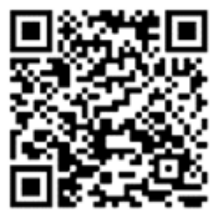

Como citar este artículo: Reyes Mata, M. P., Rojas Mayorquín, A. E., Carrera Quintanar, L., González Castillo, C., Mireles Ramírez, M. A., Guerrero García, J. J., Ortuño Sahagún, D. (2020) Los niveles de Pleiotrofina en suero se asocian al sexo y al índice de masa corporal en la esclerosis múltiple remitente recurrente. Bio Ciencias 7: (Suppl) Memorias de Congreso. LXIII Congreso Nacional de la Sociedad Mexicana de Ciencias Fisiologicas, A. C. e1097. http://doi.org/10.15741/revbio.07Suppl.e1097 


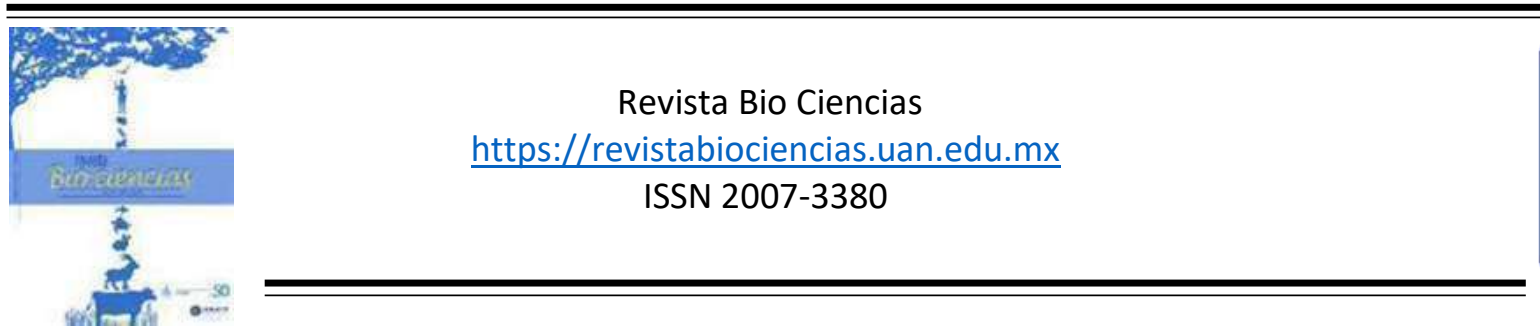

Trabajos libres: Patología Humana

Modalidad de Presentación: Cartel

\title{
Daño tubular renal causado por consumo de Té sensual en ratas macho
}

\author{
Picazo Pavon, A. M. ${ }^{1}$, Cuatecontzi De La Fuente, $I^{1}$, Cruz Lumbreras, S. R. ${ }^{2}$, Cuevas Romero, E. ${ }^{1 *}$ \\ ${ }^{1}$ Centro Tlaxcala de Biología de la Conducta. Departamento de Biomedicina. ${ }^{2}$ Universidad \\ Autónoma de Tlaxcala \\ *Autor Corresponsal: Estela Cuevas Romero. E- mail: cuevasestela@hotmail.com
}

El té sensual es usado como vigorizante sexual, contiene 14 plantas y es de venta libre, aunque con nula información sobre sus componentes. Dentro de las plantas incluidas en dicho té se encuentran Astragalus membranaceus, Epimedium brevicornum Maxim y Cistanche desertícola con propiedades protectoras del riñón. Sin embargo, también contiene Morinda ofifcinalis y Panax ginseng, las cuales pueden causar hipertensión, misma que es un factor de predisposición para daño renal agudo. En este trabajo se analizó la morfometría renal ratas expuestas a diferentes dosis de té sensual. Se utilizaron ratas macho de la cepa wistar divididas en cuatro grupos: dosis estándar de acuerdo con lo recomendado para humanos (142 $\mathrm{mg} / \mathrm{kg}$; dosis $1 ; \mathrm{n}=6)$, dosis baja (71 $\mathrm{mg} / \mathrm{kg}$; dosis $2 ; \mathrm{n}=6)$, dosis alta $(284 \mathrm{mg} / \mathrm{kg}$; dosis $3 ; n=6$ ) y grupo control (vehículo, agua destilada; Veh; $n=6)$. La administración fue vía oral, 1 vez a la semana por 2 meses. Los animales fueron sacrificados con una sobredosis de anestésico y se extrajeron ambos riñones. También se obtuvo sangre para la medición de creatinina y urea. Los riñones izquierdos fueron procesados histológicamente y teñidos con ácido peryódico (PAS). Se seleccionaron corpúsculos y túbulos proximales al azar, los cuales fueron medidos en microfotografías a 40 y 100X, respectivamente. No se encontraron diferencias significativas entre los grupos en las concentraciones sanguíneas de creatinina y urea, ni en las áreas de corpúsculos y glomérulos, así como el espacio glomerular. Sin embargo, el grosor del epitelio tubular proximal disminuyó significativamente $(p=0.0085)$ en los animales tratados con las dosis 1 y 3 , en comparación con el grupo Veh. Nuestros resultados sugieren que el té sensual podría causar daño tubular que, de no tratarse a tiempo, podría evolucionar a insuficiencia renal crónica. Ello expone la importancia de evaluar la función renal en personas que consuman este producto. 


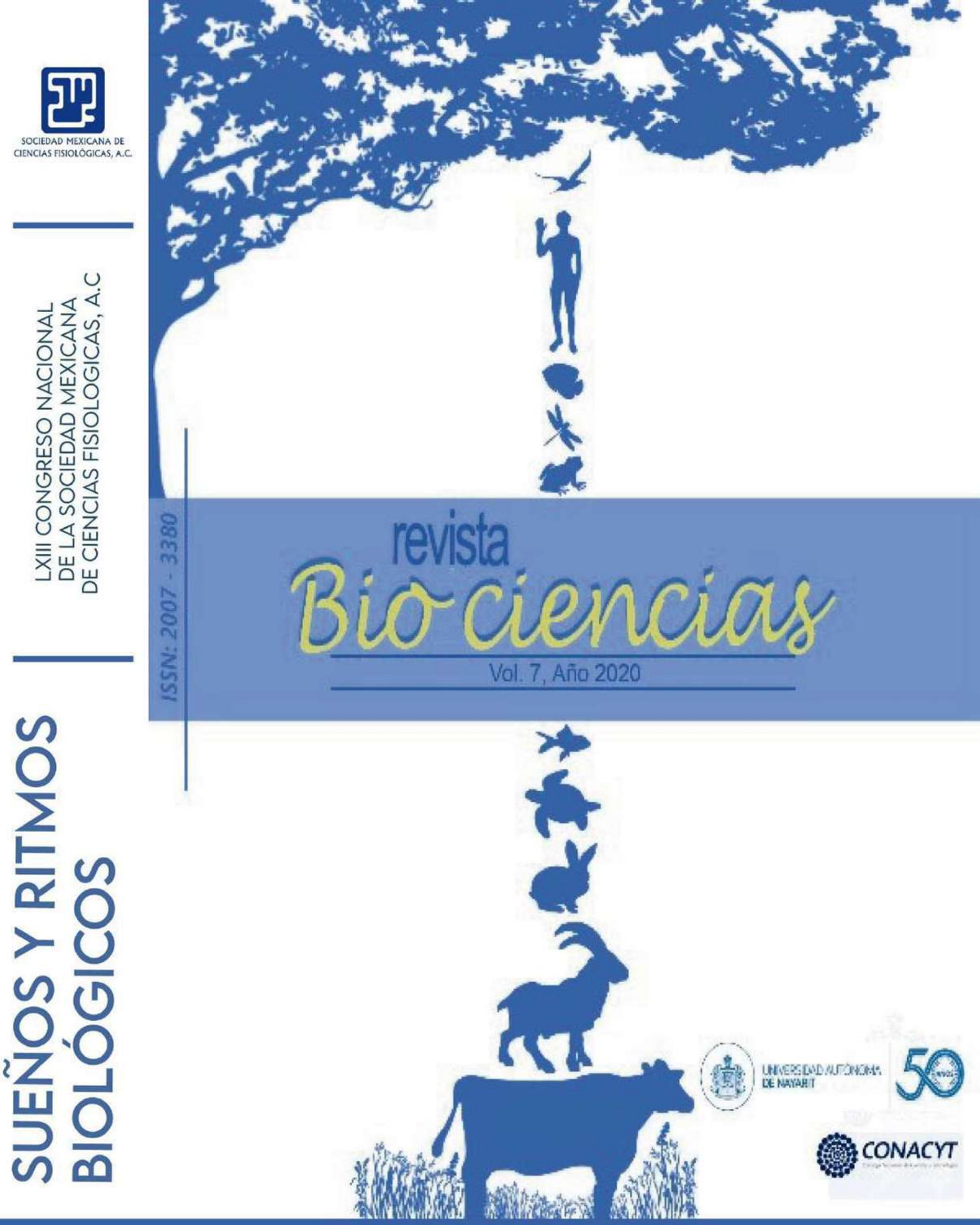

GUADALAJARA, JALISCO 13 AL 16 DE NOVIEMBRE 2020 CONGRESO ONLINE 


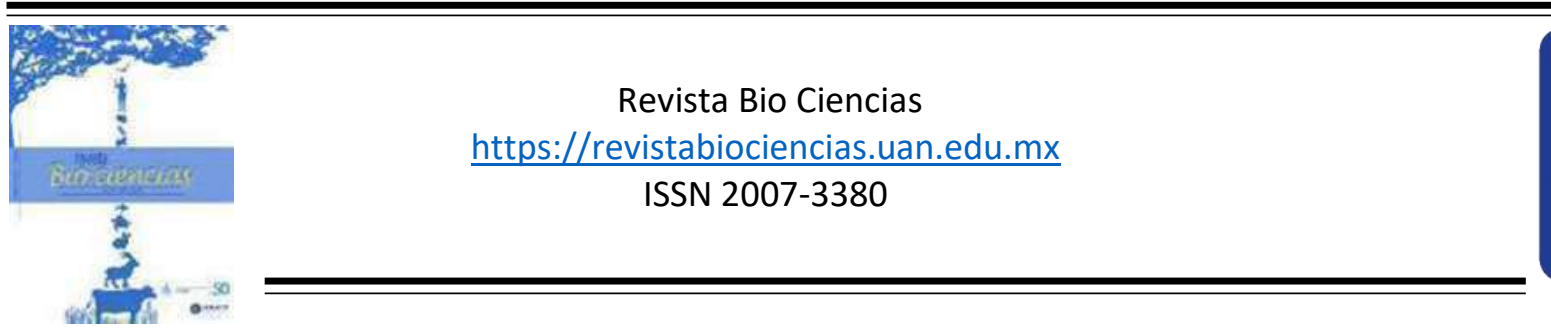

Trabajos libres: Sueño y Ritmos Biológicos

Modalidad de Presentación: Cartel

\title{
Fases de Sueño en el Acocil: Actividad Eléctrica Cerebral y Variables Autonómicas
}

\author{
Montiel Trejo, L., Peña Leal, Z. V., Osorio Palacios, M., Oliver Domínguez, I., Aguayo Solís, R., \\ Mendoza Angeles, K., Hernández Falcón, J. * \\ Universidad Nacional Autonoma de Mexico. Facultad de Medicina. Laboratorio de Fisiología. \\ *Autor Corresponsal: Jesús Hernández Falcón. E- mail: jesushf@unam.mx
}

El sueño en mamíferos es un proceso dinámico que comprende las fases de: sueño de movimientos oculares rápidos (MOR) y sueño no-MOR. caracterizadas por una actividad eléctrica cerebral específica y acompañadas de cambios en la frecuencia cardiaca (FC) y respiratoria (FR). En algunos invertebrados como el acocil se ha descrito el sueño a partir de los mismos criterios que en el vertebrado y se ha planteado la posible existencia de fases de sueño. A pesar de que en los crustáceos no se han descrito estructuras anatómicas autonómicas, se sabe que diversas alteraciones en su ambiente modifican su frecuencia cardiorrespiratoria durante la vigilia. Se desconoce si este crustáceo tiene fases de sueño y cuál es el patrón de la actividad cardiorrespiratoria durante el mismo. Nuestro objetivo fue analizar la actividad eléctrica cerebral, la FC y la FR durante la vigilia y el sueño, con la finalidad de identificar si el acocil presenta fases de sueño. Usamos acociles machos
Procambarus clarkii (L:D 12:12). Previa anestesia por frío, implantamos electrodos en cerebro, seno cardíaco y cámaras branquiales. Registramos simultáneamente la actividad conductual y electrofisiológica durante 8 horas. Para el análisis conductual consideramos animales deambulando y de lado. Utilizamos la transformada wavelet para el análisis de la actividad eléctrica cerebral y cardiorrespiratoria. Encontramos que: 1) en los acociles dormidos la FC se encuentra alrededor de los $2 \mathrm{~Hz}$ y la FR oscila de los 0.5$4 \mathrm{~Hz}$ y 2) la profundidad de sueño, medida en función de la potencia de la actividad electroencefalográfica cambia a través del tiempo y es acompañada por variaciones en la amplitud y en la potencia de las señales cardiaca y respiratoria. En conclusión, proponemos que el acocil presenta fases de sueño acompañadas de cambios en variables fisiológicas como la FC y la FR. Investigación realizada gracias al Programa UNAMDGAPA-PAPIIT IN231620. 


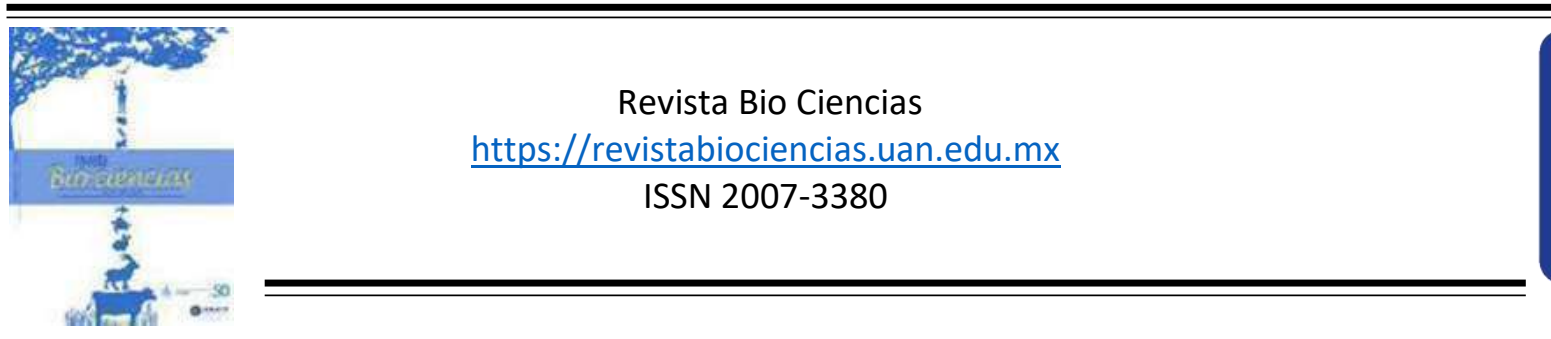

Trabajos libres: Sueño y Ritmos Biológicos

Modalidad de Presentación: Oral

\title{
Efectos de la ingesta de alcohol en el ciclo sueño-vigilia en un modelo de ansiedad
}

\author{
Fierro Rojas, A., Eguibar Cuenca, J. R., Cortés Sánchez, M. C.* \\ Benemerita Universidad Autonoma de Puebla. Instituto de Fisiología. \\ *Autor corresponsal: Ma.del Carmen Cortés Sánchez. E- mail: carmen.cortes@correo.buap.mx
}

La ansiedad es un factor importante en el desarrollo de alteraciones en el sueño. El consumo de alcohol facilita el sueño para disminuir la ansiedad, y sólo los individuos susceptibles tienen mayor probabilidad de desarrollar dependencia al alcohol. Las ratas de bajo bostezo (LY) se diferencian de las de alto bostezo (HY) por presentar una conducta ansiosa en pruebas estandarizadas, son más susceptibles al estrés agudo y muestran más depresión en la prueba de nado forzado. Nuestro objetivo fue evaluar los efectos de la ingesta crónica de alcohol sobre el ciclo sueño-vigilia en ratas HY y LY. Se emplearon ratas HY y LY macho de 3 meses de edad. Se realizó un primer registro de sueño en condiciones basales. Posteriormente, las ratas tuvieron un periodo de habituación al alcohol por 7 días, en los cuales se les proporcionó una solución de alcohol al 9.6\%, y se les realizó un segundo registro de sueño
(AL1). Después de una tercera fase de libre elección entre alcohol y agua por 3 semanas, se evaluó la preferencia de consumo y se realizó un tercer registro de sueño (AL2). Las ratas $L Y$ mostraron una preferencia significativa por el alcohol $(P<0.05)$ con respecto de las $\mathrm{HY}$. El consumo de alcohol produjo una disminución de la vigilia y un aumento en el sueño de ondas lentas en ratas LY $(P<0.05)$. Adicionalmente, produjo un adelanto de fase de la vigilia y sueño de ondas lentas en ambas sublíneas, y el sueño con movimientos oculares rápidos tuvo un adelanto de fase en las ratas HY y un retraso en las LY. En conclusión, las ratas LY, tuvieron un mayor consumo de alcohol y una afectación mayor en su sueño con respecto a las HY, lo que apoya la hipótesis de que la ansiedad las hace más susceptibles al alcohol. 


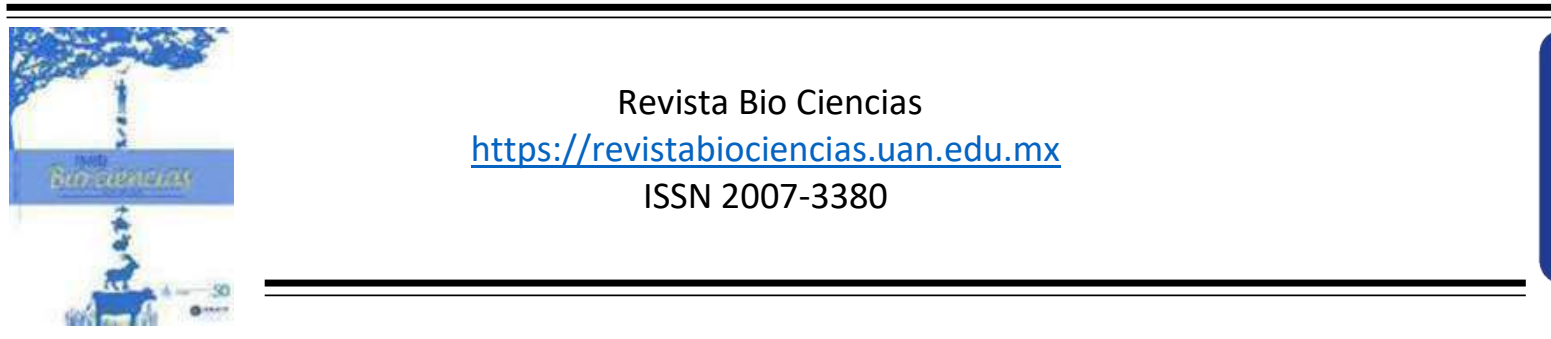

Trabajos libres: Sueño y Ritmos Biológicos

Modalidad de Presentación: Cartel

\title{
Efectos de una noche de privación de sueño sobre la percepción del tiempo
}

\author{
García García, M. A., García Alfano, D. Y., Ramírez Tules, M. C., Valdez Ramírez P., Gómez \\ Estrella, J.A. * \\ Universidad Autonoma de Nuevo León. Facultad de Psicología, Laboratorio de Psicofisiología. \\ *Autor corresponsal: Jorge Alberto Gómez Estrella. E- mail: Carmen: jage6991@gmail.com
}

La privación de sueño afecta la percepción del tiempo al estimar intervalos mayores a un segundo. Es importante analizar los efectos de $24 \mathrm{~h}$ de privación de sueño sobre la estimación de intervalos menores a un segundo. Diez estudiantes (edad=17.90 \pm 1.28 años) respondieron una tarea de bisección temporal a las 12:00 y 20:00h, después de dormir libremente 2 noches, después de $24 \mathrm{~h}$ de privación de sueño y después de una noche de recuperación. Esta tarea consistió en 20 bloques de estímulos auditivos. Primero se mostraron al participante dos estímulos: uno corto (200ms) y uno largo (800ms). Enseguida se presentaron 13 estímulos de forma aleatoria con duraciones que iban de 200 a $800 \mathrm{~ms}$, con aumentos de $50 \mathrm{~ms}$. Los participantes tenían que presionar una tecla para indicar si cada estímulo era similar al corto y otra tecla si era similar al largo. Se calcularon los porcentajes de respuestas correctas para el estímulos corto y largo, el punto de bisección temporal (duración del estímulo categorizado el $50 \%$ de las veces como largo; un punto de bisección menor significa que las duraciones de los estímulos se perciben como más largas) y la variabilidad de la bisección (la mitad del rango de las duraciones de los estímulos que se respondieron al $25 \%$ y al $75 \%$ como largos, entre menor sea la variabilidad de la bisección más precisa será la capacidad de la persona para discriminar entre los estímulos). Las respuestas correctas disminuyeron en la condición de privación de sueño a las 12:00 y 20:00h, tanto para el estímulo corto ( $F=28.89$, $p<0.001)$ como el largo $(F=22.49, p<0.001)$. En la condición de privación de sueño el punto de bisección disminuyó $(F=16.18, p<0.05)$ y la variabilidad de la bisección aumentó $(F=14.21, \quad p<0.05)$ a las 20:00h. En conclusión, la privación de sueño produce duraciones percibidas más largas. 


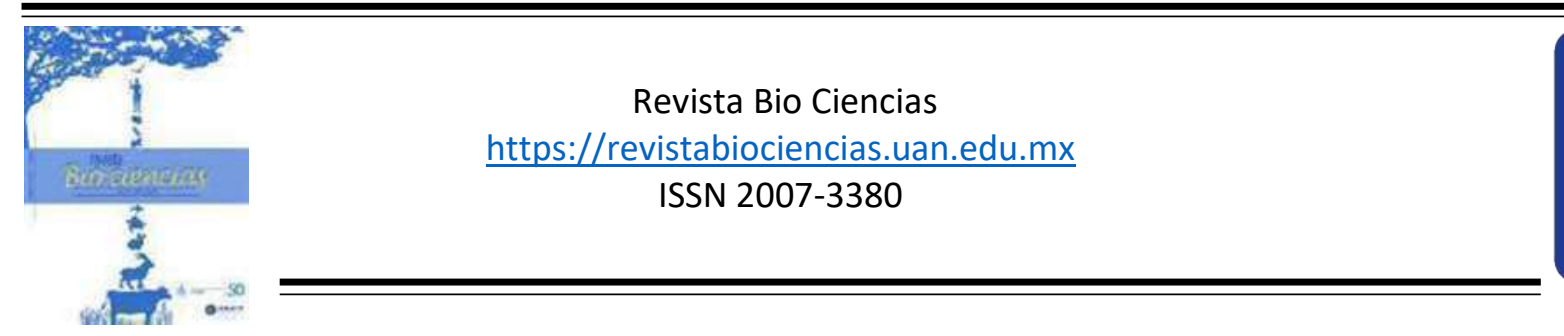

Trabajos libres: Sueño y Ritmos Biológicos

Modalidad de Presentación: Cartel

\title{
Variaciones homeostáticas y circadianas en el límite atencional
}

\author{
Ruiz Ortiz, N. M., Valdez Ramírez, P.* \\ Universidad Autonoma de Nuevo León, Facultad de Psicología. \\ *Autor corresponsal: Pablo Valdez Ramírez. E- mail Carmen: pablovaldezramirez@gmail.com
}

La atención es un proceso cognoscitivo que permite responder a un estímulo e ignorar otros. Existe un límite atencional en la cantidad de estímulos que pueden procesarse simultáneamente. Cuando se presentan de dos a cuatro estímulos consecutivos separados por intervalos menores a $200 \mathrm{~ms}$, todos pueden identificarse eficientemente. Se ha demostrado que esta capacidad se reduce debido al aumento de horas en vigilia (homeostáticas) y la hora del día (circadianas) cuando se presentan dos estímulos consecutivos. Sin embargo, no se han demostrado variaciones homeostáticas y circadianas al responder a más de dos estímulos consecutivos. El objetivo de esta investigación es identificar variaciones homeostáticas y circadianas en el límite atencional evaluando la capacidad para responder a tres estímulos consecutivos en una tarea de Presentaciones Visuales Seriales Rápidas (PVSR). Siete estudiantes universitarios (20 \pm 2.27 años) fueron registrados en un protocolo de rutina constante de 28 horas en el que se controlaron la intensidad lumínica ( $<5$ lux), la temperatura ambiental $\left(24 \pm 1^{\circ} \mathrm{C}\right)$, la alimentación ( $60 \%$ de las calorías reportadas) y la postura corporal (sentados a una inclinación de $45^{\circ}$ ). La temperatura rectal fue registrada por minuto en cada participante y cada dos horas respondieron la tarea de PVSR, en la que se presentaron tres estímulos (E1, E2 y E3) separados por intervalos de $100 \mathrm{~ms}$, mezclados entre distractores. Se encontraron variaciones homeostáticas $(r=-0.70, p<0.05)$, pero no variaciones circadianas $(F=14.69, N S)$ al responder a tres estímulos consecutivos. Los resultados indican que la capacidad para procesar múltiples estímulos de forma simultánea es reducida en cualquier momento del día y disminuye aún más con el incremento del tiempo en vigilia. Estos resultados son importantes para prevenir errores y accidentes en personas que trabajan respondiendo a múltiples tareas, en especial turnos extendidos y nocturnos como personal médico, conductores y operadores de maquinaria. 


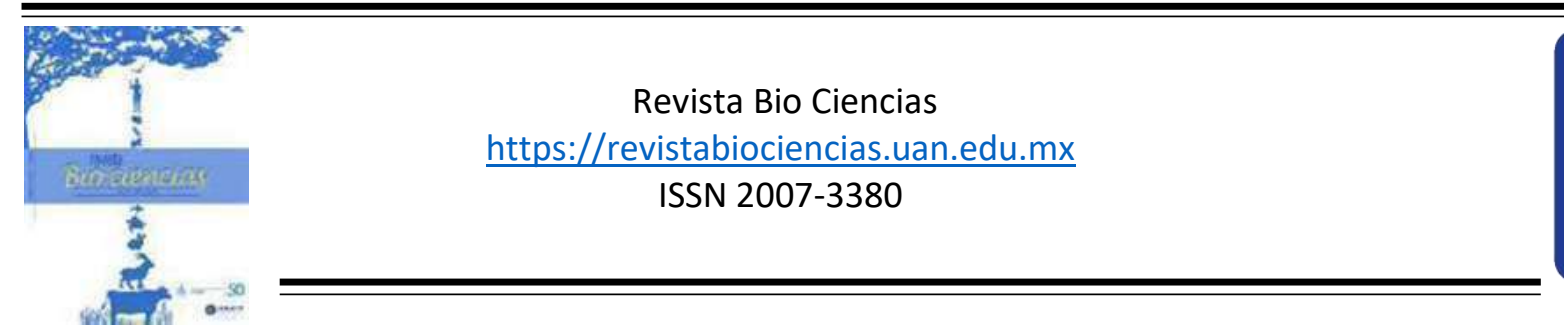

Trabajos libres: Sueño y Ritmos Biológicos

Modalidad de Presentación: Cartel

\title{
En el día del diestro-2, la mecamilamina en el núcleo supraquiasmático izquierdo inhibe las señales neurales que regulan la ovulación
}

\author{
Calderón Ramos, R. ${ }^{1}$, Ramos Puga, D.A. ${ }^{2}$, Vieyra Valdez, E. ${ }^{1}$, Domínguez Casalá, $R .{ }^{1}$, Morales \\ Ledesma, L. ${ }^{\text {* }}$ \\ ${ }^{1}$ Facultad De Estudios Superiores Zaragoza UNAM.Departamento de Biología de la Reproducción. \\ 2instituto de Neurobiología UNAM \\ *Author Corresponsal: Leticia Morales Ledesma. E- mail: Carmen: moralesledesma@yahoo.com.mx
}

El sistema colinérgico modula la actividad de las neuronas del núcleo supraquiásmatico (SCN) que expresan receptores nicotínicos (nAChR). La acetilcolina, al unirse a los nAChR, regulan la excitabilidad de las neuronas del SCN. EI SCN proyecta fibras nerviosas hacia áreas que contienen neuronas secretoras de $\mathrm{GnRH}$, siendo estas vías nerviosas la ruta por la cual el SCN regula las funciones del ovario. Se ha observado que la estimulación de los nAChR del SCN, resulta en el incremento del número de ovocitos liberados y desarrollo folicular. Hasta el momento se desconocen cuáles son los efectos de bloquear los nAChR del SCN izquierdo 0 derecho con mecamilamina (antagonista de los receptores nicotínicos) sobre la ovulación. Para ello, se utilizaron ratas hembras cíclicas de la cepa CII-ZV, a las 09:00 h del diestro-2 fueron microinyectadas con $0.3 \mu$ solución salina (vehículo, $\mathrm{Vh}$ ) 0 mecamilamina (Mec) $\quad(0.225 \mu \mathrm{g} / \quad 0.3 \mu \mathrm{l}$ solución salina) en el SCN izquierdo o derecho. Los animales fueron sacrificados en el día del estro vaginal y se analizó la proporción de animales ovulates y el número de ovocitos liberados. En comparación con su respectivo grupo con $\mathrm{Vh}$, el bloqueo de los receptores nicotínicos del SCN izquierdo o derecho, no modificó la proporción de animales ovulantes (Mec-SCN-izquierdo 7/8 vs. Vh-SCN-izquierdo 8/8; Mec-SCN-derecho $5 / 8 \quad$ vs. Vh-SCN-derecho 8/8). La microinyección de mecamilamina en el SCNderecho no modificó el número de ovocitos liberados (Mec-SCN-derecho $14.20 \pm 2.77$ vs. Vh-SCN-derecho $12.25 \pm 1.04 \mathrm{n} / \mathrm{s}$ ), $\quad$ sin embargo, el bloqueo de los receptores nicotínicos del SCN-izquierdo resultó en la disminución del número de ovocitos liberados (Mec-SCN-izquierdo $7.67 \pm 3.01$ vs. Vh-SCNizquierdo $12.00 \pm 1.31 ; p<0.05)$. Los resultados del presente estudio permiten sugerir que los receptores nicotínicos del núcleo supraquiasmático regulan de manera asimétrica la ovulación, y que son los del lado izquierdo del SNC los que están más comprometidos en la respuesta ovulatoria. 


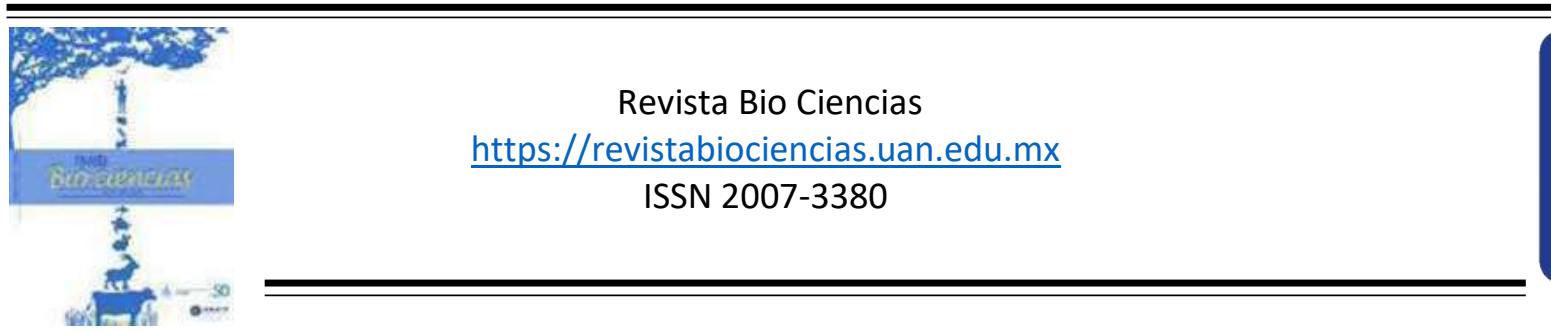

Trabajos libres: Sueño y Ritmos Biológicos

Modalidad de Presentación: Cartel

\title{
Efectos de la privación de $24 \mathrm{~h}$ sobre el automonitoreo
}

\author{
Santos Ramírez, I. R., García García, A. Ramírez Tule, C. Valdéz Ramírez, P.* \\ Universidad Autonoma de Nuevo León. Facultad de Psicología, Laboratorio de Psicofisiología. \\ *Autor corresponsal: Pablo Valdéz Ramírez. E- mail: pablovaldezramirez@gmail.com
}

El objetivo de esta investigación fue analizar los efectos de 24 horas de privación de sueño en un componente de las funciones ejecutivas: el automonitoreo. Participaron 10 estudiantes (edad:17.9 \pm 1.29 años), quienes respondieron una tarea de seguimiento computarizada en tres condiciones: 1) línea base, a las 12:00 $\mathrm{h}$ después de dormir libremente, 2) privación del dormir, a las 12:00 h y 20:00 h luego de una noche sin dormir y 3 ) recuperación, a las 12:00 h después de una noche de dormir libremente. En la tarea de seguimiento un círculo aparecía y desaparecía en la pantalla siguiendo una trayectoria lineal a velocidad constante. Los participantes debían mover el ratón de la computadora para colocar el cursor dentro del círculo y presionar el botón izquierdo del ratón con el dedo índice. La dirección de la trayectoria y la velocidad cambiaron (entre 200-730ms) cada 22 círculos. Se comparó el tiempo de reacción y el porcentaje de respuestas correctas de los círculos después del cambio de trayectoria, para determinar en qué círculo el participante disminuía su velocidad de respuesta y aumentaba su porcentaje de respuestas correctas. En la línea base y en la recuperación los participantes ajustaron su respuesta en el tercer círculo, pues redujeron su velocidad de respuesta (Círculo 2 $=378.40 \pm 74.61 \mathrm{~ms}$, Círculo $\quad 3=225.06 \pm 53.80 \mathrm{~ms} ; \quad F=27.7$, $\mathrm{p}=0.0003$ ). En la condición de privación a las $12: 00 \mathrm{~h}$, se ajustaron hasta el octavo círculo (Círculo $2=285.90 \pm 69.32 \mathrm{~ms}$, Círculo $8=171.23 \pm 30.67 \mathrm{~ms} ; F=5.93, p=0.01)$ y en privación a las $20: 00 \mathrm{~h}$ hasta el sexto círculo (Círculo 2=341.90 $\pm 126.58 \mathrm{~ms}$, Círculo $6=190.23 \pm 66.22 \mathrm{~ms} ; F=5.93, p=0.01$ ). No se observaron cambios en el porcentaje de respuestas correctas. En conclusión, la privación de $24 \mathrm{~h}$ de sueño afecta el automonitoreo, esto puede aumentar el riesgo de accidentes para quienes realizan actividades bajo los efectos de la privación de sueño y requieren responder a estímulos cambiantes. 



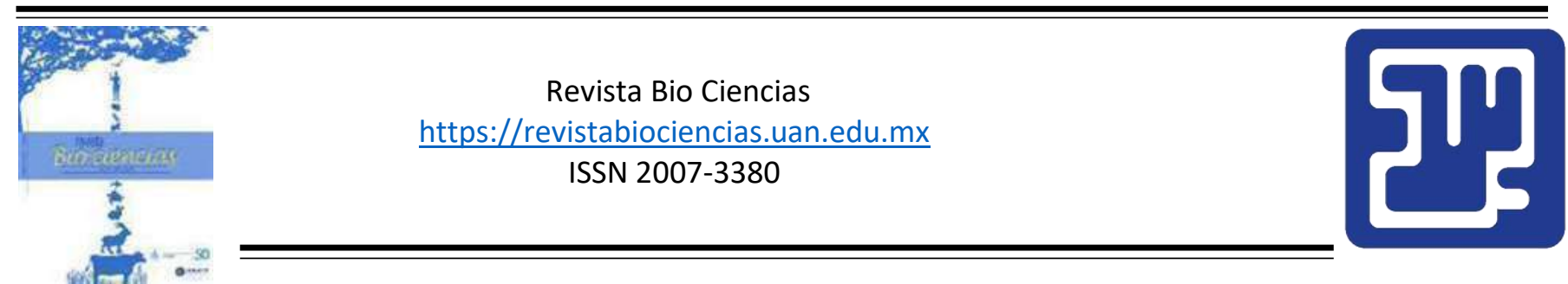

Trabajos libres: Métodos, Técnicas e Instrumentación

Modalidad de Presentación: Oral

\title{
Técnicas de Machine Learning aplicadas a la expresión facial de pacientes con Trastorno Límite de la Personalidad en una tarea de exclusión social
}

\author{
Eraña Díaz, M. L. ${ }^{1}$, Rosales Lagarde, A. ${ }^{2 *}$ \\ ${ }^{1}$ UniversidadAautónoma del Estado de Morelos. Investigación y Posgrado. ${ }^{2}$ CONACYT-UAEH \\ *Autor Corresponsal: Alejandra Rosales Lagarde. E- mail: alexiaro@rocketmail.com
}

El software "FaceReader" es usado para caracterizar, mediante algoritmos basados en unidades de acción faciales, emociones, valencia, alertamiento y otros parámetros como movimientos de cabeza. Sin embargo, el análisis conjunto de estas variables no ha sido realizado considerando a pacientes con Trastorno Límite de Personalidad (TLP) en la tarea de pelota "Cyberball". Las técnicas de "Machine Learning" (ML) consisten en programas que aprenden de los datos y tienen la capacidad de reconocer patrones. Objetivo. Generar resultados globales e individuales con técnicas de ML en participantes con TLP mediante los análisis de registros del "FaceReader" durante el "Cyberball" en sus modalidades de inclusión y exclusión. Método. 14 pacientes (edad $25.8 \pm 6.4$ ) fueron grabadas realizando el "Cyberball". Sus videos fueron analizados con el "FaceReader". Los datos fueron tratados con el software-R: "k-means" y bosques aleatorios (RF). Se hicieron informes inividuales y globales. Resultados. K-means diferenció al
$29 \%$ del total de los datos por la condición de la prueba (inclusión o exclusión); $21 \%$ por pulso y la posición de cabeza discriminó mejor al $50 \%$. Con el RF para las emociones, las variables importantes fueron: $29 \%$ (enojo y miedo, respectivamente); $21 \%$ (alegría y sorpresa, cada una). También, las emociones que diferencían las condiciones se hallaron en: $3 \%, 5 \%$, 8\% (tristeza, aburrimiento; asco, confusión e interés, cada una); y 13.5\% para alegría, enojo, sorpresa, miedo y disgusto, respectivamente. Sobre las "Action Units", se observaron diferencias para: outer brow raiser: $8.7 \%$; lip corner puller: $13 \%$; eyes closed, 13\%; y chin raiser, $35 \%$. Conclusiones. ML identifica atributos relevantes como la posición de la cabeza y establece la diferencia entre las emociones y las unidades de acción en las condiciones de inclusión/exclusión. Esta información puede asistir al médico/investigador en determinar cuáles son las variables de peso en forma global, para cada condición e individuo. una tarea de exclusión social. Revista Bio Ciencias 7: (Suppl) Memorias de Congreso. LXIII Congreso Nacional de la Sociedad Mexicana de Ciencias Fisiologicas, A. C. e1097. 


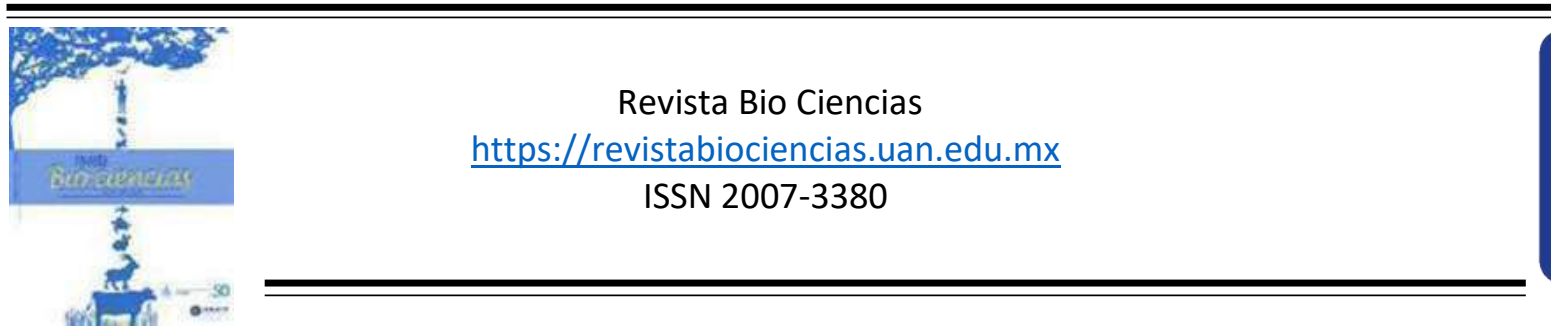

Trabajos libres: Métodos, Técnicas e Instrumentación

Modalidad de Presentación: Cartel

\title{
Facilitación de la regeneración del circuito neuromuscular del esfínter externo de la uretra de la rata hembra por estimulación eléctrica transcutánea
}

\author{
Juárez Mirto, R. ${ }^{1}$, Palacios Galicia, J. L. ${ }^{2}$, Zaca Moran P. ${ }^{3}$, Cruz Gómez, Y. ${ }^{*}$ * \\ ${ }^{1}$ Universidad Veracruzana, Centro de Investigaciones cerebrales. ${ }^{2}$ Universidad Aautónoma de \\ Guadalajara. ${ }^{3}$ benemerita Universidad Autonoma de Puebla. ${ }^{4}$ Universidad Autónoma de Tlaxcala, \\ Biología de la Conducta
}

*Autor Corresponsal: Yolanda Cruz Gómez. E- mail: cruzgomezy@yahoo.com.mx

La estimulación mecánica de la vaina clitoral (VC) induce actividad electromiográfica (EMG) del esfínter externo de la uretra. Las aferencias del reflejo viajan por el nervio dorsal del clítoris (NDC). Los objetivos del estudio fueron: 1) determinar si el umbral de estimulación eléctrica transcutánea del NDC (EET) para activar al EEU varía con el tipo de anestésico y 2) evaluar el efecto de la EET sobre la regeneración nerviosa en un modelo de distención vaginal (DV). Se utilizaron 36 ratas hembra nulíparas adultas de la cepa Wistar. Se aplicó EET a la VC de ratas en diestro anestesiadas con uretano $(n=6)$ o con zoletil- xilazina $(Z+X, n=6)$. Se determinó el umbral de la EET aplicando pulsos de corriente eléctrica $(200 \mathrm{~ms}, 0.20 \mathrm{~Hz})$. En ratas con DV, se aplicó EET o bien estimulación sham y se registró la actividad EMG del EEU al día 7 (DV+EET, $n=6$; SHEET, $n=6$ ) o al día
14 post-DV (DV+ET, $n=6$; SHEET, $n=6$ ). Se encontró que el umbral al reflejo fue significativamente mayor en ratas anestesiadas con $\mathrm{Z}+\mathrm{X}(8.3 \pm .40 \mathrm{~mA})$ que en ratas anestesiadas con uretano $(5,9 \pm 0,80$ $\mathrm{mA})$. En contraste, la amplitud de la actividad EMG del EEU fue significativamente mayor en ratas con uretano $(15,22 \pm 2 \mu \mathrm{V})$ vs. ratas con $\mathrm{Z}+\mathrm{X}(8,5 \pm 1 \mu \mathrm{V})$. En el grupo del día 7 postDV, la amplitud de la actividad EMG del EEU de los animales DV+EET fue mayor que en los animales SHEET $(P=0.002)$. No hubo diferencias significativas entre grupos al día 14 post-DV. Se concluye que el tipo de anestésico influye en el umbral del reflejo del VC-EEU y que la EET facilita la recuperación del circuito neuromuscular del EEU en lesión por DV. CONACYT: 623059 (BECA RJM); FC2016-2/2319 (Proyecto PZM); DEGESU, UATLX-CA 226. 


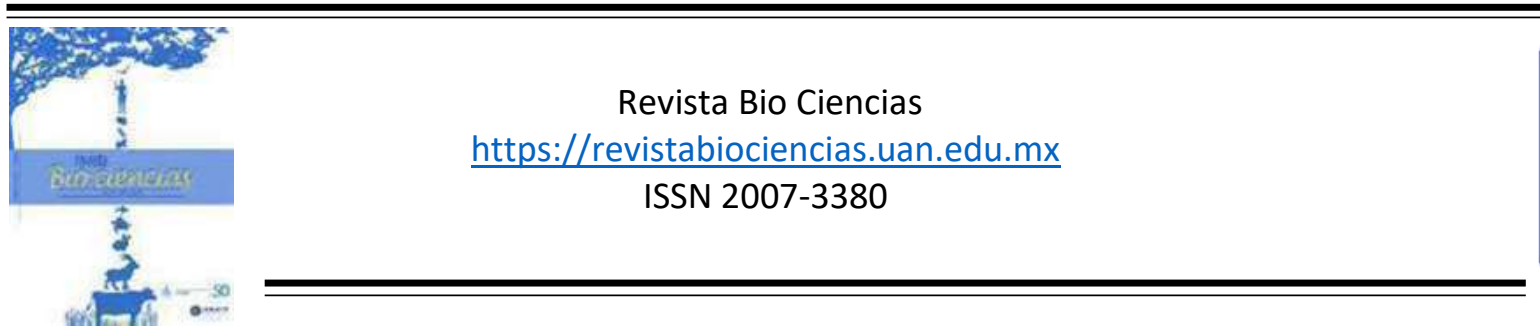

Trabajos libres: Métodos, Técnicas e Instrumentación

Modalidad de Presentación: Cartel

\title{
Variabilidad de la frecuencia cardiaca en acociles durante la interacción social
}

\author{
Oliver Domínguez, I., García Kroepfly, A. L., Osorio Palacios, M., Mendoza Angeles, K., Hernández \\ Falcón, J. *
}

Universidad Nacional Autónoma de México, Facultad De Medicina departamento de Fisiología

*Autor Corresponsal: Jesús Hernández Falcón. E- mail: jesushf@unam.mx

Un método para tratar de cuantificar la homeostasis es el uso del análisis de series de tiempo, por ejemplo, de la frecuencia cardíaca. En los invertebrados no se ha encontrado evidencia de un sistema nervioso autónomo, aun así, estos animales muestran ajustes que les permiten mantener una estabilidad interna. El acocil Procambarus clarkii, exhibe conductas agresivas hacia sus conespecíficos, que resultan en la adopción de un estatus de dominancia o de sumisión. En condiciones de laboratorio, la interacción social de tres acociles resulta en el establecimiento de un orden jerárquico con un animal dominante y dos sumisos, durante estas interacciones se han reportado cambios en la actividad eléctrica cardiorrespiratoria de los animales. Una herramienta para estudiar el sistema nervioso autónomo en vertebrados, a partir del enfoque de series de tiempo, es la variabilidad de la frecuencia cardiaca (VFC).
El objetivo de este trabajo fue analizar la variabilidad de la frecuencia cardiaca en triadas de acociles durante la interacción social en 3 condiciones: 1 ) en animales aislados; 2) compartiendo el acuario, y 3) en interacción. Utilizamos acociles adultos Procambarus clarkii, implantados con electrodos de Platino-Iridio en el seno cardíaco. Analizamos la variabilidad de la frecuencia cardiaca mediante distribuciones y métodos no lineales y encontramos que la mayor VFC se observa en el acocil dominante durante las condiciones 1 y 3 ; en la condición 2, el acocil sumiso 1 tiene la VFC más alta. Mientras que el sumiso 3 tiene la VFC más baja en todas las condiciones. En conclusión, los acociles presentan respuestas de tipo autonómico que parecen estar relacionadas con el estatus de dominancia o sumisión. Investigación realizada gracias al Programa UNAM-DGAPA-PAPIIT IN231620. 


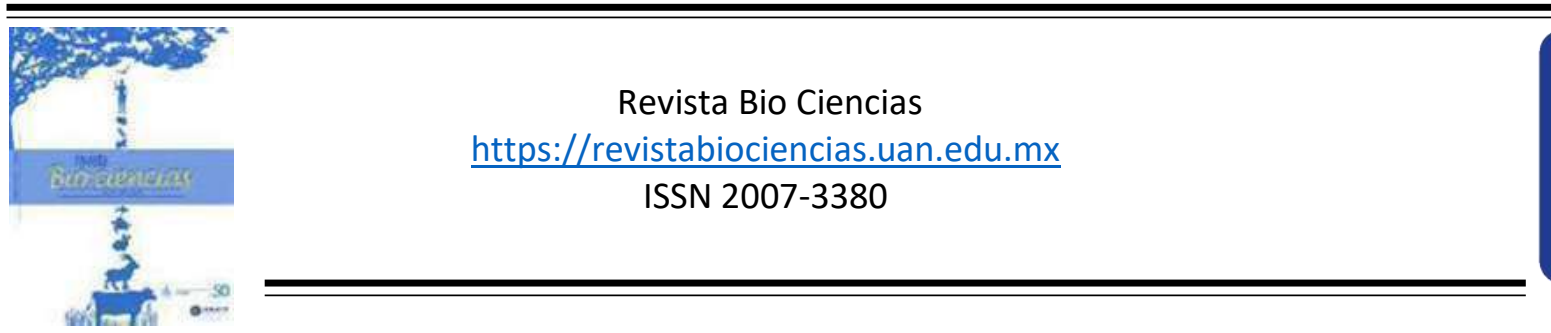

Trabajos libres: Inmunotoxicología

Modalidad de Presentación: Oral

\title{
Expresión de factores de transcripción en linfocitos de tilapia nilótica (Oreochromis niloticus) expuestos in vitro a diazoxón
}

\author{
Ramírez Ibarra, K., Toledo Ibarra, G. A., Girón Pérez, D., Ramón Ventura, G. H., Girón Perez, M.I. * \\ Universidad Autónoma de Nayarit. Centro Nayarita de Innovación y Transferencia de Tecnología \\ A.C., Laboratorio Nacional para la Investigación en Inocuidad Alimentaria-Unidad Nayarit. \\ *Autor corresponsal: Manuel Ivan Girón Perez. E-mail: ivangiron@uan.edu.mx
}

Los plaguicidas organofosforados (OP) son insecticidas de amplio espectro ampliamente utilizados en las actividades agrícolas y representan el $50 \%$ del uso mundial de plaguicidas. El diazoxon, un metabolito del OP diazinón, tiene como principal mecanismo de toxicidad la inhibición de la enzima acetilcolinesterasa (AChE), causando efectos inmunotóxicos en organismos no blanco, como vertebrados, incluidos los humanos. Sin embargo, los datos sobre los mecanismos moleculares de inmuntoxicidad aún son escasos. Por lo que el objetivo del presente trabajo fue evaluar el efecto in vitro de la exposición aguda a diazoxón sobre la expresión de los factores transcripcionales: Tbet, GATA-3, Foxp3 y RORyt, los cuales están encargados de la polarización hacia las distintas subpoblaciones de linfocitos T CD4+ (Th1, Th2 y Th17), utilizando al pez tilapia nilótica (Oreochromis niloticus) como modelo de estudio. Para cumplir con el objetivo, se aislaron células mononucleares de bazo de peces, las cuales fueron fueron contadas y caracterizadas, con base en el tamaño y granularidad, mediante citometría de flujo. Las células obtenidas se cultivaron y posterior a 24 $\mathrm{h}$ de incubación en atmósfera de $\mathrm{CO} 2$, se extrajo el RNA total mediante el protocolo Trizol y se obtuvo cDNA con retrotranscripción. Los oligonucleótidos específicos para las secuencias de los factores de transcripción de interés se obtuvieron a partir de referencias en articulos cientificos publicados y mediante diseño a través del software Primer-BLAST del NCBI . Actualmente se encuentran estandarizados cada uno de los oligonucleotidos por medio de curvas de amplificación de GPCR para continuar con la evaluación de la expresión relativa de estos genes, bajo distintos tratamientos de exposición a diazoxón, empleando el factor de elongación 1- $\alpha$ (EF-1 $\alpha$ ) como gen constitutivo. 


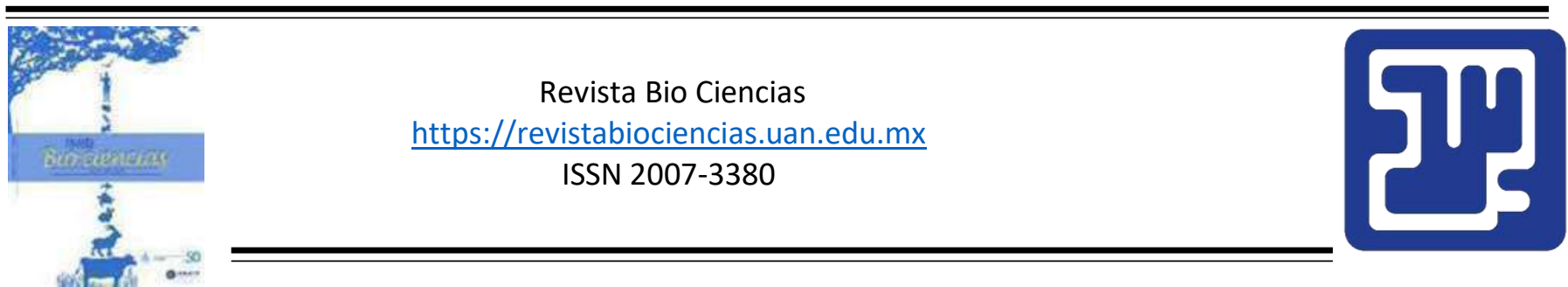

Trabajos libres: Inmunología

Modalidad de Presentación: Oral

\title{
Expresión funcional de los receptores P2X1, P2X4 y P2X7 en macrófagos humanos
}

Guerrero Alba, R.,

\author{
Universidad Autónoma de Aguscalientes. Departamento de Fisiología y Farmacología
}

*Autor corresponsal: Raquel Guerrero Alba. E-mail: bioraquelgro@gmail.com

Los receptores $\mathrm{P} 2 \mathrm{X}$ son canales iónicos que se abren en respuesta a ATP. En macrófagos humanos se ha descrito la presencia de los receptores P2X1, P2X4 y P2X7. Sin embargo, su conformación estequiométrica, sus propiedades farmacológicas y sus funciones permanecen poco conocidas y controversiales. Por tal motivo, el objetivo de este estudio fue caracterizar la respuesta de los receptores P2X en macrófagos humanos y examinar su expresión. Para el análisis de expresión se usó la técnica de PCR en célula única y para la caracterización farmacológica se utilizó la técnica de Patch Clamp (célula completa). Se encontró la presencia de ARNm de las subunidades P2X1, P2X1del, P2X4 y P2X7 en el $40 \%, 5 \%, 20 \%$ y $90 \%$ de los macrofagos humanos. De estos, el $25 \%$ coexpresaron P2X7 y P2X1; el 5\% co-expresó P2X7 y P2X 4; y el 15\% co-expresaron P2X7, P2X4 y P2X1. La aplicación de ATP $(0.01 \mathrm{mM})$ provocó corrientes entrantes con dos cinéticas de desensibilización diferente. La primera mostró una desensibilización rápida inhibida por PPADS $(1 \mu \mathrm{M})$, que a semeja a las propiedades del receptor P2X1. La segunda mostró una corriente de desensibilización lenta, insensible a PPADS pero potenciada con ivermectina $(3 \mu \mathrm{M})$ similar a las propiedades del receptor P2X4. La aplicación de altas concentraciones de ATP (5 mM) indujo tres tipos de corrientes diferentes: 1) una corriente de activación lenta nodesensibilizante en el $69 \%$ de los macrofagos e inhibida por el antagonista del receptor P2X7, A-804598 (0.1 $\mu \mathrm{M})$. 2) una corriente de activación y desensibilización rápida, presente en el $15 \%$ de los macrofagos, y 3) una corriente de activación rápida con una desensibilización bifásica, que se observo en el $15 \%$ de los macrofagos. Estos datos demuestran por primera vez, la co-expresion de los receptores P2X1, P2X4, y P2X7, y confirman la presencia funcional de estos receptores en macrófagos humanos. 